DEUTSGHE AKADEMIE DER WISSENSCHAFTEN ZU BERLIN Veröfentlichungendes Instituts fürdeutsche Sprache und Literatur

\title{
DAS DEUTSCHE WÖRTERBUCH JOHANN LEONHARD FRISCHS
}

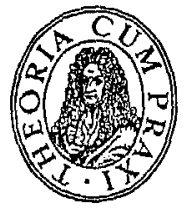

AKA DEM IE-VERLAG - BERLIN

1959 
$R 404$
3619

Copyright 1959 by Akademie -Verlag, Berlin

Alle Rechte vorbehalten

Erschienen im Akademie-Verlag GmbH, Berlin W 1, Leipziger StraBe 8-4

Lizenz-Nr. $202 \cdot 100 / 37 / 59$

Satz, Druck und Bindung: IV/2/14 $\cdot$ VEB Werkdruck Grăfennainichen 1000

Bestell- und Verlagsnummer: 2054/58/19

Printed in Germany

ES $7 \mathrm{D}$

$59 / 10.35 x+$

10,16

Stadt- U. Univ.- Bibl.

Frankfurt/Main 


\section{INHALTSVERZEIOHNIS}

Vorwort . . . . . . . . . . . . . . . . . . . . . . . . . . . . . . . . . . . . . . . . . . V
Einleitung

ERSTES KAPITEL

Johann Leonhard Frisch

ZWEITES KAPITET

Das 'Teutsch-Lateinische Wörter-Buch' und die lexikographischen Bestrebungen der Zeit um 1700 . . . . . . . . . . . . . . . . . . 10

Frischs lexikographische Zielsetzung (Specimen I 1723) . . . . . . . 10

I. Die lexikographische Erschließung der neuhoohdeutschen Gemein-

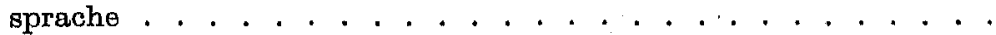

1. Der Gedanke eines Wörterbuchs der neuhochdeutschen Gemeinsprache im Sinne der Fruchtbringenden Gesellschaft . . . . . .

2. Das Fortwirken der lexikographischen Theorie der Fruchtbringen. den Gesellschaft in den Jahrzehnten um 1700 . . . . . . . . . 16

3. Frischs Verhültnis zur sprachtheoretischen Bewegung . . . . 21

II. Forschungen mit dem Ziel der geschichtlich-sprachvergleichenden Erhellung des deutschen Wortschatzes . . . . . . . . . . . . . .

1. Die Tradition der geschichtlich-sprachvergleichenden Wortforschung . . . . . . . . . . . . . . . . . . . . . . . . .

2. Frischs ursprüngliche Zielsetzung: der Gedanke eines etymologischen Wörterbuchs der deutschen Sprache (Anregung durch die germanistische, mittellateinische und romanistische Wortforschung)

III. Die Erforschung des Wortschatzes der deutschen Mundarten und Fachsprachen

1. Die Anfänge der Mundartenforschung und Frischs Mundartenstudien

.

2. Teibniz und der Gedanke eines Deutschen Wörterbuchs 'zumahl Terminorum technicorum' in der Preußischen Societät der Wissenschaften .. . . . . . . . . . . . . . . . . 54

IV. Der Gedanke einea Gesamtwörterbuchs der deutschen Sprache. . . $\quad 59$

1. Der Gedanke eines Gesamtwörterbuchs im Sinne der sprachtheoretischen Bewegung .. . . . . . . . . . . . . 
2. Der Wörterbuchplan Johannes Bödikers . . . . . . . . . . . 3. Leibnizens Vorschlag einer Gesamtdarstellung des deutschen Wortschatzes in den 'Unvorgreiflichen Gedanken'. . . . . . .

4. Die Wirkung der 'Unvorgreiflichen Gedanken' auf Frisch (Wand. lung der ursprünglichen Zielsetzung: vom etymologischen Wörterbuch zum Gesamtwörterbuch). Der Gang der lexikographischen Arbeit.

\section{DRITTES KAPITEL}

Die Quellen des 'Teutsch-Lateinischen Wörter-Buchs' . . . . . . . . . . . 73

I. Die Quellen für die Erfassung des gemeinsprachlichen Wortgutes . .

1. Der Ansatzpunkt der lexikalischen Überlieferung des neuhoch. deutschen Wortschatzes . . . . . . . . . . . . . . . . .

2. Die lexikalische Utherlieferung bis zum Beginn des 18. Jahrhunderts

3. Dor Anteil lexikalischer Quellen am Belegbestand des Usuale generale . . . . . . . . . . . . . . . . 90

4. Die Gesichtspunkte der Vorlagenverwertung . . . . . . . . . . 108

II. Die Quellen für die Erfassung des nicht gemeinsprachlichen Wortgutes 113

1. Einleitung . . . . . . . . . . . . . . . . . . . . . . . 113

2. Quellenverzeichnis zum 'Teutsch-Lateinischen Wörter-Buch' . . . 119

A. Sprachwissengchaftiche Hilfsmittel . . . . . . . . . . . . 121

1. Sprachvergleichende Werke . . . . . . . . . . . . . . 121

2. Hilfsmittel für die Erfassung des Wortschatzes nichtgermanischer Sprachen. . . . . . . . . . . . . . . . . .

3. Hilfsmittel für die Erfassung des Wortschatzes der germanischen Sprachen (außer Deutsch) ............

4. Hilfsmittel für die Erfassung des deutschen Wortschatzes . . .

B. Literarische Quellen und nicht sprachwissenschaftliche Hilfs. mittel . . . . . . . . . . . . . . . . . 136 1. Dichtung . . . . . . . . . . . . . . . . . . . . . . 136

2. Religion/Theologie . . . . . . . . . . . . . . . . 137

3. Geschichte. . . . . . . . . . . . . . . . . 141

4. Recht . . . . . . . . . . . . . . . . 156

5. Technik. Fach-, Natur-, Länderkunde . . . . . . . 172

VIE RTE KAPITEL

Das 'Teutsch-Lateinische Wörter-Buch' im Urteil des 18. Jahrhunderts . . . 180

Verzeichnis der Werke Johann Leonhard Frischs . . . . . . . . . . . . 190

Literaturverzeichnis . . . . . . . . . . . . . . . . . . . . 194

Namenregister . . . . . . . . . . . . . . . . . . . . . 198 
Der Gedanke, das germanistisohe Hauptwerk des Berliner Schulmannes, Sprach- und Naturforschers JoHANM Leonhard FrIsch zu untersuchen, ging aus von meinem verehrten Lehrer, Herrn Professor Dr. Werner Simon. Unter seiner Leitung begann ich im Herbst 1952 mit Vorarbeiten, deren Ergebnisse eine erste Niederschrift vom April 1953 zusammenfaßte. Bereits damals hatte sich meine Aufmerksamkeit vorzugsweise zwei Fragenkreisen zugewandt: der Entstehungsgeschichte und den Quellen des Wörterbuchs. Die begonnenen Untersuchungen führte ich in den folgenden Jahren auf breiterer Stoffgrundlage fort, und dankbar gedenke ich der Unterstützung, die mir während dieser Zeit zuteil geworden ist: von seiten der Bibliothek des Berlinischen Gymnasiums zum Grauen Kloster, insbesondere aber durch das Archiv der Deutschen Akademie der Wissenschaften zu Berlin und seinen Leiter, Herrn FrITz G. LANG Im. Mai 1957 wurde meine Arbeit von der Philosophischen Fakultät der Humboldt-Universität zu Berlin als Dissertation angenommen. Während der folgenden Monate habe ich die Darstellung nochmals überprüft und teilweise neu gefaßt. - Meine Untersuchung fügt sich ein in die. Reihe der Berliner Arbeiten zur Geschichte der deutschen Wortforsohung. Sie ist dazu bestimmt, einen Teil der Leistung jenes Mannes erkennbar zu machen, der nach dem Urteil J $\mathrm{JOOB}$ Grimms 'das erste gelehrte deutsche wörterbuch' schuf - ein Werk, aus dem noch die germanistisohe Wortforsohung des 19. und 20. Jahrhunderts in reichem Maße geschöpft hat. Die vorliegende Darstellung, die in der Berliner Arbeitsstelle des Deutschen Wörterbuchs der Brüder GRIMM entstanden ist, darf zugleich als Beitrag zur Vorgeschichte dieses Instituts und zu der der Deutschen Kommission in der ehemals Preußischen Akademie der Wissenschaften gelten. FRISCH war der erste Germanist, der die Arbeit ihrer Vorgängerin, der Historisch-Philologischen Societätsklasse, als Direktor leitete, und er war der erste Lexikograph, der eine geschichtiliche Darstellung des deutschen Wortschatzes im Sinne $J_{A O O B}$ GRImMs anstrebte.

Zu Dank verpflichtet bin ich dem Direktor des Instituts für Deutsche Sprache und Literatur, Herrn Professor Dr. Theodor Frrnas, für seine Bereitwilligkeit, diese Untersuchung in die Schriftenreihe des Instituts aufzunehmen.

Berlin, im Januar 1959

Gerhardt Powitz 


\section{E INLEITUNG}

Während MAx HERManN JEwIner bereits vor mehreren Jahrzehnten eine zusammenfassende 'Geschichte der neuhochdeutschen Grammatik' schreiben konnte, harrt die Geschichte der deutschen Wortforschung noch heute ihrer wissenschaftlichen Erschließung. Eine zureichende Gesamtdarstellung dieses Gebietes liegt nicht vor, und sie wird nicht vorgelegt werden können, solange die Voraussetzungen fehlen: eine bibliographische Bestandsaufnahme des wortkundlichen Schrifttums seit der Zeit des Humanismus und Einzeluntersuchungen über die wichtigsten Persönliohkeiten, Werke und Entwicklungsabschnitte. Die vorliegende Arbeit, die sich in die Reihe der für eine Gesamtdarstellung notwendigen Vorstudien einfügen möchte, verfolgt das Ziel, die Persönlichkeit und das Werk eines der führenden deutschen Lexikographen des 18. Jahrhunderts in den Umrissen zu würdigen: JoHANA LEONHARD FRISOH (1666-1743) und sein $1741 \mathrm{zu}$ Berlin erschienenes 'Teutsch-Lateinisches Wörter-Buch'.

Die Aufgabe der Untersuchung ist es, Antwort zu geben auf zwei Hauptfragen, die der wissenschaftsgeschichtlichen Forschung auf diesem Gebiet gestellt sind: die Fragen nach den theoretischen Grundlagen und nach dem sprachlichen Inhalt des Wörterbuches.

Johañ Leonhard Frisoh, nach bewegten Wanderjahren seit 1698 am Berliner Gymnasium zum Grauen Kloster tätig und seit 1706 Mitglied der Preußischen Societät der Wissenschaften, schuf in jahrzehntelanger Arbeit eine stofflioh vielschichtige und sprachkundlich tief eindringende Darstellung des deutschen Wortschatzes. Sie steht als ein Werk eigenen Gefüges in der Wörterbuchschreibung des 18. Jahrhunderts durchaus für sich. Die lexikographische Theorie, in gewissem Grade auch das angespannte lexikographische Schaffen der Jahrzehnte um 1700 hatte allerdings den Weg bereits geebnet für das Unternehmen, den Wortbestand der deutschen Sprache in einer umfassend angelegten Darstellung zu erschließen. Es ist das Ziel des ersten Teils der vorliegenden Arbeit, das Wirken der geschichtlichen Kräfte erkennbar zu machen, die den Gang der Studien Frrsores auf den Einzelgebieten der Wortforsohung und die Eigenart seiner lexikographischen Gesamtzielsetzung bestimmten. Die Untersuchungen, die sich in diesem Zusammenhang als notwendig erweisen, werden stellenweise weit ausgreifen, ja sich 
in gewissem Sinne zu einem Gesamtbild der vielgestaltigen lexikographischen Zeitbestrebungen erweitern müssen. Sie führen jedoch auch in die Kleinwelt der örtlichen Verhältnisse Berlins. Denn es soll gezeigt werden, wie die Anregungen aus der Ferne, wie die Forschungstradition des 17. Jahrhunderts und der gedankliche Allgemeinbesitz der Gegenwart aufgenommen und umgesetzt worden sind in der unmittelbaren Umgebung JoHaNa LmonHARD Frisors. Die preußische Hauptstadt der Zeit um 1700 ist kein unwichtiger Sammelpunkt lexikographischer Bestrebungen. Hier besteht seit dem Auftreten JoHannes Vorsts und JoHannms BöDIKEns eine örtliche Tradition germanistischer Studien. Hier erörtert zu Beginn des 18. Jahrhunderts die Historisch-Philologische Klasse der Preußischen Societät unter der Leitung der Brüder JABLONSkr den Gedanken eines deutschen Akademiewörterbuchs. Hier schließlich wirken LimiBnIzens Pläne für eine umfassende Darstellung des deutschen Wortsohatzes, niedergelegt in den 'Unvorgreiflichen Gedanken' und in dem Arbeitsprogramm der Historisch-Philologischen Societäts. klasse, lebendig fort.

Der zweite Teil der vorliegenden Darstellung sucht Antwort zu geben auf die Frage, welche Ausschnitte der geschichtlichen Sprachwirklichkeit das lexikographische Werk Frischs in sich aufnahm. Ausgefïhrt als Gesamtwörterbuch der deutschen Sprache, zeigt es sich einem Gedanken verpflichtet, der während des 17. Jahrhunderts heranreifte und den das 18. Jahrhundert unter dem Namen des Allgemeinen Deutsohen Wörterbuchs beharrlich weiterverfolgte. ${ }^{1}$ Es bedarf der Klärung, was dieser Gedanke, so wie Frisor ihn aufgriff und nach dem Maß seiner Kräfte zu verwirklichen suchte, für die Erfassung des deutschen Wortschatzes zu leisten vermochte. Eine solche Klärung ist notwendig, nicht nur um die geschichtliche Stellung des 'Teutsch-Lateinischen Wörter-Buchs' zu bestimmen, sondern auch um die Gründe seines starken Einwirkens auf die Wortforschung der Folgezeit erkennbar zu machen. Um die Mitte des 19. Jahrhunderts hob $\mathrm{J}_{\text {AOOB }}$ GRIMM - als Bearbeiter des Deutsohen Wörterbuchs auf die Leistungen seiner Vorgänger zurückblickend - den Quellenwert des Werkes nachdrücklich hervor:

'da es nicht wie die vorhergehenden, aus der mundart einer bestimmten gegend gesammelt und wiederum nachgeschrieben ist, sondern mit weiter umsicht ferner liegende urkunden, chroniken und gedichte zu rathe zieht und gründliche, besonnene wortableitungen aufstellt. es enthält einen wahren schatz von früher unbeachteten und auch später nur aus ihm zu entnehmenden nachrichten, weshalb es nicht veraltete und noch heute häufiger gebraucht und nachgesehn werden musz als die folgenden, ihma an fülle des stofs überlegenen werke.' 2

Es erscheinen jedoch Untersuchungen notwendig, die es ermöglichen, das zwangsläufig unbestimmt gefaßte Urteil JAOOB GRImms und späterer Forscher durch

1 Bereits 1873 hat Rudolm HTrdmbRand (Deutsches Wörterbuch 5 [1873] V-VIII) treffend den geschichtlichen Zusammenhang skizziert, dem sich FrIsoHs Schaffen auf dem Gebiet der Wortforschung einordnet.

2 JACOB GRIMM, Deutsches Wörterbuch 1 (1854) XXII. 
gesicherte Aussagen über Herkunft, Umfang. und Zusammensetzung des von Frisorr verzeichneten Sprachstoffes zu ersetzen. Die vorliegende Darstellung sucht diese Aufgabe nicht auf dem Wege wortgeschichtlicher Einzelstudien zu lösen, sondern durch den Nachweis der Quellen, die Friscr benutzte. Fin umfassendes Quellenverzeichnis wird Umfang und Zusammensetzung der Quellengrundlage in der Weise überschaubar machen, daß geschlossene Schrifttumsgruppen und die durch sie dem Wörterbuch vermittelten Sprachschichten hervortreten. Da dieses Verzeichnis die sprach- und sachkundlichen Hilfsmittel einschließt, die Frisor für die lexikographische Aufbereitung des Belegstoffes heranzog, gibt es zugleich Anhaltspunkte, die ein Urteil über den Entwicklungsstand der sprachwissenschaftlichen Methode Frrsorrs stützen können. Auf eine selbständige Behandlung der Fragen, die sich bei der Lösung dieser weiterführenden Aufgabe ergeben würden, habe ich im Rahmen der vorliegenden Arbeit jedoch verzichten müssen. 


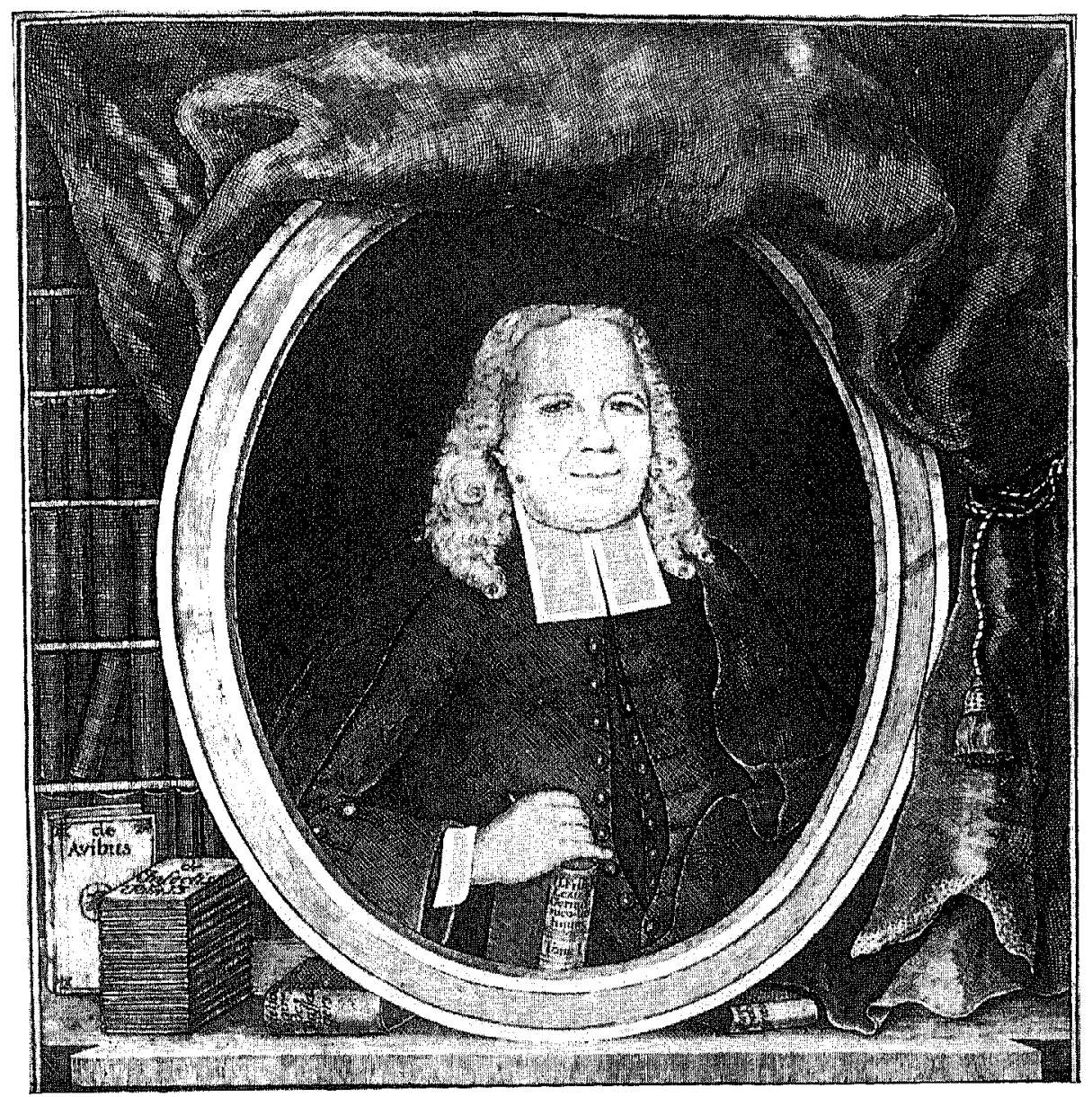

Johann Lmonhard Frisch

(Ausschnitt aus dem Titellsupfer zum Teutsch-Lateinischen Wörter-Buch) 


\section{JOHANN LEONHARD FRISCH}

JoHann Lmonhard Frisoh ${ }^{1}$ stammt aus einer Familie des gebildeten bürgerlichen Mittelstandes. Fr war der Sohn eines in Verwaltungsdiensten wirkenden Rechtslizentiaten und wurde am 19. März $1666 \mathrm{zu}$ Sulzbach in der Bayrischen Oberpfalz geboren. Vorbereitet durch Unterricht im Elternhause und auf der Sankt-Lorenz-Schule in Nürnberg widmete er sich dem Studium der Theologie an den Universitäten Altdorf (1683-1686), Jena (1686-1688) und Straßburg (1688-1690). Ohne einen festen Beruf zu ergreifen, führte er nach AbschluB der Universitätszeit mehrere Jahre ein unstetes Wanderleben (1690-1698). Er bereiste einen Teil Frankreichs und der Schweiz, wurde in Nürnberg in die Reihe der Pfarramtskandidaten aufgenommen, unterstützte als Adjunkt einen evangelischen Geistlichen in Neusohl (Nordungarn) und diente später auf dem Balkan als Dolmetscher bei kaiserlichen Dragonern. 1693 kehrte er über Oberitalien in die Heimat zurück. Er wandte sich nunmehr landwirtschaftlicher und erzieherischer Tätigkeit zu; in adeligen Diensten lebte er als Hofverwalter auf den Gütern Oberdachsbach bei Nürnberg und Arnstein in der Nähe des Eichsfeldes, später als Erzieher in Blankenburg am Harz und Erbach im Odenwald. 1698 durchwanderte er die Niederlande sowie West- und Ostfriesland; auf dem Rückwege nach Nürnberg berührte er Berlin. Sein Landsmann PaUL Astmans, Diakon an der Nikolaikirche, nahm ihn hier auf, und durch Astmanss und Spengers Vermittlung erhielt er die Subrektorstelle am Gymnasium zum Graven Kloster (1698). Frisor heiratete bald darauf und lebte seitdem ständig in Berlin, wo er nach Jahren vergeblicher Berufssuche eine bleibende Wirkungsstätte fand. Neben dem Schulamt widmete er sich bis an sein Lebensende Forschungen natur- und sprachkundlicher Art, die ihm rasch Gelehrtenruf erwarben. LeIBNIZ, mit dem er von 1706 bis 1716 in

1 Grundlegend für die Kenntnis der Iebensgeschichtlichen Tatsachen: WIPPEL, Das Leben des Weiland berühmten Rectors an dem Gymnasio zum grauen Kloster in Berlin, Johann Leonhard Frisch. Berlin 1744. BredermanN, Acta Scholastica III 3. Leipzig/Eisenach (1743) 259-264. Frsorer, J. L. Frischs Schulspiel von der Unsauberkeit der falschen Dicht- und Reim-Kunst. Berlin 1890 (Einleitung S. VII $-\mathrm{XX}$ ). Frscher, Joh. Leonh. Frischs Briefwechsel mit G. W. Leibniz. Berlin 1896 (Einleitung S. I-XXXI). 
Briefwechsel stand, veranlaßte 1706 seine Aufnahme in die Preußische Societät der Wissenschaften. 1708 wurde er zum Konrektor, 1727 zum Rektor des Grauen Klosters ernannt. Der Leopoldinischen Akademie der Naturforscher gehörte er seit 1725 als Mitglied an; 1731 übernahm er das Direktoramt in der HistorischPhilologischen Klasse der Societät. Am 21. März 1743 ist FRISCH im Alter von 77 Jahren in Berlin verstorben.

Frischs Hauptleistungen liegen auf dem Gebiet der natur- und sprachkundlichen Forschung. Die theologische Berufstradition der Familie, aus der sich bereits der Vater gelöst hatte, erfaßte ihn nicht mehr durchgreifend; es blieb bei ersten Schritten auf dem Wege zum geistlichen Amt. Äußere Umstände mögen störend eingegriffen haben; denn ein lebhaftes religiöses Empfinden, das durchaus berufsbestimmend hätte wirken können, war FrIsOH zeitlebens eigen:

'Vor allen Dingen strebete er nach der seeligen Erkenntniß des göttlichen Wortes. Auf seinen Reisen trug er im Fell-Eisen, beständig die teutsche Bibel, die LXX. Dolmetscher, nebst dem grichischen neuen Testament, bey sich, und la $\beta$ darinn mit aller Aufmercksamkeit. Ein gantzes Jahr hat er in der Fremde täglich die hohe Offenbahrung Johannis betrachtet ...'1.

Friscrss Verhältnis zum Pietismus und zu den Pietisten bedarf noch genauerer Untersuchung. In Ungarn mußte er, wie sein Biograph berichtet, wegen seiner Predigten

'viel hönischen Wiederspruch ordulden und ein Apostel Herrn Magister Franckens heissen, ob er gleich diesen. Mann noch nie gesehen und gesprochen hatte' ${ }^{\prime 2}$.

Während des Aufenthaltes in den Niederlanden bemühte sich FRIsOH um Einblicke in die

'Gemüths-Beschaffenheit etlicher damahligen Fanatioorum, Chiliasten und ausgeschriehenen Propheten's.

Er besuchte in Amsterdam den mystischen Theosophen GIoHTEr und einen Gottesdienst der Quäker, auch forschte er nach Spuren QuIRINUs Kuxrumanss. Es ist möglich, daß er von dieser Reise nach Nürnberg mit dem Vorsatz zurückzukehren gedachte, nunmehr den Beruf des Geistlichen zu ergreifen. Zwei in Berlin entstandene Schriften, eine im Manuskript abgeschlossene 'Geographia sacra' sowie die 1707 fertiggestellte deutsche Ubersetzung des russischen Katechismus, weisen noch in das Stoffgebiet der Theologie.

Mit dem Eintritt in das schulische Lehramt am Grauen Kloster verwirklichte Frisor keinen Berufsvorsatz. Vielmehr wurde dieser Sohritt durch die zufällige Vakanz der Subrektorstelle im Jahre 1698 sowie durch Bemühungen Berliner

1 WIPPES a. a. 0.14.

2 WIPPEL a. a. 0.8.

8 WIPPEL a. a. O. 10. 
Freunde veranlaßt. FrisoH war dennoch nicht unvorbereitet. Er hatte bereits in StraBburg junge französische Adlige im Deutschen unterrichtet, war in Blankenburg und Erbach als Erzieher tätig gewesen und wirkte in Berlin - unmittelbar vor Antritt des Schuldienstes - im Hause Asmmanns als Privatlehrer. Nahezu 45 Jahre hat FrIsor dem Grauen Kloster und dem Berliner Schulleben seine Kräfte gewidmet. Er hat am Gymnasium selbst, zu dessen 126. Gründungstag er im Jahre 1700 ein Schulspiel verfaßte und das er seit 1727 als Rektor leitete, in natur- und sprachkundlichen Fächern unterrichtet: in der Mathematik und Physik, im Lateinischen und Griechisohen. Daneben war er als Privatlehrer tätig (unter anderem führte er LwrBNIz in das Russische ein); auch wirkte er zeitweise an einer 'Akademie für Standespersonen' sowie als Lehrer für Französisch an der Königlich Preußischen Kadettenanstalt. Als Mitverfasser einer Griechischen Grammatik und als Herausgeber des AđAPETos beteiligte er sich an der Arbeit einer Gruppe Berliner Rektoren und Konrektoren, die mit der Schaffung einheitlicher Lehrbücher und Textausgaben für die märkischen Gymnasien beauftragt war. Zu einer von diesem Kreis herausgegebenen pädagogischen Zeitschrift lieferte er mehrere Beiträge über Einzelfragen der deutschen Schulgrammatik. Unterrichtsbedürfnisse befriedigten auch sein französisch-deutsches und deutsch-französisohes Wörterbuch (1712), eine Übersetzung des 'Vestibulums' von ComenIUs ins Russische sowie die von ihm besorgte Neuauflage (1723) der Deutschen Sprachlehre Jofannos BönirERs. Selbst das 'Teutsch-Lateinische Wörter-Buch' (1741), dem Frisor den Charalkter eines Schulwörterbuchs nachdrücklich abgesprochen hat, nimmt auf die Zwocke Lateinlernender Rücksicht. ${ }^{1}$ Seit der Übernahme des Rektorats am Grauen Kloster hat Frisor darüberhinaus einzelne seiner Forschungsarbeiten wie die Untersuchungen zu den slawischen Sprachen (1727-1736) und zu den ältesten frühneuhochdeutschen Wörterbüchern (1739) in der Form von Schulprogrammen veröffentlicht.

Als örtliche Mittelpunkte pädagogischen Lebens sind das Graue Kloster und die höheren Berliner Lehranstalten für FrIsoHs Wirken in gewissem Umfange bedeutsam geworden. Bestimmenden Einfluß auf den zentralen Schaffensbereich der Berliner Zeit, die natur- und sprachkundliche Forschungsarbeit, haben sie jedoch nicht gewonnen: die Schule vermochte vielleicht zwar das Bedürfnis der Lehre, nicht jedoch den Drang selbständiger Wahrheitsfindung zu befriedigen.

Voraussetzungen für die Aufnahme natur- und sprachkundlicher Studien hatte Friscrr während der Schul- und Universitätszeit sowie in den Jahren der Wanderschaft und des Tätigseins in praktischen Berufen erworben. Durch Sprachunterricht, durch Aufenthalte im Ausland und in verschiedenen Mundartgebieten Deutschlands, vermutlich auch bereits durch die Beschäftigung mit älteren Sprachstufen des Deutschen hatte er den Grund zu umfassenden, für Forschungszwecke verwendbaren Sprachkenntnissen gelegt. Erfahrungen auf praktischem Gebiet,

1 Frisor, TLWb. (1741) Vorbericht $)(3 a ;)(4 a$. 
die den Ausgangspunkt für spätere naturwissenschaftliche Studien bildeten, vermittelte namentlich die Tätigkeit als Hofverwalter (1693-1696). FRISCH selbst bezeugt, daß er in Oberdachsbach 'Jura und oeconomie' studierte, 'alle BaurenArbeit' mitverrichtete und in der 'Hauptmanschafft Neustatt an der Aisch, 5 meil von Nürnberg ... bey vielen hin- und herreissen alles, sogar alle Mühlen .... das meiste nach der Geometrie und Trigonometrie'1 aufzeichnete, um eine Landkarte dieses Gebietes zu entwerfen. Kennzeichnend ausgeprägt bereits zu dieser Zeit war ein reger und vielseitiger Wissenstrieb, 'die Lust etwas in der Welt zu erfahren $^{2}$ :

'Er reisete nicht wie manche, von welchen er zu sagen pflegte, daß sie nicht viel besser reiseten als die Post-Pferde, und mit einer elenden Erkenntniß weniger Neben-Dinge zurückkehreten: Sondern er besuchte die Gelehrten, zeichnete ihre Discours auf, besahe die Merckwürdigkeiten und Situation derer Oerter, und hielt von dem was ihm vorgefallen, nützliche Tage-Bücher.' ${ }^{3}$

Für den Gang der natur. und sprachkundlichen Studien FrIsoHs war es bedeutsam, da B Berlin im Jahre 1700 durch die Gründung der Preußischen Societät einen Mittelpunkt wissenschaftlichen Lebens erhalten hatte. FRIsorr wurde 1706 auf Limsnizens Vorschlag als Mitglied in die Societät aufgenommen. Seit dieser Zeit betrachtete er seine privaten Studien zugleich als Beiträge zur Erfüllung der Forschungsaufgaben, die den einzelnen Abteilungen dieser wissenschaftlichen Institution gestellt waren. Der allgemeine Tiefstand der Societätsarbeit zu Beginn des 18. Jahrhunderts und das geringe Verständnis, das seinen Forschungen entgegengebracht wurde, wirkten allerdings enttäuschend und verbitternd. Diese Stimmungen spiegeln sich wider in einer Reihe brieflicher Äußerungen gegenüber LaIBNIZ aus den Jahren 1711-1716:

'Weil die Societät, nooh in infantia ist oder dieselbe kaum verlassen, so passirten auch bey einigen Umständen solche Dinge, die dieses Alter zu haben pflegt.' 'Toh habe aber von Ew. Exc. nicht wenig Grossmuth gelernet, wie man durch die Hinderung des eigenen corporis Societatis müsse suchen durchzudringen.' 'Bey der Societät wird es fast täglich schläfferiger in allen departementen.' ‘. . liegen drey departements völlig dernieder ... Die Diplomata sind jezund so wohlfeil, dass man nur recommendieren darf.' 'Weil hier kein Mensch, mit dem ich communiciren kan, was ich finde, sollte einer, der nicht andern Antrieb hat, leicht stumpf werden.' ${ }^{\text {, }}$

Frisch versuchte, dem Niedergang der Societät durch das Streben nach persönlicher Vorbildlichkeit in der Erfüllung seiner Mitgliedspflichten entgegenzuwirken. Dieses Bemühen fand Ausdruck in den zahlreichen Fällen seines grundsätzlichen Eintretens für die Wahrung des Societätsansehens, vor allem jedoch in der tätigen Teilnahme am Leben der Societät, der er seit 1731 als Direktor der

1 Wipper a. a. O. 10; Fiscenar, Frigchs Briefwechsel mit Leibniz (1896) 41.

2 WIPPEL a, a. 0.8.

3 WIPPer a. a. 0. 6.

4 Fischer a. a. O. $32 ; 35 ; 37 ; 42 ; 45-46$. 
Historisoh-Philologischen Klasse in führender Stellung angehörte. Er arbeitete mit in allen ihren Abteilungen und scheute sich nicht, bei der Lösung praktischer Aufgaben - so bei der Einführung der Seidenraupenzucht - unmittelbar Hand anzulegen. Vor allem jedoch stellte er seine Forschungen in den Dienst der Societät. So unterstützte er die sieben Bände der 'Miscellanea ex scriptis Societatis Regize exhibitis edita' (1710-1743) durch insgesamt 53 Beiträge natur- und sprachkundlichen Inhalts, veröffentlichte als Societätsschriften zwei Werke über Seidengewinnung (1713; 1714), die 'Beschreibung von allerley Insecten' (1720-1738) sowie den 'Ersten Auszug von einigen die teutsche Sprach betreffenden Stücken' (1734). Auf die Societät bezog er sich auch in Darstellungen, die nicht unmittelbar aus der Arbeit in ihrem Dienste erwachsen waren ('Nouveau Dictionnaire' 1712, gewidmet dem Präsidenten der Societät voN PrINTzeN; 'Teutsch-Lateinisches Wörter-Buch' 1741).

FrIsoH hat mehrfach versucht, die darniederliegende Tätigkeit auch der Historisch-Philologischen Klasse zu beleben und zugleich die Publikationsmöglichkeiten auf dem Gebiet der Sprachkunde über die 'Miscellanea Berolinensia' hinaus zu erweitern. Zuerst 1713 trat er an die Klasse mit dem Vorschlag heran, es sollten auf den Sitzungen kleine sprachkundliche Abhandlungen der Mitglieder erörtert werden. Auf der Grundlage dieser Abhandlungen könne man - nach dem Muster der 'Remarques sur la langue françoise' (1647) des französischen Sprachgelehrten Da Vaugras - lieferungsweise 'Vermischte Anmerkungen' über Fragen der Rechtschreibung, Lexikographie und Etymologie herausgeben. ${ }^{1}$ Als ersten Beitrag stellte er den Artikel 'Land' zur Verfügung; jedoch verhielt sich die Klasse dem Gedanken gegenüber ablehnend. Am 3. Februar 1718 wiederholte Frssor diesen Vorschlag. ${ }^{2}$ Der Plan wurde jedoch nicht ausgeführt, auch dann nicht, als er in abgewandelter Form am 26. April 1719 (später nochmals am 5. Februar 1728) von dem Sekretar der Societät J. TH. JABLonskr vorgetragen wurde. ${ }^{3}$

Frrsor sah sich daher gezwungen, die Ergebnisse seiner laufenden Untersuchungen weiterhin in den zunächst nur zögernd erscheinenden 'Miscellanea'4,

1 Alkten aus dem Archiv der Deutschen Akademie der Wissenschaften zu Berlin. IV, 38: Protokolle der Klasse für deutsche Sprach und Geschichtsforschung 1711-1742. Protokoll vom 22.6. 1713.

2 Protokoll vom 3. 2. 1718.

${ }^{3}$ Protokolle vom 26. 4. 1719 und 5. 2. 1728.

4 In der Vorrede zum ersten Bande der 'Miscellanea' (Misc. 1 [1710] Praefatio ) () () ( 2b) hatte es über die in der Abteilung Literaria vorgesehenen Beiträge geheißen: 'grata inprimis erunt, quae Historiam Linguarnque Germanorum illustrabunt.' Aber von den 17 Aufsätzen germanistischen Inhalts, die in den Bänden der 'Miscellanea' erschienen (vgl. Harnack, Gesch. d. Königl. Preuß. Akademie der Wissenschaften zu Berlin [1900] 3, 576), haben 16 Aufsätze Friscr zum Verfasser, und auch an dem einzigen Beitrag aus anderer Feder, WACHTEns Abhandlung De lingua Codicis argentei, hat er Anteil. Die germanistischen Untersuchungen FrIscHs, soweit sie in den 'Miscellanea' erschienen sind, hat RowTHe kurz gewürdigt in: Neue Jahrbücher f. d. klass. Altertum. 1. Abt. 31 (1913) 40-41. 
in anderen Fällen unabhängig von der Societät zu veröffentlichen. So erschienen seine Abhandlungen teils in Zeitschriften ('Zufällige Anmerkungen' 1716-1718; 'Anmerkungen über die deutschen Reichssachen') teils als selbständige oder halbselbständige Publikationen ('Buchstab-Veränderung'; Specimen I und II). Erst nachdem er 1731 zum Direktor der Historisch-Philologischen Klasse ernannt worden war, erweiterten sich für ihn die Wirkungsmöglichkeiten. Es gelang Friscr nunmehr, die Arbeitsweise der Klasse umzugestalten; er führte regelmäßig Zusammenkünfte durch, auf denen er Artikel und Beiträge vorlegte, die von den Mitgliedern besprochen wurden. ${ }^{1}$ Nun bestand auch die Möglichkeit, den Plan der Herausgabe einer 'Zeitschrift für germanistische Wortforschung' zu verwirklichen. 1734 erschien 'Der erste Auszug Von einigen Die Teutsche Sprach betreffenden Stücken, Welche Der Königlichen Preußischen Societät der Wissenschafften ... Nach und nach übergeben worden.' Dieser Auszug enthält zwölf kleine Beiträge, die sämtlich oder zum größten Teil von FrIsor verfaßt worden sind. Schnell sammelte sich Stoff für weitere Folgen: am 16. Mai 1736 konnte FrIsor vor der Klasse mitteilen, daß das Manuskript für einen zweiten 'Auszug' fertiggestellt und bereits auch Beiträge für eine dritte Lieferung vorhanden seien.2

Es ist im Rahmen der vorliegenden Arbeit nicht möglich, Friscrss Leistungen auf dem Gebiet der Natur- und Sprachforsohung in vollem Umfange zu würdigen. Seine Untersuchungen auf sprachwissenschaftlichem Gebiet, soweit sie in $\mathrm{Zu}$ sammenhang stehen mit der Entstehungsgeschichte des 'Teutsch-Lateinischen Wörter-Buchs', werden im folgenden Kapitel zu berücksichtigen sein. An dieser Stelle muß es genügen, FRIsOHs Tätigkeit als Naturforscher in den wichtigsten Zügen zu kennzeiohnen.

Der Drang zu naturwissenschaftlicher Forschungsarbeit war in FrIscH stark lebendig. Zeitgenossen bezeugen, daß er 'eine grosse Lust zur Untersuchung natürlicher Dinge' 3 hegte, und rastlose Studien auf naturkundlichem Gebiet, die seit der Frühzeit des Berliner Aufenthalts die sprachwissenschaftlichen Untersuchungen begleiteten, lassen erkennen, daß für ihn die Naturforschung hinter der Sprachforschung nicht zurückstand. Wie LEIBNIz, der ihn auch in diesem Bereich zu fördern suchte, bearbeitete er ein außerordentlich vielseitiges Aufgabengebiet. So setzte er sich als Beauftragter der Societät - FRIEDRICH I. hatte ihr 1707 das Seidenbauprivileg erteilt - insbesondere in den Jahren zwischen 1707 und 1712 für die Einführung der Seidenraupenzucht in der Mark Brandenburg ein. Unter seiner Aufsicht wurden auf den Berliner Wällen und in der Umgebung der Stadt (Charlottenburg, Spandau, Potsdam, Köpenick) Anpflanzungen von Maulbeerbäumen angelegt und die Aufzucht von Seidenraupen gefördert. 1713 und 1714 veröffentlichte er zwei Schriften über die Seidengewinnung, und 1716 beauftragte

1 Protokolle der Jahre 1731-1741.

Protokoll vom 16. 5. 1736.

WIPPel a. a. O. 16. 
ihn Frimdrion Wrimelm I. mit der Abfassung einer Geschichte der Maulbeerbaumpflanzungen in Europa. Da Mitglieder der Societät seinem Unternehmen fortwährend Widerstand entgegensetzten, ging er schließlich dazu über, auf eigene Kosten und auf eigenen Gewinn zu arbeiten. In einem Brief an LeIBNIz berichtete er 1715:

'Tch habe es nun so weit vom anfang biss zum Webstuhl, dass es einem Landmann, sonderlich in kleinen Stätten nicht einen Pfennig kostet, wann er selber mit den seinen Hand anlegen kan und will.'1

Es waren die Bemühungen um die Aufzucht der Seidenraupen, die Frisor dazu veranlaßten, sich der Erforschung der Insekten zuzuwenden. Er begann seine Studien im Jahre 1713, beobachtete die Entwicklung der lebenden Tiere, bewahrte sie nach ihrem Tode in seiner Insektensammlung auf und konnte auf der Grundlage der gewonnenen Erfahrungen in den Jahren 1720-1738 die 'Beschreibung von allerley Insecten in Teutsch-Land' erscheinen lassen. Auch über diese Forschungen hat Frisor Limirniz berichtet:

'Es sind nun zwey Jahr, dass ich die insecta und ihre Natur untersuche, um zu sehen, ob Schwammerdam, Redi, Johnston, Goedart und andere in ihren observationibus nicht biseweilen betrogen worden, vieles übersehen, vieles gar nicht gesehen' (1715). 'Ich continuire meine observationes de Insectis. Die Raupe, so ich für die grösste achte, weil sie 1/4 Ellen lang wird, hab ioh diss Jahr 4 mahl; ist auch schon ein papilio ausgekrochen, und wegen des Cocons und der Grösse, die er hat, recht selzam... Ich hab auch unterschiedliche observationes de insectis insectorum, welches ausser Jonston noch keiner observirt und dieser nur muthmasslich, ich aber habe von allen die insecta selbst und ihre Verwandlung angesehen' (1716). ${ }^{2}$

Etwa in die gleiche Zeit ${ }^{3}$ fallen die Anfänge der ornithologischen Studien Frisorrs. Gestützt auf die reichen Sammlungen seines Vogelkabinetts und auf die Beobachtung der lebenden Tiere, die er zunächst stets einige Zeit auf dem Hof seines Hauses eingesperrt hielt, um über ihre Lebensweise Aufschluß zu erhalten, veröffentlichte er von 1733 an die großangelegte 'Vorstellung der Vögel Deutschlandes..., nach ihren Eigenschaften beschrieben'. Allerdings sind von den 12 Klassen dieses Werkes nur die ersten vier noch von FrIsOH selbst herausgegeben worden; erst im Jahre 1763 wurde es durch den Ornithologen FrIEdRIoH AUGUST vON ZORN-PLOBsHerm (Danzig) abgeschlossen.4

I Fisohrer a. a. O. 40.

2 FISCExar a. a. O. 37; 45.

s In der Vorrede zur ersten Lieferung (1733) B1 $1^{\mathrm{a}}$ der 'Vorstellung der Vögel Deutschlandes' berichtet FrIsch, daß es ihm danls eines selbst erfundenen Insektenpulvers möglich gewesen sei, die ausgestopften Vögel 'nun schon über 20. Jahre' aufzubewahren.

1 Stresemann, Die Erscheinungsdaten von J.L. Frischs 'Vorstellung der Vögel in Teutschland' (1733-1763). In: Ornithologische Monatsberichte 49 (1941) 1-8. 
Ein weiteres bevorzugtes Forschungsgebiet FriscHs bildete die Chemie, insbesondere die Farbenchemie. In Zusammenarbeit mit dem Färber DrmsBach verbesserte er das Herstellungsverfahren des Berliner Blaus und erzielte aus dem Umsatz dieser Farbe erhebliche Gewinne:

'ich kan so viel Farbe nicht machen, als zum voraus bestellt. Es haben mir einige Italiäner viel Geld für das Secret gebotten, aber vergeblich' (1712). 'Weil meine Farb zugleich in grossen debit kam, also dass verflossenes Jahr allein auf Paris $100 \mathrm{Pfd}$. gelieffert worden, davon wir, das Pfd. für 30 thlr., bey 3000 thlr. gezogen...' (1715). 'In Paris sind 2 fabriquen, wo man dieses Outremer gemacht, abgegangen; wozu mein Blau soll geholfen haben, weil auf einmahl $100 \mathrm{Pfd}$. dahin geschickt worden' (1716). ${ }^{1}$

Frisor hat zeitweise auch alchimistisch experimentiert, versuchsweise die künstliche Düngung eingeführt sowie Wein und Süßholz angebaut, topographische Karten gezeichnet und an der Konstruktion einer Bewässerungsmaschine gearbeitet, um 'vermittelst der Spree-Wüsserung viel schöne Stücke unsers Sandlandes zu Wiesen zu machen'2. Obwohl er, wie bereits erkennbar wurde, auch den ge. schäftlichen Ertrag dieser vielseitigen naturkundlichen Studien im Auge behielt, waren es zunächst zweckfreie Erkenntnisantriebe, die ihn der Untersuchung der Naturerscheinungen zuführten. In Selbstzeugnissen werden sie allerdings durch utilitaristische und religiöse Motive überdeckt. So wenn FrIsor in der Vorrede zum ersten Teil der 'Insektenbeschreibung' bekennt, es habe ihn bei der Erforschung der tierischen Kleinwelt das Verlangen geleitet, die Werke der göttlichen Weisheit zu betrachten:

'Sie ziehen mich nicht minder auf die Erde, als die Sterne ihre Messer an den Himmel. Wann diese mit ihrem Fern-Glaß die Allmacht Gottes betrachten, wie sich dieselbe in Erschaffung des unmäBlich-grossen Gestirns und dessen Lauffs geoffenbaret hat: So sehe ich mit meinen Vergrösserungs-Gläsern, wie eben dieses an dem unmäßlich-Kleinen Erden- und Wasser-Gewürme geschehen.' 3

Aber der untergründig wirksame empirisch-rationale Erkenntniswille verrät sich, wenn Frrsor zugleich eingesteht, er untersuche auch zu seinem 'eigenen Vergnügen, welches durch immer neue Entdeckungen vermehrt wird'4. Diesem Erkenntniswillen entspricht ein Verfahren der Untersuchung, das streng auf die Beobachtung des empirisch Gegebenen abgestellt ist und den Forscher ebenso dem Bann der wissenschaftlichen Tradition wie der Gefahr der spekulativen Umdeutung des Tatsächliohen fernhält:

'Tch habe offt vortreffliche Zeugen meiner Anmerckungen bekommen: Wo ich sie aber nicht haben können, wird die Wahrheit einem jeden, der solche Untersuchungen liebt, ein unfehlbarer Zeuge seyn, daß ich alles getreulich aufgezeichnet, nichts von andern ausgeschrieben, auch nichts leichtgläubiger oder verwegener Weise hingesetzt, womit viel ihre sonst feine Arbeit befleckt haben'5.

\footnotetext{
1 FISChER a. a. $0.36 ; 37 ; 47$.

2 Fischer a, a. O. 27.

3 Frisch, Beschreibung von allerley Insecten $1(1720))\left(3^{\mathrm{a}}-3^{\mathrm{b}}\right.$.

- Frisar a. a. O. ) ( $3^{b}$.

s Frisor a. a. O. )( 3 a.
} 
Die naturkundlichen Studien erlangen auch für FrrsoHs Arbeiten auf dem Gebiet der Sprachforschung Bedeutung. Das gilt zunächst in methodischer Hinsicht: die empirische Erkenntnishaltung, die in den exalkt beschreibenden Darstellungen naturkundlicher Gegenstände faßbar wird, bestimmt das Verfahren auch der sprachwissenschaftlichen Untersuchungen Frisors. Zur gleichen Zeit, da er die Sammlungen seines Insekten- und Vogelkabinetts Stück um Stück zu vervollständigen sucht, trägt er unermüdlich exzerpierend wortgeschichtlichen Erfahrungsstoff aus den Quellen zusammen, um Einblick zu gewinnen in die Sprache als Erscheinung der objektiven Wirklichkeit. Zweifellos wird es für die Ausbildung der sprachwissensohaftlichen Methode FrIsoHs bedeutsam, daß er es gewohnt ist, als Naturforscher scharf zu beobachten, Beobachtetes genau zu beschreiben - eine Forschungshaltung, die ihrerseits durchaus dem allgemeinen Stand des wissenschaftlichen Denkens im Zeitalter des thergangs von der deduktiven Mathematik zur experimentellen Naturwissenschaft entspricht. ${ }^{1}$ Ein Zusammenhang zwischen den natur- und sprachkundlichen Studien besteht jedoch auch in stofflicher Hinsicht. Beide Arbeitsbereiche sind für FrIsor nicht streng voneinander getrennt: so wie er als Sprachforscher mit Vorliebe auf die Realien zurückgeht und dem naturkundlichen Namengut, den Kunstwörtern der Fachsprachen (wie auch den sachgebundenen Bezeichnungen des Rechts und der Geschichte) bevorzugt Aufmerksamkeit schenkt, so greift er als Naturforsoher gerne über die Grenzen seines Gebietes hinaus, indem er die volkstümliche Nomenklatur der Tierwelt wo nur immer möglich in seine Untersuchungen einbezieht. Die 'Vorstellung der Vögel' verzeichnet sorgfältig die deutschen Namen der Vögel, und zwar 'auch mit einigen der gewöhnlichsten Pöbel-Wörter und Namen, die sie in besondern Gegenden haben'2, und. an zahlreichen Stellen schieben sich Hinweise zur landschaftlichen Verbreitung der einzelnen Bezeichnungen sowie kurze philologische Abhandlungen etymologischen Charakters in die naturwissenschaft. liche Darstellung ein. Diese sprachkundlichen Nebenstudien, die zu den Vorarbeiten für das 'Teutsch-Lateinische Wörter-Buch' gehören, zeugen davon, daß . sich in FrIsOH exakte Fachkenntnis und sprachwissenschaftliches Urteilsvermögen in fruchtbarer Weise verbanden. Auf dieser für den Sprachforscher äußerst günstigen Doppelbegabung beruht eine Reihe von Zügen, die dem 'Teutsch-Lateinischen Wörter-Buch' Eigenart und Eigenwert verleihen.

1 Hazard, Die Krise des europäischen Geistes (1949) 354-371; Hazard, Die Herrschaft der Vernunft (1949) 195-214.

2 Frisor, Vorstellung der Vögel Deutschlandes 1 (1733) Vorrede B1a. 


\section{DAS TEUTSCH-LATEINISCHE WÖRTER-BUCH UND DIE LEXIKOGRAPHISCHEN BESTREBUNGEN DER ZEIT UM 1700}

Die Vorarbeiten zum 'Teutsch-Lateinischen Wörter-Buch' erstrecken sich über einen Zeitraum von fünfzig Jahren. ${ }^{1}$ Mit dem zweiteiligen Quartband, der im Jahre 1741 erschien, gab FRISCH ein Lebenswerk aus der Hand: im frühen Mannesalter hatte er mit vorbereitenden Studien für das lexikographische Unternehmen begonnen, das er als Fünfundsiebzigjähriger - zwei Jahre vor dem Tode - abgeschlossen vorlegte.

Als Anhang zur vierten Auflage der 'Grund-Sätze der Teutschen Sprache' von JoHANnks BöDIker veröffentlichte Frisor 1723 ein 'Specimen Lexici Germanici' (Specimen I). Wie den einleitenden Sätzen des hier niedergelegten Entwurfs zu entnehmen ist, hatte er zu dieser Zeit am Wörterbuch 'schon über 30. Jahr . . . mit grossen Vergnügen'2 gearbeitet. Anfänge des Schaffens fallen demzufolge noch in das letzte Jahrzehnt des 17. Jahrhunderts, also in die Zeit, da Friscr im Alter von etwa fünfundzwanzig Jahren von seinen Reisen in Ungarn, auf dem Balkan und durch Italien nach Deutschland zurückkehrte, um sich 'nechst dem studio theologico ... auch auf Jura und oeconomie zu legen'3. Bevor er 1698 am Grauen Kloster eine feste Anstellung fand, war er an mehreren Orten als Gutsverwalter und als Erzieher tätig. In dieser Zeit wechselvollen persönlichen Schicksals. begannen die Vorstudien zum 'Teutsch-Lateinischen Wörter-Buch'.

Das Specimen I ermöglicht es nicht nur, den Anfangspunkt und die Dauer der Arbeiten am 'Teutsch-Lateinischen Wörter-Buch' zu bestimmen. Es bildet zugleich eine unserer Hauptquellen für die Kenntnis der lexikographischen. Ziel-. setzung seines Verfassers. In einem kurzen Programm und am Beispiel des Artikels 'Land' erläutertFrisch hier, 'wie er sein Teutsches Wörter-Buch einrichtet'4.

Um einen Ansatzpunkt für die folgenden Untersuchungen zur Entstehungsgeschichte des Werkes zu gewinnen, sei das im Specimen I niedergelegte Schema der Artikelgliederung, das in den Grundzügen dem Aufbaugedanken der Artikel.

1 Raumer, Gesch. d. germ. Philologie (1870) 192.

2 FrISOH, Specimen I (1723) 3.

3 Wippes, Leben Frischs (1744) 10.

- Friscr, Specimen I (1723) Titelblatt. 
des 'Teutsch-Lateinischen Wörter-Buchs' entspricht1, an dieser Stelle zusammengefaßt wiedergegeben:

\section{Schema des Artikelaufbaus ${ }^{2}$}

\section{1. Usuale generale}

Hochdeutsches Wortgut allgemeinen Gebrauchs

2. Usuale speciale (Technicum)

Wörter 'die eines besondern Gebrauchs, und nur in einigen Ländern, und Oertern, oder nur bei einigen Leuten, und ihren Wissenschafften oder Künsten und Verrichtungen gewöhnlich sind'

3. Archaeologum

'Alte, oder gar veraltete Wörter, die in allerlei öffentlichen Schrifften gefunden werden'

\section{4. Eponymologicum}

Geographische Eigennamen; die Namen der Adelsgeschlechter Deutsch. lands; altdeutsche Personennamen

\section{Etymologicum}

Angaben über Ursprung und Verwandtschaft

6. Criticum

Grammatische Angaben

Dieses Schema gewährt Einblick in die Zielsetzung des 'Teutsch-Lateinischen Wörter-Buchs', wie sie FRISCH im Jahre 1723 vorschwebte. Es sind hohe Anforderungen, die erfülltt werden sollen: beabsichtigt ist die Erfassung des deutschen Wortschatzes in weitestem Umfange (Wortschatz der Gemeinsprache der Gegenwart; Wortgut der Fachsprachen, der Mundarten und der geschichtlichen Sprachstufen; Namengut) sowie eine erschöpfende (etymologische, semantische, grammatische) Deutung der verzeichneten Spracherscheinungen.

Für das geschichtliche Verständnis dieses Wörterbuchentwurfs ist es wesentlich zu erkennen, daß FRIsoHs umfassende Zielsetzung die Ziele mehrerer Teilwörterbücher in sich schließt und daß die Auffächerung des Stoffgebietes nach Kategorien, die dies sichtbar macht, nicht das Ergebnis einer von Raum und Zeit losgelösten theoretischen Besinnung ist, sondern geschichtliche Gegebenheiten widerspiegelt. Denn es sind die Ziele verschiedenartiger lexikographischer Teilbestrebungen der Zeit um 1700, denen FrIsoH mit den Kategorien des Specimen I Rechnung trägt. Usuale generale und Criticum weisen auf den Gedanken eines Wörterbuches der Gemeinsprache der Gegenwart; Archaeologum, Etymologicum und Eponymologicum umgrenzen das Arbeitsgebiet der gesohichtlich-sprachvergleichenden Wort- und Namenforschung; und hinter der Kategorie des Usuale speciale (Technicum) stehen Bestrebungen auf dem Gebiet der Mundarten- und

1 FrisoH, TLWb. (1741) Titelblatt.

2 Frisor, Speoimen I (1723) 3-4. 
Fachsprachenlexikographie. Im folgenden soll zunächst versucht werden, Wesen und geschichtliches Wirken dieser Einzelrichtungen des Wörterbuchschaffens erkennbar zu machen und - an Hand der lebensgeschichtlichen Zeugnisse, der Vorstudien zum Wörterbuch sowie des Wörterbuches selbst - ihre Bedeutung für die lexikographische Arbeit FrISCHS auf den Einzelgebieten der Wortforschung zu bestimmen (I-III). Ein über das Einzelne hinausgreifender Abschnitt (IV) wird sodann zu zeigen haben, aus welchen geschichtlichen Voraussetzungen der Gedanke einer Gesamtdarstellung des deutschen Wortschatzes erwachsen ist, der dem 'Teutsch-Lateinischen Wörter-Buch' als Gesamtwerk zugrunde liegt und die Ergebnisse des Schaffens auf den Einzelgebieten nicht nur als äußere Klammer zusammenhält, sondern als Teile eines Ganzen auch innerlich zueinander in Beziehung setzt.

\section{Die lexikographische Erschließung der neuhochdeutschen Gemeinsprache}

Frisor wandte sich der Wortforschung zu in einer Zeit angespannten Bemühens um die lexikographische Erschließung der neuhochdeutschen Gemeinsprache. Innerhalb weniger Jahrzehnte wurden drei umfassende Darstellungen ihres Wortsohatzes veröffentlicht: KaSPar StrriLERS 'Stammbaum und Fortwachs' (1691), Matrmias Kramers 'Teutsch-Italiänisches Diotionarium' (11700/02; ${ }^{21724}$ ) und Christoph Ernst Steinbaohs 'Deutsches Wörter-Buch' (11725; ${ }^{2} 1734$ ).

Diese Werke - das Wörterbuch Matrhias Kramers allerdings nur bedingt erwuchsen aus Bestrebungen, die um die Mitte des 17. Jahrhunderts von Mitgliedern der Fruchtbringenden Gesellschaft ausgingen und bis in die erste Hälfte des 18. Jahrbunderts fortwirkten. Ihr Ziel war zum einen ein vertieftes Wesensverständnis der 'Muttersprache' schlechthin, zum anderen die grammatisch-lexikalische Festsetzung ihrer damaligen geschichtlichen Erscheinungsform: der werdenden deutschen Gemeinsprache der Zeit um 1700. Nicht zufällig wurden die Impulse, von denen diese sprachforschenden und sprachpflegerischen Bemühungen getragen waren, gerade im 17. Jahrhundert und zu Beginn des 18. Jahrhunderts stark wirksam. Der geschichtliche Vorgang des Werdens der deutschen Gemeinsprache hatte zu dieser Zeit eine entscheidende Stufe erreicht. Das 'Hochdeutsche' war soweit gefestigt, daß es - als Idee erfaßt - zum Gegenstand der theoretischen Erkenntnis und der auf Erkenntnis gegründeten Regelung gemacht werden konnte. Für die Frühentwicklung der neuhochdeutschen Wörterbuchschreibung wurde es bedeutsam, daß sich das Bemühen der in diesem Sinne wirkenden Bewegung von vormherein auch auf das Ziel einer lexikographischen Erschließung der deutschen 
Sprache richtete. Insbesondere Scrotres, der führende Theoretiker der Fruchtbringenden Gesellschaft, hob die Idee eines Deutschen Wörterbuchs in das Bewußtsein der ihm nahestehenden Kreise. Er gab damit zugleich den Anstoß zu dem angespannten lexikographischen Planen und Gestalten der folgenden Jahrzehnte: Stimeler, Kramer, Sterngach und die mit Wörterbuchentwürfen umgehenden Deutschen Gesellschaften des 18. Jahrhunderts betrachteten sich als Vollstrecker der von SoHotrisu erhobenen Forderung.

Der Gedanke, den Wortschatz der deutschen Sprache zu erfassen, war in Kreisen muttersprachlich gesinnter deutscher Humanisten bereits während des 16. Jahrhunderts herangereift. Trotz der Bemühungen Josd a Maaters (1561) und Georg Heniscrss (1616) wurde ein vollgültiges Deutsches Wörterbuch zu dieser Zeit jedoch nicht geschaffen: die gesohichtlichen Voraussetzungen seines Entstehens waren noch nicht gegeben. Erst um die Mitte des 17. Jahrhunderts hatten sich die Bedingungen gewandelt. Die nunmehr von Mitgliedern der Fruchtbringenden Gesellschaft entwickelten Pläne für ein Deutsches Wörterbuch entstanden in einer Zeit abschließenden Werdens der deutschen Gemeinsprache. Während die landschaftsgebundenen Schreib- und Sprechsprachen des 16. Jahrhunderts im Gebrauch zurücktraten, erweiterte und festigte das werdende 'Hochdeutsch' seine Geltung. Es griff allmählich hinaus über den begrenzten ständischen und landschaftlichen Bereich, in dem es ursprünglich verwendet worden war; gleichzeitig regelten Grammatiker Lautstand, Schreibung und Formenbildung. Hatte das lexikalische Werk des Schweizers JosUa MAaLme unter den Bedingungen des Reformationszeitalters noch notwendig die Gestalt eines Wörterbuches der landschaftlichen Schriftsprache annehmen müssen, so war nunmehr die sprachgeschichtliche Voraussetzung für das Entstehen eines Wörterbuches der deutschen Gemeinsprache gegeben.

SchоттеL und die in seinem Sinne wirkenden Mitglieder der Fruchtbringenden Gesellschaft haben die Idee eines Deutschen Wörterbuchs nicht nur als solche erfaßt und verkündet, sondern ihr zugleich einen festumrissenen Inhalt im Sinne der Grundanschauungen des sprachtheoretischen Denkens gegeben. Die lexikographischen Bestrebungen der Folgezeit wurden dadurch von vornherein in eine bestimmte Richtung gelenkt. Es ist an dieser Stelle notwendig, einige Grundzüge der im Kreise der Fruchtbringenden Gesellschaft entworfenen Richtlinien des Wörterbuchschaffens zu kennzeichnen. Das geplante Wörterbuch sollte in erster Hinsicht die 'Grundrichtigkeit' der deutschen Sprache erkennbar machen; und zwar zum einen durch Festsetzung des gültigen 'hochdeutschen' Sprachgebrauchs, zum anderen durch Erhellung der Etymologie und der morphologischen Struktur des deutschen Wortschatzes. Das waren Merkmale, die als konstitutive Wesenszüge jedes Deutschen Wörterbuchs galten. Die diesen Forderungen nicht entsprechenden Wortschatzdarstellungen des 16. und 17. Jahrhunderts erschienen den Mitgliedern der Fruchtbringenden Gesellschaft demgegenüber lediglich als Vorstufen zu einem Wörterbuch der deutschen Sprache im vollgültigen Sinne. 
Ein drittes bedeutsames Merkmal trat hinzu: die hohe Wertschätzung der Muttersprache im Kreise der Fruchtbringenden Gesellschaft weckte den Willen, eine eigenständige Darstellung des deutschen Wortschatzes zu schaffen. In dem Bewußtsein, das erste im strengen Sinne Deutsche Wörterbuch zu erstreben, setzte der Kreis um SoHотtel sich ab von den 'Deutschen Wörterbüchern' der Humanistenzeit (MAAIER; HGNISCH) sowie von den fremdsprachlichen Werken, in denen die Muttersprache 'wie eine Magd und Nachsprecherin gehandhabt'1 wurde. So schrieb HARSDöRFTER:

'Obwol Heinisch, Pictorius, und andre wortbücher geschrieben, haben sie doch nur auf das latein gesehen ...2 Wie alle Dictionaria andren Sprachen dienen, so soll dieses (das von Harsdörffer geplante Deutsche Wörterbuch) $\mathrm{Zu}$ der unsern Sprache allein gewidmet seyn's.

Der Weg zu dem erstrebten Deutschen Wörterbuch sollte nicht über das lexiko* graphische Umsetz- oder Abschreibeverfahren führen. Obwohl Fürst Ludwia zu Anhalt-Köthen mehrfach auf das Wörterbuch HENIscHs als ergiebige Stoffquelle hingewiesen hatte und HARSDÖRFFER für eigene Sammlungen die Werke MAaLERS und HENISCEs als Unterlage benutzte, galt in der Theorie der Grundsatz, daß man den deutschen Wortschatz aus den Quellen zu erheben habe. Der Gedanke der Exzerption literarischer Texte schwebte deutlich vor. Bereits im März 1640 erklärte es Christran Guelnz in einem Brief an den Fürsten Ludwrg für wünschenswert, daß ein 'Wörterbuch' und ein 'Redensartbuch' umgehend 'aus den besten Schrifften' verfertigt würden. ${ }^{*}$ Sсноттиц teilte in der 'Teutschen Sprach. kunst' 1641 mit, daß er ein Wörterbuch der deutschen Sprache ausarbeiten wolle, in dem jedes Wort 'mit beygefügten guten Exempelen auß allerhand Authoren erkläret würde'. Er habe dafür seit mehreren Jahren Belege 'aus mancherley Authoren' gesammelt. ${ }^{5}$ In diesem Zusammenhang steht auch SoHotreus Forderung im Wörterbuchprogramm der 'Teutschen HaubtSprache' (1663), es müßte

'mit höchstem Fleisse dahin gesehen werden, daß die Teutschen Wörter aus dem Grunde Teutscher Deutung erkläret würden, und müsten zu dessen Behuf die Teutschen Bücher durchsuchet, der Teutsche rechte Gebrauch zu rahte gezogen seyn's.

An welchen Kreis von Sprachquellen man dachte, läßt HARSDöRFFERs Wörterbuchplan vom Jahre 1648 erkennen. HARSDöRFFER fordert eine Darstellung des deutschen Wortschatzes

'aus den gründen / nemlich aus allen Teutschen Büchern, und $\mathrm{Zu}$ solcher Durchlesung wird die gesammte hilff erfordert, $d z$ nemlich einer aus den

1 Schotter, HaubtSprache (1663) 159.

2 KRAUSE, Der Fruchtbringenden Gesellschaft ältester Ertzschrein (1855) 389.

3 Kratse a. a. O. 388.

4 Krause a. a. O. 245.

5 Schotтri, Teutsche Sprachkunst (1641) 9.

- Schottel, HaubtSprache (1663) 160. 
Reichsabschieden, der ander aus dem Goldast, der dritte aus D. Luther, der vierte aus den Poëten etc. alle besondre Stammwörter, Sprüche und redarten Ziehe, und muß hierinnen großer fleiß angewendet, und nach meiner meinung kein alter, noch neuer Scribent außgelassen werden, als in welchen der Grund der Sprache Zu untersuchen kommet. Was gemein ist übergehet man'1.

Diese Äußerungen zeigen den Gedanken der Wortschatzerfassung aus den Quellen in einer kennzeichnend normativen Ausprägung. Wie das lateinische Wörterbuch die Sprache der klassischen Autoren so sollte das Deutsche Wörterbuch das vorbildliche Hochdeutsch der als mustergültig anerkannten Schriftsteller verzeichnen. Die rein feststellende Haltung gegenüber der Sprach wirklichkeit blieb den Wortschatzsammlern fremd. Sie entsprach zum einen nioht der theoretischen Zielsetzung, die Idee der Sprache, ihre wesensmäBige 'Grundrichtigkeit' zu erfassen. Zum anderen würde sie der sprachgeschichtlichen Lage um die Mitte des 17. Jahrhunderts nicht gerecht geworden sein. Das Werden der neuhochdeutschen Gemeinsprache war um diese Zeit noch nicht abgeschlossen; sprachliche Einheit bahnte sich zwar an, wurde aber durch Fremdeinflüsse sowie durch Gegenkräfte im Innern fortwährend noch bedroht. Insofern bildete der sprachliche Ausgleich des 17. Jahrhunderts nicht nur die Voraussetzung, sondern auch noch das Ziel des Wörterbuchs. Es stellte sich in den Dienst der Aufgabe, den sprachlichen Einigungsvorgang zu fördern. Gegenüber der Willkür des noch immer stark uneinheitlichen Sprechens und Schreibens sollte es das Gültige festlegen und durch den Akt der Kodifizierung das auf dem Wege zur Hochsprache Erreichte sichern und fortführen. Dies galt zum einen für die kritische Sichtung des Stoffes: die Aussonderung oder Kennzeichnung mundartlicher und fremder Wörter; zum anderen betraf es die semantische und insbesondere die formal-grammatische Bestimmung des verzeichneten Wortgutes. Das Wörterbuch trat damit in enge Beziehung zur Grammatik, ja setzte diese geradezu voraus. So schrieb SchоттеL im Jahre 1645:

'Eine allerseits gantze, aus den gründen der Sprache und nach grundrichtiger gewohnheit eingerichte, und mit algemeiner beliebung angenommene Sprachkunst würde müßen, Zweiffels ohn, (dem Wörterbuch) vorhergehn und Zur durchgehenden Leitung angenommen werden'2.

Die sprachregelnden Bemühungen des Schottelkreises ruhten auf der Grundlage theoretischer Besinnung. Laienhaft forschend setzten sich Mitglieder der Fruchtbringenden Gesellschaft mit dem Phänomen der Sprache am Stoff der Muttersprache auseinander. Der Erkenntniswille dieses Kreises war im letzten nicht auf die Sprache als empirische Erscheinung gerichtet. ScноттеL, dem führenden "Theoretiker, war es darum zu tun, die zeitlose Wesenhaftigkeit, die Idee der Muttersprache zu erforschen. Zwar sah er in ihr keine rein metaphysische Größe,

1 Kratese a. a. O. 388-389.

2 Krause a. a. O. 296. 
da er die Sprachwirklichkeit soweit anerkannte, als sie ihm Vollzug der Idee ('hochdeutsch') zu sein schien. Aber das, was er zu erkennen und in den Formen der Grammatik und des Wörterbuchs darzustellen beabsichtigte, war das hinter der Erscheinung liegende Urbild: das 'grundrichtige' Gefüge der grammatischen Gesetze und der lexikalischen Einheiten der Muttersprache.

Die Aufgabe der normativen Grammatik und des normativen Wörterbuchs sollte demnach nicht darin bestehen, die Sprache willkürlichen Gesetzen zu. unterwerfen, sondern lediglich darin, die in ihr liegenden Gesetze bewußt zu machen. Wesentlich ist, daß es den Sprachtheoretikern um die Erkenntnis der 'Grundrichtigkeit' nicht nur im Bereich jener sprachlichen Erscheinungen zu tun war, die Gegenstand der normativen Darstellungsformen bildeten. Das Streben nach Erfassung der 'Grundrichtigkeit' richtete sich auf das Wesensganze der Muttersprache. Im Bereich der Wortforschung wirkte es sich aus in der Neigung zu etymologischen Deutungsversuchen, vor allem jedoch in dem Streben, eine strukturell gegliederte Darstellung des deutschen Wortschatzes zu liefern. Denn Grundüberzeugung war, daß der deutsche Wortschatz nicht eine Summe von Einzelwörtern, sondern ein geordnetes Gefüge lexikalischer Einheiten bilde. Das Wörterbuch sollte dieses Gefüge erkennbar machen. Bezeichnend in diesem $\mathrm{Zu}$ sammenhang ist SoHotreus Urteil über das unvollendete Wörterbuch des Augsburgers Geokg Henisor. In diesem Werk sei, so bemerkt Sohotrer,

'die positio thematum, wie auch derivatio und compositio oftmals übergangen und misgesetzet. Welches auch, weil vera linguae principia ex fundamentis Grammaticis, qud ad radices, derivandi terminationes et doctrinam componendi damals ohnzweiflich nicht allerdings bekant oder beliebt, ordentlich und gründlich nicht hat geschehen können's.

Bedenkt man, daß dieses Buch als Stoffgrundlage für neue lexikalische Vorhaben immerhin empfohlen und benutzt wurde; so ist ersichtlich, wie sehr der Nachdruck der lexikographischen Bemühung auf theoretischem Gebiet lag. Das Wörterbuch übernahm die Aufgabe einer systematischen Wortschatzdarstellung: die Erfassung der Stammwörter und der Bildungsverwandten jedes Stammwortes in genealogischem Zusammenhang. Das bedeutete für die Stoffanordnung Verzicht auf streng alphabetische Anlage zugunsten der Darstellung nach Wortsippen und verleitete bei der Stoffgewinnung zum Abtasten der Wortbildungsmöglichkeiten teilweise über die Grenzen des sprachlich Wirklichen hinaus.

\section{2}

Die Pläne für ein Deutsches Wörterbuch, die seit der Mitte des 17. Jahrhunderts entworfen wurden, standen im Zeichen dieser von sprachtheoretischen Grundanschauungen bestimmten Richtlinien des lexikographischen Schaffens. Eine

1 SoHotrex, Teutsche HaubtSprache (1663) 159. 


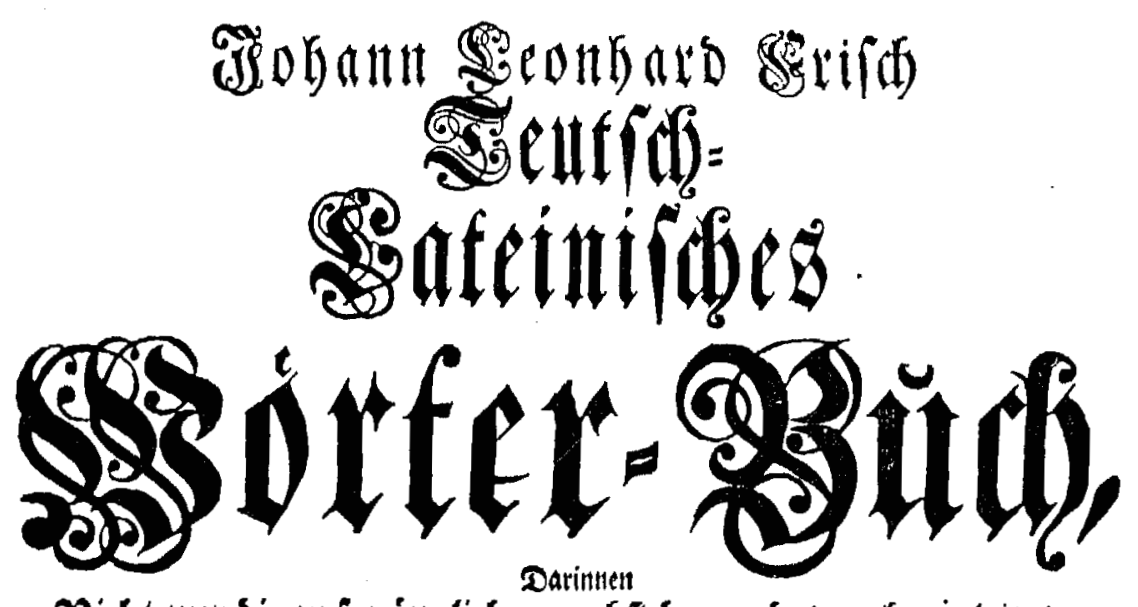

Sidet nut bie utipuiltgliden, nebit benen bayon berseleiteten uno jufammengereşten allgemein gebräud)liden $\mathfrak{B d r t e r ; ~}$

Sonsern aud) die bey den mififtn

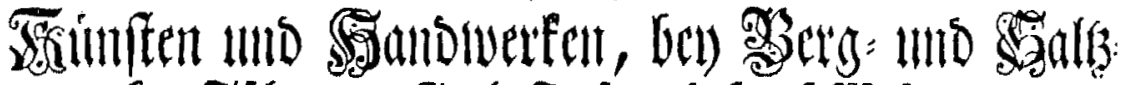

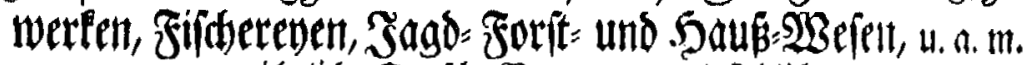

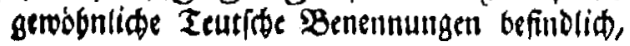

Bor allen,

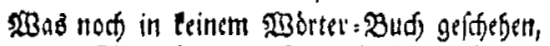

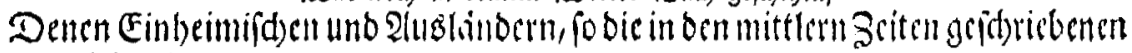

Siftorien, Ebronifen, Lberfesungen, Reimen u. D. g. mit igren wirnteten

Mortern und auboritungen verpefien wollen, móglideft us bienten,

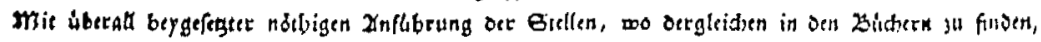
Eamt angstingler

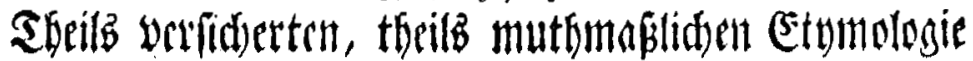
und critifoten Inmerfungen;

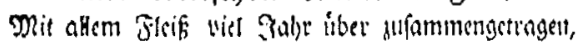

Lnd jest ben Galcbrten zut beliebigen 3 ermebrang und Dertefferung ibcrlajin.

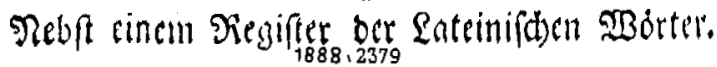

26COx

Perlin,

Zertegts equriftoph Gottlieg Nicolat

74 I. 
Darstellung des deutschen Wortschatzes, die sie verwirklicht hätte, ging aus dem Kreise SchoтTELs allerdings nicht hervor. Äußere Schwierigkeiten sowie der Vorrang grammatischer und wortschatztheoretischer Arbeiten verhinderten das Zustandekommen des Werkes. Mehrere Jahrzehnte blieb es bei Entwürfen und Ansätzen zur Belegsammlung, obwohl der Wörterbuchgedanke in der Zeit zwischen dem Erscheinen der grammatischen Hauptschriften SoHonteLs - der 'Teutschen Sprachkunst' (1641) und der 'Teutschen HaubtSprache' (1663) außerordentlich lebhaft erörtert wurde. Von ScHotreu selbst gingen die richtungweisenden Anregungen aus. Seit den dreißiger Jahren sammelte er für ein Deutsches Wörterbuch 'also, daß ein jedes Wort zu seinem Stamme oder Wurtzel gebracht ... würde'1. Ziel und Anlage des Werkes umschrieb das knappgefaßte Programm in der Einleitung zur 'Teutschen Sprachkunst'. Ein Meinungsaustausch, insbesondere mit dem Fürsten LoDwra, der lebhaft bemüht war, das Unternehmen in die Wege zu leiten, sowie mit HARSDÖRFFER erstreckte sich über mehrere Jahre. 1647 sah sich SoHOTTEL wegen beruflicher Überlastung jedoch gezwungen, den Wörterbuchplan aufzugeben. ${ }^{2}$ HARSDöRfFER befand sich zu dieser Zeit bereits im Besitz eigener Sammlungen 'fast aus allen Poeten und vielen Deutschen Scribenten Zusammen getragen'3. Nunmehr griff er den Gedanken SoHотruls auf und entwarf 1648 den ersten durchgearbeiteten Plan eines Deutschen Wörterbuchs im Sinne der Sprachtheorie. ${ }^{4}$ Im Mitgliederkreis der Fruchtbringenden Gesellschaft ging HaRSDöRFrens Entwurf von Hand zu Hand, aber der Vorschlag, das Werk als Gemeinschaftsarbeit anzugreifen und in einem Jahre zu vollenden, fand keinen Widerhall. 1656 und 1657 verhandelte SoHotres mit G. NedMarK nochmals über den Wörterbuchplan - wiederum ohne Ergebnis. ${ }^{5}$ Mit dem Programm in der 10. Lobrede des ersten Buches der 'Teutschen HaubtSprache' $(1663)^{6}$ zog SoHotrex den Schlußstrich unter diese erfolglosen Bemühungen, schuf zugleich aber eine Grundlage für das Fortwirken der sprachtheoretischen Auffassungen in den folgenden Jahrzehnten.

Erst um die Wende des 17. Jahrhunderts wurde das von der Fruchtbringenden Gesellschaft erstrebte Wörterbuch der deutschen Gemeinsprache verwirklicht: im Jahre 1691 erschien 'Der Teutschen Sprache Stammbaum und Fortwachs' von KaSPaR STrELER, ein Jahrzehnt später (1700/02) 'Das herrlich Grosse Teutsch-Italiänische Dictionarium' von Matthias Kramer. Die beiden führenden Lexikographen der Zeit um 1700 suchten die von ScHotTEL gestellte Aufgabe auf verschiedenen Wegen zu lösen. Während STIELER - selbst Mitglied der Frucht-

1 SoHоттег, Teutsche Sprachluunst (1641) 9 .

2 Krafse a. a. O. 384-385.

a KraUse a. a: O. 385.

4 KRAUSE a. a. O. 387-392.

s HiLdirarand in: Deutsches Wörterbuch 5 (1873) II-III.

- Schoтtzi, Teutsche HaubtSprache (1663) 159-160; das Programm findet sich bereits in der zweiten Auflage der 'Teutschen Sprachkunst' (1651) 297-300. 
bringenden Gesellschaft - sich auch in der Ausführung von sprachtheoretischen Auffassungen durchgreifend bestimmen ließ, folgte Krammin einer im Anschluß an pädagogische Reformerwägungen JoHANN JоAOHIM BECHERs entwickelten lexikographischen Methode. Diese Methode war aus den Erfahrungen des Fremdsprachenunterrichts erwachsen; sie lieferte Ergebnisse, die dem Wörterbuch MatTHIAs Kramers eine Vorzugsstellung in der Frühgeschichte der deutschen Lexikographie sichern. ${ }^{1}$ Trotz seines hohen Leistungsvermögens und trotz einer Neuanflage im Jahre 1724 wurde das Werk als Deutsches Wörterbuch zu seiner Zeit jedoch nicht gebührend gewürdigt; es blieb während des 18. Jahrhunderts weithin unbeachtet. Als einziges repräsentatives Deutsches Wörterbuch galt bis zum Erscheinen der Darstellungen ChrrstopH ERNST SteINBadHs der 'Stammbaum und Fortwachs' KaSPar STrIELERS.

Es war bedeutsam, daß sich der Kreis der sprachkundlich Arbeitenden bestimmter Schwächen dieses Werkes frühzeitig bewußt wurde. Bereits KrammR setzte sich in der Vorrede zum 'Teutsch-Italiänischen Dictionarium' mit der Darstellung StrELERS kritisch auseinander. Er wandte sich gegen die Überspitzung des Prinzips der Anordnung nach 'Stammwörtern', die ein doppeltes Nachschlagen erforderlich mache, insbesondere jedoch dagegen, daß STIELER

'auf eine gantz eigen-sinnige / aller gesunden Vernunfft widerstrebende Critique gegründet / viel / offenber von Griechisch- Lateinisch- oder auch Frantzösischen Gründen hergekommene nunmehr teutsche Wörter dennoch von teutschen Stamm-Wörtern ... gantz lächerlich und capricieux erzwingen' 2

wolle, Ein zweiter Einwand galt SrIELERs Neigung, den deutschen Wortschatz um Wörter zu erweitern,

'die sich zwar nach den Gesetzen der teutsohen Derivir. und Componir-Kunst von einem Stamm-wort abstammen lassen / aber noch nie nirgend in gangbare Ubung kommen seynd's.

Diese Bedenken trafen zwei Hauptansatzpunkte der lexikographischen Bemühungen STrELERs. Es ist kennzeichnend, daB sie 1734 in ähnlicher Form von Christoph ERNst SternbaCH erneut erhoben wurden. ${ }^{4}$ Auch Steingadr wies darauf hin, daß STIELER 'Worte nach eigenem Belieben' ansetze, und auch er distanzierte sich von dem willkürlichen Verfahren der etymologischen Herleitung, das sich auch auf die Stoffanordnung nachteilig auswirke, so daß man beispielsweise das Wort Mutter unter Amme, das Wort Tochter unter Ziehen suchen müsse. Außerdem wies er auf grammatische Fehlinterpretationen STrELIERS hin; insbesondere bemängelte er, daß das Werk 'nicht nach der allgemeinen Schreib-

1 Isinc, Die Erfassung der deutschen Sprache des ausgehenden 17. Jahrhunderts in den Wörterbüchern Matthias Kramers und Kaspar Stielers (1956).

- Kramer, Teutsch-Italiänisches Dictionarium 1 (1700) (a) $4^{\mathrm{b}}$.

- Kramer a. a. O. (e) $2^{\text {b. }}$.

4 Steinbach, Vollst, Deutsches Wörter-Buch $1(1734) * * 3^{b}-4^{b}$. 
art eingerichtet' sei. Diese Äußerungen Starnbaorrs bezeugen, daß das Wörterbuch STrELERs die Erwartungen selbst der Kreise nicht voll erfüllte, die der Sprachauffassung ScHotTmLs verbunden waren.

Es ist daher verständlich, daß die Bemühungen um ein Wörterbuch der deutschen Gemeinsprache auch nach dem Erscheinen von Srrourers 'Stammbaum und Fortwachs' weitergingen. Träger des Wörterbuchgedankens waren neben Einzelforschern die Nachfolgeorganisationen der Fruchtbringenden Gesellschaft: die sprachpflegenden Deutschen Gesellschaften, die zu Beginn des 18. Jahrhunderts in einer Reihe deutscher Residenz-, Universitäts- und Handelsstädte entstanden. Je mehr man einzusehen begann, daß ein Deutsches Wörterbuch von einem einzelnen nicht geschaffen werden könne, um so fester klammerte sich die Hoffnung gerade an das Wirken dieser Vereinigungen. Schon 1690 hatte Christian Gryphius (seit 1686 Rektor am Gymnasium zu St. Maria Magdalena in Breslau) unter Hinweis auf das unvollendete Werk GEORG HENISOHs gefordert, da $B$

'eine Versammlung der gelehrtesten Leute zusammen kommen / und weil es doch einem zu verrichten unmöglich mit gesammter Hand sich dieser herrlichen Arbeit unterfangen solte.' 1

Er äußerte die Zuversicht, daß die 'hochlöbliche fruchtbringende / oder eine an. dere zu diesem Zweck aufgerichtete Gesellschafft das Verlangen der Inn- und Ausländer'2 nach einem Deutschen Wörterbuch erfüllen werde.

Die Geschichte der Deutschen Gesellschaften des 18. Jahrhunderts ist wenig erforscht; ihre Bemühungen um ein Wörterbuch der deutschen Gemeinsprache wurden bisher noch nicht zusammenfassend gewürdigt. Es muß hier deshalb genügen, darauf hinzuweisen, daß zahlreiche dieser Vereinigungen, die seit dem Anfang des 18. Jahrhunderts in Bern, Mannheim, Hamburg, Göttingen, Helmstedt, Halle, Weimar, Jena, Leipzig, Frankfurt (Oder), Greifswald, Königsberg und andernorts entstanden, das Ziel verfolgten, ein Deutsches Wörterbuch zu schaffen. Von besonderer Bedeutung für die Entwicklung der Deutschen Gesellschaften war das Wirken von GoTTERIED WILEwLM LiEIBNIZ. LmIBNIz hatte nicht nur in der 'Ermahnung an die Teutsche' (1679) die Gründung einer Teutsch. gesinnten Gesellschaft gefordert und in den 1697 niedergeschriebenen 'Unvor. greiflichen Gedanken' für eine Vereinigung dieser Art ein allerdings sehr viel weiter gespanntes lexikographisches Forschungsprogramm entworfen. Er hatte in Berlin die Preußische Societät der Wissenschaften (1700) miterrichtet, deren Historisch-Philologische Klasse die Aufgabe einer Teutschgesinnten Gesellschaft wahrzunehmen und auf der Grundlage von Entwürfen der Brüder JABLONskI ein Deutsches Wörterbuch zu schaffen beabsichtigte. Von LiIBNIz angeregt war auch der Plan, in Wien eine unter der Schirmherrschaft des Kaisers stehende

1 GRYPHrus, Der Deutschen Sprache Alter und Wachsthum (1708) 167.

2 Gryphios a. a. O. 168. 
'Carolinische Academie' für die Pflege der cleutschen Sprache zu errichten. ${ }^{1}$ Während seines Aufenthaltes in Wien hat LEIBNIZ in dieser Richtung am kaiserlichen Hof Verhandlungen geführt. Er wurde dabei von dem kaiserlichen Rat und Antiquitäten-Inspektor CARI GUSTAV HaRaEUS (1671-1730) unterstützt. In einem Promemoria, das Heraeus später in seinen 'Gedichten und Lateinischen Inschriften' (Nürnberg 172I) abdrucken ließ², bezeichnete er es als die Aufgabe der Gesellschaft, die Arbeiten Sorromress und STrzLeRs fortzuführen. Neben einer deutschen Grammatik und einer deutschen Stillehre sollte auch ein vollständiges deutsches Wörterbuch 'von allen Stamm-Worten und zu dultenden Redens.Arten, samt Meldung der guten Schreiber, so sich deren glücklich bedienet's geschaffen werden. Der gesetzgeberische Charakter der Akademio und. der von ihr herausgegebenen Werke wird ausdrücklich betont:

'so kommt es hier insonderheit auf den Nachdruck einer zur Ab-und Einsetzung der Worte genugsam berechtigten Gesellschaft an, nach deren Aussprüchen nicht weniger, als in Frankreich nach der Academie, die zweiffelende oder streitende sich richten, und die lernende sich helfen können. ${ }^{14}$

Die einzige Darstellung des deutschen Wortschatzes, die in den ersten Jahrzehnten des 18. Jahrhunderts vollendet und veröffentlicht wurde, war clas 'Deutsche Wörter-Buch vel Lexicon Latino-Germanicum' ChristopH ERNST StwinBACHs. ${ }^{5}$ Das Werk erschien in erster Auflage zu Breslau 1725. Der damals siebenundzwanzigjährige Verfasser hatte 1724 bereits eine kurze deutsche Grammatilk veröffentlicht. Das Wörterbuch, das er bald darauf fertigstellte, entstand zu einer Zeit, da die Einsicht sich durchsetzte, daß die Darstellung des Wortschatzes der deutschen Sprache nicht das Werk eines einzelnen sein könne. STEINBadr war sich bewußt, daß der gedrängte Abriß, den er vorlegte, nicht als das von den Zeitgenossęn erstrebte Deutsche Wörterbuch anzusehen sei. Von vornherein hatte er darauf verzichtet, den Sprachstoff aus den Quellen zu erheben. Seiner Darstellung legte er vielmehr den deutschen Index zu dem lateinischen Wörterbuch Johandes Linderers zugrunde. ${ }^{6}$ Sternbachs Hauptanliegen war es, das Wortgut der deutschen Sprache zu deuten im Sinne des Stammwortgedankens der Sprachtheorie. Er ordnete daher die alphabetische Wortreihe LiNDNERs um, indem er Stammwörter aussonderte und ihnen die zugehörigen Ableitungen und Zusammensetzungen angliederte. Dabei begnügte er sich nicht damit, sprach-

1 Kropp, Leibniz' Plan der Gründung einer Societät der Wissenschaften in Wien. In: Archiv für österreichische Geschichte. 40 (1869) 157-255; KLUGr, Von Luther bis Lessing ( ${ }^{5} 1918$ ) 236-237; MULTRTT, Deutsche und romanische Sprachreiniger. In: GRM. 17 (1929) 135-136.

2 Heramus, Gedichte und Lateinische Inschriften (1721) 264-276.

3 Htgraeus a. a. O. 274.

4 Herramus a. a. O. 269.

E. ScHzöder, Chr. E. Steinbach. In: ADB. 35 (1893) 684-686.

6 Stmingaor, Follst. Deutsches Wörter-Buch 1 (1734) ** $6^{\text {b }}$. 
geläufige Nennformen als 'Stammwörter' anzusetzen, sondern er suchte 'die sonderbare Einrichtung der deutschen Wörter'1 zu ergründen, das heißt: in der sprachgeschichtlichen Dimension zu 'Wurzeln', zu Urformen (voces ratione derivationis solum annotatae ${ }^{2}$ ) vorzustoßen. Kennzeichnend für den unempirischen Charakter des dabei angewendeten Herleitungsverfahrens sind die Beispiele, die Sternbach selbst in der Vorrede des Wörterbuchs anführt. ${ }^{3}$ Er stellt hier ruchlos zu dem Stammwort gerochen mit der abhängigen Bildung Der Ruch (wie Flug zu geflogen), 'welches vor diesem so viel mag geheissen haben, als: Recht, Gerechtigkeit'. Ähnlich verbindet er leidselig mit einer Grundform Leidsal (wie trübselig zu Trübsal) ('mag vor diesem seyn im Gebrauch gewesen, das so viel hat heissen müssen, als das anitzo gebräuchliche Wort Leid').

In zweiter Auflage erschien das Wörterbuch zu Breslau 1734; es war nunmehr auf zwei Bände erweitert. Der Stoffzuwachs entstammte einerseits ergänzend benutzten lexikalischen Hilfsmitteln (dem deutschen Index zu dem lateinischen Wörterbuch von FABER; dem Zeitungslexikon; HeDERTCrrs 'Promtuarium Latinitatis') andererseits literarischen Quellen (OPITz, RAcher, Lohensters, Hommannswaldad, Stoppe, Günterer). Die Gesichtspunkte der Bearbeitung hatten sich nicht gewandelt; in der Vorrede lehnte STEINBAOH das alphabetische Wörterbuch nachdrücklich ab:

'soll es (das Wörterbuch) ... die Richtigkeit einer Sprache völlig zu erkennen geschickt seyn, so ist nöthig Grundwörter zu setzen, und die daher geleiteten Wörter in gehöriger Ordnung dabey an zu mercken, damit es dem Leser den Begreiff leichter mache'4.

Erkennbar geworden sind das Wesen der lexikographischen Anschauungen der Fruchtbringenden Gesellschaft und die Kraft ihres geschichtlichen Fortwirkens in den Jahrzehnten um 1700. Unter dem Eindruck der Wörterbuchtheorie HARSDÖRFFERS und SOHOTTELS und ihrer ersten Gestaltgebung im 'Stammbaum und Fortwachs' KaSPAR Streume wandte sich das lexikographische Planen und Schaffen, eingegrenzt auf das Stoffgebiet der werdenden deutschen Gemeinsprache, den Zielen des normativen Kodifizierens und der etymologisch-strukturellen Durchgliederung des Wortschatzes zu. Dabei bestimmte oder beeinflußte die sprachtheoretische Auffassung vom Wesen eines Deutschen Wörterbuches die Anschauungen nicht nur der wenigen, die in diesen Jahrzehnten tatsächlich an einem Deutschen Wörterbuch arbeiteten. Der Gedanke, eine Darstellung des deutschen Wortschatzes im Sinne HarsDörFrers und ScHotTeLs zu schaffen, zählte zu den Standardforderungen der Deutschen Gesellschaften, die zu Anfang

1 Strminbaor, Deutsches Wörter-Buch (1725) a $3^{\mathrm{a}}$.

2 Strernbach, Vollst. Deutsches Wörter-Buch 1 (1734) Praefatio 6a.

3 Stminbach, Deutgches Wörter-Buch (1725) a $3^{\text {b-a }} 4^{\text {b }}$.

4 Stmisbach, Vollst. Deutsches Wörter-Buch $1(1734)^{* *} 1^{\mathrm{b}}$. 
des 18. Jahrhunderts das Erbe der Fruchtbringenden Gesellschaft antraten. Namentlich durch sie wurden breitere Kreise mit dem Gedankengut der Gruppe um ScHotrel vertraut. Möglichkeiten des Einwirkens auf jeden erneuten Versuch einer lexikalischen Erschließung der deutschen Sprache waren damit gegeben.

Auch Frisch ist mit dem Gedankengut der Sprachtheorie des 17. Jahrhunderts in Berührung gekommen. Allerdings bleibt es ungewiß, wann er die lexikographischen Auffassungen SoHotrels und die Darstellung StrwLERs kennenlernte. Da die Anfänge seines Wörterbuchschaffens ungefähr in die Zeit fallen, in der STIkLER den 'Stammbaum und Fortwachs' (Nürnberg 1691) soeben hatte erscheinen lassen, ist die Frage nicht abwegig, ob etwa die Veröffentlichung dieses Werkes den Anstoß zur Aufnahme der Arbeiten am 'Teutsch-Lateinischen Wörter-Buch' gegeben habe. Für eine solche Annahme bieten sich keine sicheren Anhaltspunkte. Zwar zeigt sich FrIsch 1711 mit dem Schicksal des STIELERschen Wörterbuchnachlasses gut vertraut. ${ }^{1}$ Auch besaß er, wie der Auktionskatalog seiner Bibliothek ausweist', neben SototTELs 'Teutscher HaubtSprache' (1663) Des Spaten teutscher Sprache Stammbaum, durchschoßen und hier und da mit MS. notis versehen', und beide Werke sind bei der Bearbeitung des 'TeutschLateinischen Wörter-Buches' wiederholt als Quellen hinzugezogen worden. Aber es läßt sich nicht nachweisen, daß Frrsorl bereits in dieser frühen Zeit sich mit ihnen beschäftigt hat ${ }^{3}$ und da $B$ sie den Anstoß erteilten, der in ihm den Gedanken reifen ließ, ein Deutsches Wörterbuch zu verfassen.

Allerdings ergab sich die Notwendigkeit der Auseinandersetzung mit Auffassungsweisen sprachtheoretischer Prägung für FRISOH mehrmals während der fünfzig Jahre des Schaffens am 'Teutsch-Lateinischen Wörter-Buch'. Die Werke SCHOTтELs und STIELERs mögen ihm zufrühest die Kenntnis der lexikographischen Anschauungen der Fruchtbringenden Gesellschaft vermittelt haben, seit der Jahrhundertwende auch das deutsch-italienische Wörterbuch MaTwrias Kramers, das Frisor besaß und für die Darstellung des Usuale generale als lexikalische Hauptquelle benutzte. Die Tatsache, daß Frisch diese Werke für geeignet hielt, als Stoffgrundlage der eigenen Darstellung des deutschen Wortsohatzes zu dienen, darf nicht darüber hinwegtäuschen, daß er gegenüber ihren theoretischen Grundlagen ernste Bedenken trug. Sie kommen an mehreren Stellen des 'TeutschLateinischen Wörter-Buchs' zum Ausdruck. So heißt es im Artikel 'Ur':

'Vom Schottelio wurde endlich ur ganz förmlioh unter die Teutschen kleinen Ergrösserungs-Wörter aufgenommen. p. 255. sq. Da fiengen die Sprach-Künstler, sonderlich einige Poeten, an mit diesem ur neue Composita zu machen und auszusäen, und freueten sich, daß die Sprach mit einem so schönen Frund

I Vgl. S. 25.

2 Bibliotheca, Joh. Leonh. Frischii (1743) 64.

- Das früheste Zeugnis liegt vor in den Berufungen auf Strexer, Soнotrres und HarsDörfrFer, die sich in der 'Untersuchung des Grundes und Ursachen der Buch. stab-Veränderung' (1703) 4; 30; 44 finden. Zur Datierung dieser Schrift vgl. S. 39-40. 
bereichert worden. Die Lexicon-Schreiber halfen getreulich dazu, auoh in frem. den Sprachen, als Somnerus im Angels. Cramer im Ital. Du Fresne in Gloss. Lat. bey dem Wort ordalium, u. a. m. Der Spate in seinem Sprach-Schatz dichtet nicht nur mehr Wörter als Schottel, sondern er setzt das ur noch tieffer in die Teutsche Sprach ...' $(2,4080)$.

In scharfem Ton erhebt Frisch den Vorwurf der Sprachbereicherung namentlich gegen das stoffreiche 'Teutsch-Italiänische Dictionarium' MaT'THIAS Kramers. Am Ende des Artikels 'Haus' findet sich die Bemerkung:

'Ein gewisser Wörter-Sammler hat nach seiner Art, die Teutsche Sprach unnöthiger Weise mit Wörtern zu vermehren gesucht, die man nicht braucht, und die wider die Regeln formirt sind' $(1,429 \mathrm{~b})$.

Die angeführten Beispiele lassen erkennen, daß nur KRAMER gemeint sein kann, und an mehreren Stellen wird er im Zusammenhang mit gleichgerichteten kritischen Äußerungen dann auch namentlich erwähnt. ${ }^{1}$

Im zweiten Jahrzehnt des 18. Jahrhunderts wurden sprachtheoretische Auffassungen an Frisor herangetragen von Seiten der Historisch-Philologischen Klasse der Berliner Societät der Wissenschaften. Die Gründer der Societät hatten der Klasse bereits frühzeitig die Aufgabe gestellt, ein Wörterbuch der deutschen Sprache auszuarbeiten. Schritte zur Durchführung dieses Vorhabens wurden jedoch erst unternommen, als FirmDRICH I. anläßlich der Eröffnungsfeier der Societät am 19. Januar 1711 der Historisch-Philologischen Klasse erneut den Auftrag erteilte, ein 'vollständiges deutsches Wörterbuch' zu schaffen. ${ }^{2}$ Der König mochte sich von dem Gedanken an das Wörterbuch der Académie Française leiten lassen; auch die Möglichkeit, daß eine (1694 gegebene) Anregung JoHANNmS BöDIKERs nachwirkte, ist nicht auszuschließen. ${ }^{3}$ An der Societät war es nun, den Auftrag auszuführen. Als Direktor der Historisch-Philologischen Klasse amtierte der Numismatiker JoHANN KaRL SoHOTT; aber nicht er war die treibende und richtungweisende Kraft. Vielmehr bereiteten der Hofprediger DanImL ERNST JABLONSKI und sein Bruder, der Societätssekretar JohanN Theodor JABLONskI, die Aussprache über das Wörterbuchunternehmen vor: sie arbeiteten - vielleicht unmittelbar im Auftrage des Königs - einen Entwurf des geplanten Werkes aus. Im Archiv der Preußischen Akademie der Wissenschaften fand Adolf Harnack 'verschiedene Aufsätze über die Einrichtung eines deutschen Wörterbuchs, größtentheils von des Hofpredigers Hand'4. Einen dieser Entwürfe D. E. JABLONSKIs (mit der Datierung: 1711) hat HaRRAOK im Urkundenband seiner Ge-

1 Friscri, TLWb. (1741) 1, 73a; 1, 233b; vgl. 2, 408c. Daß FrIschs Bedenken nioht allein der Neigung zur Sprachbereicherung galten, sondern auch dem spekulativen Verfahren der Herkunftsbestimmung, wie insbesondere STIELER es angewandt hatte, bezeugen weitere kritische Einwände (1,334b; 2, 408c).

2 Harnack, Gesch. d. Königl. Preub. Akademio der Wissenschaften zu Berlin (1900) 1, 177.

3 Vgl. S. $63-64$.

4 HaRnack a. a. O. 1, 193. 
schichte der Akademie abgedruckt. ${ }^{1}$ Er ist teilweise identisch mit dem 'Entwurf eines deutschen Wörterbuchs von dem Herrn Rath Jablonsky zu Berlin aufgesetzet', der 1738 in den Leipziger 'Beyträgen Zur Critischen Historie der Deutschen Sprache, Poesie und Beredsamkeit' erschien." Aus einer redaktionellen Begleitnote der 'Beyträge' geht hervor, daß JABLONSKI den Entwurf dem seit 1717 am Dresdener Hof lebenden Kriegsrat JoHANN von Bessmr mitgeteilt hatte und daB 1721 ein Mitglied der Leipziger Teutschübenden Poetischen Gesellschaft von ihm Kenntnis erhielt. ${ }^{3}$

Diese Entwürfe gewähren Einblick in die lexikographischen Auffassungen, die im Jahre 1711 den Gang der Aussprache in der Historisch-Philologischen Klasse bestimmten.

JABLONSKI beruft sich einleitend auf die Generalinstruktion der Societät und erinnert an die ihr als 'deutschgesinnter Gesellschaft' zugewiesene Aufgabe der Sprachpflege. Ausgangspunkt seiner Betrachtungen ist der Gedanke einer Gesamtdarstellung des deutschen Wortschatzes in drei getrennten Wörterbüchern: Lexicon etymologicum, Lexicon technicum, Lexicon usuale. Nur um das Lexicon usuale ist es ihm zu tun; ein Wörterbuch der Gemeinsprache der Gegenwart sei vordringlich. Die Pläne für das Lexicon etymologicum und Lexicon technioum werden vorerst zurückgestellt; diese Werke würden lediglich einem begrenzten Benutzerkreis zugute kommen und zudem schwer ausführbar sein.

Die ins einzelne gehenden Ausführungen über Zielsetzung und Anlage des geplanten Wörterbuches zeigen $\mathbf{J}_{\text {ABLONSKI }}$ in der Nachfolge SoHotrels und STrEL\#Rs. Er erstrebt eine normative Darstellung, ein Wörterbuch, durch das

'die Grundrichtigkeit erforschet, verbeßert und befestiget, und ein beständig bleibender Sprachschaz zusammengetragen werden könte'4.

Insbesondere geht es ihm um die Regelung der Rechtschreibung,

'damit das Werk auch in diesem nötigen Stück als eine zuverläßige Richtschnur gelten ... möge's.

Auch der Gedanke einer Erfassung der Wortschatzstruktur erscheint wieder: Ableitungen und Zusammensetzungen sollen nicht an ihrer alphabetischen Stelle, sondern unter dem Stammwort angeführt werden; ein alphabetisches Register wie in STrELmRs 'Stammbaum und Fortwachs' könne den Inhalt für Nachschlagezwecke erschließen. Der Stoff des Wörterbuches schließlich soll aus den Quellen, und zwar 'aus bewärten und solchen Schriften die ingemein zum Muster und Urbild unserer Sprache angenommen sind'6 erhoben werden. JABLONSKI

I HARNACK a. a. O. 2, 223-225.

2 Beyträge Zur Critischen Historie 5 (1738) 480-493:

3eyträge Zur Critischen Historie 5 (1738) 480 .

- Harnagk a.' a. 0. 2, 223.

- HaRNack a. a. O. 2, 225.

- Harnack a. a. 0. 2, 224. 
widmet in diesem Zusammenhang der Ausarbeitung eines Quellenkanons ('Authores classici' der deutschen Sprache) besondere Aufmerksamkeit. Historisches, mundartliches und fachsprachliches Wortgut soll nur soweit in das Wörterbuch Eingang finden, als es der Erhellung des gemeinsprachlichen Wortschatzes dient.

Ein Entwurf dieses Inhalts wurde der Historisch-Philologischen Klasse auf ibrer ersten ordentlichen Zusammenkunft am 12. Februar 1711 vorgelegt. J. Trr. JABLONski erinnerte daran, daß seit der Gründung der Societät der Plan bestanden habe, ein Deutsches Wörterbuch zu schaffen. Es sei 'aus bekannten Ursachen' bisher unausgeführt geblieben; der König wünsche jedoch, daß die 'Teutschgesinnete Abtheilung' nunmehr unverzüglich mit der Arbeit beginne. In der Aussprache einigte man sich im AnschluB an den Entwurf J $J_{A B L O N S K I s}$ dahingehend, daß es die Aufgabe des Wörterbuchs sein werde, die Rechtschreibung der deutschen Wörter festzulegen, Fremdwörter durch deutsche Ausdrücke zu ersetzen und grammatische Fehler 'in gemeinem Reden und Schreiben' zu verbessern. ${ }^{1}$

Damit war die Richtung der lexikographischen Arbeit auf das Ziel eines orthographisch-grammatischen Wörterbuchs der neuhochdeutschen Gemeinsprache festgelegt. Die Voraussetzung einer Wortschatzdarstellung dieser Art bildete wie bereits SoHotrel erkannt hatte - eine normative Grammatik. Es war daher folgerichtig, daß sich die Klasse unverzüglich der Erörterung grammatischer Grundsatzfragen zuwandte. Ein wiederum von JABLONSKT ausgearbeitetes Gutachten rückte die Rechtschreibfrage in den Vordergrund. Die Aussprache darüber schleppte sich allerdings über mehrere Jahre hin und endete schließlich ergebnislos. Rascher verkümmerten Ansätze zu organisatorischen Maßnahmen: so der Plan eines Briefwechsels mit auswärtigen Gelehrten über Wörterbuchfragen und der Gedanke, den Berliner Literaten Benjamin Neukrmar mit der Abfassung des Werkes zu beauftragen. ${ }^{2}$ Auch eine (von FrisoH veranlaßte?) Anfrage in Erfurt nach dem Verbleib des nicht mehr gänzlich ausgedruckten Manuskripts der Fortsetzung von STIELERS 'Stammbaum und Fortwachs' führte nicht zum Erfolg. ${ }^{3}$ Auf der Sitzung am 30. April 1711 nannte der Direktor Schoтt unter den Aufgaben der Klasse an zweiter Stelle zwar noch die 'Ausfertigung eines vollkommenen Sprachschazes'4. Aber in den folgenden Jahren trat neben den Erörterungen über JABLONSKIs Rechtschreibentwurf die Arbeit an einer von der Klasse geplanten Tacitusübersetzung beherrschend in den Vordergrund.

Ein neuer Vorstoß - im Jahre 1718 - ging aus von FrisoH. Das Protokoll der Sitzung vom 3 . Februar dieses Jahres ${ }^{5}$ berichtet, daß ein von ihm vorgelegter Wörterbuchentwurf mit dem Probeartikel 'Land' zu dieser. Zeit unter den Mit-

1 Protokoll vom 12. 2. 1711.

2 Protokoll vom 12. 2. 1711.

3 Protokoll vom 9.7. 1711.

4 Protokoll vom 30. 4. 1711.

5 Protokoll vom 3.2. 1718.

8 Powitz, Frischs Wörterbuch 
gliedern der Klasse umlief und auf der Sitzung besprochen wurde. Die Stellungnahme der Klasse zu diesem Entwurf war bezeichnend: aus dem Gesamtplan wir dürfen ihn mit dem 1723 veröffentlichten Specimen I gleichsetzen - sonderte man den Gedanken des Dictionarium usuale als allein erwägenswert ab. Und zwar mit der Begründung, ein gegenwartssprachliches Wörterbuch sei vordringlich und nur ein Werk dieser Art in absehbarer Zeit ausführbar. Die Aussprache stand im Zeichen der Frage, wie die Arbeit an dem Wörterbuch zu organisieren sei. Der Gedanke eines Gemeinschaftsunternehmens drängte sich auf: da das Verfassen eines Wörterbuchs

'eines Menschen arbeit nicht sei, (müßten) gehülfen angeworben werden, es sei hie oder anderswo, die gewiße wörter oder ganze buchstaben übernehmen, und nach der in specimine vorgelegten methode ausarbeiten wolten'.

Einen zweiten Plan unterbreitete der Hofrat ScHLÜTER: er schlug vor, BENJAMrN NeUKIROH als Bearbeiter des Dictionarium usuale gegen Honorar fest anzustellen und das von NwUkIRCH Ausgearbeitete in einem abschließenden Arbeitsgang 'collegialiter' durchzusehen. FrIScH erhielt den Auftrag, bei NEUKIRoH vorzufühlen. Wirklicher Nachdruck stand hinter diesen Plänen nicht. Statt dessen wandte sich die Klasse wiederum theoretischen Fragen zu:

'weil es vor allen dingen auf die conformitaet in Orthographia ankomme, würde man sich zu forderst darüber vereinigen müßen'.

In der Zeit bis zur t'bernahme des Klassenvorsitzes durch Frisor (1731) hat die Klasse sich nur noch einmal mit dem Wörterbuchgedanken befaßt. Am 22. November 1725 legte der Sekretar aus den Akten der Societät zwei Entwürfe eines Deutschen Wörterbuchs vor, und zwar ein Konzept von LwIBNIzens Hand 'etwaß unordentlich aufgesezt' und einen Entwurf von Oelvens. ${ }^{1}$ Der Entwurf LaIBNIzens wurde am 24. Januar 1726 verlesen, 'wobei verschiedenes ausgesezet, und zu anderweitrer überlegung verschoben' wurde. ${ }^{2} \mathrm{Zu}$ dieser Zeit hatte die Klasse den Plan, ein Wörterbuch der Societät zu schaffen, wohl endgültig aufgegeben. Bei der Festlegung der Klassenaufgaben auf der Sitzung am 5. Februar 1728 wurde das Wörterbuch nicht mehr berücksichtigt. ${ }^{3}$

Wie sind diese Vorgänge zu bewerten? Als Mitglied der Historisch-Philologischen Klasse war FrIScH im Jahre 1711 Zeuge der Erörterungen, die über die Schaffung eines Deutschen Wörterbuches der Preußischen. Societät entscheiden sollten. Der Aussprache lag ein Entwurf der Brüder JABLoNSKI zugrunde, die sich leiten ließen von dem Gedanken an eine Darstellung des deutschen Wortschatzes im Sinne der Sprachtheoretiker des 17. Jahrhunderts. Sie erstrebten ein Werk, das den Sprachstoff aus den Quellen erheben, ihn orthographisch-grammatisch regeln und im

1 Protokoll vom 22. 11. 1725.

2 Protokoll vom 24. 1. 1726.

s Protokoll vom 5. 2. 1728. 
Sinne des Stammwortgedankens ordnen sollte. Ein Entwarf dieses Inhalts wurde zur Grundlage der lexikographischen Planung der Societät. Die Historisch-Philologische Klasse jedoch, die das Vorhaben ausführen sollte, vermochte die ihr gestellte Aufgabe nicht zu lösen; sie erwies sich als arbeitsunfähig. Wie FriscH sich zu dem Wörterbuchunternehmen stellte, berichten die Protokolle der Jahre nach 1711 zunächst nicht; jedenfalls hat er kaum etwas unternommen, um es von sich aus tätig zu fördern. Gegen diese Zurückhaltung hebt es sich scharf $a b$, daß er im Jahre 1718 die Wörterbuchfrage erneut aufgreift und der Historisch-Philologischen Klasse einen 'Gegenplan' unterbreitet. Denn um einen Gegenplan mit anderer, umfassenderer Zielsetzung handelte es sich. Eis war FrISCr offensichtlich darum zu tun, die in der Societät als korporativer Forschungsinstitution gegebenen weitreichenden. Möglichkeiten zu nutzen und eine Darstellung des deutschen Wortschatzes in sehr umfassendem Sinne zur Aufgabe der Klasse zu machen. Aber nun begannen innere Gegensätze sich auszuwirken: die Mehrheit der Mitglieder wünschte nicht die Durchführung des Gesamtplans, sondern besann sich auf die alte Zielsetzung, die sie als Teilziel in diesem Gesamtplan wiederfand: auf das Usuale und die 'conformitaet in Orthographia' kam es ihr vor allem an. Es soll an dieser Stelle nicht untersucht werden, welche lexikographische Zielsetzung Frisch vorschwebte, als er diesen Vorstoß unternahm; festgestellt sei, daß er in der Ausarbeitung eines Deutschen Wörterbuches im Sinne der Sprachtheorie nicht die vordringliche Aufgabe des lexikographischen Schaffens seiner Zeit sah.

Als Angehöriger der Historisch-Philologischen Klasse hatte sich FRIsOH auch mit den Auffassungen ChristopH ERNST StmInBaOHs auseinanderzusetzen. Am 24. Januar 1726 erfuhren die Mitglieder der Klasse nämlich, daßB Sterrsaor sein im Vorjahre zu Breslau erschienenes 'Deutsches Wörter-Buch' der Societät zugesandt habe mit dem. Erbieten, ihr hinsichtlich der Pflege der deutschen Sprache 'mit seinem fleiß zu dienen'1. Steinsach mochte hoffen, zum Zeichen der Anerkennung in die Societät aufgenommen zu werden. Im Kreise der Klassenmitglieder setzte sich jedoch von vornherein eine für ihn ungünstige Stimmung durch. Die Antwort der Societät fiel unverbindlich aus: man munterte ihn dazu auf, die muttersprachlichen Studien fortzusetzen. STErNBACH war jedoch nicht gewillt, sich abweisen zu lassen. Am 14. März lag der Klasse erneut ein Schreiben vor, in dem er seine 'Lehrart' erläuterte und ein Gutachten der Societät erbat." Frisch erteilte dieses Gutachten. Er äußerte sich schroff ablehnend: das Wörterbuch sei sehr unvollständig; 'die Lehrart gründe sich auf unerwiesene, und nach belieben angenommene Säze'; die etymologischen Ableitungen seien vielfach unrichtig. Mit dieser Stellungnahme verband die Klasse in ihrer Antwort den Vorschlag, StrenvbaOH möchte 'zum Versuch' einen Artikel nach dem von FrIsoH

1 Protokoll vom 24. 1. 1726.

2 Protokoll vom 14. 3. 1726. 
entworfenen Muster 'Land' ausarbeiten. In Wahrheit hoffte man wohl, die Korrespondenz werde nun ein Ende finden. StennbaOr blieb indessen hartnäckig; am 4. Juli hatte die Klasse sich mit einem nach FrIScHs Methode bearbeiteten Probeartikel zu befassen. ${ }^{1}$ Die Stellungnahme der Mitglieder ist aus dem Sitzungsprotokoll nicht ersichtlioh. Erst unter dem Datum des 27. November 1727 erfahren wir Weiteres: STELNBACH hatte sich erneut an die Societät gewandt und ein 'Specimen de Constructione Linguae Germanicae' überreicht." Am 5. Februar 1728 verlas Frisorr ein negatives Gutachten über 'Specimina' SrminBaorrs. Es wurde nach Breslau gesandt, woraufhin SreinbaOr im Mai mit einer 'Widerlegung' antwortete. ${ }^{8}$

Der Streit wurde zuletzt außerhalb der Societät weitergeführt. In der Vorrede zur zweiten Auflage seines 'Deutschen Wörter-Buchs' (1734) machte STEINBACr grundsätzliche Bedenken gegen Frisors Specimina von 1723 und 1727 geltend.4 Vom Standpunkt seiner sprachtheoretischen 'Tehrart' und unter Hinweis auf die Bedürfnisse der deutschlernenden Ausländer übte er Kritik an der inhaltlichen Breite ('viel unnöthiges werde mit ein flissen . . ., so . . e einem Ausländer . . wenig Nutzen schaffen möchte'), vor allem jedoch an den methodischen Grundlagen des geplanten Werkes. Frisce führe Zusammensetzungen unter ihrem Bestimmungswort (also weitgehend an alphabetischer Stelle) auf:

'Brandvogel kommt unter brennen, Landrecht unter das Wort Land, da doch von rechtswegen das erste unter Vogel, letzteres aber unter Recht oder nach meiner Einriohtung unter Roch, gerochen, zu stehen kommen sollte'.

Auch die streng alphabetische Abfolge der Ableitungen (ohne Berücksichtigung der Wortart) billigte er nicht: 'da man doch substantiva und adjectiva ordentlich nach einander auf Spatens (Stielers) oder meine Art setzen kan'.

Obwohl Sternbach abschließend versöhnlich einlenlate, antwortete FrISOH 1741 im Vorbericht des 'Teutsch-Lateinischen Wörter-Buchs' mit einer scharfen Abfertigung ohne Nennung des Gegners. ${ }^{5}$ Dem Vorwurf inhaltlicher Breite begegnete er mit dem Hinweis, sein Wörterbuch sei nicht 'allein für Classen-Schüler' bestimmt.

'Der Auctor hat es anfänglich vor sich gesammlet, was kümmert sich ein anderer darum, wie groß es werden wird. Darnach ist es auf Gutbefinden, und wegen einiger Umstände vor andere Leute herausgegeben worden, die es auch nicht unter dem Arm in die Schul tragen dürfen, dazu sein (Steinbachs) Wörter-Buch, so aus zweyen nicht dünnen Octav-Bänden bestehet, eben auch das bequemste nicht ist.'

1 Protokoll vom 4. 7. 1726.

2 Protokoll vom 27. 11. 1727.

s Protokolle vom 5. 2. 1728 und 27. 5. 1728.

4 Strempach, Vollst. Deutsches Wörter-Buch 1 (1734)**6a ; vgl. bereits Stern. BACH, Deutsches Wörter-Buch (1725) a $3^{\mathrm{a}}$.

s FrISch, TLWb. (1741) Vorbericht $)\left(2^{\mathrm{b}}\right.$. 
Auch die Kritik an dem Grundsatz der alphabetischen Abfolge wies Frisor zurück. Zu dem Einwand SteInBaors, das Wort Landrecht müsse unter dem Stichwort Recht oder nach seiner 'Einrichtung' unter Roch erscheinen, bemerkte er:

'Was wird das bey der Jugend und den Ausländern für Nutzen schaffen? Wer wird es unter Roch suchen? Aber das ist, wie er (Steinbach) bald darauf sagt, nach seiner Art. Das Wort Brand-Vogel... soll, nach dieser seiner Art, und zwar, wie er hinzufügt, von Rechts wegen, unter Vogel gesetzt werden. Diese Schluß-Formel, von Rechts wegen, ist bey den Juristen sonderlich wichtig. Sonsten werden gelehrter Männer gründlichere Erinnerungen bey dem Verfasser allezeit ... sehr angenehm seyn'.

Die Kritik an den Wörterbüchern STIELERs und Kramærs, das Abweichen von den lexikographischen Auffassungen der Brüder JABLONSKI sowie die Auseinandersetzungen mit StrinbaOH lassen erkennen, daB Frisor den von der Fruchtbringenden Gesellschaft ausgehenden Bestrebungen, ein Wörterbuch der neuhochdeutschen Gemeinsprache im sprachtheoretischen Sinne zu schaffen, in mancher Hinsicht zurückhaltend, ja abweisend gegenüberstand. Es ist daher wohl berechtigt anzunehmen, daß es nicht Forderungen und Vorschläge im Geiste SoноттELs und HaRsDöRFFERs waren, die in den Jahren um 1690 das Wörterbuchschaffen FrISCHs anregten und ihm die Richtung wiesen. An Verständnis für die Aufgabe, den Wortschatz der neuhochdeutschen Gemeinsprache lexikographisch zu erfassen, fehlte es ihm dabei keineswegs. FrIschs Haltung in der Auseinandersetzung mit den Plänen der Brüder J ABLONSKr zeugt nicht von Unaufgeschlossenheit gegenüber diesem Arbeitsgebiet, sondern verrät den freieren Blick eines Gelehrten, dessen Gesichtskreis über diesen begrenzten Teilbereich der Wortforschung hinausreichte. Während die Nachfahren ScHotrels in dem Bewußtsein, eine sprachgeschichtlich drängende Aufgabe zu erfüllen, die Schaffung einer normativen, sprachtheoretisch unterbauten Darstellung des gemeinsprachlichen Wortschatzes für das höchste Ziel der zeitgenössischen Wortforschung erklärten, stand für FRIsor dieses Vorhaben auch dann nicht im Vordergrund, als es mit den Kategorien Usuale generale und Critioum schließlich zum festen Bestandteil des eigenen Wörterbuchplans geworden war. Bereits 1703 sah er sich veranlaßt, der Kritik DU CANGES beizustimmen, der 1678 in der Vorrede zu seinem 'Glossarium ad scriptores mediae et infimae Latinitatis' 1 den zeitgenössischen Wörterbuchverfassern vorgeworfen hatte, sie hätten 'fast allezeit nur die gewöhnlichsten Wörter gesetzet' und 'die blosse Bedeutung derselben angezeiget'2. Indessen

1 DU CANGW, Glossarium ad scriptores mediae et infimae Latinitatis 1 (1883) XX (Praefatio).

2 Frisch, Untersuchung des Grundes und Ursachen der Buchstab-Veränderung (o. J.) 3-4. Es widerspricht dieser Annahme nicht, daß FrIsch 1727 vor der Historisch-Philologischen Klasse erklärte, er wolle 'wenigstens das Lexicon Usuale zum stand bringen' (Protokoll vom 16. 1. 1727). 
prägt sich der Gegensatz der Standpunkte nicht nur aus in der Stellung zur Frage der Rangordnung des gemeinsprachlichen Aufgabengebietes; die Auseinandersetzung mit STIELER, Kramer und insbesondere mit Stempach zeigt; daß abweichende Auffassungen auch hinsichtlich der Methode des lexilkographischen Schaffens bestanden. Die folgenden Untersuchungen, die der Frage gelten, inwieweit die Darstellung des Usuale generale den Grunderfordernissen eines Deutschen Wörterbuchs im sprachtheoretischen Sinne gerecht wird, werden Frischs Haltung gegenüber dem Aufgabengebiet des gemeinsprachlichen Wortschatzes bestimmter hervortreten lassen.

Die hohe Zahl von Belegen lexikalischer Herkunft im Usuale generale ${ }^{1}$ macht zunächst deutlich, daß FriscH nicht das Ziel verfolgte, ein Deutsches Wörterbuch auf der Grundlage der Quellen zu schaffen. Während ihm für das Usuale speciale, für das Archaeologum und Etymologicum ausgedehnte Stoffsammlungen zur Verfügung standen, geschöpft aus Quellenwerken, die geschichtliches, mundart. liches und fachsprachliches Wortgut zu liefern vermochten, verwertete er für das Usuale generale nur in begrenztem Umfange das literarische Schrifttum. Es ist hier nicht zu prüfen, inwieweit der Rückgriff auf die lexikalische UUberlieferung angesichts des Leistungsstandes, den die neuhochdeutsche Wörterbuchschreibung in den Jahrzehnten um 1700 erreicht hatte, berechtigt und sinnvoll war. Wesentlich ist, daß FRIschs Forschungsimpuls sich nicht auf das hochsprachliche Schrifttum, nicht auf die 'authores classici' der neuhochdeutschen Gemeinsprache richtete. Und dies zu einer Zeit, in der die Brüder JABLONSKI (1711) einen umfangreichen Quellenkanon für ein künftiges Deutsches Wörterbuch ausarbeiteten und Christoph ERNSt SteminbaOH für sein 'Deutsches Wörter-Buch' (1734) Belege aus literarischen Werken des 17. Jahrhunderts sammeln ließ. Der Aufruf HARSDÖRFFERS (1648), eine Darstellung des deutschen Wortschatzes 'aus allen Teutschen Büchern' zu schaffen, und ScHortels Forderung (1663), es müßten 'die Teutschen. Wörter aus dem Grunde Teutscher Deutung erkläret' werden, wirkten also zu Beginn des 18. Jahrhunderts nach, aber FrIsorr bestimmten sie nicht. Zwar sind einige der von HARSDÖRFFER beispielsweise ge-

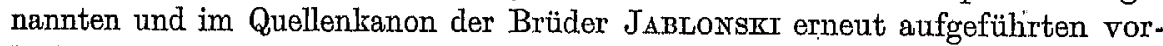
bildlichen Schriften des 16. und 17. Jahrhunderts (wie die Werke Lurthens und die Reichsabschiede) auch für das 'Teutsch-Lateinische Wörter-Buch' als Quellen benutzt worden. Aber die Gesichtspunkte der Verwertung sind durchaus unterschiedlich: während es FRISCH um das nichthochsprachliche (historische, landschaftliche, rechtssprachliche) Wortgut in diesen Quellen. der frühneuhochdeutschen Zeit zu tun ist, möchte JABLOXsskr in ihnen 'die Rechtschreibe-, Füge- ynd Ordnung der Sprache'2 erfassen. Die aus Einsicht in die Mängel des Umsetz- und Abschreibeverfahrens und aus einer stark emotionalen Wertschätzung der Mutter-

t. Vgl. S. 106.

2 Hariaci a. a. O. 2, 224. 
sprache erwachsene Forderung, ein Deutsches Wörterbuch auf der Quellengrundlage des deutschen Schrifttums zu schaffen, hat für FrIsor keine verpflichtende Geltung gewonnen. Auch an dieser Tatsache erweist sich, daß ihm die Erfassung des gemeinsprachlichen Wortschatzes der Gegenwart kein vorrangiges Anliegen war.

Enthält demnach das 'Teutsch-Lateinische Wörter-Buch' nicht den Wortschatz der als mustergültig angesehenen deutschen Schriftsteller im Zeitalter des Barock und der Frühauflklärung, so machen sich in der Darstellung des gemeinsprachlichen Wortgebrauchs (Usuale generale) dennoch normative Gesichtspunkte geltend, die beweisen, daß die Festsetzung der gültigen 'hoohdeutschen' Ausdrucksmittel auch für FrIsorr zu den Aufgaben eines Deutschen Wörterbuchs gehörte. ${ }^{1} \mathrm{Im}$ Wörterbuchentwurf des Specimen I erscheint das Criticum denn auch als voll ausgebildete Kategorie. Zwar trat es im Gesamtgefüge des abgeschlossenen Werkes später zurück, so daß FRIsor im Vorbericht des 'Teutsch-Lateinischen Wörter-Buchs' 1741 schreiben konnte:

'Die wenigen Critischen Anmerckungen, so man hier bey einigen Wörtern mit angehängt, verdienen nicht, daß man dieses Buch deßwegen ... ein Lexicon Criticum nennt. Es ist nicht überall so viel dabey, als um einiger Ursachen willen im Specimine vom Wort Land gewesen.' 2

Aber der Sinn für grammatische Fragen der Gegenwartssprache war in FriscH stark lebendig. Dies bezeugen die Beiträge grammatischer Art in den 'Zufälligen Anmerckungen' (1716-1718), die Bearbeitung der Sprachlehre JoHANNES BöDIKERs (1723) sowie weitere grammatische Forschungen in den dreißiger Jahren, deren Ergebnisse FrIscH in einer eigenen Deutschen Sprachlehre niederzulegen beabsichtigte. ${ }^{8}$ Mit den Arbeiten für dieses Werk wollte er nach Abschluß des Schaffens am 'Teutsch-Lateinischen Wörter-Buch' beginnen; Vorstudien sind zum Teil auf den Klassensitzungen der Jahre 1733-1741 unterbreitet und im 'Ersten Auszug' sowie im 'Toutsch-Lateinischen Wörter-Buch' veröffentlicht worden.

1 Wie sehr für ihn dieses Merkmal den Begriff des Wörterbuchs mitbestimmte, bezeugen zwei. Äußerungen in den Artikeln 'laden' und 'bei'. Hier werden die zusammengezogenen Formen bein und beis getadelt: 'daß einige auch beyn für bey den, beys für bey das, so gar in die Lexica drucken lassen, ist unerträglich' (1, 91c); dort wendet sich FRIScH gegen das Perfekt ich habe geladt 'so zum verdorbenen 'Teutsch des Pöbel-Redens, nicht ins Lexicon gehört' (1, 563c).

2 FrIsch, TLWb. (1741) Vorbericht )( $1^{\mathrm{b}}$; vgl. )( $4^{\mathrm{a}}$.

3 Protokolle vom 3. 11. 1740;23. 2. 1741 (Frisore verliest einen Aufsatz "von den Ursachen warum bishero keine Teutsche ausführliche Grammatil geschrieben worden'). In einem nicht genau datierbaren Sitzungsprotokoll des Jahres 1742 heißt es dann, daß er 'nunmehr Gottlob mit seinern teutschen lexico fertig worden und selbiges bereits abgedrucket'; jetzt wolle er es sich angelegen sein lassen, 'eine 'Teutsche Grammatilk zum Stande zu bringen'. U'ber FriscH als Grammatiker vgl. JiLIINEK, Gesohichte der neuhochdeutschen Grammatik 1 (1913) 205-206. 
FrISOr bemüht sich im Wörterbuch nicht nur darum, das verzeichnete Wortgut fortlaufend grammatisch zu bestimmen; er nimmt auch in zahlreichen kritischen Äußerungen zu Fragen der Sprachrichtigkeit Stellung. Seine Angriffe richten sich gegen den Sprachgebrauch des 'Pöbels', gegen Fremdwörter und Modeausdrücke der 'rasenden Zeitungsschreiberei', gegen Auswüchse des Juristendeutsches und 'närrische Schreiberregeln', gegen das Verdeutschungsstreben insbesondere der Grammatiker sowie gegen die Neuerungssucht schlechthin, namentlich dort, wo sie zu fehlerhaften Bildungen führt. Indem so der gemeinsprachliche Wortschatz der Zeit um 1700 vom grammatisch-stilistischen Standpunkt aus erläutert und gesichtet sowie durch Bedeutungsangaben in seinem semantischen Geltungswert bestimmt wird, leistet das 'Teutsch-Lateinische Wörter-Buch' gleich den $\mathrm{ihm}$ vorausgehenden Darstellungen Wesentliches für die Festigung der werdenden deutschen Schriftsprache des 18. Jahrhunderts. Ohne Zweifel ist die Hinwendung zu dem Aufgabengebiet der normativen Behandlung des Wortschatzes mitbewirkt durch Anregungen, die der neuhochdeutschen Wörterbuchschreibung im 17. Jahrhurdert aus dem Kreise der Fruchtbringenden Gesellschaft zugingen. Frisor setzt hier traditionelle Bemühungen fort, löst sich zugleich jedoch von den theoretischen Voraussetzungen, auf denen diese Bemühungen bis dahin beruhten.

Die Eigenständigkeit FriscHs wird deutlich, wenn man es unternimmt, sein Verhältnis zu der sprachtheoretischen Forderung einer etymologisch-strukturellen Erhellung des deutschen Wortschatzes zu bestimmen. Den Anregungen SoHortroLs folgend, hatten STrELER und StrinBach diese Aufgabe sehr ernst genommen. Für Frisor bildete, wie noch zu zeigen sein wird, die Erforschung etymologischer Zusammenhänge ursprünglich geradezu das Hauptziel des Wörterbuohschaffens. Aber der Ausgangspunkt, von dem her STIELER und StrenisaCH in den Arbeitsbereich der Etymologie eintraten, war keineswegs der FrIscHs. In der Methode der Herkunftsbestimmung prägt sich dieser Gegensatz deutlich aus. Wie wir bereits sahen, war sich FrISOH der Gefahren bewußt, die ein spekulatives, unempirisches Vorgehen auf diesem Gebiet in sich barg. Legte er seinen eigenen Standpunkt auch niemals zusammenhängend dar, so lassen gelegentliche Außerungen, die wiederum vor der Willkür der 'falschen Etymologen' warnen, die Grundzüge der in ihm sich verkörpernden Forschungshaltung immerhin erkennbar werden. So heißt es bereits auf der ersten Textseite des Wörterbuchs:

'Man muß aber allezeit mehr auf die Verwandschafft der Wörter in andern Sprachen sehen, welche eben solche und einerley Sache bedeuten, als auf die Muthmassungen der Etymologie'1.

In ähnlichem Sinne urteilt FRISOH in der Vorrede des Werkes; auch hier wird dem spekulativen Verfahren der Herkunftsbestimmung der Grundsatz entgegengestellt, daß eine Etymologie durch das Studium gegebener sprachlicher (und auBersprachlicher) Tatsachen zu finden sei:

1 Frisch, TLWb. (174l) 1, Ib. 
'Durch das Christentum, durch die Künste und Wissenschafften, duroh die Handlung und Kaufmannschafft, durch den Krieg . . . ist ein solches Mengsel im Teutschen entstanden, daß ein Etymologus alle diese (Fremd-) Sprachen, und zwar nicht obenhin wissen muß, wenn er bey den neu eingenommenen und aufgekommenen Wörtern auf den Grund kommen will. Geschweige wie weit er in die Verbindungen der Historien muß eingesehen haben; weloh Erkänntniß der seltsamen Sprach-Arten unter uns dazu erfordert wird ...., wenn ihn die vielen. Schwärmereyen der falschen Etymologen nicht sollen in ihren Irrgarten hinreissen.' 1

Angesichts des grundsätzlichen Gegensatzes im Methodischen, der sich hier abzeichnet, ist es unwahrscheinlich, daß Frischs etymologische Studien von Seiten der sprachtheoretischen Wörterbuchschreibung angeregt oder wesentlich beeinflußt worden sind; sie müssen aus andersartigen geschichtlichen Voraussetzungen erwachsen sein. Dagegen hat der sprachtheoretische Gedanke, den Wortschatz in seinem Aufbaugefüge darzustellen, $d$. h. die einzelnen Wörter nicht in streng alphabetischer Folge, sondern zu Wortsippen geordnet vorzuführen, die Anlage auch des 'Teutsch-Lateinischen Wörter-Buchs' bestimmt. Bereits STIELER, Kramer und Steinbach hatten dieses Ordnungsprinzip gewählt. Frrsor wendet es ohne methodische Strenge an, nur insoweit, als es ihm ermöglicht, die sprachliche Gesamtheit Grundwort-Ableitungen-Zusammensetzungen geschlossen zu behandeln. Innerhalb des Artikels folgt die Anordnung dagegen weitgehend dem Alphabet; wir erinnern uns dabei, daß gerade dieses Vorgehen einer der Angriffspunkte für die von sprachtheoretischen Gesichtspunkten bestimmte Kritik Srminbachs gewesen war. Wesentlicher ist noch, daß stark ausgeprägte theoretische Neigungen SchotтaLs, StraLmes und Stmingaons wie die Suche nach künstlichen 'Stammformen' und der Drang, den 'Reichtum' der deutschen Sprache durch den Ansatz zahiloser möglicher Wortbildungen zu erweisen, in Frisch keinen Widerhall gefunden haben. Die Auseinandersetzung mit STEINBadH über die Frage der 'Stammformen' und der gegen STIELER und KRAMER erhobene Vorwurf der Sprachbereicherung machten bereits deutlich, daß FRIsor sich von dem Willen zu streng empirischer Erfassung der Sprachwirklichkeit leiten ließ. So erscheint im 'Teutsch-Lateinischen Wörter-Buch' - schon KRAMER war so vorgegangen - als Stichwort nicht eine erschlossene einsilbige Stammform, sondern das Grundwort in seiner Nennform; und die Aufnahme nur potentiell vorhandener Bildungen wird in der Vorrede des "Teutsch-Lateinischen Wörter-Buchs" nochmals ausdrücklich abgelehnt:

'Diejenigen, welche solche (Wörter-)Bücher geschrieben, auch die so es mit vielem Vorzug gethan, sind bisher mit einer seltsamen Krankheit befallen gewesen, daß sie durch eine unzeitige Vermehrung unsre Sprache mit Compositis und Derivatis bereichern wollen. Von dieser Vermehrungs-Sucht ist man hier nicht angefochten worden. Man hat nur die gebräuchlichen zusammengesucht., ${ }^{2}$

1 Frrsor, TLWb. (1741) Vorbericht $)\left(1^{\mathrm{a}}-1^{\mathrm{b}}\right.$.

2 Frisch, TLWb. (1741) Vorbericht $)\left(3^{\mathrm{b}}\right.$. 


\section{Forschungen mit dem Ziel der geschichtlich-sprachvergleichenden Erhellung des deutschen Wortschatzes}

Die Jahrzehnte um 1700, erfüllt von lexikographischen Bestrebungen im Geiste der Theoretiker der Fruchtbringenden Gesellschaft, empfangen ihr Gepräge zugleich durch bedeutsame Fortschritte auf dem Gebiet der germanistischen Wortforschung im engeren Sinne. Zwei seit langem gestellte Aufgaben werden in diesen Jahren - dem Erkenntnisstande der Zeit entsprechend - erstmals gelöst: es gelingt, den altdeutschen. Wortschatz in einem umfassenden Wörterbuch zu sammeln und semantisch zu erschließen; und es gelingt weiterhin, den neuhochdeutschen Wortschatz auf historischem und sprachvergleichendem Wege etymologisch aufzuhellen. Zugleich setzen erste Studien im Bereich der deutschen Mundarten und Fachsprachen ein, die das Arbeitsfeld der Wortforschung wesentlich erweitern. Der angespannte Erkenntniswille, der sich namentlich in der tieferen Durchdringung des geschichtlichen und in der Neuersohließung des sondersprachlichen Aufgaben bereiches äußert, ist der Wille einer Forschungsbewegung, die auf eigenen Voraussetzungen ruht.

Die germanistische Wortforschung ${ }^{1}$ hat sich auf der Grundlage humanistischer Bestrebungen des 16. Jahrhunderts entwickelt, und zwar von zwei Ansatzpunkten aus: dem sprachvergleichenden und dem historischen Studium des Wortschatzes.

Sprachvergleichende Untersuchungen, soweit sie die Muttersprache berücksichtigten, stellten sioh seit dem 16. Jahrhundert vornehmlich in den Dienst der Aufgabe, das verwandtschaftliche Verhältnis des Deutschen zu den klassischen Sprachen und zu dem Hebräischen zu bestimmen. Für die Geschichte der etymologischen Wortforschung erlangten diese Bestrebungen dadurch Bedeutung, daß man den Nachweis des genealogischen Zusammenhangs der Sprachen, um den es zu tun war, so gut wie ausschließlich auf dem Wege des Wortschatzvergleichs zu führen suchte. So sammelten bereits im 16. Jahrhundert Männer wis Johannes Camerarius, Sigismund Gelennius, Konrad Gmsner und Wolfgang

1 Die Geschichte der germanistischen Wortforschung, die J. G. EokarT in seiner 'Historia studii etymologici linguae Germanicae hactenus impensi' (Hannover 1711) als erster bearbeitete, ist später nur im Rahmen umfassender wissenschaftsgeschichtlicher Darstellungen gewürdigt worden: E. C. REIOHARD, Versuch einer Historie der deutschen Sprachkunst (Framburg 1747); TH. Benfex, Geschichte der Sprachwissenschaft und orientalischen Philologie in Deutschland (München 1869); R. v. RAUmTr, Geschichte der Germanischen Philologie vorzugsweise in Deutschland (München 1870); H. PAUL, Geschichte der germanischen Philologie. In: GrundriB der ger. manischen Philologie 1 (Straßburg 21901) 9-158; J. DÜNNINarR, Geschichte der deutschen Philologie. In: Deutsche Philologie im AufriB I (Berlin ${ }^{2} 1957$ ) 83-222. 
LAzIUS deutsch-altsprachliche Wortgleichungen. Während des 17. Jahrhunderts gingen die Arbeiten auf diesem Gebiet fort, und auch jene Forscher übernahmen jetzt das sprachvergleichende Verfahren, die in der etymologischen Erhellung des deutschen Wortschatzes eine eigenständige Aufgabe sahen. Der Tradition der sprachvergleichenden Studien ist ein erheblicher Teil jener philologischen Schulung und jenes Bestandes an Einzelergebnissen zu verdanken, die es zu Beginn des 18. Jahrhunderts erstmals ermöglichten, die Etymologie des deutschen Wortschatzes zusammenfassend darzustellen. Es sei hervorgehoben, daß die in der Zeit um 1700 als Sprachvergleicher arbeitenden Germanisten bereits wesentliche Förderung erfuhren durch die historischen Wortschatzstudien auf dem Gebiet der Altsprachen, des Mittellateins (Du Cangt; Vossrus; Spelman) sowie der romanischen Sprachen (MÁNAGE), insbesondere aber auch dadurch, daß sie mit den geschichtlich vorgehonden Forschern auf dem Gebiet der germanischen Sprachen selbst Hand in Hand arbeiteten.

Untersuchungen wortgeschichtlicher Art waren ursprünglich eng an die Fortschritte der Textveröffentlichung gebunden; sie dienten vorzugsweise dem Ziel, den Wortbestand der durch Ausgaben erschlossenen Denkmäler zu erfassen und zu erläutern. Seit dem Anfang des 16. Jahrhunderts hatte man in Deutsohland damit begonnen, Werke des altgermanischen Schrifttums durch Handschriftenabdrucke zugänglich zu machen. Ws war zu dieser Zeit keineswegs in erster Hinsicht das Streben nach Erkenntnis der Sprache, das Gelehrte oftmals nicht. philologischer Disziplinen veranlaßte, germanische Handschriften des Mittelalters aufzuspüren und zu veröffentlichen. Der Wert der Texte lag für die Herausgeber vielmehr im Inhaltlichen. Nichtsdestoweniger wirkten sprachwissenschaftliche Forschungsantriebe mit: die Förderung des Studiums insbesondere des altgermanischen Wortschatzes wurde frühzeitig ein selbständiger Nebenzweck der Editionsarbeiten. Denn Hand in Hand mit der Textveröffentlichung ging das Bemühen um Texterklärung. Den Ausgaben wurden in zahlreichen Fällen sprachlich erläuternde Anmerkungen oder Glossare beigegeben. Hier liegen erste Ansätze zu einer geschichtlichen Erforschung des deutschen Wortschatzes. Wie sehr das Studium der Sprache bereits als eigenständige Aufgabe galt, geht daraus hervor, daß nicht nur Textglossare entstanden, sondern auch Pläne für zusammenfassende, semantisch und etymologisch erklärende Wörterbücher des Altdeutschen ausgearbeitet wurden.

Historiker, Ethnographen und Geographen wie Beatus RHENands, Sebastian MÜnster, Johannms Stunpe und WolfGang LaZius, die sich auf der Grundlage der wiederentdeckten antiken Quellen dem Studium der Frühgeschichte Germaniens widmeten, befanden sich unter den ersten, die in ihren Werken Proben aus altdeutschen Denkmälern abdrucken ließen. Belangvoller war der Ertrag reformatorisch-kirchengeschichtlicher Studien des Fuadus ILLYrious; ihnen ist die Erstausgabe von OTFRIDs Evangelienbuch (1571) zu verdanken, die mit einer 'Erklerung der alten Teutschen worten' von A. P. GASSAR erschien. Den wichtig- 
sten Anteil an der Frschließung altdeutscher Quellen hatten jedoch deutsche Juristen, die sich rechtsantiquarischen Studien widmeten und zunächst Ausgaben der altgermanischen Stammesrechte (SrohaRd 1530; HEROLD 1557; LINDENBRoG 1613 mit Glossar) veranstalteten, dann aber eine Reihe bedeutender altdeutscher Denkmäler (FREHER und GoLDAST 1604-1610) mit sprachlichen Erläuterungen veröffentlichten. Im Verlaufe des 17. Jahrhunderts wurde die Wortforschung namentlich von dieser Seite gefördert, indem Gelehrte wie WrHnER (1619), Brsold (1629), Limnaeus (1629), Sphided (1657) und Sohottmi (1671) altdeutsche Rechtsausdrücke untersuchten. Im Kreise der Juristen reifte auch zuerst der Gedanke eines altdeutschen Wörterbuchs: Marquard FrEHDR (1565-1614) und Friedrion Lindenbrog (1573-1648) entwarfen Pläne für ein Werk dieser Art.

Diese Studien auf dem Gebiet der germanistischen Sprachforschung wurden durch gleichgerichtete Bestrebungen in den germanischen Nach barländern Deutschlands wesentlich gefördert. Gelehrte wie LrPsIus, Jurros (Erstausgabe des Codex argenteus mit gotischem Glossar 1665) und TwN KATE in den Niederlanden,

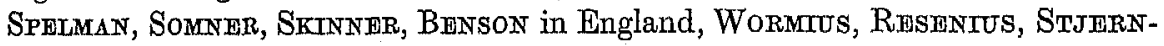
HJELM und VERELIUS in den skandinavisohen Ländern arbeiteten tatkräftig mit an der Herausgabe altgermanischer Texte und an der lexikographischen Erschließung ihres Wortbestandes.

Auch JUSTUS GeORG Schotrmu, der sich in den Jahren zwischen 1641 und 1663 zu dem führenden Grammatiker Deutschlands emporarbeitet, ist der Tradition der germanistischen Wortforschung verpflichtet. Als Jurist durchaus in Fühlung mit den editorischen und wortgeschichtlichen Arbeiten jener Männer, die seit dem 16. Jahrhundert ein historisches Verständnis des deutsohen Wortschatzes angebahnt hatten, baut er auch als Theoretiker der neuhochdeutschen Gemeinsprache auf dem gelehrten Fundament des geschichtlichen und des vergleichenden Sprachstudiums seiner Zeit. Indessen gelangen durch ihn Methoden und Erkenntnisse dieser Disziplinen in ein Arbeitsgebiet, das von vornherein unter eigenem Gesetz steht und sich in der Folgezeit selbständig fortentwickelt. Gewiß bleiben die 'sprachtheoretische Bewegung' und die germanistische Wortforschung im engeren Sinne weiterhin in wechselseitiger Beziehung; aber es bilden sich zugleich Wesensunterschiede aus, die in den Jahrzehnten um 1700 geradezu als Gegensätze empfunden werden können. Die Richtungen haben sich nunmehr so weit gefestigt, daß der einzelne mit der Wahl seines Studiengebietes und der zugehörigen Forschungsaufgaben und Forschungsmethoden eine für ihn kennzeichnende Entscheidung trifft. Die Nachfahren SoHotrels, festgelegt auf den Stofflkreis der Gemeinsprache, suchen vornehmlich die geschichtlich drängende Aufgabe der 'Gestaltung' einer deutschen Hochsprache zu bewältigen. Sie verbinden mit diesem praktischen Anliegen das theoretische Ziel, das einzelne Wort und das Wortschatzgefüge insgesamt im Sinne der 'Grundrichtigkeit' rational zu zerlegen, und zwar wesentlich von der Seite der Form her: durch Zurückgehen auf die 'Stammform' 
als Etymon und durch Aufweisen der morphologischen Struktur des Wortschatzes. Es ist wesentlich zu erkennen, daß neben diesen Bestrebungen konstruktionsfreudiger Theoretiker, deren Arbeiten teilweise in das Reich der Sprachspekulation übergreifen, eine stärker der empirischen Einzelforschung zugewandte Richtung der Sprachbetrachtung sich durchsetzt. Ihre Vertreter blicken über das Gebiet der Gemeinsprache der Gegenwart hinaus in den weiträumigeren Stoffkreis der geschichtlichen Sprachstufen, der Mundarten und der Fachsprachen. Das Wortgut der Rechts- und Geschichtsquellen, die handwerklichen Nomenklaturen und die Eigenheiten landschaftlicher Sprechgebräuche stellen ihnen die Aufgabe der Sprachgestaltung nicht. Leitend für sie ist vielmehr das Bestreben, die ungeheure Mannigfaltigkeit des geweiteten sprachlichen Erfahrungsbereiches als solche zum Besitz des erkennenden Bewußtseins zu machen, zunächst beobachtend und sammelnd, auf einer höheren Stufe ordnend und erläuternd. Feststellung des Gegebenen und Erklärung des Gegebenen heißen die Grundforderungen. Und es ist in der Eigenart des Gegenstandes begründet - in der Sachbezogenheit und in der etymologisch-semantischen Undurchsichtigkeit des zu erfassenden Wortgutes -, daß sich die Erklärung, ohne den Problemen der Form aus dem Wege zu gehen, mit Nachdruck auf den Wortinhalt richtet: nach dem ursprünglichen Sinn, dem semantischen Geltungswert, dem Begriffswert des einzelnen Wortes wird vorzugsweise gefragt. Im Bereich dieser Disziplinen festigen sich eine voraussetzungslose Anschauung des Erkenntnisgegenstandes Sprache und die Ansätze zu einer Methode der Wortforschung, die in späterer Zeit die wissenschaftliche Erschließung des Wortschatzes ermöglichen sollte.

In den Jahrzehnten um 1700 verstärkten sich die Bestrebungen auf dem Gebiet der historischen und der (historisch-sprachvergleichenden) etymologischen Wortforschung in einem zuror nicht gekannten Maße. Diese Tatsache ist in erster Hinsicht bedingt durch die raschen Fortschritte jener Zeit in der Herausgabe altdeutscher Quellen. Zwar war eine beachtliche Reihe alter Denkmäler bereits vor dem Ausgang des 17. Jahrhunderts gedruckt worden. Aber immer wieder traten Handschriften bisher unveröffentlichter Werke ans Licht, und die Textgestalt bereits herausgegebener Werke bedurfte - wie die Einsicht in neuaufgefundene Parallelhandschriften lehrte - vielfach der Verbesserung. 1669 hatte Petrer Lambeorus, Bibliothekar der kaiserlichen Bibliothek in Wien, eine Reihe kleinerer althochdeutscher Denkmäler sowie eine Probe der Psalmen Notkers veröffentlicht und aus der Wiener Handschrift Ergänzungen zu der OTFRID-Ausgabe des Fladus IrLyriods mitgeteilt. Johannms Sohilter, Jurist, Historiker und führender Sprachforscher, seit 1686 in Straßburg tätig, gab 1696 das Ludwigslied und 1698 ein Specimen seiner geplanten OTERID-Ausgabe sowie JAKoB TwINGERS VON KÖNIGSHOFIn Straßburgische Chronik heraus. 1706 veröffentlichte Johann Phimipp Panthen in Greifswald die Übersetzung des Tatran und des IsIdorus de nativitate domini. Wie SoHmTer plante Diederich von Stade eine Neuausgabe von OTrRIDs Evangelienbuch; er ließ 1708 ein Specimen drucken, 
das auch einige katechetische Texte der althochdeutschen Zeit enthielt. Gesammelt erschienen die althochdeutschen katechetischen Denkmäler 1713 in JoHANs GEORg ECKaris 'Catechesis Theotisca'. 1720 legte ECTKarT das lateinisch-althochdeutsche Gedicht De Heinrico vor. Der Benediktiner Burnmard Proz im Stift Melk machte 1721 das Wessobrunner Gebet und die Monseer Glossen, JoHANN Dredmans in Stade im gleichen Jahre Teile des Hrabanischen Glossars zugänglich. 1727-1728 erschien in drei Bänden Sormrers 'Thesaurus Antiquitatum Teutonicarum', dessen erster und zweiter Band unter anderem OTFRIDs Evangelienbuch, die Utbersetzungen des Tatian und des Isidon, die Interlinearversion der Benediktinerregel, NotkrRs Psalmen, Wrutrrams Hohelied, das Rolandslied, don STrICKER und die sogenannten Paraenetiker erstmals oder in verbesserter Textgestalt darbot. Einen vorläufigen Abschluß erreichten die Bemühungen um die Erschließung althochdeutscher Denkmäler mit der Veröffentlichung des Hildebrandliedes, der Kasseler, Florentiner, Hrabanischen und Lindenbrogschen Glossen sowie einer Reihe kleinerer althochdeutscher Texte durch JoHaNn Gmorg Eokarr im Jahre 1730.

Die gesteigerte Editionstätigkeit förderte in starkem Maße die Bemühungen um die historisch-etymologische Erforschung des deutschen Wortschatzes. An ihnen waren die Herausgeber selbst maßgeblich beteiligt; die Mehrzahl der in den Jahrzehnten um 1700 veröffentlichten Textausgaben erschien mit sprachlich erläuternden Anmerkungen, die bevorzugt der Deutung altdeutschen. Wortgutes galten, oder mit beigefügter lateinischer Ubersetzung. Der rasche Quellenzuwachs belebte zugleich den Gedanken, die bis dahin erschlossenen Teile des altdeutschen Wortschatzes in einem zusammenfassenden historisch-etymologischen Wörterbuch darzustellen. Bereits während des 17. Jahrhunderts hatten Gelehrte außerhalb Deutschlands Wortgut des Gotischen, Altnordischen und Angelsächsischen in lexikalischen Werken erfaßt. In Deutschland selbst hatte die etymologische Forschung durch Einzeluntersuchungen sowie durch die Erörterung ihrer methodologischen Grundfragen (ClaUBBRG; Vorsmitus; MorHoF) Förderung erfahren. Aber das bereits von Fraher und LINDENBRog geplante historisch-etymologische Wörterbuch des Altdeutschen war noch immer nicht verwirklicht worden. In der Schaffung dieses Werkes sah die Forschung der Zeit um 1700 eine ihrer Hauptaufgaben. Es überrascht daher nicht, daB in diesen Jahren mehrere Gelehrte - in verschiedenen Teilen Deutschlands und zum Teil unabhängig voneinander wirkend - mit Entwürfen und Vorarbeiten für eine Darstellung dieser Art beschäftigt waren. Da die Mehrzahl der Vorhaben unvollendet blieb, ist es schwierig, einen Eindruck von der Breite dieser Bestrebungen zu gewinnen. Aber getragen waren sie nicht nur von den wenigen, deren Namen mit den Wörterbucharbeiten, die seit dem Ende der zwanziger Jahre im Druck erschienen, unmittelbar verbunden sind. Hingewiesen sei insbesondere auf die Vorarbeiten JoHaNs Gmorg EoKarTs, der in seiner 'Historia studii etymologici linguae Germanicae hactenus impensi' (1711) die Geschichte der etymologischen Wortforschung in Deutschland aus der Sicht 
der Zeit um 1700 zusandmenfassend darstellte, nachdrüoklioh die Forderung eines etymologischen Wörterbuchs der deutschen Sprache erhob und zugleioh ankündigte, daß er dieses Werk selbst schaffen werde:

'In dem grossen Wercke, worüber ich bey Neben-Stunden beschaefftiget bin und davon dieses ein kleiner Vortrab ist, werde ich clen Vhrsprung und das Alterthum unsrer Teutschen Sprache aus allerley alten Monumenten untersuchen und erklaeren, dabey alle schweren und heutiges Tages moistens unverstaendliche Worte, so in den Gesetzen, Lehn- und andern Rechten, auch allen übrigen in Archiven sonderlich liegenden verjahrten Schrifften vorkommen, erklaeren, und über dieses eine grosse Menge von allerley Historischen Untersuchungen zugleich mit berühren.' 1

ECKarTs Wörterbuch wurde nicht vollendet; aber 1727 veröffentlichte J. G. WAOHTER unter dem Titel 'Glossarium Germanicum' die methodische Grundlegung und den Abriß eines etymologischen Wörterbuches, dessen vollständige Ausgabe (1737) den Wissensstand der Zeit auf dem Gebiet der etymologischen Erforschung des deutsohen Wortschatzes widerspiegelte. Diese Darstellung wurde nach der sprachgeschichtlichen Seite hin ergänzt durch das 'Glossarium ad scriptores linguae F'rancicae et Alemannicae veteris', das EuIAs Frrck 1728 als dritten Band des ScHWTERschen 'Thesaurus Antiquitatum Teutonicarum'vorlegte. SchILTERs Schüler J. G. Scherz (1678-1754), der bereits an dem Thesaurus mitgearbeitet hatte, sammelte seinerseits mehrere Jahrzehnte hindurch für ein 'Glossarium Germanicum medii aevi', das allerdings erst lange Zeit nach seinem Tode durch J. J. OBERLIN herausgegeben wurde (1781/84). Gleichfalls noch in die erste Hälfte des 18. Jahrhunderts fallen die Vorarbeiten für das 'Glossarium Germanioum medii aevi' (1758) des Rechtsantiquars CrrR. G. HaLTAus (1702-1758), dem 1738 ein 'Specimen Glossarii Fori Germanici' vorausgegangen war.

2

Das lexikographische Schaffen JOHANN LEONHARD FRISOHs gliedert sich ein in diese Forschungsbestrebungen der Jahrzehnte um 1700. Vorarbeiten zum 'Teutsch-Lateinischen Wörter-Buch' und lebensgeschichtliche Zeugnisse, die bis in die Jahre um 1700 zurüokreichen, lassen erkennen, da $B$ FRISCHs Studien bereits in der Frühzeit des Berliner Aufenthalts vorzugsweise dem Stoff- und Aufgabenbereich der etymologischen Wortforschung gelten. So behandeln seine beiden ersten sprachwissenschaftlichen Veröffentlichungen, die 'Untersuchung des Grundes und Ursachen der Buchstab-Veränderung' $\left(1703^{2}\right)$ und der Miscellanea-Auf-

1 J. G. EOKART, Historia studii etymologici (1711) Widmung 5-7.

2 In einem vom 29. Februar 1716 datierten Brief an den Lübecker Gymnasialrektor J. H. v. Stemen (in: J.H. v. SEELEN, Memoria Stadeniana [1725] 336-339) äuBert sich Disderich vON STADE über FrisoHs 'Untersuchung des Grundes und Uraachen der Buchstab-Veränderung etlicher Teutschen Wörter' (Berlin o. J.). Diese Stelle hat Anlaß gegeben, das Erscheinen der Schrift in das Jahr 1716 zu setzen: 
satz 'Origo quorundam vocabulorum Germanicorum et cum aliis linguis affinitas' $\left(1710^{1}\right)$, Fragen der Herkunft einzelner deutscher Wörter. Und in mehreren Äußerungen aus der Frühzeit des lexikographischen Schaffens bekennt sich FrIsor ohne Vorbehalt zu dieser Zielsetzung. So spricht er 1708 - LEIBNIZ gegenüber in Hinblick auf das Wörterbuchrorhaben schlechthin von seiner "Teutschen Etymologie-Arbeit'2, und 1712 bemerkt er, es sei sein Vorsatz, 'etwas gründliches und ausführliches von der Teutschen Etymologie dereinsten zu verfertigen's.

Es fragt sich, welche geschichtlichen Kräfte FrrscHs Forschungsbemühen hinlenkten auf das Ziel der etymologischen Erhellung des deutschen Wortschatzes, das zu dieser Zeit geradezu als alleiniges Ziel des Wörterbuchschaffens erscheint. Antwort zu geben vermag die Untersuchung der während der Berliner Frühzeit entstandenen Vorstudien zum 'Teutsch-Lateinischen Wörter-Buch'. Mustert man die Reihe der sprachwissenschaftlichen Hilfsmittel, die FrIsor in diesen Arbeiten vornehmlich zugrunde legt, so treten aus der Gesamtheit der Quellenschriften drei Hauptgruppen hervor:

\section{Werke der germanistischen Wortforschung}

\section{LIPsius Glossarium. 1605. \\ Goldast Constitutiones Imperiales. 1609.}

so datieren die Leipziger Critischen Beyträge 3 (1735) 644 und später E. C. RarCHARD, Historio der deutschen Sprachkunst (1747) 423. Von REIoHaRd übernahm diese Angabe R. v. Raumer für seine Geschichte der germanischen Philologie (1870) 191. Daß die Schrift in Wahrheit vor 1711 gedruclkt wurde, hätte man bereits aus ihrer Erwähnung in J. G. Eckarts Historia studii etymologioi (1711) 313 schließen können. Daß sie vor 1708 verfaßt ist, ergibt sich daraus, daß sich FrIscre auf dem Titelblatt als 'Sub-Rector im Berlinischen Gymnasio' bezeichnet (er wirlkte in diesem Amt von 1698 bis 1708); ferner daraus, daß er in einem undatierten, 1737 oder bald danach geschriebenen Brief an J. Heumann (abgedruclet in: J. HEUMaNi, Opuscula [1747] 470-471) berichtet: "Vor 30 Jahren hab ich ein Büchlein heraus gegeben: Vntersuchung des Worts Au und Gau' (Herkunft und Gesetze des Lautwandels dieser Wörter werden in der 'Buchstab-Veränderung' behandelt). Diese Angabe FrIschs ist allerdings nicht genau. Denn das Schriftchen erschien noch um einige Jahre früher, wofür Hinweise im übrigen wiederum im Werlce selbst gegeben waren (so mußte esauffallen, daß sich Frisch auf dem Titelblatt als Subrektor und noch nicht als Mitglied der Societüt [seit 1706] einführt; ferner daß ScHILTER [gest. 1705] in der unten [S. 42] abgedruckten Stelle offensichtlich noch als Lebender behandelt wird). Die genaue Kenntnis des Druckjahres sichert ein Finweis, den ich Ferm F. G. LANGE, Archivar der Deutschen Akademie der Wissenschaften zu Berlin, verdanke: die 'Nova Literaria Germaniae Collecta Hamburgi' (September 1703) 32l-324 enthalten anstatt einer Besprechung einen lateinischen Auszug der 'Untersuchung' und setzen ihr Erscheinen in den Juli 1703.

1 Misc, Berol. 1 (1710) 60-83; der Aufsatz war vermutlich bereits 1707 im Manuskript abgeschlossen, vgl. zur Datierung Harnack, Gesch. d. Königl. Preuß. Akamdemie der Wissenschaften zu Berlin (1900) 1, 150 .

2 Frscher, Frischs Briefwechsel mit Leibniz (1896) 17.

s Frsoh, Nouveau dictionnaire (1725) Vorrede 6. 
LINDENBROG Glossarium vocum difficilium. 1613.

Wormros Specimen lexici runici. 1650.

Cladbirg Ars Etymologica Teutonum. 1663.

JUNIUS GIossarium Gothicum. 1665.

StJERnHJelm Glossarium Ulphila-Gothicum. 1671.

Soнотres De singularibus quibusdam in Germania juribus. 1671.

RÚDBECK Atlantica, 1675.

2. Werke der mittellateinischen Wortforschung

Vossids Etymologicon linguae latinae. 1653.

DU CaNGE Glossarium ad scriptores mediae et infimae Latinitatis. 1681.

Spermary Glossarium archaiologicum. 1687.

3. Als Hauptwerk der romanistischen Wortforschung

Ḿtínagif Origines de la langue françoise. 1694.

Ein in den Umrissen durchaus gültiges Bild der geschichtlichen Voraussetzungen des 'Teutsch-Lateinischen Wörter-Buchs' zeichnet sich in dieser Liste sprachwissenschaftlicher Hilfsmittel ab. Es sind die Namen führender Philologen des 17. Jahrhunderts, die sich hier vereinigen. Im Umgang mit ihren Werken hat FRISOH nicht allein die unentbehrliche methodische Schulung erworben und eine Fülle sprachlichen Tatsachenstoffes und erklärender Hinweise sich zu eigen gèmacht; auch der Wörterbuchgedanke selbst, so dürfen wir annehmen, ist von der in diesen Männern sich verkörpernden Forschungsbewegung ausgegangen. Der Vorsatz, einzelne deutsche Wörter hinsichtlich ihrer Herkunft zu untersuchen und die Ergebnisse dieser Untersuchungen in einem Wörterbuch zusammenzufassen, d. h. den deutschen Wortschatz als Ganzes unter etymologischem Gesichtspunkt darzustellen, hat hier seinen Ursprung.

Es ist zunächst die im Bereich der germanistischen Wortforschung erhobene Forderung eines etymologischen Wörterbuchs der deutschen Sprache, die in dem lexikographischen Schaffen Frrsors zu dieser Zeit wirksam wird. Daß der Gedanke auf die Anregung einer bestimmten Persönlichkeit zurückgeht, läßt sich allerdings nicht erweisen. Juluus HindemanN, der Geschichtsschreiber des Gymnasiums zum Grauen Kloster in Berlin, hat 1874 vermutet, Friscris Wörterbuchplan beruhe unmittelbar auf einer Anregung Johannes Schutens. Sohnter war, worauf HmID mMans hinwies, 1686 als Professor nach Straßburg berufen worden und FrIsorr als Student konnte in den Jahren 1688-1690 dort mit ihm bekannt werden. ${ }^{1}$ Aber diese Vermutung ist nicht haltbar. Frisor empfing den Impuls seines Wörterbuchschaffens nicht ausschließlich von Seiten der germanistischen

1 HeidemanN, Geschichte des Grauen Klosters zu Berlin (1874) 202; vgl. DüNNINGBr, Geschichte der deutschen Philologie. In: Dt. Philologie im Aufriß 1 (21957) 108.

$\$$ Powita, Frischg Worterbuch 
Wortforschung oder in noch engerem Sinne von Seiten Somminks. Wohl aber verdankt er dessen sprachgeschichtlich-etymologischen Arbeiten im Rahmen umfassenderer Anregungen Wesentliches. Als aufschluBreich in dieser Hinsicht erweist sich ein Zeugnis aus der Frühzeit des Wörterbuchschaffens; in der 1703 erschienenen 'Untersuchung des Grundes und Ursachen der Buchstab-Veränderung' bemerkt. Frrsor im Anschluß an ein Zitat aus den 'Antiquitates Ducatus Thuringiae' (1688), des thüringischen Historikers CASPAR SagtTTARTUS:

'Auf welchem Blat dieser Historien-Schreiber des weitberủhmten Rechtsge-. lehrten Herrn Schilters gedencket / den er in dergleichen Untersuchungen der. alten Worte zu Rath gezogen / wodurch er mich zugleich meiner Pflicht gegen diesen theuren Mamn erinnert / der ich aus dessen Schrifften nicht wenig Hủlffe. zu meiner vorhabenden Arbeit gefunden / und noch gro̊ssere zu finden hoffe / wann ich werde das Glủck haben / sein treffliches Werck von Erklårung derWỏrter einiger gar alten Teutschen Schrifften dermaleins im Druck zu sehen.' $x$

Diese ÄuBerung, so eindrücklich sich in ihr die innere Verwandtschaft der Forschungsrichtungen beider Männer bekundet, entzieht zugleich der Vermutung den Boden, FRIScH könnte durch SoHnTER persönlich zur Aufnahme des Wörterbuch-. schaffens veranlaßt worden sein.

Abzuweisen ist auch der Gedanke einer ursprünglichen Anregung durch GorTFRIDD WIHELM LEIBNIZ. Denn Frisch kann LeibNIz, der 1697 die 'Unvorgreiflichen Gedanken' niedergeschrieben hatte, erst in den Jahren zwischen 1700 und 1706 persönlich kennengelernt haben, also zu einer Zeit, da er bereits etwa ein Jahrzehnt an seinem Wörterbuch arbeitete. Aber auch LEIBNIZ hat das bereits eingeleitete Unternehmen nachhaltig gefördert, im Gegensatz zu ScHILTER, der durch seine Schriften und mit der Fülle seines philologischen Einzelwissens auf Friscr einwirkte, vor allem im persönlichen (mündlichen und brieflichen) Verkehr und durch Anregungen, die weniger den stofflichen Einzelheiten als dem Gedanklich-Allgemeinen gegolten haben werden. Aus der Art und Weise, wie Frisor in seinem Briefwechsel mit LeIBNIz (1706-1716) auf das Wörterbuch und auf die Vorarbeiten zu diesem Werk eingeht, darf man vielleicht schließen, daß beide vorher in Berlin darüber auch gesprochen haben. Und daß FRISOH auf Teilnahme stieß, geht schon daraus hervor, daß er keine Bedenken trägt, LeIBNIz 1708 und. 1709 zu berichten: er bemühe sich um den Erwerb der Wörterbücher des Angelsächsischen von SkINNER (1671) und SomNER-BENSON (1701); auch forsche er nach den altgermanischen Glossaren des Fravcrsous JunIUs. ${ }^{2}$ Unmittelbar bedeutsam jedoch für das Werden des Wörterbuches war es, daß Frisch in einer. Stunde der Mutlosigkeit, als das Unternehmen gänzlich in Frage gestellt schien, wesentlich durch den Zuspruch LErBNIZens wieder aufgerichtet wurde. 1711 kündigte J. G. ECKART, wie bereits erwähnt, in seiner 'Historia studii etymologici

1 FaIScH, Buchstab-Veränderung (1703) 30.

2 Fiscrm, Frischs Briefweohsel mit Leibniz (1896) 17; 22; 23. 
das Erscheinen eines umfassenden etymologischen Wörterbuches an. ${ }^{1}$ Im Rahmen eines Utberblicks über die zeitgenössische Wortforschung würdigte EokaRT hier bereits FrIscrs erste Veröffentlichungen ${ }^{2}$, die 'Buchstab-Veränderung' (1703) und sogar den soeben erst erschienenen Aufsatz in Band I der 'Miscellanea Berolinensia' (1710). Fr hatte (gewiß auch durch LmrBNIz) erfahren, daß FRIsor selbst in der Arbeit an einem etymologischen Wörterbuch begriffen war, und fand Worte nicht nux der Anerkennung (vir in hoc studiorum genere non parum versatus), sondern sogar der Aufmunterung:

'Quod si majus opus Etymologicum, cui insudare eum intelligo, lucem aliquando viderit, maximo id usui esse poterit prudentioribus linguae cultoribus.'

Aber das forschungsgeschichtlich unterbaute, theoretisch wohl durchdachte Programm EckarTs entmutigte Frisor dennoch tief; sicher auch deshalb, weil er zu dieser Zeit noch durchaus am Anfang des eigenen Werkes stand. ${ }^{3}$ Er wandte. sich an LEIBNIZ; dieser aber versicherte ihm:

'wenn gleich unser viel über dieser Arbeit wären, würden wir doch alle genug zu thun finden, und das Werck nicht erschöpfen.'4

Im Juli 1715 konnte Frrsor neugefestigt schreiben:

'Herr Eckart hat mich mit seinem etymologischen teutschen Lexicon fast erschreckt, aber ich habe mich doch wider erhohlt und fahre fort, in dieser Materie meine gedancken aufzuzeichnen; es wird doch immer einer etwas haben, das der andere nicht hat.' 5

Nach dem Erscheinen der 'Buchstab-Veränderung' (1703) und des Miscellanea. Beitrages vom Jahre 1710 trat FrISOH erst im Jahre 1723 mit einer bedeutenderen sprachwissenschaftlichen Veröffentlichung hervor : seiner Bearbeitung der Grammatik Johannes Böprkgrs mit dem Specimen I als Anhang. Für die Geschichto des Wörterbuches ist vor allem das Specimen von Belang: es verkündet eine neue Zielsetzung und veranschaulicht sie durch den Musterartikel 'Land', dem 1727 als Specimen II die Musterartikel 'Brand, Brennen' folgen. Der hier wie dort

1 EoKart, Historia studii etymologici (1711) 323-332.

2 EokaRT a. a. O. 313-314.

3 In der 'Buchstab.Veränderung' und in dem Miscellanea-Aufsatz von 1710 behandelt Friscr die Wörter: Aa, Au (Gau); Adel, Adler, Aar.

4 Frrsor, TLWb. (1741) ) ( $1^{\text {b }}$ - Man vergleiche Lemsizens Wiener Aufzeichnungen vom 23. Dezember 1712 (Krope, Leibniz' Plan der Gründung einer Societät der Wissenschaften in Wien. In: Archiv für österreichische Geschichte 40 [1869] 221), in denen es über Erkars heißt: 'Eine Person, so bey mir gewesen, habe ich zu dieser arbeit (das Glossarium Germanicum) aufgemuntert, und die wird hierin verhoffentlich ein ansehnliches leisten. Doch gehöhren mehr hände zu einem so grossen gebäude.'

5 FIsCHER, Frischs Briefwechsel mit Leibniz (1896) 37. - FRISOH fährt fort: 'Ich möchte gern die correspondenz dieses hierinmen so erfahrenen Mannes haben. Ich hab gehört, er sey auf Hannover gekommen, weiss aber keine addresse an ihn.' 
erkennbare Wandel der ursprünglichen Absicht, ein etymologisches Wörterbuch zu schaffen, reioht in das zweite Jahrzehnt des 18. Jahrhunderts zurück und wird mitbedingt gewesen sein durch die Erschütterung, die EoKaRTs 'Historia studii etymologici' auslöste. Zwar starb ECKART im Jahre 1730, ohne das von ihm angekündigte Wörterbuch vollendet zu haben; ạber bis zu jenem Zeitpunkt mußte FrIsCh damit rechnen, daß ECKART ihm zuvorkommen werde. Schon in den Jahren 1720 bis 1722 war FrIsor zudem auf den Sitzungen der HistorischPhilologischen Societätsklasse in Berlin mit dem Manne zusammengetroffen, der das lange erstrebte etymologische Wörterbuch der deutschen Sprache wirklich abschließen und veröffentlichen sollte: JoHann Grorg WaOHTER. ${ }^{1}$ Sein 'Glossarium Germanicum continens origines et antiquitates totius linguae Germanicae' erschien im Jahre 1737; aber diesem Werk war 1727 eine kürzere Ausgabe voraus. gegangen, und schon einige Jahre vorher wird FRISCH von dem Vorhaben WAarTERs unterrichtet gewesen sein. $1741 \mathrm{im}$ Vorbericht des 'Teutsch-Lateinischen Wörter-Buchs' heißt es :

'Nachdem endlich der berühmte Herr Wachter sein Glossarium herausgegeben, hat man demselben die weitläufftige Nachricht von der Verwandtschafft vieler noch gebräuchlioher Wörter mit dem alten Gothischen, Angelsächsischen und andern noch bis jetzt gewöhnlichen Sprachen, meistens überlassen, und nur das, was man ehedessen dazu geschrieben gehabt, ehe sein Buch herausgekommen, behalten.'2

Es scheint, daß das Wissen um die Wörterbuchplëne EorarIs und Wachtwrs den Boden bereitet hat für einen Wandel der ursprünglichen Zielsetzung FrrsoHs. Es konnte der Entschluß heranreifen, die eigene Darstellung, ohne den Gedanken eines etymologischen Wörterbuchs gänzlich aufzugeben, stärker zu einem historischen Wörterbuch umzugestalten. Die Belege im Archaeologum der Specimina von 1723 und 1727 zeugen bereits von umfassend angelegten Exzerptionsarbeiten. Und es ist wesentlich, daB unter den benutzten Quellen nicht nur das Monseer Glossar, die Evangelienharmonien Otrrids und TATIANs und der Schwabenspiegel erscheinen, sondern auch Urkunden und Chroniken des Spätmittelalters, die Postille KrIsersbergs, die Bibelübersetzung LothHers und das Wörterbuch Josua MaAlers. Die Forschungen zum Wortschatz der frühneuhochdeutschen Zeit sollten für den Fortgang der historischen Wortschatzstudien FrIsorrs bald eine zunächst nicht zu ermessende Bedeutung gewinnen. Denn unter dem Eindruck der Fortschritte der zeitgenössischen Wortforschung, namentlich unter dem Eindruck der Veröffentlichung des 'Thesaurus Antiquitatum Teutonicarum (1727-1728) von Johandes SoHmTER verlagerte sich für F'RISOH das Schwer' gewicht auch im Archaeologum, und zwar vom Stoffgebiet des Althochdeutschen und Mittelhochdeutschen hinweg. Der dritte von Elias Frick besorgte Band des SonسmERschen 'Thesaurus' erläuterte die altdeutschen Texte des ersten und

1 Protokolle vom 25. 4. 1720; 19. 9. 1720; 13. 2. 1721; 15. 5. 1721; 15. 1. 1722.

2 FrisCH, TLWb. (1741) Vorbericht $)\left(1^{\text {b. }}\right.$ 
zweiten Bandes durch ein vorerst erschöpfendes 'Glossarium ad soriptores linguae Francicae et Alemannicae veteris'. Vieles von dem, was Frisch ursprünglich darzustellen beabsichtigte, wurde hier vorweggenommen. Er entsprach der veränderten Forschungslage jedoch dadurch, daß er sich entschloß, das "Teutsch-Lateinische Wörter-Buch' dem altdeutschen Glossar SoHmirers als Ergänzungswörterbuch für den wenig erforschten Wortschatz der frühneuhochdeutschen Zeit anzufügen:

'Des Herrn Schilters Glossarium Teutonicum hat ihn (den Verfasser) einer grossen Arbeit überhoben, weil der ganze Schatz von den urältesten Teutschen Schrifften darein gekommen ist. Indem es aber nur bis an Zeiten reicht, die man noch recht dunkel nennen kan, nemlich kurz vor- und kurz nach der Erfindung des Buchdruckens, darinnen man Historion und Chroniken findet, wo auf allen Seiten Wörter stehen, die dem Leser am Verstand solcher Schrifften hinderlich fallen; so ist dadurch Gelegenheit gegeben worden, in diesem gegenwärtigen Wörter-Buch die Hand an eine schöne Aerndte zu legen, davon keiner sagen kan, es sey in eine fremde geschehen.'1

Auch drei der germanistischen Beiträge FRISCHs im fünften und sechsten Band der 'Miscellanea Berolinensia' sind als Supplemente zu ScHrurerrs 'Glossarium Teutonicum' gekennzeichnet. ${ }^{2}$ In einer Vorbemerkung zu dem orsten dieser Beiträge äußert sich FrIsorr in grundsätzlicher Form über die Notwendigkeit einer Ergänzung des altdeutsohen Glossars SoHmTERs. In ihm sei zwar der Wortschatz OtrRIDs und des Tatian, NotkmRs und Willirams erfaßt, sehr vieles aus der älteren Sprache aber fehle noch:

'Quot obsoleta, aut obscurioris significationis, aut usus rarioris inveniuntur, quae Thesauro huic inseri possunt? Omnes certe quotquot huic egregio studiorum generi operam dant, tenentur ea, quae legendo talia scripta inveniunt, operi huic Schilteriano addere, ut subinde perfectius fiat.' 3

Frischs lexikographisohes Schaffen ist nicht nur mit dem Wirken führender deutscher Sprachgelehrter wie SoHILTER, LaIBnIz, Eorart und Wachrter verbunden. Es steht zugleich in enger Beziehung zu der im 17. Jahrhundert stark aufstrebenden historischen Forschung auf dem Gebiet des Mittellateins und der romanischen Sprachen. Namentlich den berühmten französischen Philologen CHARLES DV CANGT (Glossarium ad scriptores mediae et infimae Latinitatis. 11678) und Grulds Ménagm (Origines de la langue françoise. ${ }^{11650 .}{ }^{2} 1694$ ) verdankt FrIsCH Wesentliches. Zeugnisse der Auseinandersetzung mit ihren Werken liegen vor in berichtigenden und ergänzenden 'Observationen' FRISCHs, deren Entstehungsdaten sich über vier Jahrzehnte verteilen. Waren diese Beiträge auch ausgesprochen kritischer Art, so wußte FRISOH den Wert der Wörterbücher Ménages und Du CANGES doch zu schätzen. Der Gedanke, für die deutsche

I Frisor, TLWb. (1741) Vorbericht )( $2^{\mathrm{a}}$.

2 Misc. Berol. 5 (1737) 198-200; 201-210; 6 (1740) 193-194.

s Misc. Berol. 5 (1737) 198. 
Sprache ein Werk zu sohaffen, wie es Mínagt für das Französische und Do CANGE für das Mittellateinische vorgelegt hatten, hat FrisoH während der Frühzeit seiner lexikographischen Arbeit zumindest mitbestimmend geleitet.

Das wichtigste Zeugnis dafür, daß dem mittellateinischen Wörterbuch DO CANGRs richtungweisende Bedeutung bereits für die Anfänge des lexikographischen Schaffens zukommt, enthält die 1703 erschienene Schrift Frisors über die 'Buchstab-Veränderung'. Hier heißt es, die Untersuchung beginne mit dem Worte 'Aa',

'weil es nicht so sehr im gemeinen reden und schreiben bekant / damit sich die gelehrten Ausländer nicht länger beschweren / man untersuche nur die gewöhn. lichsten Worte; was aber ein wenig veraltet/das setze man beyseit. Unter diesen ist absonderlich der gelehrte Frantzösische Herr Carolus du Fresne, welcher in der Vorrede des von ihm herausgegebenen Erklärungs-Buchs der falschen und fremden Wörter deren letztern Lateinischen Schrifften / also schreibet:

Es wäre zu wünschen / daß unter allen Völckern sich gelehrte Männer hervor thäten / welche ihrer Wörter Eigenschafft / Bedeutung / Nachdruck / Ursprung / ja auch die nicht mehr gewöhnliche und längst veraltete Wörter genau untersucheten und erkläreten.

Und bald darauf sagt er:

Wann gleich einige bisher gewesen / so Wörter-Bücher geschrieben / haben sie fast allezeit nur die gewöhnlichsten Wörter gesetzet; die andern ausgelassen; die blosse Bedeutung derselben angezeiget / von ihrem Ursprung aber nicht das geringste gemeldet / vielleicht / weil sie denselben nicht wusten. Dann diesen zu untersuchen / wird grosse Kunst und Wissenschafft / nebst hëuffigem Lesen vieler Schrifften erfordert. Welches gemeiniglich bey denen nicht ist / die sich über dergleichen Arbeit machen'1.

Neben Du Cavge und Mtarage waren es namentlich der niederländische Philologe Germard Vossios (De vitiis sermonis et glossematis Latino-barbaris. 1645) und der Engländer HerRx SpmLMan (Glossarium archaiologicum continens latinobarbara ... vocabula. ${ }^{1} 1626 .{ }^{3} 1687$ ), die mit ihren Werlzen auf die etymologischsprachgeschichtliche Forschungsarbeit FrIscrs einwirkten. Wie das ausführliche programmatische Zitat aus dem mittellateinischen Wörterbuch DU CANGEs am Anfang des lexikographischen Schaffens steht, so beruft sich FrIsorr noch im Jahre 1739, unmittelbar vor Abschluß der Arbeiten am 'Teutsch-Lateinischen Wörter-Buch', auf das Vorbild des 'Archaeologus' von HwNRY SPELMax. In der kurzen Untersuchung 'De primis in Germania typis editis lexicis Germanicis' (1739) heißt es unter nochmaligem Hinweis auf die Hauptziele des Wörterbuchschaffens:

'Non enim tantum scholasticae juventuti soribo, sed et multis aliis, exempli cause omnibus, qui simul Etymologiam plerarumque vocum desiderant, item, qui historias patriae nostrae, chronica, et alia proxime praeteritorum secu-

1 Frisce, Buchstab-Veränderung (1703) 3-4. 
lorum scripta legere cupiunt, nec Lexicon habent, quo simul voces horum librorum tanquam medii aevi, contineantur, ut in Archaeologo quodam Spel. manniano"1.

Vor allem erweisen jedoch die fremdsprachlichen Studien FrisoHs den Zusammenhang mit der romanistischen und mittellateinischen Wortforschung. Diese Studien, die sich außer auf das Französische und Mittellateinische auf die Germania, die Altsprachen und das Slawische richteten, waren vorzugsweise sprachvergleichender Art. Sie dienten dem Ziel, die für die Herkunftsbestimmung deutscher Wörter aufschlußreichen Wortschatzerscheinungen (namentlich das fremde Lehngut im Deutschen, die Reste altertümlichen deutschen Wortgutes in fremden Sprachen) zu erfassen. Zweifellos kommt diesen Untersuchungen ein selbständiger Wert zu; es darf jedoch nicht übersehen werden, daß ihre Ergebnisse weithin in Hinblick auf die Erforschung des deutschen Wortsohatzes gewonnen worden sind.

In Zusammenhang mit romanistischen Studien FrIscress entstand der 1712 in erster Auflage erschienene 'Nouveau dictionnaire des passagers', ein französischdeutsches Wörterbuch mittleren Umfangs (1730: 1696 Sp.; 1739: 2040 Sp.) mit ergänzendem deutsch-französischen Registerteil (1730: 704 Sp.; 1739 : 744 Sp.). FrIScr stellte das Werk, ohne zu den Quellen zurückzugehen, 'aus den vollkommensten und neuesten (französischen) Dictionariis'2 zusammen, und zwar mit dem Ziel, ein Hilfsmittel für praktische Bedürfnisse zu schaffen. Die Durchsicht seiner Vorlagen benutzte er jedoch auch dazu, den französischen. Wortschatz unter etymologischem Gesichtspunkt planmäßig zu durchforschen. Was er dabei an Ergebnissen gewann, bezeichnete er im Wörterbuch durch Zusatz des Etymons hinter jedem Stiohwort; eine ausführliche Begründung mußte er späteren Veroffentlichungen vorbehalten. Diese etymologischen Studien standen unter dem besonderen Blickpunkt der germanisch-romanischen Wechselbeziehungen auf dem Gebiet der Wortgeschichte. Das bezeugen mehrere Äußerungen FrIsoHs. So schreibt er nach Abschluß der Arbeiten am 'Nouveau dictionnaire' (12. Sep. tember 1708) an LFIBNIZ:

'Nun kan ich sagen, was von altteutscher Sprach noch im heutigen Französi(s)ch übrig; und weil ich es in diesem Werck nicht hab ausführen können, warum ich dieses oder jenes Wort zu einem andern Ursprung als die andern geführt, werde ich es in einem absonderlichen scripto mit der Zeit thun.'3

Ähnlich heißt es in der Vorrede zum 'Nouveau dictionnaire':

'Weil auch mein Vorsatz ist, etwas gründliches und ausführliches von der Teutschen Etymologie, dereinsten zu verfertigen; in Ermangelung aber der alten Teutschen Schriften zu denjenigen Sprachen gehen muste, welche noch einige Spur der alten Teutschen Wörter haben, worunter absonderlich die Frantzösische ist, habe ich dieselbe so durchsucht, als vielleicht noch wenige

1 Frisor, De primis lexicis (1739) $)\left(4^{b}\right.$.

2 FrISOr, Nouveau dictionnaire (1730) Titelblatt.

3 Frscher, Frischs Briefwechsel mit Leibniz (1896) 16-17. 
gethan haben, und in vielen den wahren Ursprung gefunden, den andere wegen ermangelnder Wissenschaft der alten und ietzigen Teutschen Sprache nicht finden können.' 1

Diese Äußerungen sind in mehrfacher Hinsicht aufschlußreich. Sie bezeugen das Vorwalten des etymologischen und sprachvergleichenden Interesses für die Frühzeit des lexilrographischen Schaffens; sie lassen erkennen, daß die fremdsprachlichen Studien sich einordnen in die Reihe der Vorarbeiten zum 'Teutsch. Lateinischen Wörter-Buch'; und sie enthalten schließlich versteckt polemisch Hinweise auf die Werke der französischen Sprachforscher, mit denen FrISOH sich auseinanderzusetzen hatte und von deren Ergebnissen er im einzelnen ab. wich. Denn die Gelehrten, denen er mangelnde Kenntnis der deutschen Sprache vorwirft, sind Ménage und Du Cange. Studien zu den 'Origines de la langue françoise' von GILLES MéNAGE, die FrTsor wohl zur Zeit der Abfassung des 'Nouveau dictionnaire' aufnahm, hat er bis an sein Lebensende unablässig fortgesetzt. Bereits 1712 berichtete er LEIBNIz brieflich über diese Forschungen.. ${ }^{2}$ Erstmals im Jahre 1714, dann insbesondere nach der Ubernahme des Direktoramtes in den Jahren von 1733 bis 1741 verlas er Auszüge seiner MLANAGE-Observationen ror den Mitgliedern der Historisch-Philologischen Societätsklasse. ${ }^{3} 1737$ und 1740 wurde ein Teil dieser Untersuchungen unter dem Titel 'Origines vocum quarundam linguae Gallicae et simul observationes et supplementa ad Dn. Menagii origines linguae Gallicae' in den 'Miscellanea Berolinensia' gedruckt. Zugleich widmete sich Frisch mittellateinischen Wortstudien zum Glossarium DU CaNGGs. Daß auch sie in Zusammenhang stehen mit der Erforschung der deutschen Etymologie, geht hervor aus der Äußerung FrisoHs: die hohen Anforderungen, die DU CANGI an den Bearbeiter eines etymologischen Wörterbuches stelle, hätten ihn fast zurückgeschreckt,

'wann ich nicht in seinem vorgedachten Wörter-Buch selbst eine grosse Zahl Teutscher Wörter Ursprung und Erklärung gefunden / die ihm unbelkant gewesen / welches bey Gelegenheit soll gezeiget werden. Wordurch ich ferner fortzufahren nicht wenig aufgemuntert worden."

Mittellateinische Studien FrrsoHs werden zufrühest bezeugt für die Entstehungszeit der 'Buchstab-Veränderung', sodann für die Jahre 1712, 1719, 1722, 1738 und 1740. ${ }^{6}$ Ein Teil der Untersuchungsergebnisse sollte gleichfalls in den Mis-

1 Frisch, Nouveau dictionnaire (1752) ) ( $5^{\mathrm{b}}$; vgl. das Protokoll vom 13. 9. 1714: 'wenn neben der Teutschen Etymologie die Französische mit untersucht würde, solte eine der andern vortreflich zu statten kommen.'

2 Frschrr, Frischs Briefwechsel mit Leibniz (1896) 34.

Protokolle vom 1. (?) 10. 1714; 5. 3. 1722; 12.3. 1733; 21. 5. 1733; 21. 1. 1734;

18. 3. 1734; 17.6. 1734; 1. 9. 1735; 4. 4. 1737; 7. 4. 1740; 3. 11. 1740;23. 2. 1741.

4 Misc. Berol. 5 (1737) 217-222; 6 (1740) 195-203.

5 Frisce, Buchstab-Veränderung (1703) 4.

- Fischer, Frischs Briefwechsel mit Leibniz (1896) 33-34; Protokolle vom 2. 2.1719 ; 5. 3. 1722 ; 20. 3. $1738 ; 3.11$. 1740 . 
cellanea Berolinensia' veröffentlicht werden; FriscHs Beitrag ist jedoch nicht hier, sondern in einer mit dem ersten Heft eingegangenen Berliner Monatsschrift, den 'Anmerkungen über die deutschen Reichssachen' (21741) erschienen. ${ }^{1}$

Frühzeitig zog FrIsorr im übrigen auch die slawischen Sprachen in den Bereich seiner etymologischen Forschungen. Er bemühte sich, germanisch-slawische Wortgleichungen aufzufinden, und berichtete LEIBNIz 1709 über diese Studien. Auch hier ist die Beziehung zur Erforschung der Etymologie des deutschen Wortschatzes deutlich klargelegt:

'Die Russische, sowohl vulgare als gelehrte oder sclavonische Sprach gibt mir in der teutschen etymologie ein grosses Licht und hab ich einige 100 Wort schon aufgezeichnet, welche wir mit ihnen gemein haben.'2

1711/12 war F'RrsoH mit Untersuchungen zu deutschen Ortsnamen slawischer Herkunft beschäftigt. ${ }^{3}$ Die gewonnenen Ergebnisse legte er in einem Aufsatz nieder, den er am 1. September 1718 der Klasse zur Veröffentlichung in den 'Miscellanea' anbot. ${ }^{4}$ Bereits 1717 hatte er in den Berliner 'Zufälligen Anmerkungen' eine grammatisch-etymologische Untersuchung erscheinen lassen 'Von einigen.Wörtern / so aus der Sclavonischen Sprach / und derselben Töchtern oder Mund-Arten genommen / aber von den meisten falsch buchstabirt / oder gesohrieben / oder' ausgesprochen werden'5. Zu WAowrers Aufsatz 'De lingua Codicis argentei' ${ }^{3}$ steuerte FrIscr eine Reihe gotisch-slawischer Wortgleichungen bei. ${ }^{7}$

\section{Die Erforschung des Wortschatzes der deutschen Mundarten und Fachsprachen}

Maßgebliche Voraussetzungen der lexikographischen Tätigkeit FrIscrs sind in der germanistischen, mittellateinischen und romanistischen Forschungstradition des 17. Jahrhunderts erkennbar geworden. Thr schloß bereits der junge Berliner Lexilkograph sich an, indem er sich das Ziel setzte, den gegenwartssprachlichen und clen historischen Wortschatz (auch das Namengut) der deutschen Sprache etymologisch-semantisch erläutert darzustellen. Im Specimen I (1723)

1 Neue Zeitungen von Gelehrten Sachen (1741) 359.

2 Frsceen, Erischs Briefwechsel mit Leibniz (1896) 24.

3 Protolkoll vom 30. 4. 1711; Frsceme, Frischs Briefwechsel mit Leibniz (1896) 33.

4 Protokoll vom 1.9. 1718.

5 Zufällige Anmerckungen 4. Stück (1717) 294-302.

- Misc. Berol. 2 (1723) 40-47; vgl. Protokoll vom 1. 10. 1722.

7 Misc. Berol. 2 (1723) 43-44. Frischs Bedeutung als Slawist würdigt E. Erchrer, Johann Leonhard Frisch und die rusaische Sprache. Ein Kapitel deutscher Slawenkunde. In: Die deutsch-russische Begegnung und Leonhard Euler (1958) 94-111. Vgl. auch W. BrRntagks, Johann Leonhard Frigch und seine Beziehungen zu RuBland. A. a. O. 112-124. 
ontsprachen dieser Zielsetzung die Kategorien des Etymologicums, des Archaeologums und des Eponymologicums. Sie bilden den Kernbestandteil dieses Entwurfs.

Auch der sprachtheoretischen Bewegung des 17. Jahrhunderts ist Frrsor verpflichtet. Indem er den Gedanken aufgriff, den Wortschatz der neuhochdeutschen Gemeinsprache lexikographisch zu bearbeiten, folgte er dem Aufruf der Theoretiker der Fruchtbringenden Gesellschaft, die diese geschichtlich drängende Aufgabe in das Bewrutsein ihrer Zeit gehoben hatten (Usuale generale; Criticum). Es bleibt die Frage nach der Herkunft der Kategorie des Usuale speciale (Technicum) im Specimen I. Die Untersuchungen, die sich in diesem Zusammenhang als notwendig erweisen, werden erneut in das Gebiet der germanistischen Wortforschung führen, allordings nicht in den Aufgabenbereich ibrer geschichtlichsprachvergleichenden Teildisziplin. In den Jahrzehnten um 1700 entfalteten sich die Anfänge des wissenschaftlichen Studiums der deutschen Mundarten und der deutschen Fachsprachen. Einer der wichtigsten Förderer dieser neueinsetzenden Forschungsbemühungen war GotTrRIed WrrFelm LeIBNIz. Er war es, der in den Jahrzehnten um 1700 unermüdlich auf die Notwendigkeit der Erfassung des mundartlichen und fachsprachlichen Wortgutes hinwies, und diese Anregung hat auch auf FrIsOH, auf den Gang seiner Studien im Bereich des sondersprachlichen Wortschatzes nachhaltig eingewirkt.

Die sprachliche Sonderart der deutschen Stämme und Landschaften ist seit alter Zeit wahrgenommen worden und hat früh zu laienhafter Beschäftigung mit den Mundarten angeregt. Im Kreise ScHоттеLs vertieften sich derartige Wahrnehmungen erstmals zu theoretischen Anschauungen vom Wesen und Wert der Mundart. Die neuentwickelte Auffassungsweise trug den sprachgeschichtlichen Gegebenheiten des 17. Jahrhunderts sowie bestimmten Grundüberzeugungen der Fruchtbringenden Gesellschaft Rechnung. Daraus ergab sich, daß nicht die Verschiedenheiten im Laut., Formen- und Wortbestand der Einzelmundarten im Blickfeld lagen, sondern der Gegensatz des Mundartlichen schlechthin zur werdenden Hochsprache : die regellose Vielfalt der landschaftlichen Sprechgebräuche gefährdete das Bemühen des Grammatikers um verbindliche Sprachnormen. Im Geschichtsbild des Theoretikers standen die Mundarten auf der Spätstufe eines Verfalls, dem die uralte, ehedem so vollkommene und nunmehr in ihrer Vollkommenheit wieder herzustellende deutsche Hauptsprache in früher geschichtlicher Zeit zum Opfer gefallen sein sollte. So erklärte SorroxтEr, nachdem er unter anderem die Sprache OTFRIDs als ein 'durch Unart und Unacht der Mund-Arten bestäubert' ${ }^{1}$ und entfremdetes Deutsch gekennzeichnet hatte:

I SoHonym, Horrendum Bellum Grammaticale (1673) 88; vgl. SIGRID v. D. Schulanburg, Leibnizens Gedanken und Vorschläge zur Enforschung der deutschen Mundarten. (Abh. d. Preuß. Akademie d. Wissenschaften. Philos.-Hist. Klasse. [1937] 10). 
'Wie dann diese Zeit annoch / aus dem uhralten alhier beschriebenen Landverderblichen Sprach-Unwesen viel Unlautförmiges annoch behalten und behelt: Dan wer kan leugnen / wie an etzlichen Oerteren in Schwaben / Bairen / in der Sohweitz und sonsten / sonderlich auf dem Lande und unter den gemeinen Leuten solche braitgeslieffene / Waite und braite Wörter annoch ausgesprochen werden / daß man darauf kegelen und bosselen möchte ... Was das gemeine Volk nach mancherlei Mundart ausknarret / bleibt und ist zwar Teutsch / aber das Echt- und Rechtsein / Zier / Grund und Wollaut ist darunter nicht sonderlich vorhanden.' 1

Selbst die Auffassungsweise des Sprachtheoretikers ließ jedoch den Weg offen zu einer bedingt-anerkennenden Bewertung der Mundart. Für ihn wurde sie dort wertvoll, wo sie zur Erhellung des 'Urbildes' der Muttersprache beizutragen vermochte; so wenn es sich darum handelte, den Stammwortbestand des Deutschen in vollem Umfange zu erschließen und semantisch oder etymologisch verdunkeltes Wortgut der Gemeinsprache zu deuten. Für SoHo'xteL wahrten namentlich die niederdeutschen Mundarten, in denen er Ursprüngliches und geschichtlich Ältestes erhalten fand, eine Sonderstellung. ${ }^{2}$ Neben dem Streben nach etymologisch-semantischer Erhellung des gemeinsprachlichen Wortgutes wirkte auch das ebenfalls bereits bei Sorotren erkennbare Bemühen, Lücken im Ausdrucksbestand der Schriftsprache durch die Einführung mundartlicher Bezeichnungen zu schließen, in der Mundartenforschung des 18. Jahrhunderts fort. Das Ziel dieser Bestrebungen war die Erforschung der Mundart noch nicht um ihrer selbst, sondern um der Hochsprache willen, und so wie hier der Mundart kein Eigenwert zuerkannt wurde, so war auch die Mundartenforschung, unter diesem Aspekt betrieben, noch keine eigenwertige und selbständige Disziplin.

Es war daher bedeutsam, daß das Studium des Wortschatzes der deutschen Mundarten zugleich von Kreisen ausging, die der historisch-etymologischen Wortforschung verbunden waren und sich stärker von dem Gesichtspunkt objektiver Wirklichkeitserkenntnis leiten ließen. Zwar erhob die Mundartenforschung sich dort, wo von ihr ethnographische Aufschlüsse (LeIBNIZ) oder ein tieferes Verständnis historischer Quellen erwartet wurden, noch nicht über den Rang einer Hilfswissenschaft der Geschichtsforschung. Aber zum einen mußte diese Hilfsdisziplin in sich selbständig ausgebaut werden, zum anderen setzte gerade hier das Bestreben an, das Studium des mundartlichen Wortschatzes als eigenständige sprachwissenschaftliche Forschungsaufgabe zu betreiben. Es gliederte sich damit ein in das Gesamtgebiet der germanistischen Wortforschung. In ihrem Rahmen sollte es dazu beitragen, Einblick zu vermitteln in die Geschichte und das Wesen der deutschen Sprache. Vorbilder des Auslands ${ }^{3}$ sowie das Beispiel CladbBrars, der für ein (nur auszugsweise erschienenes) etymologisches Wörterbuch der deut-

1 Sokotrex, Horrendum Bellum Grammaticale (1673) 90.

2 Schotrel, Teutsche HaubtSprache (1663) $159 ; 176 ; 1274$.

3 JOHN RAY, Collection of English words 1674; Grnles Mriage, Origines de la langue françoise 11650. ${ }^{2} 1694$. Vgl. S. v. D. Schulanburg a. a. O. 5. 
schen Sprache zwischen 1651 und 1665 mundartliches, insbesondere niederfränkisches Wortgut gesammelt hatte, wirkten in der Zeit um die Wende des 17. Jahr. hunderts anregend auf jenen Forscherkreis ein, der den Gedanken der Erfassung mundartlichen Wortgutes in Deutschland besonders nachhaltig gefördert hat: die Gruppe um Lenzanz. ${ }^{1}$ Unabhängig von ihr waren bereits zu dieser Zeit in verschiedenen Teilen Deutschlands am Werk: Johann Ludwig Prasor. in Bayern (Glogsarium Bavaricum 1689); Christran Meisner in Schlesien (Silesia loquens 1705); Johananes Cadovius MüLugr in Ostfriesland (Sammlungen für ein ostfriesisches Idiotikon um 1700); KONRAD MEL in Hessen (Voces Cattorum nationales, vor 1725); DTED RRIOH voN STADe in bremischen Raum (Vocabula WursatoFrisica, vor 1718). Diese sich anbahnende Forschungsbewegung hat LEIBNIZ von seiner Seite aus zu fördern gesucht, indem er unermüdlich dazu aufforderte, den Sonderwortschatz der deutschen Mundarten zu erfassen. Mit zahlreichen Sammlern und Gelehrten, die den Fragen der Mundartenforschung aufgeschlossen gegenüberstanden, verbanden ihn Beziehungen. So mit HIOB LUDOLF ${ }^{2}$, der LrIBNIzens Drängen auf Schaffung von Mundartenwörterbüchern und insbesondere die Forderung nach einem 'Glossarium Thuringicum vel Misnicum' unterstützte (1693-1695), und mit Gerhard Mrim in Bremen, dem Bearbeiter des 'Glossarium Saxonicum' (1694-1703), von dem die Fäden weiterführen zu v. Stradu und Dieomane, zu Lodolf und dem Gothaer Joachm Bartegolomäus Mmier, zu dem abt Molanus, der mit seinen Landpfarrern das Werk förderte, und zu JOHANN ANDERSON, dem Hamburger Bürgermeister, der den Wörterbuchnachla $\beta$ Marcrs erwarb. ${ }^{3}$ Im Briefwechsel stand LaIBNIZ auch mit dem niedersächsischen Gelehrten Justus JoHan KeLp, zu dessen 'Glossarii Chaucici Specimen' (Sammlungen bereits vor 1696) er eine Reihe von Anmerkungen niedergeschrieben hat (veröffentlicht in den Collectanea Etymologica). ${ }^{4} 1695$ hat LinIBNIz ferner das 'Memoriale linguae Frisicae' des JoHannes Cadovius MüLLwe durch Vermittlung des ostfriesischen Staatsrats HeIrrior AvEManN in Aurich zur Einsichtnahme erhalten und von dem Werk einen Auszug anfertigen lassen. ${ }^{5}$

In das Bild dieser Bestrebungen, die teils von LEIBNIZ ausgehen, teils von ihm gefördert werden, fügen sich die Mundartstudien ein, denen sich FRIsCH seit der Frühzeit seines Berliner Aufenthalts gewidmet hat. ${ }^{6}$ Nachweislich zuerst im Jahre 1709 war er damit beschäftigt, Sammlungen für ein Glossarium Marchicum anzulegen. ${ }^{7}$ Er hat LEIBNIz von diesem Vorhaben berichtet und 1710 brieflich einige

1 S. V. D. SchulenbuRg a. a. O. $5 ; 11-12$.

S. V. D. SOHULENBURG a. a. O. 12.

8 S. v. D. Schulenbura a. a. O. 13-30. Uber Leibnaz als Anreger der Mundartenforschung in der Schweiz vgl. TrüMrY, Schweizerdeutsche Sprache und Literatur im 17, und 18. Jahrhundert (1965) 89-90.

4 S. v. D. SoHULenbuas: a. a. O. 30-33.

5 S. v. D. Sohulmendrg a. a. O. 33-35.

- S. V. D. Schulgnborg a. a. O. 36-37.

7 Frsorren, Frischs Briefwechsel mit Leibniz (1896) 24. 
Proben mitgeteilt. Bezeichnenderweise war es wesentlich etymologischer Forschungsdrang, der ihn dazu veranlaßte, der märkischen Mundart seine Aufmerksamkeit zuzuwenden; ihre Wortschatzeigentümlichlkeiten erschienen ihm bemerkenswert:

'Es lauffen freylich einige Wörter mit in das Niedersächsische, einige ins Pommerische, haben aber alle, soviel ich gesamlet, etwas besonders wegen der Etymologie oder anderer Umstände.'

Frisors Aufmerksamkeit galt nicht nur der märkischen Mundart. Als 1725 der Historisch-Philologischen Klasse ein handschriftliches hessisches Mundartenglossar ('Voces Cattorum nationales') KonRad Mrus vorgelegt wurde, war er es, der ein kritisches Gutachten ausarbeitete, in dem er die echt 'cattischen' Ausdrücke von den auch sonst mundartlich verbreiteten sonderte und Beiträge zur Erläuterung schwieriger Wörter lieferte. ${ }^{2}$ Auch dem Wortgut anderer Mundarten, insbesondere seiner fränkisch-bairischen Heimatmundart hat FRIscr Aufmerksamkeit geschenlst. In späteren Jahren äußerte er sich dann in grundsätzlicher Form über den Wert und die Wege der Erforschung des mundartlichen Wortschatzes. Am 24. Januar 1726 unterbreitete er der Klasse 'eine methode, wie ein Glossarium einzurichten's. Diese Schrift sollte in hundert Exemplaren gedruckt und den auswärtigen Mitgliedern zugesandt werden. Sie ist vielleicht identisch mit dem 'Entwurf eines Registers, das in jedem Lande kan gemacht werden, von Wörtern, die nur einige Leute gebrauchen', der 1734 in dem 'Ersten Auszug' erschien. ${ }^{4}$ Es handelt sich um eine aus den Erfahrungen der märkischen Mundartstudien erwachsene programmatische Grundlegung ("Entwurf was für Wörter in jeder Provintz und Gegend von Teutschland, sonderlich in der Mark Brandenburg zusamme[1]n sind'), in der FrISCH dazu auffordert, Mundartenwörterbücher für alle Teile des deutschen Sprachgebietes zu schaffen, und im Untertitel ('Zur Beförderung des so nöthigen Allgemeinen Teutschen Wörter-Buchs') auf die Notwendigkeit einer Gesamtdarstellung des deutschen Wortschatzes hinweist. Der Hauptnachdruck ruht auf der Kennzeichnung des Wortgutes, das die Bearbeiter der Mundartenwörterbücher erfassen sollen: Frrsor denkt an landschaftlich-mundartliche Ausdrücke der realen Lebensbereiche, des Hauswesens, der Viehzucht, des Ackerbaus, der Fischerei, des Forst- und Jagdwesens, des Kirchen- und Schuldienstes, der örtlichen Verwaltung und landschaftlicher Rechtsverhältnisse.

Das Glossarium Marchicum ist nicht erschienen; aber die Sammlungen märkischen Wortgutes, die es aufnehmen sollte, und weitere mundartliche Samm-

1 FISChER a. a. O. 25.

2 Protokolle vom 20.9. 1725 und 22. 11. 1725.

Protokoll vom 24. 1. 1726.

4 Der erste Auszug Von einigen Die Teutsche Sprach betreffenden Stüclien (1734) 3-5, erneut abgedruckt in : Frschen, Frischs Briefwechsel mit Leibniz (1896) $61-62$. 
lungen F'RISOHs sind in das 'Teutsch-Lateinische Wörter-Buch' eingegangen. Sie finden sich dort im Etymologicum und im Usuale speciale. Wann der Gedanke sich durchgesetzt hat, mundartliches Wortgut in die Darstellung des 'TeutschLateinischen Wörter-Buchs' einzubeziehen, bleibt ungewiß; sicher aber nicht erst im Jahre 1723, als das Specimen I veröffentlicht wurde. Denn bereits 1709 ar. beitete FRIsor an einem Glossarium Marchicum. Zu dieser Zeit hatten die einsetzenden Bestrebungen der deutsohen Mundartenforschung ihn also bereits erfaßt und konnten sich auf das Schaffen am 'Teutsch-Lateinischen Wörter-Buch' auswirken. Es wird nicht zufällig sein, daß der Plan des Glossarium Marchicum zum ersten Male in einem Schreiben Frisors an Larbntz für uns greifbar wird. Dieser Sachverhalt deutet vielmehr darauf hin, daß es Anregungen LmIBNIzens waren, die FrIsor in das Gebiet der Mundartenforschung (und der Erforschung des sondersprachlichen Wortschatzes) einführten.

Diese Annahme gewinnt dadurch an Wahrscheinlichkeit, daß für Frrsor das Usuale speciale wesentlich Technioum ist. Seine programmatischen Darlegungen im Entwurf von 1734 hatten bereits die engen Beziehungen zwischen Mundart und volkstümlicher Fachsprache erkenmbar werden lassen. Die Aufforderung, Wortgut der Fachsprachen zu sammeln, bildete jedoch ein zweites wesentliches Anliegen Lieibnrzens auf dem Gebiet der Wortforschung, für das er mit großem Nachdruck eingetreten ist. LerBNIzens Bemühungen in diesem Sinne können hior nicht in vollem Umfange geschildert werden; es muß genügen, jenen Ausschnitt seines Wirkens für diesen Gedanken darzustellen, der für FrRIsorr unmittelbar bedeutsam werden konnte: sein Eintreten für die Schaffung eines Deutschen Wörterbuchs 'zumahl Terminorum technicorum' im Rahmen der Preußischen Societät der Wissenschaften zu Berlin.

Die Gründung der Historisch-Philologischen Klasse der Societät ist nicht LeIBNIZens Werk. Am 19. März 1700 bestätigte der Kurfürst in Oranienburg einen von dem Hofprediger D. E. JABLONSEI ausgearbeiteten 'Vorschlag wegen Anrichtung eines Observatorii und Academiae Scienciarum'1. Dieser Entwurf JABLONSKIS sah vor, es solle

'ein vollstëndig Collegium oder Academias Scienciarum in Physicis, Chimicis, Astronomicis, Geographicis, Mechanicis, Opticis, Algebraicis, Geometricis und dergleichen nützlichen Wissenschafften nach und nach etablirt werden.' 2

Die einseitige Ausrichtung auf den naturwissenschaftlichen Arbeitsbereich entsprach durchaus der Absicht LimbNIzens. Am 12. März 1700 hatte er JABLoNskI von Hannover aus geschrieben, er sei der Ansicht,

1 Harnaor, Gesch. d. Königl. Preuß. Akademio der Wigsenschaften zu Berlin (1900) 2, 58.

2 Harnack a. a. O. 2, 59. 
'die Societät unter Churfürstl. Protection ... sollte aus einigen membris ordinariis nebst einem Directore mit vielen Honorariis bestehen, welche . . . totam Matheseos et Physices latitudinem zu dem hauptsächlichen Objecto hätten, sonderlich aber auf gemeinnützige Applicationes bedacht wären. Dazu würde gehören cura Astronomia, Mechanicae, Architectonicae, Chymiae, Botanicae et Anatomicae.' 1

In einer Denkschrift von Ende März 1700 betonte LEIBNIz nochmals, daß es auf die Förderung der 'realen Wissenschaften Mathesis und Physica ankomme'2.

Inzwischen war in Berlin eine für den Aufbau der Societät bedeutsame Entscheidung getroffen worden. Der Kurfürst hatte ihrer Gründung zugestimmt mit dem Bemerken,

'daB man auch auf die Cultur der Teutschen sprache bey dieser Fundation gedencken möchte, gleichwie in Frankreich eine eigene Academie hiezu gestifftet. ${ }^{3}$

Auf diese persönliche Anregung FrIEDRIoHs III. geht die Einrichtung der Historisch-Philologischen Societätsklasse zurück. Freudig begrüßte JABLOASSKI die Erweiterung des ursprünglichen Planst, wurde sich jedoch auch sofort der Schwierigkeit bewuBt, den Bereich der Sprachkunde in die geschlossene Gesamtheit der naturwissenschaftlichen Arbeitsgebiete einzugliedern:

'... Inmassen einem Teutschen Fürsten freylich nichts mehr anstehen will, als der edlen, aber sehr verwilderten Mutter-Sprache sich anzunehmen ... Und wird nur zu dencken seyn, wie die Teutsche Sprach-Kunst mit denen übrigen Wissenschafften zu verbinden seyn werde. ${ }^{5}$

JABLONSkIs Äußerung verdeutlicht auch, in welchem Sinne die Anregung des Kurfürsten zu verstehen war: FRIEDRICH III. beabsichtigte, der Societät sprachpflegerische Aufgaben zuzuweisen, wie in Frankreich die Académie Française sie wahrnahm. LxarBNTzens Gedanken gingen andere Wege. Bereits am 28. März sandte er JABLONSEI ein Promemoria zu über 'den hochlöblichsten Vorschlag, so von Curfürstl. Durchlaucht kommen, von Zusammenfassung der Teutsch- und Wissenschaftsliebenden Gesellschaft' ' . Dieses Promemoria ist nicht erhalten;

1 HaRnagk a. a. O. 2,69.

2 HARNACK a. a. O, 2, 79.

S Harnaor a. a. O. 2, 71.

4 Wenige Monate nach der Stiftung der Societät äußerte sich Faisor im Schulspiel (aufgeführt am 22. Noveraber 1700):

Wer weiß, was dieser Fủrst auch uns fưr Gnad bestimmet?

Wer. weiß, was Er fủr Glantz der Teutschen Sprach noch giebt?

Dieweil Er sie bereits zu solchem Rathschluß nimmet,

Der uns genugsam zeigt, daß Er ihr Wohlseyn liebt.

Schulspiel 14 Fischer.

5 HARNACK a. a. O. 2, 71.

- HARNACK a. a. O. $2,82$. 
sein Inhalt ergibt sich jedoch - zumindest teilweise - aus einem Brief LEIB. NIZens an JABLONSKr vom 31. März 1700. Die Angliederung der Teutschliebenden Gesellschaft, so urteilt LeIBNIZ, sei

'die vernünftigste und schicklichste Sache von der Welt, dafern es auf die von mir ausgeführte Weise genommen wird. Denn eben dadurch belrommt man herrliche Gelegenheit im Nahmen Churfürstl. Durchlaucht Dero Bedienten hin und wieder um Berichten und Beschreibungen anzusprechen, dadurch zu. gleich zu gründlicher Nachricht von den Sachen und zu rechter Benennung derselben in Teutschem zu gelangen.'

Noch immer den Blick auf das Ziel einer Societät der realen Wissenschaften gerichtet, suchte LeIBNIz die Anregung des Kurfürsten abzuwandeln im Sinne eines Leitgedankens seiner Bildungsbemühungen: durch naturwissenschaftlichtechnische Beschreibungen die Sach- und (fachterminologische) Sprachkunde wechselseitig zu fördern. Der Vorschlag (wenn Lemsnry in dem Promemoria sich auf ihn beschränkt hat) wäre geeignet gewesen, die innere Einheit der Societät als naturwissenschaftlicher Forschungsanstalt zu wahren. In den abschließenden Gründungsverhandlungen "verschob sich die Zielsetzung jedoch auch für ihn. Es war bedeutsam, daß nun auch die Erforschung der deutschen und brandenburgischen Geschichte in den Kreis der Societätsaufgaben aufgenommen wurde; dadurch erlangte die Historisch-Philologische Klasse neben der MathematischPhysikalischen Klasse Eigengewioht. So umriß denn der von LeIBNrz entworfene Stiftungsbrief, erlassen am 11. Juli 1700, das Arbeitsgebiet nicht einer naturwissenschaftlichen Forsohungsanstalt, sondern einer auch geisteswissensohaftliche Disziplinen umschließenden 'Societät der Wissenschaften'. In der HistorischPhilologischen Klasse sollte

'was zu erhaltung der Teütschen Sprache in ihrer anständigen reinigkeit, auch zur ehre und zierde der Teütschen Nation gereichet, absonderlich mit besorget werden, also daß es eine Teütsch gesinnete Societet der Scientien seyn, dabey auch die gantze Teütsche und sonderlich Unserer Lande Weltliche- und Kirchen-Historie nicht verabsäumet werden.' 2

Diese allgemein gehaltene Formulierung des Stiftungsbriefes erläuterte LEIBNIZ in Zusammenarbeit mit JABLONSKI und anderen in der gleichzeitig erlassenen Generalinstruktion genauer. Der Passus, der die sprachkundliche Zielsetzung der Societät festlegt, verrät, daß unterschiedliche Auffassungen berücksichtigt werden mußten. Zum einen wurde die Historisoh-Philologische Klasse auf sprachpflegerische Aufgaben hingewiesen: 'damit auch die uhralte teutsche Haubtsprache in ihrer natürlichen anständigen Reinigkeit und Selbststand erhalten werde ${ }^{3}$, habe sie darauf zu sehen, daß die kurfürstlichen. Kanzleien ein fremdwortfreieres Deutsch schreiben. Zum anderen jedoch heißt es: es solle

\footnotetext{
${ }^{1}$ Harnack a. a. O. 2, 82.

2 Harmack a. a. O. 1, 94.

3 HARNAGK a. a. O. 2, 107.
} 
'der Societaet mit teutschen Benennung- und Beschreibungen derer vorkommenden Dinge und Würckungen von erfahrnen Leuten in allerhand Lebensarten an Hand gegangen, nicht weniger aus denen Archiven und Registraturen sowoll die alten, nummehr abgegangenen, als aus denen Provintzen verschiedene bey dem Landmann nur etwan noch übliche, sonst aber unbekante Worte, worin ein Schatz des teutschen Alterthumbs, anch derer Rechte und Gewohnheiten Unserer Vorfahren, theils zu ErkäntnüB der Uhrsprünge und Historien, theils auch zu Erleuterung heutiger hohen und anderen Rechte, Gewohn- und Angelegenheiten verbongen stecket, angemercket, gesamlet und mitgetheilet werden.' 1

Diese Sätze stammen ohne Zweifel aus LeibnIzens Feder. Limraniz suchte der Societät ein 'Privileg' zu sichern, das es ermöglichen sollte, die sprachkundliche Tätigkeit der Historisch-Philologischen Klasse auf eine feste Grundlage zu stellen. Seine Auffassung des Arbeitsziels der Klasse, die sich in den Bestimmungen des angeführten Abschnitts der Generalinstruktion deutlich genug verrät, ging hinaus über die sprachpflegerische Zielsetzung, die dem Kurfürsten und JABLONSKr vorschwebte, aber auch über den Vorschlag, den er selbst im Promemoria vom 28. März niedergelegt hatte. Zwar der Gedanke, technische Beschreibungen und Benennungen zu sammeln, blieb weiterhin im Vordergrund: noch im Juli 1700 entwarf LEIBNIZ eine 'sehr ausführliche Darlegung, wie man die deutschen Termini technici für die Wissenschaften, Künste und Handwerke durch Studium der Volkssprache in den verschiednen Gebieten gewinnen könne'2. Aber diese Anregung erschien nunmehr im Zusammenhang eines sprachwissenschaftlichen Forschungsprogramms, das auch die Sammlung altertümlichen und mundartlichen Wortgutes vorsah und das selbst wieder Teil der umfassenden Vorschläge zu sein scheint, die Lerbarz 1697 in den 'Unvorgreiflichen Gedanken' niedergelegt hatte.

Es ist wahrscheinlich, daß L\#IBNIz während seines Berliner Aufenthalts im Jahre 1700 das Manuskript der 'Unvorgreiflichen Gedanken' bei sich führte ${ }^{3}$ und daß er es für die Verhandlungen über die sprachkundlichen Aufgaben der Historisch-Philologischen Klasse als Unterlage benutzte. In den 'Unvorgreiflichen Gedanken' hatte LeIBNIZ den organisatorischen Zusammenschluß deutscher Sprachforscher im Dienste einer gemeinsamen Aufgabe gefordert: der Schaffung einer Gesamtdarstellung des deutschen Wortschatzes. Es fällt auf, daß in den urkundlichen Zeugnissen aus dem Gründungsjahr der Societät Arbeitsweise und Arbeitsziel der Historisch-Philologischen Klasse selbst nicht geregelt werden. Denn die in der Generalinstruktion niedergelegte Anregung, einen Stamm von 'Gewährsleuten' durch obrigkeitliche Verfügung zur Mitteilung sprachlich bemerkenswerten. Wortgutes zu verpflichten, bezieht sich nicht auf die Arbeit der Klasse, sondern auf die Beihilfe der nicht zur Societät gehörenden Gewährsleute. Zumindest die

1 HARMAOK a. a. O. 2, 107.

2 HARNAOK a. a. O. 2, 112.

a LeIbNIZ an D. E. JABLONSKI 30. 8. 1700 (HARNACK a. a. 0. 2, 123; vgl. 1, 104).

5 Powitz, Frisohs Wörterbuch 
Frage, für welches Ziel die Mitglieder der Historisch-Philologischen Klasse arbeiten, wofür sie die etwa einlaufenden Beiträge der auswärtigen Sammler verwerten sollten, muß jedoch frühzeitig erörtert worden sein: den Gründern der Societät schwebte der Gedanke vor, ein Deutsches Wörterbuch zu schaffen. Allerdings wird es erst zu Anfang des Jahres 1702 unter den Aufgaben der Historisch-Philologischen Klasse erwähnt. In einem von LmIBNIZ zu dieser Zeit erstatteten Rechenschaftsbericht heißt es :

'man hat in dem Alterthum der teutschen Sprache nicht wenig entdecket, das Celtische mit dem Teutschen zusammen gehalten ... und hoffet, dermahleins zu einem rechtschaffenen teutschen Wörter-Sohaz gelangen zu können, sonderlich da durch hohe Hülffe die Kunst- und andere besondere Wörter, so bey verschiedenen Sorten der Menschen in Gebrauch, zusammen zu bringen seyn möchten, so den Sprachen und Künsten zugleich zur Beförderung gereichen wïrde. ${ }^{1}$

Die Herkunft des Wörterbuchgedankens ist nicht mit Sicherheit zu bestimmen. Fest steht lediglich, daß der Plan - nachdem er grundsätzlich gebilligt worden war - in dem Kreise der Beteiligten nicht einheitlich aufgefaBt worden ist. LEIBNIZ Ließ nie Zweifel an seiner seit dem Erlaß der Generalinstruktion offaziellen Ansicht, die er noch in amtlichen Schriftstïcken der Zeit um 1710 als Ansicht. auch des Stifters der Societät geltend machte. So schrieb er Ende März 1711 in einer Eingabe an FrIEDRIOH I., es sei die Aufgabe der Societät seit der Zeit ihrer Gründung gewesen,

'sonderlich ..., E. Mt. selbst eigenem erleuchteten Absehen nach, zu einem teutschen vollständigen Wörterbuch und zumahl Terminorum technicorum zu gelangen, wodurch vermittelst Erkenntniß der Wörter auch die Erkenntniß der Sachen, Künste, Kunst- und Handwercke selbst befördert würde.' 2

Man darf zweifeln, ob dio Schaffung eines Deutschen Wörterbuches dieser Art jemals das Ziel des Königs gewesen war. Jedenfalls kam LisBnIzens Auffassung im entscheidenden Augenblick nicht zur Geltung. Es waren die lexilkographischen Anschauungen der Brüder JABLONSKI, die sich im Jahre 1711 in der HistorischPhilologischen Klasse durchsetzten. Dagegen hat LeIBNIzens Forderung unverkennbar eingewirkt auf FriscH. Aufmerksamkeit für den Bereich des fachsprachlichen Wortgutes bezeugt bereits der 'Nouveau diotionnaire' (1712), in dem FrTSCH 'Alle Frantzösische Wörter, auch der Künste und Wissenschafften' (Titelblatt) verzeichnet, und zwar im Unterschied zu den bis dahin gebräuchlichen Wörterbüchern, die

'unter vielen andern auch die meisten Kunst-Wörter (terminos technicos) ausgelassen, so daßi man sie zum Lesen der Frantzösischen Bücher, so von gewissen Wissenschaften handeln, nicht brauchen kan.'3

1 HARRACK a. a. O. 2, 148.

2 HaRnACK a. a. O. 2, 214.

a Fisor, Nouveau dictionnaire (1752) )( $4^{a}$. 
Über den Plan eines Wörterbuches der deutschen Fachausdrücke, das der in Berlin lebende Nationalökonom PaUL Jakob Marperger zu schaffen beabsichtigte, urteilte FRISOH 1711 zwar noch skeptisch:

'es wird sehr zerstümmelt sein, weil er allein thun will, was dorten (in Frrankreich) ihrer so viel in so langer Zeit kaum gethan.'

Aber 1723 bildet das Technicum einen festen Bestandteil des Wörterbuchplans, und 1727 finden wir Frrsor mit Sammelarbeiten gerade für den fachsprachlichen Wortschatzbereich beschäftigt. In einem Protokoll dieses Jahres heißt es:

'Eine neue probe habe er (Frisch) gemacht, voces Technicas zu sammlen, in dem Er so viel Teich-Ordnungen, als er haben können, durchlesen, und die darin angemerkte wörter, so bei dieser sache gebraucht werden, ausgezogen: dergleichen Er mit anderen, als Bergwerks- Jagd. Fischerei- und s. w. Sachen auch tuhn, und die bei einem jeden gewerb vorkommende eigene wörter und redens. arten sammlen wolle.'2

\section{Der Gedanke eines Gesamtwörterbuchs der deutschen Sprache}

Die Untersuchung zur Entstehungsgeschichte des 'Teutsch-Lateinischen Wörter-Buchs' ging aus von der im Specimen I niedergelegten lexikographischen Zielsetzung. Es ergab sich, daß die Kategorien dieses Entwurfs auf drei gesonderte Aufgabenbereiche der Wortforschung zurückweisen und daß FrIscHs Schaffen auf jedem der drei Gebiete in Zusammenhang steht mit lexikographischen Forschungsbestrebungen der Zeit um 1700. Als Kernbestandteile des Wörterbuchplans erwiesen sich die Kategorien des Etymologicums, Archaeologums und Eponymologicums. Zu ihnen traten zum einen das Usuale generale und das Criticum, zum anderen das Usuale speciale (Technicum). Der Grundgedanke, der dieses Nebeneinander verschiedenartiger Teilziele in die innere Geschlossenheit der Gesamtzielsetzung des Specimen I umsetzte, ist bisher nicht faßbar geworden. Auch er aber ist erwachsen aus den Forschungsbestrebungen der Zeit um 1700 und konnte an FrISOH von. verschiedenen Seiten aus herangetragen werden.

Der Gedanke eines Gesamtwörterbuchs der deutschen Sprache, wie ihn FrIsOH im Specimen I darlegte und im 'Teutsch-Lateinischen Wörter-Buch' zu verwirklichen suchte, gewann bereits im Kreise der Fruchtbringenden Gesellschaft in bestimmtem Grade Gestalt. Gewiß: das lexikographische Planen HarsDöRHWERs und SoHOTrmLs trug in erster Hinsicht der geschichtlichen Notwendig-

1 Frschen, Frischs Briefwechsel mit Leibniz (1896) 33.

2 Protokoll vom 16. 1. 1727. 
keit Rechnung, ein Wörterbuch des gemeinsprachlichen Wortschatzes zu schaffen. Die Arbeit auf lexikographischem Gebiet wurde damit für die Folgezeit auf einen begrenzten Stoffbereich (den Wortschatz der Gemeinsprache) und anf bestimmte Zielsetzungen (normative Kodifizierung der sprachlichen Gegebenheiten; Darstellung des Wortschatzgefüges) festgelegt. Das Streben nach Einsicht in das Wesen der Muttersprache, der Wille, ihren Reichtum und ibr hohes Alter erkennbar zu machen, bereiteten jedoch auch den Boden für den Gedanken einer allseitigen Erfassung und eines vertieften Verstehens des deutschen Wortschatzes. HARSDÖRFFER und Schotrid selbst, so soheint es, waren sich noch keiner Scheidung bewußt zwischen einem Wörterbuch des gemeinsprachlichen Wortschatzes und einer stofflich umfassenderen lexikalischen Darstellungsform. Ihre Wörterbuchentwürfe ließen jedoch die Grenzen verschwimmen. So sprach sich HARsDÖRFFER 1648 dafür aus, "termini technici von allen handwercken, handlungen und Arbeiten' sowie altes deutsches Wortgut (aus dem Sachsenspiegel, den Werken Goldasts, Bmsolds, WmHNars und Spmrdmis) seien in das Wörterbuch der Gemeinsprache einzuberiehen. ${ }^{1}$ Sonotrer seinerseits wies 1663 auf die niederdeutschen und niederländischen Stammwörter hin und forderte gleichfalls die Erfassung des fachsprachlichen Wortgutes. ${ }^{2}$ Tiefer noch als diese Einzelanregungen wirkte auf die Folgezeit die 'Teutsche HaubtSprache' als Gesamtwerk. Sсноттец bekannte, sie enthalte nicht nur eine Darstellung der deutschen Grammatik, sondern auch eine 'mannigfaltige Erklärung und Andeutung / so die gantze Sprache und das alte Teutsche Wesen angehet'3. Das Streben des Theoretikers, ein Bild der deutschen Sprache in der Gesamtheit ihrer Erscheinungsformen, in Geschiohte und Gegenwart zu entwerfen, wies dem lexikographischen Planen der Zeit um 1700 den Weg über das Wörterbuch des gemeinsprachlichen Wortschatzes hinaus. Die Formen wurden klar geschieden, als KASPAR STIELER und Matrhias KRaMmR - mehrere Jahrzehnte nach dem Höhepunkt des Wirkens der Fruchtbringenden Gesellschaft - lexikographische Auffassungen SoHotrwis zil verwirklichen suchten und dabei erkennen mußten, daß sie nicht voll ausführbar waren.

STLELER und IKramor legten nicht den Wörterbuchentwurf der zehnten Lobrede, sondern einen umfassenderen Plan Sorotrmus zugrunde, den beide in den Vorreden ihrer Wörterbücher in den Einzelzügen beschreiben. Im Mittelpunkt steht der Gedanke einer Gesamterfassung und geschichtlich-etymologischen Erhellung des deutschen Wortschatzes, Nach STIELBR wäre zu seiner Ausführung die Kenntnis 'des teutschen Altertums, aller darzu gehörigen alter Schriften / Briefschaften und Urkunden', der hoch- und niederdeutschen Mundarten sowie insbesondere der germanischen Fremdsprachen erforderlich. ${ }^{4}$ Ein genaueres Bild vermitteln die

1 Krause, Ertzschrein (1855) 388-389.

2 Schotrin, Teutsche HaubtSprache (1663) 159; 160.

3 Schotriti a. a. O. 178.

4 Srrecter, Der Teutschen Sprache Stammbaum und Fortwachs $(1691))()()\left(2^{a}\right.$. 
Angaben KrammRs; ein vollgültiges Deutsches Wörterbuch im Sinne Schotтels sollte nach seiner Ansicht über das Wörterbuch der Gemeinsprache hinaus

den Wortschatz der Fachsprachen sowie das Namengut der deutschen Sprache (Tier-, Gesteins-, Pflanzen-, Orts- und Personennamen) erfassen und 'mit der Historie und Antiquität' erklären,

Angaben über die landschaftlich-umgangssprachliche Geltung und die mundartliche Lautung hochdeutscher Wörter enthalten,

historisches Sprachgut verzeichnen ('was unsere Altvätter disfalls hier oder dorten in ihren Gesetzen, Rechten ..., Ordnungen und Gewonheiten gehabt haben'),

selten gebrauchte Ableitungen und Zusammensetzungen, Bildungen der Dichtersprache sowie deutsche Sprichwörter buchen. ${ }^{1}$

StrmLer und Kramer blieben sich also des Ziels einer stofflich umfassenden, erklärenden Darstellung des deutschen Wortschatzes bewuBt. Sie selbst erfüllten jedoch nur Teile der Gesamtaufgabe. STIELER bekannte ausdrücklich, er sei nicht in der Lage, den umfassenden Wörterbuchplan SoноттнLs auszuführen, und auch Kramar beschränkte sich bewußt auf den Wortschatz der Gemeinsprache. ${ }^{2}$ Verwandte Gedankengänge beherrschen jedoch noch 1734 ChristopH ERNST StEINBACH: ein über das eigene Werk hinausgehendes 'gantz vollständiges Wörterbuch' betrachtet er als das Ziel der zeitgenössischen Bemühungen um die Muttersprache. ${ }^{3}$ Er denkt dabei insbesondere an den bis dahin nur unzureichend erschlossenen Wortbestand der deutschen Mundarten und der Fachsprachen.

Der Gedanke des Gesamtwörterbuchs, wie StIELER und Kramer im Anschluß an Soноттег ihn formuliert hatten, konnte Friscr bereits in der Frühzeit des Schaffens am 'Teutsch-Lateinischen Wörter-Buch' erreichen. Das Fehlen quellenmäßiger Unterlagen erschwert es allerdings, die fördernden Anregungen zu bestimmen, die FRIsor möglicherweise empfangen hat während der ersten Jahre seines Aufenthaltes in Berlin. Hier hatte Jortannes Vorstrus (1623-1676) als Rektor des Joachimsthalschen Gymnasiums und Bibliothekar der kurfürstlichen Bibliothek 1669 eine Reihe etymologischer Einzeluntersuchungen unter dem Titel 'Observationes in linguam vernaculam' veröffentlicht. Diese sprachgeschichtlich $\theta$ Forschungsarbeit wurde zum Ausgangspunlat einer örtlichen 'Tradition' germanistischer Studien, als deren Träger in der Zeit um 1700 führende Lehrkräfte der Berliner Gymnasien sowie einzelne Mitglieder der Preußischen Societät der Wissen-

1. Kramen, Teutsch-Italiänisches Dictionarium 1 (1700) (f) $1^{\mathrm{a}}-$ (f) $3^{\mathrm{b}}$.

2 StIELeR a. a. O. $)()()\left(2^{a} ;\right.$ Kramer a. a. O. (f) $3^{b}-4^{a}$.

3 Strinbaor, Vollst. Deutsches Wörter-Buch 1 (1734)**8a. 
schaften hervortraten. Ein Jahr vor Vorstrus' Tod übernahm JoHANNEs BöDIKER (1641-1695), der Verfasser der einflußreichsten deutschen Schulgrammatik in der Zeit zwischen SoHotret und Gotrsored, das Rektoramt am Cöllnischen Gym. nasium. BöDIKERs 'Grund-Sätze Der Deutschen Sprachen im Reden und Schreiben'1 (Cölln a. d. Spree 11690. ${ }^{2} 1701 .{ }^{31709)}$ ) erwuchsen aus sprachkundlichen Bemühungen im Sinne ScHotrists. Wie dieser strebte er danach, dem Hochdeutschen eine 'kunstrichtige Verfassung'" zu geben, um die bis dahin herrschende 'tollkühne Einbildung' und 'sohlüpfrige wanckende Gewohnheit' 3 im Sprechen und Schreiben zu beseitigen. Fortschritte auf diesem Wege hatte er ursprünglich von einem vollständigen Wörterbuch 'der gültigen Wörter und Redens-Arten' 4 erhofft, für das er in der Vorrede der 'Grund-Sätze' programmatische Leitgedanken entwickelte. ${ }^{5}$ Die Einsioht in die Sohwierigkeiten der Ausführung des Plans, insbesondere auch in die Notwendigkeit des Vorangehens einer Sprachlehre ${ }^{6}$ veranlaßte ihn jedoch, sich der Grammatik zuzuwenden, während der Wörterbuchentwurf unausgeführt blieb.

Bedeutsam war, daß BöDIK - wie der Entwurf erkennen läßt - den Gedanken aufnahm, den Gesamtwortschatz der deutschen Sprache zu erschließen. Zwar bestimmte auch ihn weithin das Leitbild eines Wörterbuches der neuhochdeutschen Gemeinsprache. Das geplante Werk sollte das Gültige festlegen 'in der Redekunst, in Versen, in Brieffen, und andern Verrichtungen"?. Es sollte zu diesem Zweck die Stammwörter, 'darauf das gantze Wesen beruhet', mit den zugehörigen Ableitungen, Zusammensetzungen, Synonyma, Epitheta, Fügungen und Sprichwörtern, auch die 'Kunst- Gemein- und Ticht-Wörter' erfassen und diese grammatisch und semantisch erklären. ${ }^{8}$ Andere Bestandteile des Plans lassen jedoch erkennen, da $B$ nicht daran gedacht war, die Darstellung auf das in der Gemeinsprache der Gegenwart 'Gültige' zu beschränken. In der Vorrede der 'Grund-Sätze' macht BöDIRER eine Reihe von Vorläufern seines Bemühens um ein Deutsches Wörterbuch namhaft; $\theta$ r nennt hier unter anderem Huqo Grotrus als Erklärer 'etlicher Longobardischen und Gohtischen Gesetzen', LrNDEnBRoG und Frener, Juntus, Spelman und Morhof.' Die Reihe der Namen macht deutlich, daßihn Beziehungen mit der Tradition der historisch-sprachvergleichenden Wortforschung verbanden. Mit dem Ziel einer Gesamtdarstellung sollte wie der Entwurf dann im einzelnen ausführt - durchforscht werden ${ }^{10}$ : neben dem

1 JELLINEK, Gesch. d. nhd. Grammatik 1 (1913) 195-202; 205-206; 217-219.

2 BödTKEr, Grund-Sätze (1690) a $5^{b}$.

3 Bödikm a. a. 0 , a $6^{a}$.

- Bödrker a. a. O. a $6^{\mathrm{a}}$.

5 Bödiker a. a. O. a 8a-b $3^{a}$.

- Bödiker a. a. O. a $7^{\mathrm{b}}$ f.; b $4^{\mathrm{a}}$.

7 Bödiker a. a. O. a $6^{a}$.

8. Bödtrer a. a. O. b $2^{b}$ f.

- Bödiker a. a. O. a $6^{a}-a 7^{a}$.

${ }^{10}$ Böniker a. a. O. a $8^{\mathrm{a}}-\mathrm{b} 2^{\mathrm{b}}$. 
Hoohdeutschen das Oberdeutsche, Mitteldeutsche, Niederdeutsche und Niederländische; sodann das Altgermanische und Altdeutsche (die gotische Bibel, die Stammesrechte, OtFRID, die Heldenlieder und Meistergesänge); die neueren germanischen Sprachen und die wiohtigsten nichtgermanischen Fremdsprachen. Im Bereich des Hochdeutschen jedoch nicht nur die sprachlich vorbildlichen Schriften Luthers, KeISERSBergs und der Reichsabschiede, sondern auch historisch-antiquarische Rechtsdarstellungen (GoLdast, BESOLd, LINDENBROG, WHHNER, SPEIDEL), Chroniken, Urkunden, Werke des juristischen, medizinischen und naturwissenschaftlich-technischen Fachschrifttums sowie - für deutsche Eigennamen und Wörter in fremdsprachlicher Überlieferung - ausländische Geschichtswerke.

Wieviel an Vorarbeiten hinter diesem großzügigen Plan stand, ist schwer zu erkennen. Sicher ist, das BödTKer unter Mitarbeit seines Sohnes KarL Edzard Quellen exzerpierte und den gewonnenen Sprachstoff auszuwerten begann. Zur Zeit seines Todes (1695) lagen drei Einzelartikel (brennen, brechen, danken) und ein Register der deutschen Stammwörter ausgearbeitet vor; außerdem fand sich eine noch ungeordnete Belegmasse. ${ }^{1}$ Bereits 1690 jedoch hatte BöDIKER mit Rücksicht auf sein fortgeschrittenes Alter das Wörterbuchvorhaben - wenn auch nur zögernd - aufgegeben; KARL EDZARD BöDIKER sollte die Vorarbeiten übernehmen und das Werk zu Ende führen,. In den 'Grund-Sätzen' (1690) war bei der Mitteilung des Entwurfs außerdem der Wunsch ausgesprochen worden, der Cöllnische Magistrat oder der Kurfürst (FRIEDRIor IIII.) möchten das für Berlin und den brandenburgischen Herrscher ehrenvolle Werk ('Lexicon Germaniae Brandenburgicum') unterstützen; denn es gehöre zu den Arbeiten 'so niemand von ihm selbst ohn Hülffe der Durchl. Landes-Obrigkeit vermag's'. Erfolg wird diesem Ersuchen nicht beschieden gewesen sein; auch wohl 1694 nicht, als dem Kurfürsten anläBlich der Einweihung der Universität Halle die drei ausgearbeiteten Artikel überreicht wurden. ${ }^{4}$ In der zweiten Auflage der 'Grund-Sätze' (1701) erstattete KARI EDzard BöDIKER in einem Schreiben (vom 26. Januar 1699) an den Augsburger H. A. LANGENMANTEL Bericht über den Wörterbuchnachlaß seines Vaters. 5 Er bekannte, das Werk sei 'non . . unius hominis labor' und der Aufgabe es fortzuführen fühle er sich nicht gewachsen. ${ }^{6}$ Indessen ließ er den Probeartikel 'brennen' abdrucken?; dieser Artikel findet sich auch in der dritten Auflage der 'Grund-Sätze' (1709).

Damit war das Schicksal des von BöDIKER geplanten Deutschen Wörterbuches besiegelt. Es ist jedoch möglich, daß von dom Gedanken selbst"weiterwirkende

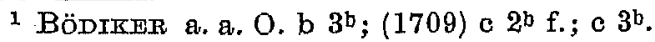

2 Bödtrer a. a. O. b $3^{\text {b. }}$.

s Bödiker a. a. O. a $8^{a} ;$ b $3^{b}$ f; b $6^{a} f$.

4 BödrkmR, Grund-Sätze (1709) c 3a; JeLLINEK, Gesch. d. nhd. Grammatik 1 (1913) 195.

5 Bödiker a.a. O. c $1^{\mathrm{a}}-\mathrm{c} 4^{\mathrm{b}}$.

6 Bödikgr a. a. O. c $2^{\mathrm{a}}-\mathrm{c} 2^{\mathrm{b}}$.

7 BöDIKER a. a. O. 277-354. 
Anregungen ausgegangen sind. Zwei Spuren lassen sich verfolgen. Die eine weist auf den Kurfürsten FrIEDRTon III., den Stifter der Societät, und auf die Wörterbuchpläne der Historisch-Philologischen Societätsklasse. Die andere führt zu FRISCH: als Konrektor, dann als Rektor am Grauen. Kloster hat er die vierte und fünfte Auflage der 'Grund-Sätze' (1723. 1729) besorgt. Weit früher jedoch - wir wissen nicht wann - wird er von dem Werk und damit von dem Wörterbuchent. wurf BöprKERs Kenntnis erhalten haben. Die geschichtlichen Zeugnisse reichen nicht aus, um die Frage zu entscheiden, in welcher Weise dieser Entwurf auf den Grundriß des 'Teutsch-Lateinischen Wörter-Buchs' und auf den Gang der Arbeiten eingewirkt hat. Stellt man BöprKers programmatischen Leitgedanken in den 'Grund-Sätzen' (1690) FrIsoHs Auffassungen im Specimen I gegenüber, so tritt neben trennenden Zügen eine wesentliche Gemeinsamkeit hervor. Beide Lexikographen stehen in Fühlung mit der Tradition der historisch-sprachvergleichenden Wortforsohung und streben dem Ziel einer Gesamtdarstellung dos deutschen Wortschatzes zu. Der von BöDIkgR abgesteckte Quellenbereich, der die deutschen Mundarten und die germanischen Nachbarsprachen, vor allem jedoch die historischen Sprachstufen des Deutschen (Altgermanisch, Altdeutsch, Frühneuhochdeutsch) einbezieht, deckt sich im Umriß mit dem Quellenbereich, den Frisor für das 'Teutsch-Lateinische Wörter-Buch' durch Exzerption tatsächlich erschlossen hat.

Was wir festzustellen vermögen, ist dies: während der Frühzeit der lexiko. graphischen Arbeit FrISCHs ist in Berlin mehrmals (zuerst 1690) ein Wörterbuch. entwurf veröffentlicht worden, der in seiner Zielsetzung der Zielsetzung des späteren 'Teutsch-Lateinischen Wörter-Buchs' nahesteht. Es ist möglich, daßB die Kenntnis dieses Entwurfs dazu beigetragen hat, FrIscHs lexikographische Bemühungen auf das Ziel einer Gesamtdarstellung des deutschen. Wortschatzes hinzulenken. Ungeklärt bleiben weiterreichende Fragen: so ob FrIsCH das Wörterbuchvorhaben BöDrkeRs etwa geradezu als Fortsetzer weiterführte, nachdem KaRL Edzard BöDIkER 1701 öfentlich von dem Unternehmen seines Vaters zurückgetreten war, und ob etwa Vorarbeiten BöDIKERs in FRISOFrs Hände gelangt und für das 'Teutsch-Lateinische Wörter-Buch' verwertet worden sind. Fest steht dagegen, daß Frrscr in der Zeit um 1720, als er die Sprachlehre für die vierte Auflage von Grund auf umarbeitete, sich mit dem Wörterbuchplan auseinanderzusetzen hatte. Er entschloB sich jetzt, Plan und Probeartikel BöDIx ers durch einen eigenen Plan und einen eigenen Probeartikel ('Land') zu ersetzen und den Briefwechsel zwischen KaRL EDZARD BöDIKER und LANGENMANTEL auszuscheiden. Im dritten Teil der 'Grund-Sätze' ('Wortfügung') findet sich 1723 unter dem LXIX. Satz 'Zu rein-Teutschen guten Wörtern und Red-Arten wird ein gutes Teutsches Lexicon sehr helffen' folgende Bemerkung FrisoHs:

'Es ist in des Herrn Bödekers Grund-Sätzen bei diesem LXIX. Satz, in der zweiten Auflage derselben von dessen Herrn Sohn, der Zeit Archi-Diacono zu Wriezen an der Oder, oin schöner Abriß eines Teutschen Lexicons hinzu 
getahn worden, welchen wir aber gedachter zweiten Auflage als etwas Besonderes, und als ihren Vorzug lassen, gleich wie wir der ersten Auflage die gelehrte Vorrede des Hn. Auctoris von einem solchen Lexico deßwegen gelassen haben. In dieser dritten Auflage unterstehe ich mich einen kurzen Entwurf, samt einem Exempel zu einem Teutschen Wörter-Buch zu Ende derselben anzuhängen, wohin ich den geehrten Leser allhier verweise.'1

FrIscHs Entwurf und Specimina (I 'Land' 1723; II 'Brand' 1727) lassen neben der Gemeinsamkeit der lexikographischen Zielsetzung Unterschiede im Theoretischen und Methodischen erkennbar werden; sie machen deutlich, daB FrISCH zu dieser Zeit bereits selbständige Auffassungen und ein selbständiges Arbeitsverfahren entwickelt hatte.

Einen weiteren geschichtlichen Ansatzpunkt der Bemühungen um ein Gesamtwörterbuch der deutschen Sprache fassen wir in dem Wörterbuchprogramm, das GotThRIED WILHelm LeIbnxz 1697 in den 'Unvorgreiflichen Gedanken' niederlegte.

Die 'Unvorgreiflichen Gedanken'2 gliedern sioh ein in die Reihe der Bestrebungen, die Pflege der Muttersprache wirksam zu fördern durch den ZusammensohluB berufener Gelehrten in einer Sprachgesellschaft oder Akademie. LEIBNIz blickt auf das Vorbild der Akademien der Hauptländer Westeuropas (Frankreich, Italien, England), rückschauend auch auf das Vorbild der Fruchtbringenden Gesellschaft in Deutschland. Daß 'Privat-Anstalt' nicht ausreiche, daß eine 'Versammlung oder Vereinigung' die notwendige organisatorische Voraussetzung für die Pflege der Muttersprache bilde, das ist seine feste Uberzeugung. Es gilt, in Deutschland durchzusetzen, was das weiter fortgeschrittene Ausland bereits verwirklicht hat,

Das Progtamm der Sprachpflege, das LeIBniz für die von ihm erstrebte Deutsche Sprachgesellschaft entwirft, ist in seinen Hauptzügen Wörterbuchprogramm. Auch die Akademien Frankreichs und Italiens hatten Wörterbücher ihrer Landessprachen geschaffen, die Fruchtbringende Gesellschaft hatte ein Deutsches Wörter. buch geplant. Die Arbeitsrichtung war also vorgezeichnet. Aber die Accademia della Crusca, die Académie Française und die Fruchtbringende Gesellschaft er. strebten zu ihrer Zeit ein Wörterbuch des 'durchgehenden Gebrauchs'. LEIBNIZ gesteht zu, daß darauf 'auch anfangs am meisten zu sehen's sei. Aber er läßt keinen Zweifel daran, daß er diese lexikographische Zielsetzung nunmehr für unzureichend hält; sie entspricht nicht mehr der Wissenschaftslage der Zeit. Und die in Deutschland zu gründende Sprachakademie soll nicht die Entwicklung der älteren nationalen Akademien Europas nachvollziehen, sondern sich sogleich der Lösung der Aufgabe widmen, die sich aus dem inzwischen erreichten Erkenntnis- 
stand auf dem Gebiet der Wortforschung ergibt. Diese Aufgabe aber umschließt mehr; LEIBNIZ fordert eine Gesamtdarstellung des deutschen Wortschatzes ('eino Musterung und Untersuchung aller Teutschen Worte' 1 ) in drei getrennten Wörterbüchern: Lexicon (der Gemeinsprache), Cornu Copiae (der termini technici), Glossarium (etymologioum).

Diese Zielsetzung ergab sich für Lurbniz nicht so sehr aus der Prüfung des Entwicklungsstandes der einheimischen germanistischen Wortforschung als vielmehr aus der Zusammenschau der Leistungen, die Frankreich als das zu jener Zeit in der Sprachforschung führende Land Europas aufweisen konnte. Die Académie Française hatte 1694 ein Wörterbuch der französischen Literatursprache vorgelegt; Einzelgelehrte wie GHLEs MtinaGe (Origines de la langue françoise 1650. 21694), Antornt Furemitre (Diotionnaire universel 1690) und Thomas CORNELLE (Dictionnaire des arts et des sciences 1694) hatten Wörterbücher des historischen Wortschatzes und der termini technici geschaffen. Was in Frankreich - wenige Jahre von der Niederschrift der 'Unvorgreiflichen Gedanken' - im Zusammenwirken der Akademie und einzelner unabhängiger Forsoher geleistet worden war, diente LEIBNIZ als Vorbild für das Programm einer umfassenden Darstellung des deutschen Wortschatzes. ${ }^{2}$ Eine 'Vereinigung aus Anregung eines hocherleuchteten vornehmen Haupts' sollte diesen Entwurf ausführen. ${ }^{8}$

Auch im Kreise derer, die im Sinne Schorrels sprachkundlich arbeiteten, war man sich bewußt, daß die Schaffung eines Gesamtwörterbuchs nicht die Aufgabo eines einzelnen würde sein können. Nur der Einsatz vereinigter Kräfte, das wußte man, würde es ermöglichen, den Wortschatz der deutschen Sprache in seinem Gesamtumfang zu erfassen und zugleich etymologisch, semantisch, grammatisch zu erklären. Es zeugt von einer klareren Einsicht in die Schwierigkeit der gestellten Aufgabe, daß LEIBNIz bei dieser Schlußfolgerung nicht Halt machte. Er besa $B$ in höherem Maße den Blick für die Weite und für die Besonderheit jedes der drei großen Aufgabengebiete des lexilkographischen Schaffens seiner Zeit: der Erforschung des Wortschatzes der Gemeinsprache, der Sondersprachen und der historischen Sprachstufen. Er sah: wollte man die Teilziele der drei Arbeitsbereiche zu einer Gesamtzielsetzung zusammenfassen, so würde diese im Rahmen eines einzigen Wörterbuchs nicht mehr ausführbar sein. Es war denn auch der Plan nicht eines Gesamtwörterbuchs, sondern einer Gesamtdarstellung des deutschen Wortschatzes in drei getrennten Wörterbüchern, der in die 'Unvorgreiflichen Gedanken' einging.

Da LEIBNIz sich darum bemüht, die Aufgaben der drei Hauptarbeitsgebiete der Wortforschung zusammenfassend darzustellen, so bezieht er auch die für ihn nicht vorrangige Forderung nach einem Wörterbuch des gemeinsprachlichen

1 LeIsaiz a. a. O. (\$ 32) 72.

2 Leibniz a. a. O. $(\$ 35 ; 37) 73 ; 74$.

3 Leibniz a. a. $0 .(\$ 30) 72$. 
Wortschatzes der Gegenwart in das Programm der 'Unvorgreiflichen Gedanken' ein. Seine Auffassung des Arbeitsziels in diesem Bereich ist dadurch gekennzeichnet, daß er absieht von dem sprachtheoretischen Anliegen der etymologisoh-morphologischen Wortschatzdurchgliederung, den Gedanken der normativen Darstellung jedoch aufgreift und in den Mittelpunkt rückt. Das geplante Wörterbuoh soll der Ausbildung der deutschen Gemeinsprache dienen, damit sie zu einem leistungsfähigen, der Nation würdigen Mittel der Verständigung werde. Es soll die Reinheit des Wortschatzes fördern, indem es warnt vor Wörtern niederer Stillage, vor veraltetem und mundartlichem Wortgut sowie vor entbehrlichen Fremdwörtern. Und es soll vor allem die Ausdrucksfähigkeit, den 'Reichtum' der deutschen Sprache steigern durch die Wiederbelebung 'entlegener' oder veralteter Wörter guter Eignung, durch die Einbürgerung von Wörtern der germanischen Nachbarsprachen und der deutschen Mundarten sowie - in begrenztem Umfange - durch die Ein. führung neugebildeter Wörter. $\mathrm{Zu}$ diesem $\mathrm{Zweck}$ hält auch LEIBNIz das Studium der Quellen für notwendig, insbesondere der 'mustergültigen' Quellen des 16. und 17. Jahrhunderts (LuTher; Reichsabschiede, Rechtsordnungen; Paractisus; Theuerdank, Hars SAOHS; Avmantinus, StUMPF; OpItz, Zmsen).

Mit dem Gedanken, ein Glossarium Iitymologicum zu schaffen, entsprach LarBNIZ einer Forderung, die im Kreise der historisch-sprachvergleichenden Wortforschung in Deutschland seit langer Zeit erhoben worden war. LirbNIz gestaltete auch diese Zielsetzung in besonderer Weise aus. Er trug bereits den ersten Schritten der Mundartenforschung Rechnung, wenn er nachdrücklich auf die Notwendigkeit der Erfassung auch des mundartlichen Wortgutes hinwies. ${ }^{1}$ Und er betonte einen gerade für ihn als Historiker kennzeichnenden Forschungsgesichtspunkt, wenn er in der etymologischen Erhellung der 'uralten', d. h. ursprüngliche Verhältnisse bewahrenden deutschen Sprache ein Mittel zur Erklärung des Altertums und der Historien, des Ursprungs der europäischen Völker und Sprachen erblickte. ${ }^{2}$ Er möchte insbesondere nach den germanischen Bestandteilen im Griechischen, Lateinischen und in den romanischen. Sprachen forschen lassen, um den Anteil des 'Deutschen' am Wortschatz dieser Sprachen zu bestimmen. Daß ein etymologisches Wörterbuch darüberhinaus für die Wortforschung als selbständige Disziplin und für das Verständnis des Wortgutes der Gemeinsprache wertvolle Aufschlüsse würde liefern können, verkannte LEIBNIz nioht. ${ }^{3}$ Allerdings mußte er sich 1697, unmittelbar vor dem Einsetzen des Aufschwungs der germanistischen Wortforschung, noch auf Männer wie SchotTtg, Morrof und PRASOH als Träger der sprachwissenschaftlichen Tradition in Deutschland berufen. ${ }^{4}$ SoHruter, v. STADE, ECKART und WACHTER waren noch nicht hervorgetreten; aber in dem später überarbeiteten Paragraphen 51 der 'Unvorgreiflichen Gedanken', in dem LisibNIZ

\footnotetext{
1 L.taniz a. a. O. $(\S 32 ; 33) 72 ; 73$.

2 LETBNIZ a. a. O. (\$ $41 ; 46) 75 ; 76$.

8 LEIBNIz a. a. O. (\$ 49) 77.

4 LmIBNIZ a. a. O. (\$ 41) 75.
} 
unter den ihm bekannten und zum Teil von ihm angeregten Wortforschern GRRHARD MEIER und 'noch einige andere treffliche Leute..., so mit dergleichen umgehen' erwähnt, wird dem Wandel der Lage bereits Rechnung getragen; neben EOKART und von STADw kann auch FRIsch an dieser Stelle gemeint sein. ${ }^{1}$

Nur andeutungsweise vorgebildet im Gedankengut der germanistischen Wortforschung des 17. Jahrhunderts war jene lexikographische Zielsetzung, die das bevorzugte Anliegen LeIBNIZens bildete: das Wörterbuch der deutschen Berufsund Fachsprachen. In den Paragraphen 36,38 und 39 der 'Unvorgreiflichen Godanken' sohildert LeIBNIz, wie er auf die Akademien Frankreichs, Englands und Italiens einzuwirken suchte, um sie zur Abfassung eines Wörterbuches der termini technici zu veranlassen. ${ }^{2}$ Was ihn bewog, auf die Notwendigkeit der Schaffung derartiger Werke mit besonderem Nachdruck hinzuweisen, war allerdings nicht so sehr die Einsicht in den Wert des berufssprachlichen Wortgutes für die Sprach. forschung. LerbnIz erwartete vielmehr, daß durch Erklärung der Kunst.Worte die Wissenschafften selbst erläutert und befördert würden'. 'Denn weil ... die Worte den Sachen antworten, kan es nicht fehlen, es muß die Erläuterung ungemeiner Worte auch die Erkäntniß unbekandter Sachen mit sich bringen.'3 Was LeIBNIz vorschwebte, waren also Wissensenzyklopädien (Begriffs- und Sachwörterbücher), nicht Darstellungen des berufssprachlichen Wortgutes unter sprachwissenschaftlichem Gesichtspunkt. In den 'Vnvorgreiflichen Gedanken' äußert sich die Zuversicht, daß ein Werk dieser Art, geschaffen auf der Grundlage der an konkreten Bezeichnungen so reichen deutschen. Sprache, von besonderem Wert sein werde. ${ }^{4}$ Der Gedanke eines internationalen Wissensaustausches mit Hilfe enzyklopädisoher Werke steht hinter dieser Anregung. LimiBNIz sucht die Ausführung des ihm vorzugsweise bedeutsamen Vorhabens durch methodische Hinweise vorzubereiten: mehrere sachkundige Bearbeiter sollen sich zu einer Arbeitsgemeinschaft zusammenfinden und unter anderem im Abfrageverfahren 'von den Leuten jeder Profession selbst' Auskünfte einholen. ${ }^{5}$

\section{4}

Leirisiz führte das Manuskript der 'Unvorgreiflichen Gedanken' vermutlich bei sich, als er im Jahre 1700 in Berlin über die Gründung der Preußischen Societät der Wissenschaften verhandelte. Noch in Hannover hatte er von der Anregung des Kurfürsten erfahren, die Pflege der deutschen Sprache in den Kreis der Societätsaufgaben einzubeziehen. Mit der Frrichtung der Historisch-Philologischen Klasse, die diese Aufgabe wahrnehmen sollte, schien die organisatorische Voraussetzung gegeben zu sein, um den in den 'Unvorgreiflichen Gedanken' niedergelegten

I LEIBNIz a. a. O. (\$ 51) 78 .

Letriniz a. a. $0 .(\$ 36 ; 38 ; 39) 73 ; 74$.

LexbNIz a. a. O. (\$ 36) 74; (\$ 40$) 75$.

- Lefibniz a. a. O. (\$ 40) 74 .

5 Lemibniz a. a. O. (\$ 53) 78 . 
Wörterbuchplan zu verwirklichen. Es wurde bereits dargestellt, wie LerBNIz in Auseinandersetzung mit den Auffassungen der Brüder J ABLONSKr versuchte, diesen umfassenden Plan, insbesondere aber den Plan eines Wörterbuchs der termini technici zur Grundlage der germanistischen Arbeit der Klasse zu machen. ${ }^{1}$ Blieb seinen Bemühungen auch der Erfolg versagt, so waren Teile des Inhalts der 'Unvorgreiflichen Gedanken' im Kreise der Mitglieder der Historisch-Philologischen Klasse jedenfalls bereits im ersten Jahrzehnt des 18. Jahrhunderts bekannt. Auffassungen LaIBNIzens hatten in die Akten der Societät Eingang gefunden, und auch der 1711 vorgelegte Wörterbuchentwurf JABLONSKrs verriet inhaltlich (Dreiteilung der lexikographischen Gesamtaufgabe) und terminologisoh (Usuale, Technioum, Etymologicum) die Einwirkung Leibnizischer Gedankengänge.

Durch persönlichen Umgang mit LaIBNIZ oder im Kreise der Klassenmitglieder wird FRISOr bereits zu dieser Zeit mit lexilographischen Auffassungen LeIBNrzens vertraut geworden sein. Er lernte sie in geschlossenem Zusammenhange kennen und wurde nochmals nachdrücklich auf sie hingewiesen, als J. G. EorarT im Jahre 1717 die 'Unvorgreiflichen Gedanken' in den 'Collectanea Etymologica' veröffentlichte. Es wird lkein Zufall sein, daß Frisor im folgenden Jahre als Mitglied der Historisch-Philologischen Klasse einen energischen Vorsto B in der Wörterbuchfrage unternahm, und zwar einen Vorstoß im Sinne LaIBNIZens. Er sah, wie es LisibNIZ im Jahre 1700 gesehen hatte, daß gerade die Historisch-Philologische Klasse zur Lösung der umfassenden Aufgabe berufen war, die LeIBNIZ in den 'Unvorgreiflichen Gedanken' abgesteckt hatte. Er bemühte sich daher, die Klasse zu lexikographischer Arbeit in diesem Sinne anzuregen. Spätestens zu dieser Zeit werden die Auffassungen der 'Unvorgreiflichen Gedanken' jedoch auch auf die Gesamtplanung des Wörterbuches eingewirkt haben, an dem FRISOH damals seit zweieimhalb Jahrzehnten arbeitete. ${ }^{2}$

Ergebnis dieser Auseinandersetzung mit lexikographischen Auffassungen LisBsrzens war der Wörterbuchentwurf, den FrIscr im Jahre 1718 festlegte und im Jahre 1723 als Specimen I veröffentlichte. ${ }^{3}$ Das hier ausgearbeitete Programm

1 Vgl. S. 54-58.

2 Für ein solches Einwirken waren die Voraussetzungen in den Jahren um 1715 insofern besonders günstig, als der Wörterbuchplan Eckarrs gerade zu dieser Zeit die ursprüngliche Zielsetzung FrIscHs - den Gedanken des etymologischen Wörterbuchs - in Frage gestellt hatte. LerBarzens Auffassungen konnten das entstehende Vakuum auffüllen.

${ }^{3}$ Eine Vorstufe des Specimen $\mathrm{I}$ ist bereits im Jahre 1713 entstanden. Am 22. Juni dieses Jahres verlas Frrsch vor der Historisch-Philologischen Klasse einen Artikel 'Land', über den die anwesenden Mitglieder damals urteilten: die Darstellung sei ' $\mathrm{zu}$ dem vorhabenden Zweck (das geplante orthographisch-grammatische Wörterbuch) ... allzu weitläufig' (Protokoll vom 22. 6. 1713). Fünf Jahre später, am 3. Februar 1718, nahm die Klasse in gleichem Sinne Stellung. Das Urteil des Jahres 1713 bezieht sich auf einen Musterartikel entweder im Rahmen des von FrIscr geplanten etymologischen Wörterbuchs oder im Rahmen eines Gesamtwörterbuchs, das die Klasse ausführen sollte. 
einer Gesamtdarstellung schloß die verschiedenartigen Teilziele, die in der Frühzeit des Schaffens unter dem Leitbegriff des etymologischen Wörterbuchs ge. standen hatten, zu einer neuen Gesamtzielsetzung zusammen, die den lexiko. graphischen Grundauffassungen LimanIzens entsprach. Im einzelnen sind Umbildungen der Gedankengänge LEIBNIzens allerdings nicht zu verkennen. So ist FRISCHs Usuale speciale zwar wesentlich Technicum; es soll jedoch auch Wortgut aufnehmen, das 'nur in einigen Ländern, und Oertern' gebräuchlich ist, d. h. den Wortbestand der Fachsprachen und der Mundarten als 'Sprachgut begrenzter Geltung' zusammenfassen. Das steht im Gegensatz zu der Absicht Leirinzzens, ein Wörterbuch ausschlieBlich der termini technici zu schaffen, den Wortschatz der Mundarten hingegen im Etymologioum mitzubehandeln. Tine zweite Abweichung den 'Unvorgreiflichen Gedanken' gegenüber liegt darin, daß FRISOH aus dem Etymologicum, dem nach LirBNrzens Auffassung der gesamte zur Herkunftsbestimmung dienliche Sprachstoff einzuverleiben wäre, das Archaeologum, das Eponymologioum (und das mundartliche Wortgut) als selbständige Gruppen herauslöst. Die Ausgliederung dieser Kategorien läßt erkennen, daß die Erfassung des ihnen zugehörigen Wortbestandes um seiner selbst willen (nicht nur als Mittel etymologisoher Deutung) ein wesentliches lexikographisohes Anliegen FrIsCHs bildete.

Die bedeutsamste Abweichung bestand indessen darin, daB Frrson im Gegensatz zu LEIBNIz den Plan der Gesamtdarstellung nicht in drei selbständigen Werken, sondern in einem Wörterbuch zu verwirklichen unternahm. Das "TeutschLateinische Wörter-Buch' erhielt damit das Aufbaugefüge eines Gesamtwörterbuchs ${ }^{1}$, und in diesem Sinne wurde es ausgeführt. Mit den Exzerptionsarbeiten muß FRrsor frühzeitig begonnen haben. Aus den gewonnenen Stoffsammlungen gingen zunächst einzelne sprachgeschichtlich-etymologisohe Untersuchungen hervor, wie sie in der 'Buchstab-Veränderung' und in den 'Miscellanea' I (1710) und II (1723) niedergelegt sind. 1713 entstand der Artikel 'Land'; er wurde 1718 erneut vorgelegt und 1723 mit der Aufforderung, Zusätze und Verbesserungen einzusenden, gedruckt. Am 24. Januar 1726 konnte FrIscH vor der Klasse mitteilen, $\mathrm{da} ß$ er auf Grund der Veröffentlichung des Artikels zahlreiche Beiträge erhalten habe. ${ }^{2}$ Er legte zugleich den Artikel 'Brand' vor, der 1727 als zweites Specimen erschien. Zu dieser Zeit waren die Vorarbeiten soweit vorangeschritten, da $B$ F'RIsoH mit der zusammenhängenden Ausarbeitung des Wörterbuches beginnen konnte. Am 16. Januar 1727 berichtete er vor der Klasse, daß ex

1 Frisce selbst bozeichnet das Specimen I als 'Entwurff und Muster eines Teutschen Haupt-Wörter-Buchs' (BödrKra-FrIscrr, Grund-Sätze Der Teutschen Sprache [1723] Titelblatt). Der dem 18. Jahrhundert geläufigere Ausdruck 'Allgemeines Deutsches Wörterbuch' findet sich $1734 \mathrm{im}$ Untertitel des Programms zur märkischen Mundartforschung, vgl. \$. 53 .

\& Protokoll vom 24. 1. 1726. 
'noch immerhin an seinem Dictionario arbeite, und weil er von Auswärtigen schlechten beitrag zu hoffen habe, wolle er sich allein darüber machen, und kein Specimen mehr heraus geben, sondern das werk selbst angreifen, und wenigstens das Lexicon Usuale zum stand bringen.'1

In die Zeit zwischen 1727 und 1741 fällt der größte Teil der Darstellungsarbeiten. Im Jahre 1734 berichtet JoHanN UlRIOH KöNIG in der Vorrede zu STELNBaOHs 'Vollständigem Deutschen Wörter-Buch':

'Der Herr Rector Frisch in Berlin darf sich ebenfals sohmeicheln, nicht weniger Danck (als Wachter) zu verdienen, wenn er sein vollständiges Wörterbuch, wovon er mir, schon vor einigen Jahren, einen so bewundernswürdigen Vorrath in seinem Hause gewiesen, dermahleinst an das Licht treten lassen wird.' 2

1731 wurde FrIsCH zum Direktor der Historisch-Philologischen Klasse ernannt; das Verpflichtende dieser Stellung wirkte anspornend und beschleunigend auf den Fortgang der lexikographischen Arbeit:

'Der Königlichen Societät der Wissenøchafften zu Berlin aber, sonderbare Gütigkeit gegen dem Verfasser, hat das größte Gewicht, und den kräfftigsten Trieb gegeben, indem sie ihn nicht allein vor viel Jahren unter die Zahl ihrer Mitglieder aufgenommen, und seine Arbeit in Beförderung der Richtigkeit der Teutschen Sprache sich allezeit gefallen lassen, sondern ihn auch vor einiger Zeit in diesem Punct und der Teutschen Historie mit in das Directorium genommen. Wodurch er im höchsten Grad verbunden worden, ohnabläßig über dieser Arbeit zu bleiben.' 3

Die Klasse nahm jetzt einen gewissen fördernden Anteil an dem Fortgang des Wörterbuchsohaffens; selbständige Beiträge aus dem Kreise der Mitglieder sind FrIsOH, so scheint es, jedoch nicht zugegangen."

Daß ein Großteil der Darstellungsarbeiten in die dreißiger Jahre fällt, geht auch daraus hervor, daß die Zahl der sprachgeschichtlichen Miscellanea-Beiträge jetzt erheblich anschwillt (16 gegenüber 3 in den zwanziger Jahren). Der 1734erschienene vierte Band der 'Miscellanea' brachte mehrere Aufsätze Frisors über Herkunft und Bedeutung verdunkelter deutscher Wörter, der gleichzeitig veröffentlichte 'Erste Auszug' Abhandlungen vorzugsweise sprachgeschichtlichen Charakters zur Erklärung 'der alten und in vielen Wörtern und Redens-Arten undeutlich gewordenen Chroniken's.

1 Protokoll vom 16. 1. 1727.

2 Srmingaor, Vollst. Deutsches Wörter-Buch 1 (1734) * $4^{\text {b. }}$.

3 FaIsor, TLWb. (1741) ( $1^{\mathrm{b}}-2^{\mathrm{a}}$.

4 Bereits 1727 hatte allerdings J. TH. JABLONSKr einen Teil des von ihm ausgearbeiteten Artikels 'Stein' vor der Klasse verlesen und Faiscr übergeben (Protokoll vom 20. 2. 1727). Es scheint ein Einzelfall tätiger Mithilfe geblieben zu sein.

5 Frisor, Der erste Auszug Von einigen Dio Teutsche Sprach betreffenden Stücken (1734) $4^{\mathrm{b}}$. 
Diese Beiträge stellen nur einen Teil der Ergebnisse dar, die FrIsor zu dieser Zeit auf dem Gebiet der Wortforschung gewann. In einem Brief an J. HuUmanN schreibt er um 1737 über seine Beiträge zu dem 'Ersten Auszug':

'Viel hab ich noch liegen in die folgenden Auszüge zu geben. Das meiste hab ich in mein Lexicon zusemmen geschrieben, vvoran ich täglich einige Stunden arbeite."

1737 ersohien der fünfte Band der 'Miscellanea'; auch hier veröffentlichte Frisor mehrere wortgeschichtliche Untersuchungen. Am Ende der dreißiger Jahre begannen die Vorbereitungen für den Druck des Werkes. Am 1. Oktober 1738 konnte Frisort der Klasse bereits Einblick gewähren in einen Teil des Manuskripts, und zwar in 'den Theil über die Buchstaben C. D. E.'2 Am 12. Februar 1739 legte er dann

'im Mscript einen starcken folianten vor, worin or den Buchstaben F, zu seinem großen Teutschen Lexico ausgearbeitet, meldet dabey, daß er daßelbe schon bis auf lit. $O$. fortgesetzet, und itzo schon mit dem hiesigen Buchführer Nicolai im Handel stünde das werck herauszugeben.' 3

Einer der letzten Vorboten des Wörterbuches war das Schulprogramm 'De primis in Germania typis editis lexicis Germanicis' (1739). Hier heißt es:

'Caeterum quia in hoc multorum annorum labore, veluti in alto mari navigans, exclamare possum: Terram video, ob exiguam partem reliquam, de libro edendo jam jam cum bibliopola ago." 4

Der sechste Band der 'Miscellanea' (1740) brachte nochmals einige wortgeschichtliche Untersuchungen Frisors. Der Prorektor WIPPwL war bei der Herstellung des Manuskriptes zum Druck behilflich ${ }^{5}$; das Werk erschien schließlich 1741 in zwei Teilen mit einem Umfang von 1169 Textseiten im Dreispaltendruck in Quarto. ${ }^{6}$

1 Frison an Heumann in: Heumand, Opuscula (1747) 471.

2 Protokoll vom 1. 10. 1738.

s Protokoll vom 12. 2. 1739.

4 Frisor, De primis lexicis (1739) )( $4^{\mathrm{b}}$.

5 Reionand, Versuch einer. Historie d. dt. Sprachkunst (1747) 420-421; BrwderMANN, Acta Scholastica III 3 (1743) 263.

- Angeschlossen ist ein 116 Seiten umfassendes 'Register Der Lateinischen Wörter'. 


\section{DIE QUELLEN DES TEUTSCH-LATEINISCHEN WÖRTER-BUCHS}

\section{Die Quellen für die Erfassung des gemeinsprachlichen Wortgutes}

I

Die Mitglieder der Fruchtbringenden Gesellschaft, die um die Mitte des 17. Jahrhunderts den Ruf nach einem Deutschen Wörterbuch erhoben, dachten keineswegs an ein Wörterbuch im Sinne eines streng alphabetischen Nachschlagewerks. Sie forderten vielmehr eine die Grammatik ergänzende systematische Darstellung des deutschen Wortschatzes, die geeignet sein sollte, wesenhafte Merkmale der Muttersprache erkennbar zu machen. ScHotreaL und HARSDÖRFFER, den maßgebenden Theoretikern, war bewußt: wer ein Wörterbuch dieser Art schaffen wollte, würde den Wortschatz aus den Quellen erfassen müssen. Umfangreiche Stoffsammlungen, den Werken der sprachlich mustergültigen Schriftsteller entnommen, sollten die Grundlage eines Deutsohen Wörterbuches bilden. Die Lexikographen KASPaR Stimler, Matimas Kramer und Christoph Ernst Strensade, die in den Jahrzehnten um 1700 bemüht waren, das von der Fruchtbringenden Gesellschaft geforderte Werk zustande zu bringen, wußten sehr wohl um diese methodische Richtlinie. Sie sahen sich jedoch nicht in der Lage, ein Deutsches Wörterbuch allein auf der Grundlage des aus den Quellen geschöpften Beleggutes zu verfassen: als einzelne standen sie einer Aufgabe gegenüber, die nur im Zusammenwirken vieler hätte gelöst werden können. Sie waren daher auf Vorarbeiten, auf bereits vorhandene lexikalische Darstellungen der deutschen Sprache angewiesen. Ein zeitgemäBes Deutsches Wörterbuch fehlte zwar bis zu dem Erscheinen des 'Stammbaums' von KaSPar STIRLER (1691); aber deutsches Wortgut war zu dieser Zeit bereits 150 Jahre hindurch in fremdsprachlichen Wörterbüchern erfaßt worden. Auf sie griffen die Bearbeiter der ersten Deutschen Wörterbücher zurück. Die Folge war, daß Umfang und Eigenart des Inhalts ihrer Werke mitbestimmt wurden durch Umfang und Eigenart des Inhalts der fremdsprachlichen Wörterbücher, die sie als Vorlagen benutzten. Die Erfassung des Wesens und der Entwicklung der Fremdsprachenwörterbücher ist angesichts dieses inneren Zusammenhangs der Gattungen für das Verständnis der Frühgeschichte der deutschen Lexikographie wesentlich.

Die während des 17. Jahrhunderts in Deutschland gebräuchlichen Wörterbücher des Lateinischen, Französischen und Italienischen waren in ihren deutschfremdsprachlichen Teilen leistungsfähig genug, um den Bearbeitern der ersten 
Deutschen Wörterbücher Einblick zu gewähren in den Grundwortschatz der deutschen Sprache. Sie vermochten dies, obwohl ihre Verfasser (und die Ver. fasser der von ihnen benutzten Vorlagen) nicht das Ziel verfolgt hatten, den deutschen Wortschatz darzustellen. Die Gattung der fremdsprachlichen Wörterbücher hat ihren Ursprung in der humanistischen Bewegung des 16. Jahrhunderts; ihre frühesten Vertreter sind die von deutschen Humanisten um die Mitte dieses. Jahrhunderts verfaßten 'Lexica Latino-Germanica'. Zwar ging ihnen bereits. eine Tradition vorans, die über die spätscholastischen lexikalischen Wiegendrucke auf die handschriftlichen Glossensammlungen des Früh- und Hochmittelalters zurückreicht. Aber die Wörterbuchschreibung der Humanisten entfaltete sich im ganzen unabhängig von dieser Tradition. Sie hatte ihre Wurzel in dem Zeitbedürfnis, die Gesamtheit der literarischen Denkmäler der Antike, den Wortschatz des durch zahlreiche Handschriftenfunde und Textausgaben erst jetzt faßbar gewordenen klassischen Lateins lexilkographisch bearbeitet zu sehen. Diese Aufgabe suchten in den Hauptländern des europäischen Humanismus umfassende, aus den Quellen geschöpfte lateinische Wörterbücher zu lösen.

Neben foliantenstarken Werken, erwachsen aus dem Bedürfnis der gelehrtphilologischen Forschung, erschienen frühzeitig Wörterbuchabrisse für den schulischen und außerschulischen Sprachunterricht. $\mathrm{Zu}$ den Standardwerken beider Gattungen zählten die Wörterbücher, die seit dem vierten Jahrzohnt des 16. Jahrhunderts aus der Offizin des französischen Druckers und Philologen RoBmzTUS StepHaNus hervorgingen. Im Jahre 1531 veröffentlichte StrapHaNus unter dem Titel 'Thesaurus Linguae Latinae' ein umfassendes lateinisches Wörterbuch mit lateinischen und französischen Interpretamenten. Auf der Grundlage dieses Werkes erschien 1538 ein 'Dictionarium Latinogallicum'. Dieses lateinischfranzösische Wörterbuch, das nicht für Gelehrte, sondern für Lernende bestimmt. war, diente seinerseits einem 'Dictionaire Françoislatin, contenant les motz et. manieres de parler François, tournez en Latin' (Paris 1539) als Vorlage. Das 'Dictionarium Latinogallicum' wirkte auch über die Grenzen Frankreichs hinweg: im Jahre 1541 ließen die Schweizer Penrus Chournos und Jorannes Frisios in Zürich ein 'Dictionarium Latino-germanicum' drucken; sie hatten den Lemmabestand des lateinisch-französischen Wörterbuchs übernommen und die französischen Interpretamenta ins Deutsche übersetzt. ${ }^{1}$ FrIsrus legte das Werk 1556 unter dem gleichen Titel erneut vor; im selben Jahre erschien ein Schulabriß ('Novum Dictionariolum Puerorum'), dem ein deutsch-lateinischer Teil angefügt worden war.

Fristus stand in Verbindung mit Konrad Gessmr. Von diesen beiden Männern ging der Gedanke aus, ein dem 'Dictionaire Françoislatin' entsprechendes deutschlateinisches Wörterbuch zu schaffen. Für die Lösung dieser Aufgabe gewannen

1 Edgar Ewing Brandon, Robert Bstienne et le dictionnaire français au XVI siècle (1904) 64; 119-120; De WITT T. StaRnes, Renaisance Dictionaries. EnglishLatin and Latin-English (1954) 89-95; 375. 
sie ihren Landsmann Josua MaAder. Das Werk erschien 1561 unter dem Titel 'Die Teütsch spraach'.

Die 'Teütsch spraach' Josua MaAdERs steht in der ersten Reihe der humanistischen Wörterbüicher des 16. Jahrhunderts, deren Angaben den Ausgangspunkt für die lexikalische Überlieferung der Folgezeit bilden. Sie unterscheidet sich von der Mehrzahl der zu dieser Zeit erschienenen Wortschatzsammlungen dadurch, daß sie nicht nur die Zwocke eines Fremdsprachenwörterbuchs verfolgte. Das Werk erwuchs aus den Bemühungen eines Humanistenkreises, in dem die Liebe zur deutschen Sprache und der Wille zu deutschphilologischer Forschungsarbeit als eigenständige Kräfte lebendig waren. Mit dem Motiv, ein deutsch-lateinisches Wörterbuch für den Schulbedarf zu schaffen, vereinigten sich in diesem Kreise theoretische Antriebe: das Ziel Maariers und der ihm Nahestehenden war es auch, den 'Reichtum' der deutschen Sprache, d. h. auf lexikalischem Gebiet den Umfang und die Vielgestaltigkeit des deutschen Wortschatzes erkennbar zu machen.

Der Weg allerdings, den man einsohlug, um dieses Ziel zu erreichen, konnte nicht zu einem eigenständigen Deutschen Wörterbuch führen. MaALER wählte das 'Umsetzverfahren', im wesentlichen auf der Grundlage des 'Dictionarium Latinogermanicum' (1556) von JoHannes Frisius. Man wird nicht verkennen, daß zu jener Zeit allein mit Hilfe dieses Verfahrens ein leistungsfähiges Deutsches Wörterbuch geschaffen werden konnte. Denn die damals vorhandenen lexikalischen Darstellungen des Deutschen wie etwa das 'Dictionarium Germanicolatinum' von Perrus Dasypodius (Straßburg 1536), das Reimwörterbuch des Wetterauers ERASmos Alberus (Frankfurt a. M. 1540) oder das 'Novum Dictionariolum Puerorum' (Zürich 1556) boten nur sehr unvollständige Angaben. Der Weg der Quellenexzerption aber war noch nicht gangbar. Selbst der Gedanke, dieses in der klassischen Philologie schon damals geltende lexikographische Arbeitsverfahren anzuwenden, blieb dem Schweizer Humanistenkreis fern. KoNRAD GESNER war von der Leistungsfähigkeit der Vorlage MAaLERs durchaus überzeugt:

'Hoc ipsum autem Dictionarium potius quàm ullum aliud ei (Maaler) proponendum suasimus, quòd et caeteris omnibus copiosius esset . . . et simul Germanicae linguae materiam suppeditaret uberrimam"1.

Die gewissenhafte Nutzung der im Umsetzverfahren liegenden Möglichkeiten der Stoffgewinnung ließ in der Tat ein Wörterbuch verhältnismäBig hohen Leistungsvermögens entstehen. Es gelang MaALER, nicht nur den Umfang des deutschen Wortbestandes in den Grundzügen überschaubar zu machen, sondern in Form gedrängter Artikel auch Aufschluß zu geben über Bedeutung und Gebrauch des einzelnen Wortes. Dies sei veranschaulicht am Beispiel des Artikels 'Schlag' im Wörterbuch MaAders (355 $)$ :

1 MaALeR, Die Teütsch spraach (1501) $3^{\text {b. }}$. 
1. Grundbedeutung:

(1) Das schlahen vnd tülppen. Verberatio, Contusio, Planctus, Pulsatio, Per. cussus ...., Percussio, Verberatus ...

(6) das hindenauf schlahen mit den fuissen. Calces.

2. (3) 'Pulsschlag': Die pulB. Pulsus arteriarum. Schlag der hertzaderen.

(4) 'Taktschlag, Takt': Mensur deß gesangs. Modus.

Das singen nach dem Schlag. Modulatus.

Dem Schlag nach/Wol gerympt. Numerose.

In den Schlag vnd mensur gemacht. Modulatus.

In Schlag oder mensur dantzen/der dantzmaß nach dantzen. Ludere in numerum, Saltare ad tibicinis modos.

Nach dem Schlag/Nach der weyß. Modulate.

3. (6) 'SchlagfluB, Schlaganfall': Das gůt. Paralysis, Apoplexia.

Der den Schlag/Dz gủt oder den tropff hat vnd alle empfindtnuB seiner glideren verleürt. Attonitus.

4. (2) 'Münzgepräge': Der Schlag einer müntz. Comma.

Der Artikel gewährt einen gewissen Einblick in das Leben des Wortes 'Schlag' im (Schweizer-)Deutschen um die Mitte des 16. Jahrhunderts. Erfaßt ist außer der Grundbedeutung eine Reihe besonderer Verwendungsweisen, die sich auf mehrere semantische Gruppen verteilen. Ohne Zweifel bedeutet der Artikel MaArmas gemessen an der Kargheit der Angaben zeitgenössischer Wörterbücher - einen Schritt vorwärts auf dem Wege zu einer in den wesentlichen Erscheinungen vollständigen Erfassung der Sprachwirkliohkeit. Ein Vergleich mit der Darstellung des Wortgebrauchs im 'Dictionarium Germanicolatinum' (Straßburg 1536) des Petros Dasyponios könnto diesen Fortschritt veranschaulichen. Entscheidendes Kriterium für das Leistungsvermögen eines Wörterbuches ist jedoch nicht sein Verhältzis zu früher oder gleichzeitig erschienenen lexilalischen Darstellungen, sondern sein Verhältnis zur Sprachwirklichkeit. Um in dieser Hinsicht ein Urteil über die 'Teütsch spraach' Josua MaAcmes zu gewinnen, sei im folgenden ein Bild des Wortgebrauchs im Schweizerdeutsohen des 16. Jahrhunderts entworfen, und zwar an Hand des Artikels 'Schlag' im Schweizerischen Idiotikon 9 (1929) 185-197:

\section{SCHLAG ${ }^{3}$}

la. Schlag mit der Hand, dem Fuße, einem Werkzeug u. dgl.

a) als einmaliger Vorgang, insb. in der Wendung: zu Schlag kommen; über. tragen: Unglüok, Unfall

1d. In taktmäßiger Wiederholung

a) Schlag der Adern, des Herzens

B) durch taktmäßiges Schlegen erzeugte Geräusche, Klänge: Glockenschlag

y) Takt, Rhythmus

1 Nur die für das 16. Jahrhundert bezeugten Verwendungsweisen sind berücksichtigt; sie erscheinen kursiv, soweit MAALER sie in seinem Wörterbuch verzeichnet. 
3a. Krankheiten mit Lähmungserscheinungen

a) Schlaganfall

B) 'Schlag am Hals'

4b. Gepräge einer Münze

6. Furche, Graben; Weg zwischen zwei Rebstücken

9a. Sprengladung eines Geschosses

9b. Vorrichtungen, die zufallen und dadurch abschließen

B) Klappe, Schiebetür an einer Falle, einem Käfig; die Falle, der Käfig selbst, insb. in der Wendung: den Vogel im Schlag haben 'Gewalt über jemanden haben'

10a. Amtliche Veranschlagung, allgemein geltender Verkaufspreis

10b. Gebot bei Versteigerungen

12a. Art und Weise

Die auf breiter Quellengrundlage ruhende Darstellung des Schweizerischen Idiotikons läßt den reichentfalteten Gebrauch des Wortes im Schweizerdeutschen des 16. Jahrhunderts erkennen. Ein Vergleich mit dem Artikel Masrmas lehrt nun, da $B$ zwar einzelne der zum festen Sprachbesitz gehörenden Verwendungsweisen im Wörterbuch wiedererscheinen, daß aber der Wortgebrauch in seinem Gesamtumfang nicht wirklichkeitsgetreu erfaßt worden ist. Die Darstellung MaALERs ist unvollständig und unausgewogen: es fehlt nicht nur schlechthin eine Reihe von Verwendungsweisen, sondern es fehlen mehrfach gerade die stark bezeugten, für den Wortgebrauch kennzeichnenden Anwendungsmöglichkeiten (von den sechs besonders dicht belegten Gruppen sind erfaßt: $3 \mathrm{a} a$ und $4 \mathrm{~b}$; es fehlen die Gruppen $6,10 a$ sowie die verbreiteten redensartlichen Verbindungen ' $z u$ Schlag kommen' la $\alpha$ und 'den Vogel im Schlag haben' $9 \mathrm{~b} \beta$. Andererseits ist eine für das Gesamtbild des Sprachgebrauchs unwesentliche Nebengruppe wie I d $\gamma$ im Wörterbuch MaAcers durch die reichste Zahl von Belegen vertreten).

Diese Mängel erklären sich aus der Entstehungsweise des Artikels. Das Gebuchte ist unvollständig und in seiner Zusammensetzung zufällig, weil es nicht aus dem Bemühen heraus gewonnen wurde, die Sprachwirklichkeit planvoll zu erfassen, sondern abhängig ist von dem lateinischen Wortbestand eines lateinisch-deutschen Wörterbuchs. Dieser Befund läßt es zweckmäßig erscheinen, die Bedingungen zu untersuchen, die maßgebend sind für das Auftreten des einzelnen deutschen Belegs im Wörterbuch MaAuERs.

Die Belege des Artikels 'Schlag' sind als Utbersetzungsbelege vorlagengebunden. Sie beruhen auf einer Reihe lateinischer Autorenstellen, die in den Wörterbüchern von Stephanus und Frisios aufgeführt werden. So liegen dem Ansatz der Bedeutung 'Pulsschlag' zugrunde: zum einen der Gebrauch des Wortes pulsus durch Puinids, zum anderen die Buchung dieses Gebrauchs durch Sterinanus und Frisrus. Fehlte eine entsprechende Verwendungsweise im klassischen Latein oder wäre sie - falls vorhanden - von dem Lexikographen des klassischen Lateins 
übersehen worden, so fehlte im Wörterbuch Maarers der deutsche Beleg. Damit ist eine Voraussetzung erkennbar geworden, die Umfang und Eigenart des deutschen Belegbestandes in entsoheidender Weise bedingt: nur jener Ausschnitt der deutschen Sprachwirklichkeit wird im Deutschen Wörterbuch erfaßt, der durch fremdsprachliche Belege semantisch abgedeckt wird.

Zwischen die Buchung der Autorenstelle im lateinischen Wörterbuch und den Ansatz des Stichworts oder Belegs im Deutschen Wörterbuch schiebt sich ein überbrückender Arbeitsgang: die Übersetzung der Autorenstelle ins Deutsche. Dieser Arbeitsgang ist ebenfalls von wesentlicher Bedeutung, und zwar deshalb, weil es darauf ankommt, in welchem Umfange und in welcher Weise die Belege des lateinischen Wörterbuchs übersetzt werden.

Ein Blick in die Vorlage MaAlers, das 'Dictionarium Latinogermanicum' (1556) von JoHaNNms Frisius, zeigt, daß Frisius nicht sämtliche lateinischen Belege übersetzt. Beispielsweise wird zwar die bereits erwähnte Purnrus-Stelle 'Pulsus arteriarum' (arteriarum pulsus, hist. nat. 11, 219) deutsch wiedergegeben, aber im gleichen Artikel 'Pulsus' bleiben ein TacrTos-Beleg (venarum pulsus) und ein Crcero-Beleg (impetus pulsusque remorum) ohne Glossierung. Infolgedessen hat der Purntus-Beleg für den Artikel MaAdirs einen deutschen Beleg 'hervorgebracht', der TaorTus- und der Cronko-Beleg dagegen nicht (dabei ist wesentlich, daß die CroEro-Stelle, wenn sie mit deutscher Übersetzung versehen worden wäre, das im Wörterbuch MaAzmas entworfene Bild des Wortgebrauchs um einen neuen Zug bereichert hätte). Die Dichte der Glossierung im lateinischen Wörterbuch steht also in einem gesetzmäßigen Verhältnis zu Umfang und Art des Artikelinhalts im Deutschen Wörterbuch: je stärker glossiert wird, um so umfangreicher und mannigfaltiger das deutsche Beleggut. Die lückenhafte Glossierung der Vorlage (FrIsros) hat die ohnehin eingeschränkte Arbeitsgrundlage für MAAr.z weiter eingeengt. Auch UngleichmäBigkeiten des deutschen Beleg. bestandes in entgegengesetzter Richtung (übermäßige Bezeugung einer Beleg. gruppe) erklären sich daraus, daß Frisros ungleichmäßig, d. h. in diesem Falle au Bergewöhnlich dicht glossiert hat (vgl. die Gruppe 'Taktschlag, Takt' ld $\gamma$ ).

Die übersetzerische Fähigkeit des Wörterbuchbearbeiters kann Unzulänglichkeiten dieser Art in gewissem Grade ausgleichen. Die Aufgabe, den lexikographisch gerado erst erschlossenen Wortschatz des klassischen Lateins mit angemessenen muttersprachlichen Interpretamenten zu versehen, stellte den humanistischen Uhersetzer allerdings vor große Schwierigkeiten. Zeugnisse seines Ringens um den treffenden deutschen Ausdruck sind neben Lehnprägungen, die zum Teil in die lexikalische Uberlieferung und von dort in die Schriftspraohe übergehen ${ }^{1}$, umschreibende Wiedergaben des fremden Wortinhalts; zum Beispiel:

1 Isrna, Die Erfassung der dt. Sprache des ausgehenden 17. Jhs. in den Wörterbüchern Matthias Kramers und Kaspar Stielers (1956) 18-29. 
Calces . . . Ein stoß mit den füssen / Das hindenaufschlahen mit den fủssen.1 Attonitus .... Der den schlag/das gůt/oder den tropff hat/vnd alle empfindtnuß seiner glideren verleürt. ${ }^{2}$

Eine Reihe solcher Umschreibungen ist schon von MAALER ausgeschieden worden; so erscheint 'das hindenaufschlahen' nicht als Stichwort, sondern MaAror setzt den Beleg unter 'Schlag' an. Bedeutsam ist nicht nur, daß in anderen Fällen derartige erklärende Bildungen zum Stichwort erhoben werden und in die lexikalische Uberlieferung eindringen, sondern auch, daß auf diese Weise fortlaufend Belege für die deutschen Benennungen verloren gehen, die den Sinn der lateinischen Vorlage angemessen wiedergegeben hätten, dem Lexikographen aber ungeläufig waren. Im Falle 'calces' hat MAALER berichtigend eingegriffen und den Beleg an die ihm zukommende Stelle gesetzt, im Falle 'attonitus' jedoch ist das nicht geschehen: eine angemessene U'bersetzung hätte einen Beleg für eines der Stichwörter '(vom Schlage) gerührt, getroffen, gelähmt' o. ä. ergeben müssen. An dieser Stelle entstand bedingt duroh die Übersetzungsweise eine Lücke.

Mängeln dieser Art wirken die Variation des Interpretamentums und die idiomatische Sinnwiedergabe entgegen. In dem Bestreben, den Sinn der fremdsprachlichen Vokabel genau zu erfassen, reiht der Utbersetzer gerne Synonyma aneinander oder aber bedient sich der idiomatischen Utbersetzungsweise an Stelle der wörtlichen Übertragung. Beide Möglichkeiten seien an Beispielen veranschaulicht.

1. Im 'Dictionarium Latinogermanioum' (1556) 104 übersetzt F'RISIUs: Apoplexia . . . : Der Schlag / tropff / oder das gưt. Indem der Utbersetzer hier mehrere ihm geläufige Ausdrücke nebeneinanderstellt, schafft er die Voraussetzung für drei Lemmaansätze im Wörterbuch MAALERs.

2. Für die Glossierung der lateinischen Ausdrücke 'modus' und 'numerus' (Dictionarium Latinogermanicum [1556] 828; 884) verwendet Frisius neben den wörtlichen Entsprechungen 'Mittel, maaß, weyß' und 'Zaal' zur Wiedergabe der Bedeutung 'Takt' das dem (Schweizer-)Deutschen eigene, dem Lateinischen sinngemäß (nicht wörtlich) entsprechende 'Schlag'. Auf diese Weise ist die Bedeutungsgruppe 3 (4) für den Artikel 'Schlag' in Wörterbuch MaAfers gewonnen worden.

Die Untersuchung hat erkennen lassen, daß das 'Umsetzverfahren' für die lexikographische Erfassung der deutschen Sprachwirklichkeit nur bedingt geeignet war. Nur jener Ausschnitt des Sprachgebrauchs konnte in das deutschfremdsprachliche Wörterbuch Eingang finden, zu dessen Buchung ein (lexikographisch erfaßtes und angemessen übersetztes) lateinisches Wort herausforderte. Die lexikographische Aufarbeitung des klassisch-lateinischen Schrifttums wirkte sich nicht nur dahin aus, daß neugeschaffene Einzelprägungen in die lexikalische

1 Frisius, Dictionarium Latinogermanicum (1556) 177.

2 Frisius a. a. O. 135.

a MaAlar, Die Teütsch spraach (1561) 198b (gůt); 355a (schlag); 409b (tropff). 
Uberlieferung des deutschen Wortschatzes eingingen, sondern Umfang und $\mathrm{Zu}$ sammensetzung des Belegbestandes insgesamt wurden durch das Lateinische bestimmt.

Nachdem am Beispiel eines Durohschnittsartikels das Werden eines Werkes veranschaulicht worden ist, auf dessen Angaben sich die lexikalische Utberlieferung der späteren Zeit wesentlich stützt, sei im folgenden die Entwicklung der deutschen Wörterbuchschreibung während des 17. Jahrhunderts und in den Jahr. zehnten unmittelbar vor dem Auftreten JoHANN LEONHARD FrisoHs im UmriB gekennzeichnet. Als Ausgangspunkt dient eine Ubersicht, die die Gesohiohte der lexikographischen Darstellung des Artikels 'Schlag' in der alt- und neufremdsprachlichen Überlieferung sowie in den Deutschen Wörterbüchern der Zeit um 1700 erläutern soll. Beschränkung auf eine Auswahl wesentlicher Werke (soweit wie möglich gleichen Formats) war unumgänglich. Zugrunde gelegt sind:

\section{Altfremdsprachliche Wörterbücher.}

Wolfande SchönslmDER, Promtvarivm Germanico-Latinvm. Auggburg 1618. Johatr Jacos Dentrzerer, Clavis linguae Latinae. Basel 1686.

Benjamta Hedertch, Promtvarivm Latinitatis. Leipzig 1729.

2. Neufremdsprachliche Wörterbücher.

Lmvinus Housios - Francisous Marminus Ravelius, Dictionarium TeutschFrantzösisch-Italiänisch. Frankfurt am Main 1616.

Nathanaet Duez, Diotionarium Germanico-Gallico-Latinum. Amsterdam 1664.

Christian Ludwia, Teutsch-Englisches Lexicon. Leipzig 1716.

3. Deutsche Wörterbücher.

Kaspar Strexer, Der Teutschen Sprache Stammbaum und Fortwachs. Nürnberg 1691.

Matthias Kramer, Das herrlich Grosse Teutsch-Italiänische Dictionarium. Nürnberg $1700 / 02$.

Caristoph Ernst Steinbach, Vollständiges Deutgches Wörter-Buch. Breslau 1734.

In der folgenden Utbersicht ist die ursprüngliche Abfolge der Bedeutungsgruppen (kenntlich gemacht durch die vorangestellten Ziffern in runden Klammern) aufgehoben worden. Um einen Vergleich zu ermöglichen, war es notwendig, die Belegreihen in die Rubriken eines gleichbleibenden Gliederungsschemas einzuordnen. Aus Raumgründen fielen die grammatischen Angaben sowie die Ubersetzungen der einzelnen Verwendungsbeispiele fort. Nicht Zugehöriges wurde ausgeschieden.

Die Ubersicht läßt das Werden der lexikalischen Uberlieferung und das in den Jahrzehnten um 1700 erreichte Leistungsvermögen der alt- und neufremdsprachlichen Gattung sowio der zu dieser Zeit erscheinenden Deutschen Wörterbücher in den Hauptzügen erkennbar werden. 


\begin{tabular}{|c|c|c|}
\hline $\begin{array}{l}\text { SoHÖNSLEDIER } \\
(1618) \text { z } 5^{b}-\mathrm{z} 6^{a}\end{array}$ & $\begin{array}{l}\text { DENTZLER } \\
(1686) 2,245\end{array}$ & $\begin{array}{l}\text { Hederich } \\
\left(1729^{1}\right)\end{array}$ \\
\hline (2) Schlag / verberatio & (4) schlag / streich / ictus & $\begin{array}{l}\text { (1) Schlag, Puff, plage } \\
\text { [einen Schlag, } \\
\text { Schlåge] bekom- } \\
\text { men } \\
\text { [Schlåge] leiden } \\
\text { du wirst der [Schlå- } \\
\text { ge] mehr bekom- } \\
\text { men } \\
\text { er wird durch Schlå- } \\
\text { ge besser } \\
\text { das Puffen der } \\
\text { Schlåge } \\
\text { Schlag von einem } \\
\text { Knaben } \\
\text { einen damit [mit } \\
\text { Schlågen] züch- } \\
\text { tigen } \\
\text { der Schlåge ver- } \\
\text { dient hat } \\
\text { damit [mit Schlå- } \\
\text { gen] hinter einema } \\
\text { her seyn } \\
\text { [Schlag] euf den } \\
\text { Kopf } \\
\text { [Schlåge] die die } \\
\text { Knechte einem } \\
\text { geben } \\
\text { der dergleichen } \\
\text { [Schlåge] immor } \\
\text { belkómmt } \\
\text { der solche [Schlåge] } \\
\text { immer verdienet } \\
\text { [Schlåge] für einen } \\
\text { andern leiden } \\
\text { [Schlåge] hat die Le- } \\
\text { gion bekommen } \\
\text { Blitzes, ictus ful- } \\
\text { minis }\end{array}$ \\
\hline $\begin{array}{l}\text { (6) Item Schlag / die puls / } \\
\text { pulsus arteriarum }\end{array}$ & $\begin{array}{l}\text { (2) schlag des puls / der } \\
\text { hertzaderen / pulsus } \\
\text { arteriarum }\end{array}$ & \\
\hline
\end{tabular}

1 zitiert nach der Ausgabe 1753, Sp. 1988-1989. 


\begin{tabular}{|c|c|c|}
\hline $\begin{array}{c}\text { SOHÖNSTHDER } \\
(1618) z 5^{b}-z 6^{z}\end{array}$ & $\begin{array}{l}\text { DENTZLIER } \\
(1686) 2,245\end{array}$ & $\begin{array}{c}\text { HIDFRIOH } \\
\text { (1729) }\end{array}$ \\
\hline $\begin{array}{l}\text { (4) Schlag / tact / mensur } \\
\text { deB gsangs / modus } \\
\text { das singen nachm' } \\
\text { sehlag } \\
\text { gschwind / lang- } \\
\text { samer schlag } \\
\text { auffn' schlag singen } \\
\text { [auffn' schlag] dant- } \\
\text { zen }\end{array}$ & $\begin{array}{l}\text { (1) schlag der uhr / sonus } \\
\text { horologii } \\
\text { Auf den schlag da } \\
\text { seyn } \\
\text { (5) schlag / tact / modus }\end{array}$ & $\begin{array}{l}\text { (3) Klang, sonus, der Uhr } \\
\text { (4) in dor Music, modus }\end{array}$ \\
\hline $\begin{array}{l}\text { (1) der Schlag / apoplexia } \\
\text { [vom Schlag] ge. } \\
\text { troffen } \\
\text { [Schlag] auff einer } \\
\text { seitten }\end{array}$ & $\begin{array}{l}\text { (3) der schlag / apoplexia } \\
\text { Vom schlag getrof- } \\
\text { fen, getroffen wer- } \\
\text { den } \\
\text { Halber sohlag }\end{array}$ & $\begin{array}{c}\text { (6) Kranckheit, apoplexia } \\
\text { er ist vom Schlage } \\
\text { gerủhret worden }\end{array}$ \\
\hline $\begin{array}{l}\text { (8) Schlag der múntz / } \\
\text { figura }\end{array}$ & $\begin{array}{r}\text { (7) schlag der mủntz / nota } \\
\text { Sie sind eines schlags }\end{array}$ & (5) auf der Můntze, nota \\
\hline $\begin{array}{l}\text { (5) auff disen Schlag/vide } \\
\text { auff dise Weis }\end{array}$ & $\begin{array}{c}\text { (8) schlag / weis / modus } \\
\text { Auf den schlag }\end{array}$ & $\begin{array}{l}\text { (7) Art, modus } \\
\text { auf diesen Schleg } \\
\text { eines Schlags Leute }\end{array}$ \\
\hline $\begin{array}{l}\text { (9) Schlag / werth / pre- } \\
\text { tium }\end{array}$ & $\begin{array}{l}\text { (9) schlag / werth / pre. } \\
\text { tium }\end{array}$ & \\
\hline $\begin{array}{l}\text { (7) Schlag / raggetle / } \\
\text { pyrobolus charteus }\end{array}$ & $\begin{array}{l}\text { (6) schlag / vogelschlag / } \\
\text { decipula. }\end{array}$ & \\
\hline
\end{tabular}

\begin{tabular}{c|c|c}
\hline $\begin{array}{c}\text { HuLsios } \\
\text { (1616) 282 }\end{array}$ & $\begin{array}{c}\text { Dowz } \\
(1664) 438\end{array}$ & $\begin{array}{c}\text { LUDWIG } \\
\text { (1716) 1609-1610 }\end{array}$ \\
\hline $\begin{array}{l}\text { (1) Schlag / streich / Vn } \\
\text { coup }\end{array}$ & $\begin{array}{c}\text { (1) Schlag / oder streich / } \\
\text { Vn coup } \\
\text { Schlag auff die hand } \\
\text { oder auff die finger } \\
\text { Schläge leyden oder } \\
\text { ertragen }\end{array}$ & $\begin{array}{c}\text { (1) Schlag ein stroich, a } \\
\text { stroke } \\
\text { Er gab mir einen } \\
\text { sohlag mit seinem } \\
\text { stock }\end{array}$ \\
&
\end{tabular}




\begin{tabular}{|c|c|c|}
\hline $\begin{array}{c}\text { HoxsTus } \\
(1616) 282 \\
\end{array}$ & $\begin{array}{c}\text { DUthz } \\
(1664) 438\end{array}$ & $\begin{array}{l}\text { LUDWIG } \\
\text { (1716) } 1609-1610\end{array}$ \\
\hline$\because$ & $\begin{array}{l}\text { Schlåge oder stỏsse } \\
\text { kriegen } \\
\text { Sich vor schlåge } \\
\text { hủten }\end{array}$ & 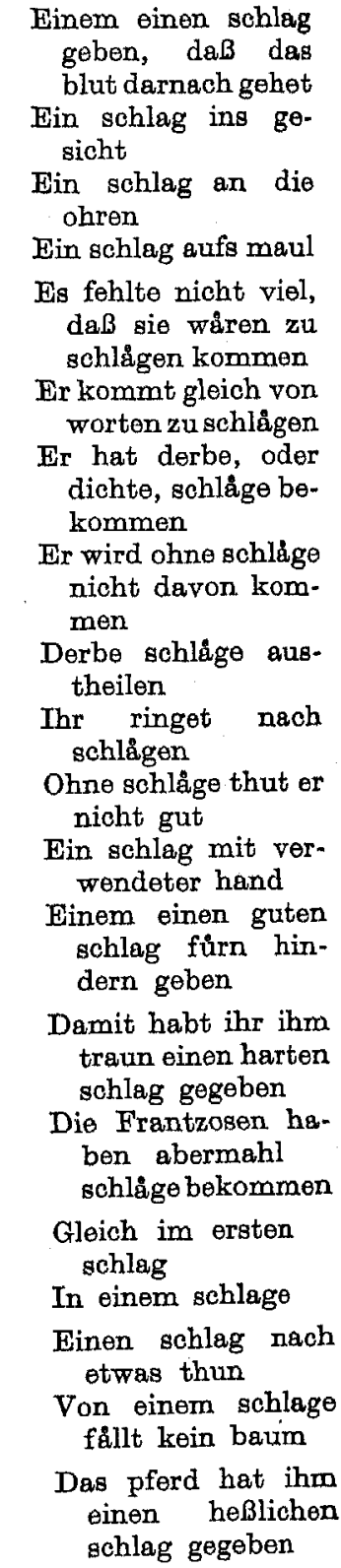 \\
\hline
\end{tabular}




\begin{tabular}{|c|c|c|}
\hline $\begin{array}{l}\text { HULSIUS } \\
(1616) 282\end{array}$ & $\begin{array}{c}\text { Dunz } \\
(1664) 438 \\
\end{array}$ & $\begin{array}{c}\text { LUDWIG } \\
\text { (1716) } 1609-1610\end{array}$ \\
\hline & $\begin{array}{l}\text { Schlag / oder klang } \\
\text { eines schlags / das } \\
\text { platzen eines schlags }\end{array}$ & $\begin{array}{l}\text { Der schlag von einer } \\
\text { auffliegenden pul- } \\
\text { vermủhle } \\
\text { Die thůr gab einen } \\
\text { starcken schlag } \\
\text { Der man thåt einen } \\
\text { harten schlag, oder } \\
\text { fall, auf die erde }\end{array}$ \\
\hline & $\begin{array}{l}\text { (3) Sohlag in der musick / } \\
\text { Vne mesure en musi- } \\
\text { que }\end{array}$ & $\begin{array}{l}\text { (2) Schlag halten, ein ums } \\
\text { ander schlagen (to keep } \\
\text { turns in striking) } \\
\text { (4) es ist zwôlffe auf dem } \\
\text { schlag } \\
\text { (8) Ein schlag in der mu- } \\
\text { sic, s, tact }\end{array}$ \\
\hline $\begin{array}{l}\text { (2) Schlag / Tropff / die } \\
\text { Hand Gottes / L'apo- } \\
\text { plexie } \\
\text { Sohlag auff einer } \\
\text { reiten } \\
\text { Mit dem Schlag be- } \\
\text { ruihrt }\end{array}$ & $\begin{array}{l}\text { (4) Schlag / oder tropff / } \\
\text { die hand Gottes / } \\
\text { L'apoplexie } \\
\text { Schlag Gottes auff } \\
\text { einer seiten } \\
\text { Mit dem schlag be- } \\
\text { rủhrt oder gerúhrt }\end{array}$ & $\begin{array}{l}\text { (3) Er ist vom schlage ge- } \\
\text { rúhret worden } \\
\text { Der helbe schlag }\end{array}$ \\
\hline $\begin{array}{l}\text { (4) Schlag auff der Mủntz/ } \\
\text { Le coing de la monnoye }\end{array}$ & $\begin{array}{l}\text { (2) Schlag auff der muintz / } \\
\text { Le coin ou la marque } \\
\text { de la monnoye }\end{array}$ & $\begin{array}{l}\text { (5) Hundert ducaten alle } \\
\text { von einem schlage }\end{array}$ \\
\hline $\begin{array}{l}\text { (3) Schlag / Art / Weise / } \\
\text { Frȩon }\end{array}$ & $\begin{array}{l}\text { (5) Schlag / oder eine art } \\
\text { vnd weise / Vne façon }\end{array}$ & $\begin{array}{l}\text { (6) Alle meine karten sind } \\
\text { von einem schlage } \\
\text { Ich habe keine kar- } \\
\text { ten von solchem } \\
\text { schlage } \\
\text { Gantz auf einen an- } \\
\text { dern schlag } \\
\text { Eben auf diesen } \\
\text { schlag } \\
\text { Von solchem schlag } \\
\text { hab ich keine } \\
\text { knopfe mehr }\end{array}$ \\
\hline
\end{tabular}




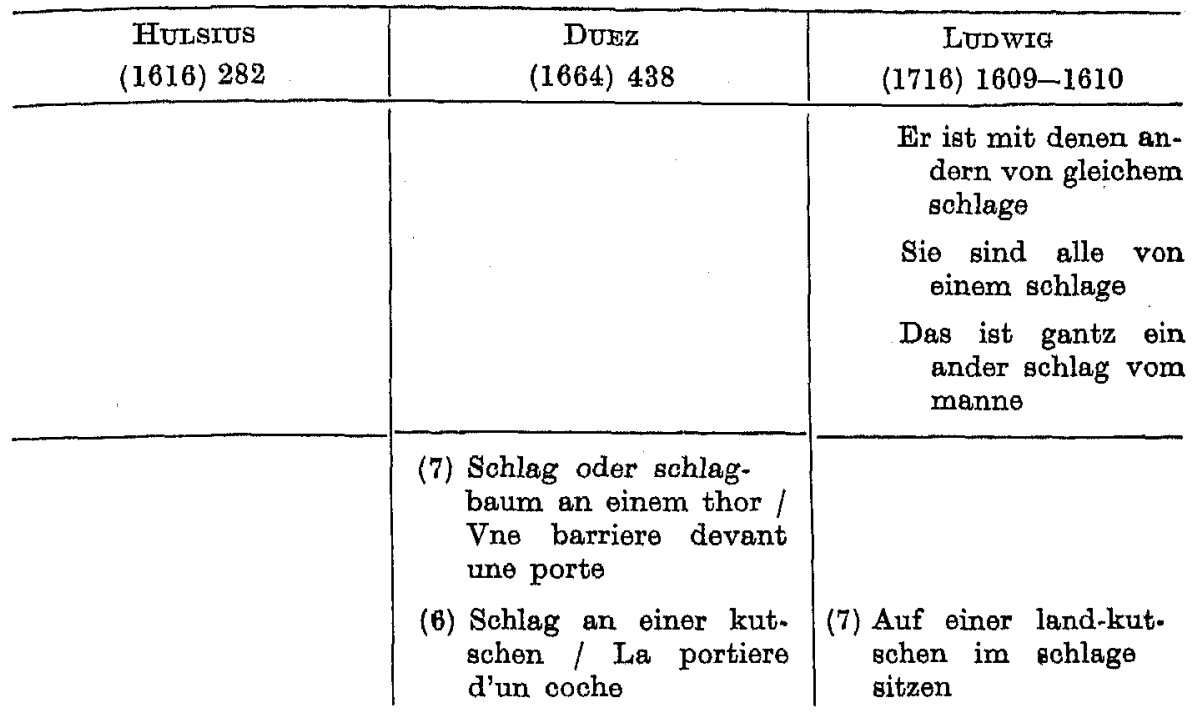

\begin{tabular}{|c|c|c|}
\hline $\begin{array}{c}\text { STIELER } \\
\text { (1691) } 1812\end{array}$ & $\begin{array}{c}\text { KRAMER } \\
(1702) 2,544^{\mathrm{b}}-545^{\mathrm{a}}\end{array}$ & $\begin{array}{l}\text { STEINBACH } \\
(1734) 2,427\end{array}$ \\
\hline $\begin{array}{l}\text { (1) Schlag percussio } \\
\text { Harter Schlag } \\
\text { Gelinder Schlag } \\
\text { Er hat Schlåge be- } \\
\text { kommen } \\
\text { Schlåge austeilen } \\
\text { Einem derbe Schlåge } \\
\text { geben } \\
\text { Schlåge darvon tra- } \\
\text { gen } \\
\text { Den Schlågen ent- } \\
\text { gehen } \\
\text { Mit Schlågen worzu } \\
\text { gebracht werden } \\
\text { Schlåge fůlen } \\
\text { Schlåge versetzen }\end{array}$ & $\begin{array}{l}\text { (1) Schlag / Battuta } \\
\text { einem einen Schlag } \\
\text { geben } \\
\text { viel Schlåge } \\
\text { viel Schlåge geben } \\
\text { er hat ihm nicht } \\
\text { einen Schlag ge- } \\
\text { ben } \\
\text { Schlåge mit Fåusten } \\
\text { Schlåge verdienen ò } \\
\text { verdienet haben } \\
\text { einem Schlåge geben } \\
\text { Schlåge krigen / be. } \\
\text { lrommen / darvon } \\
\text { tragen / einneh- } \\
\text { men / leiden } \\
\text { die Schläge mit nach } \\
\text { Hause nehmen } \\
\text { er hat Sohlåge krigt } \\
\text { Schlåge austheilen / } \\
\text { versetzen }\end{array}$ & $\begin{array}{l}\text { (1) Schlag plaga } \\
\text { Schlåge leiden } \\
\text { er wird von Schlä- } \\
\text { gen besser } \\
\text { viele Schlåge be- } \\
\text { kommen } \\
\text { die Sohlâge der } \\
\text { Knechte } \\
\text { einen mit Schlågen } \\
\text { zůchtigen } \\
\text { der Knabe bekommt } \\
\text { Schlåge } \\
\text { mit Schlågen hinter } \\
\text { einem her seyn } \\
\text { ein Schlag auf den } \\
\text { Kopf } \\
\text { Schlåge bekommen } \\
\text { vor einen andern } \\
\text { Schlåge leiden }\end{array}$ \\
\hline
\end{tabular}




\begin{tabular}{|c|c|c|}
\hline $\begin{array}{c}\text { STIBLER } \\
(1691) 1812\end{array}$ & $\begin{array}{c}\text { KRAMER } \\
(1702) 2,544^{\mathrm{b}}-545^{\mathfrak{a}}\end{array}$ & $\begin{array}{l}\text { STEINBAOH } \\
(1734) 2,427\end{array}$ \\
\hline & 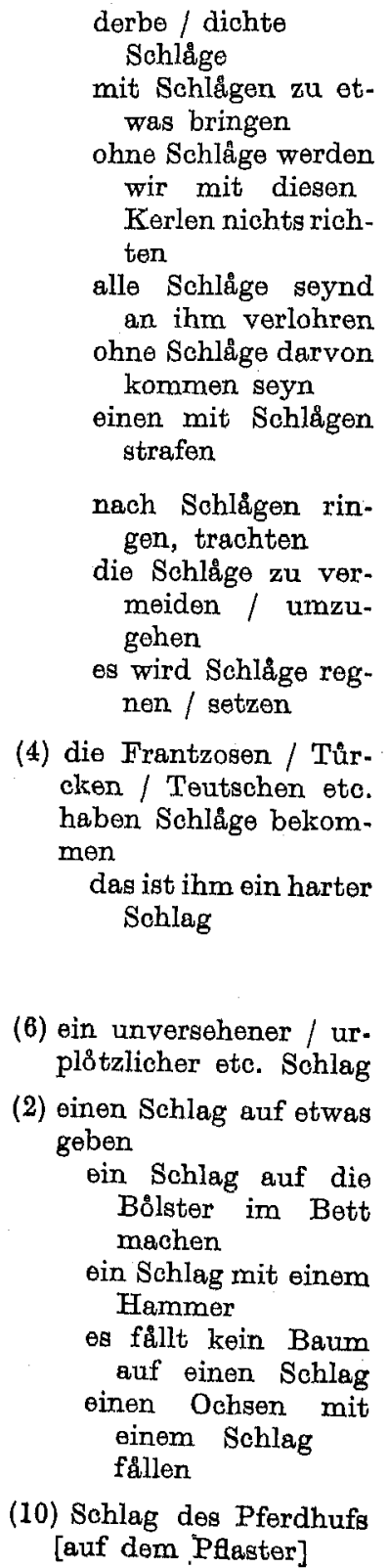 & $\begin{array}{l}\text { (2) der Feind hat Schlåge } \\
\text { bekommen, hostis pro- } \\
\text { fligatus est } \\
\text { Doch muß ich diesen } \\
\text { Schlag mit Sanftmuth } \\
\text { nur ertragen (Hof- } \\
\text { mannswaldau) 〈fortu- } \\
\text { nae ictum ferre〉 }\end{array}$ \\
\hline
\end{tabular}




\begin{tabular}{|c|c|c|}
\hline $\begin{array}{c}\text { STIMLER } \\
\text { (1691) } 1812\end{array}$ & $\begin{array}{c}\text { KRAMER } \\
(1702) 2,544^{\mathrm{b}}-545^{\mathrm{a}}\end{array}$ & $\begin{array}{l}\text { STEINBAOH } \\
\text { (1734) } 2,427\end{array}$ \\
\hline & $\begin{array}{l}\text { (3) das Pferd hat ihm einen } \\
\text { Schlag geben } \\
\text { (7) das in Feuer gerahtene } \\
\text { Pulver / der Wetter- } \\
\text { stral / die Raggete } \\
\text { otc. thate einen hef- } \\
\text { tigen Schlag } \\
\text { ich hab den Schlag } \\
\text { gehórt } \\
\text { (5) oinen Schlag thun / } \\
\text { geben } \\
\text { der Mann thåt einen } \\
\text { harten / erschreck- } \\
\text { lichen Schlag auf } \\
\text { die Erde } \\
\text { der Wagen thåte } \\
\text { einen Schlag }\end{array}$ & \\
\hline $\begin{array}{l}\text { (3) Schlag porrò in mu- } \\
\text { sicis est nota sive } \\
\text { signum soni aut vocis, } \\
\text { it. mora } \\
\text { Ganzer Schlag } \\
\text { Halber Schlag } \\
\text { Vier Schlåge } \\
\text { Acht Schlåge }\end{array}$ & $\begin{array}{l}\text { (9) man thåte etliche } \\
\text { Schlåge mit der Glocke } \\
\text { (12) Schlag in der Musick } \\
\text { falscher Schlag }\end{array}$ & $\begin{array}{l}\text { (6) einer Uhr) horae so- } \\
\text { nitus } \\
\text { Ich werde mit dera } \\
\text { Schlage da seyn }\end{array}$ \\
\hline $\begin{array}{l}\text { (4) Porro Schlag morbus } \\
\text { est, apoplexia } \\
\text { Schlag auf einer } \\
\text { Seite / sive halber } \\
\text { Schlag } \\
\text { Er ist vom Schlage } \\
\text { getroffen }\end{array}$ & $\begin{array}{l}\text { (13) mit dem Schlag ge- } \\
\text { troffen, gerúhrt werden } \\
\text { einer / so mit dem } \\
\text { (vom) Schlag ge- } \\
\text { rúhrt } \\
\text { ein halber Schlag }\end{array}$ & $\begin{array}{l}\text { (3) pro SchlagfluB) apo- } \\
\text { plexia } \\
\text { Vom Schlage ge- } \\
\text { troffen oder ge- } \\
\text { rúhrt werden } \\
\text { der halbo Sohlag }\end{array}$ \\
\hline $\begin{array}{l}\text { (5) In re monetaria est der } \\
\text { Schlag/monetae figura }\end{array}$ & $\begin{array}{l}\text { (11) 1000. Ducaten von } \\
\text { einem Schlag } \\
\text { ich kenne den Schlag } \\
\text { nicht }\end{array}$ & $\begin{array}{l}\text { (5) das Geld von einem } \\
\text { Sohlage, pecunia ejus- } \\
\text { dem notae }\end{array}$ \\
\hline
\end{tabular}




\begin{tabular}{|c|c|c|}
\hline $\begin{array}{c}\text { StIELigr } \\
\text { (1691) } 1812\end{array}$ & $\begin{array}{c}\text { KraMHR } \\
(1702) 2,544^{\mathrm{b}}-545^{\mathrm{a}}\end{array}$ & $\begin{array}{l}\text { STEINBACH } \\
(1734) 2,427\end{array}$ \\
\hline $\begin{array}{l}\text { (2) Schlag / etiam pro } \\
\text { consvetudine ponitur, } \\
\text { ut: } \\
\text { Auf den elten Schlag } \\
\text { Auf einen andern } \\
\text { Schlag } \\
\text { Auf einen Sohlag } \\
\text { Ein leichter Schlag } \\
\text { Auf diesen Schlag } \\
\text { Der Befehl lautete } \\
\text { auf diesen Schlag }\end{array}$ & $\begin{array}{l}\text { (14) Schlag / Modo } \\
\text { auf diesen Schlag } \\
\text { wer betriegen will / } \\
\text { der machts auf } \\
\text { diesen Schlag } \\
\text { oben ouf diesen } \\
\text { Schlag } \\
\text { auf einen andern } \\
\text { Schlag } \\
\text { auf einen andern } \\
\text { Schlag zugehen } \\
\text { wieder auf den vo- } \\
\text { rigen Schlag kom- } \\
\text { men } \\
\text { von diesem Schlag } \\
\text { hab ioh 3. Ballen }\end{array}$ & $\begin{array}{l}\text { (4) idem ac: Art, Weise) } \\
\text { modus } \\
\text { Mache es auf diesen } \\
\text { Schlag } \\
\text { Leute eines Schlages } \\
\text { sie sind eines Schla. } \\
\text { ges } \\
\text { sie sind Vỏgel von } \\
\text { einem Schlage }\end{array}$ \\
\hline & $\begin{array}{l}\text { (8) es seynd viel Schlåge } \\
\text { auf diesem Fuhrwege }\end{array}$ & $\begin{array}{l}\text { (7) pro Schlagbaum vor } \\
\text { einem Thore) remis. } \\
\text { siorius vectis } \\
\text { Den Schlag herunter } \\
\text { lassen } \\
\text { (8) der Eingang in eine } \\
\text { Landkutsche) staticula } \\
\text { Die in den Schlägen } \\
\text { sitzen, stehen große } \\
\text { Gefahr aus }\end{array}$ \\
\hline
\end{tabular}

1. Deutlich tritt hervor, wie ein einmal gegebener Grundbestand lexikalischer Angaben sich fortpflanzt. Ständig weitergegeben in den Werken des fremdsprachlichen Überlieferungsstranges, doch auch in den seit dem Ende des 17. Jahrhunderts entstehenden Deutschen Wörterbüchern werden die Grundbedeutung des Stichwortes sowie bestimmte im Sprachbewußtsein besonders sicher haftende Verwendungsweisen wie Schlag 'Schlaganfall, Schlagfluß'; 'Münzgepräge'; 'Art und Weise'. Diese Angaben finden sich (außer: Schlag 'Art und Weise') bereits bei MaALER; sie setzen sich in der späteren Überlieferung lückenlos fort und bilden den Grundbestand, auf dem sioh die Darstellung des Wortgebrauchs in den einzelnen Wörterbüchern aufbaut.

2. Der von den einzelnen Lexikographen erfaßte Bereich des Wortgebrauchs weitet sich allmählich, aber nicht jede neuhinzutretende Buchung wird zum festen 
Bestandteil der Überlieferung. Schwankungen dieser Art (im Umfang und in der Zusammensetzung des Belegbestandes) sind nicht von vornherein zu werten als Ausdruck eines geschichtlichen Wandels oder landschaftlicher Unterschiede des Sprachgebrauchs. Unmittelbare Beobachtung der Sprachwirklichkeit ist nur in sehr begrenztem Umfange anzunehmen. Vielmehr ist damit zu rechnen, daß einzelne Wörterbuchbearbeiter das 'Umsetzverfahren' erneut angewendet oder aber im 'Abschreibeverfahren' deutsch-fremdsprachliche Vorlagen eines anderen Überlieferungsstranges hinzugezogen haben. Diese lexikographische Arbeitsweise ermöglichte einerseits den Ausbau des Belegbestandes, wirkte andererseits jedoch einer zusammenhängenden Entwicklung der lexikalischen Ubberlieferung entgegen. Die Verfasser neuer deutsch-fremdsprachlicher Wörterbücher begannen ihre Arbeit nicht damit, daß sie die Gesamtheit der Angaben der bereits vorliegenden Wortschatzdarstellungen planvoll verwerteten. Sie legten vielmehr eine oder mehrere ihnen zur Hand befindliche Vorlagen zugrunde und schufen mit ihrer Hilfe ein neues Werk. Stetiger Neuansatz ist daher zu beobachten; nur innerhalb der Gattung bleibt eine gewisse Kontinuität gewahrt.

3. Trotz der im Ganzen noch unzulänglichen Methode des lexikographischen Schaffens ist ein allmählicher Leistungsanstieg nicht zu verkennen. Die altfremdsprachlichen Wörterbücher des 17. und 18. Jahrhunderts erfassen den semantischen und phraseologischen Anwendungsbereich des Wortes in ständig wachsendem Umfange. Fünfzig Jahre nach dem Erscheinen der 'Teütsch spraach' Josua MaALERs nimmt die auf breiter Quellengrundlage ruhende altfremdsprachliche Gattung die führende Stellung ein. Die ersten neufremdsprachlichen Wörterbücher, die zu dieser Zeit entstehen, reichen an den verhältnismäßig hohen Leistungsstand der deutsch-lateinisohen Wortschatzdarstellungen nicht heran, wie etwa die Gegenüberstellung des Artikels 'Schlag' in den Wörterbüchern von HutsIUs (1616) und SchöNSLEDER (1618) veranschaulicht. Die neufremdsprachlichen Werke holen diesen Rückstand jedoch in kurzer Zeit auf. Bereits das Wörterbuch von Dutz (1664) erfaßt den Wortgebrauch nahezu im gleichen Umfange wie das Wörterbuch Dentzlers (1686) und bietet zum Teil Angaben, für die in der altfremdsprachlichen Überlieferung kein Vorbild sich findet.

4. Wörterbücher vom Leistungsgrad der zuletzt genannten Darstellungen standen am Ausgang des 17. Jahrbunderts den Verfassern der ersten Deutschen Wörterbücher als lexikalische Hilfsmittel zur Verfügung. In Werken der alt- und neufremdsprachlichen Gattung bot sich ihnen die feste Utberlieferung eines Grundbestandes von Belegen, der als Ausgangspunkt für die Erfassung des deutschen Wortschatzes dienen konnte. Der erste Anlauf allerdings führt noch nioht zur vollen Leistungshöhe der Fremdsprachenwörterbücher. STrELLER (1691) vermehrt zwar die Anga ben über den Wortgebrauch erheblich, erfaßt aber im Artikel 'Schlag' den semantischen Geltungsbereich des Wortes nicht im gleichen Umfange wie etwa das zeitgenössische altfremdsprachliche Wörterbuch DexTzLERs (1686). Nur das fest überlieferte lexikalische Grundgerüst ist im Wörterbuch verzeichnet, und 
erst STmINBACH (1734) gelingt es, ein breiteres semantisches Feld abzudecken, so daß nunmehr ein Leistungsgleichstand etwa mit dem zeitgenössischen deutschlateinischen Wörterbuch HWDERICHS (1729) erreicht ist.

Eine deutlich erkennbare Sonderstellung nehmen das deutsch-italienische Wörterbuch MaTTHAS KRAMERS (1700/02) und das von ihm abhängige deutsch-englische Wörterbuch Christian Lodwigs (1716) ein. Insbesondere das Werk KRaMERs gewährt durch eine hohe Zall von Belegen Einblick in phraseologischsyntaktische Eigenheiten des Wortgebrauchs und in Bereiche des semantischen Geltungsgebietes, die bis dahin lexikographisch unerschlossen geblieben waren. Das durchschnittliche Leistungsvermögen der zeitgenössischen Wortschatzdarstellungen ist bei weitem überboten. Dieser außerordentliche Fortschritt wurde. ermöglicht durch die Anwendung neuartiger methodischer Grundsätze des lexikographisohen Schaffens, die den Weg ebneten für eine wirksame Erfassung der deutschen Sprachwirklichkeit. ${ }^{1}$

\section{3}

Das Ziel der folgenden Untersuchungen ist es, Einblick zu vermitteln in Her-. kunft, Umfang und Zusammensetzung des im Usuale generale des 'TeutschLateinischen Wörter-Buchs' verzeichneten Sprachgutes. Als Grundlage der Darstellung dionen zwölf größere Artikel, die stellvertretend stehen mögen für die Artikel des Usuale generale in ihrer Gesamtheit. Um den Gefahren der Stoffbegrenzung zu begegnen, zugleich um Einblick zu gewinnen in den Werdegangund in die sprachliche Zusammensetzung des Wörterbuches, wähle ich nicht eine. alphabetisch zusammenhängende Wortreihe, sondern Einzelartikel, die sich annähernd gleichmäßig über die Buchstaben des Alphabets sowie gleichmäßig auf die Wortklassen Verb und Substantiv verteilen. Ausschlaggebend für die Wahl jedes einzelnen Stichwortes war, daß es nach Bedeutung und Gebrauch sowie hinsichtlich seines Besitzes an Ableitungen und Zusammensetzungen als repräsentativer Bestandteil des gemeinsprachlichen Grundwortschatzes gelten konnte. Folgende Artikel werden herangezogen: bringen; gehen; hommen; nehmen; schlagen; stoßen. Auge; Feuer; Gnade; Herz; Leben; Recht.

Zum Gang der Untersuchung ist zu bemerken: Als Ausgangspunkt dient eine vergleichende tabellarische Ubersicht über den Artikel gehen (S. 92-100), in der den einzelnen Belegen des 'Teutsch-Lateinischen Wörter-Buchs', soweit sie im. Rahmen dieses Vergleichs als überlieferungsgebunden erkennbar sind, die Belege. der Vorlagen zugeordnet werden. Ubberprüft wird die Abhängigkeit der Belege. FrIsoHs von den Belegen der beiden stoffreichsten Deutschen Wörterbücher der. Zeit um 1700: des deutsch-italienischen Wörterbuchs Matrmasas Kramers (1700/02). und des deutsch-lateinischen Wörterbuchs Christoph Ernst Strminbadus (1734).

1 IsIng, Die Erfassung der dt. Sprache des auggehenden 17. Jhs, in den Wörterbüchern Matthias Kramers und Kaspar Stielers (1956) 47-64. 
Im weiteren Verlauf der Darstellung suche ich die am Beispiel gehen gewonnenen Ergebnisse zu sichern durch Aufschlüsse, die der Vergleich der restlichen elf (aus Raumgründen nicht in Tabellenform darstellbaren) Artikel liefert.

In der Tabelle werden nicht nur die von FRISCB übernommenen, sondern sämtliche vergleichbaren Belege der Vorlagen aufgeführt. Die fremdsprachlichen Bedeutungsangaben sind teilweise unwesentlich gekürzt, Belege für unfeste Adverbialverbindungen (z. B.: entzwei gehen, nahe gehen) sowie Belege mit falschem Stichwort bis auf wenige Fälle ausgeschieden worden. Die voran. gestellte eingeklammerte Ziffer gilt als laufende Nummer des Belegs innerhalb des Artikels.

Abkürzungen :

\begin{tabular}{|c|c|c|}
\hline $\mathbf{F}$ & $=$ & Frison \\
\hline $\mathrm{K}$ & $=$ & KRAMER \\
\hline $\mathbf{S}$ & $=$ & SteInBaOH. \\
\hline St & $=$ & STIELTER \\
\hline $\mathrm{H}$ & $=$ & FIEDTRIOH \\
\hline o. N. & $=$ & (Beleg) ohne (Herkunfts)nachweis \\
\hline KS usw. & $=$ & $\begin{array}{l}\text { Kramar/SteINBaCH } \\
\text { (Nin Sigel dieser Art besagt: Beide Vorlagen enthalten } \\
\text { eine gleichwertige Entsprechung; oder: Die eine Vorlage } \\
\text { lieferte den Beleg, die andere das Interpretamentum). }\end{array}$ \\
\hline
\end{tabular}

Artikel gehen:

Kramer (1700) $1,473 \mathrm{c}-478 \mathrm{~b}$.

STEINBAOH (1734) 1 , 538-540.

FrIsch (1741) 1, $330 \mathrm{a}-330 \mathrm{c}$.

Einen ersten Anhaltspunkt für die Beurteilung des Verhältnisses zur lexikalischen Uberlieferung bietet ein Vergleich des Artikelaufbaus im 'Teutsch-Lateinischen Wörter-Buch' und in den Wörterbüchern STIELERs, Krambrs und STrEnBAOHs, Während STImLimR die Belege unter dem Stichwort 'Gehen' ohne zu gruppieren aneinanderreiht, sind Kramer und STEINBaCH bemüht, den Artikel nach bestimmten semantischen oder grammatischen Gesichtspunkten zu gliedern, und zwar in unterschiedlicher Weise. Streng grammatisch durchdacht ist die Anordnung STHINBACHs; KrAMER sucht demgegenüber semantische und grammatische Gesichtspunkte zu verbinden. Vergleicht man die Gliederungsweise FriscHs mit den Aufbauplänen des Artikels in den Wörterbüchern Kramers und Stransachs, so sind Gemeinsamkeiten unverkennbar:

KrAMER

1. Gehen, im eig. Sinne

2. Gehen, im übertr. Sinne

3. Gehen, mit Infinitiv

4. 'Gehen lassen'

5. 'Ts geht'

6. Gehen 'im Schwange gehen'
Frisor

1. Gehen, im eig. Sinne

2. Gehen, im übertr. Sinne

3. 'Es geht'

4. Gehen, mit Präposition
SteiraaOH

1. Gehen, absolut

2. Gehen, mit Dativ

3. Gehen, mit Adverb

4. Gehen, reflexiv

5. Gehen, mit Verb

6. Gehen, mit Präposition 


\begin{tabular}{|c|c|c|}
\hline KRAMER $1700 / 02$ & STHINBACH 1734 & Frarsch 1741 \\
\hline $\begin{array}{l}\text { (18) einen guten Schritt gehen (cami- } \\
\text { nare, far' un buon passo) }\end{array}$ & & $\begin{array}{l}\text { (1) einen guten Schritt gehen (sagt } \\
\text { man von Pferden; veloci gradu } \\
\text { incedere) }\end{array}$ \\
\hline $\begin{array}{l}\text { (19) seines Wegs gehen (passare il suo } \\
\text { camino) }\end{array}$ & & $\begin{array}{l}\text { (2) seines Weegs gehen (viam suam } \\
\text { abire) }\end{array}$ \\
\hline $\begin{array}{l}\text { (20) eine Meil Wegs gehen (caminare, } \\
\text { fare un miglio) }\end{array}$ & & $\begin{array}{l}\text { (3) eine Meile gehen (conficere spa- } \\
\text { tium mille passuum) }\end{array}$ \\
\hline $\begin{array}{l}\text { (21) ein gut Stück Wegs gehen (far un } \\
\text { buon camino, un buon pezzo di } \\
\text { strada) }\end{array}$ & . & $\begin{array}{l}\text { (4) ein gutes Stück Weeges gehen } \\
\text { (magnam itineris partem con- } \\
\text { ficere) }\end{array}$ \\
\hline $\begin{array}{l}\text { (110) wo einer gehet und stehet, plagen } \\
\text { einen die Bettler (dovunque } \\
\text { l'huomo si trovi, i mendichi lo } \\
\text { importunano) }\end{array}$ & & $\begin{array}{l}\text { (5) wo er geht und steht (ubi ubi } \\
\text { est) }\end{array}$ \\
\hline $\begin{array}{l}\text { (111) er ... hat nichts, als wie er ... } \\
\text { gehet und stehet (egli } \ldots \text { non } \\
\text { hà niente al mondo, non hà hene } \\
\text { alcuno) }\end{array}$ & & $\begin{array}{l}\text { (6) er hat nichts als wie er geht und } \\
\text { steht (praeter quotidianam } \\
\text { vestem nil possidet; pauper est) }\end{array}$ \\
\hline $\begin{array}{l}\text { (11) sich müd, sich Blattern in die } \\
\text { Füsse gehen (stancarsi) }\end{array}$ & $\begin{array}{l}\text { (30) er hat sich müde gegangen (eum } \\
\text { deambulatio ad languorem dedit) }\end{array}$ & $\begin{array}{l}\text { (7) ich hab mich müde gegangen } \\
\text { (defessus sum deambulando) }\end{array}$ \\
\hline $\begin{array}{l}\text { (120) leise, still gehen (andare, cami- } \\
\text { nare piano, senza strepito) }\end{array}$ & $\begin{array}{l}\text { (28) leise gehen (suspenso gradu in- } \\
\text { cedere) }\end{array}$ & $\begin{array}{l}\text { (8) leise gehen (suspenso gradu in- } \\
\text { cedere) }\end{array}$ \\
\hline $\begin{array}{l}\text { (86) müssig gehen (andare, stare } \\
\text { otioso) }\end{array}$ & $\begin{array}{l}\text { (19) müssig gehen (otiari, vacare a } \\
\text { negotiis) }\end{array}$ & (9) müßig gehen (otiari) \\
\hline $\begin{array}{l}\text { (146/147) gehen lassen (lasciar' andare, } \\
\text { it. lasciar stare in pace) }\end{array}$ & $\begin{array}{l}\text { (33) einen gehen lassen (missum ali- } \\
\text { quem facere) }\end{array}$ & $\begin{array}{l}\text { (10) einen gehen lassen (mit frieden } \\
\text { lassen, missum facere aliquem) } \\
\text { (11) einen gehen lassen (nicht auf- } \\
\text { halten, dimittere) }\end{array}$ \\
\hline
\end{tabular}




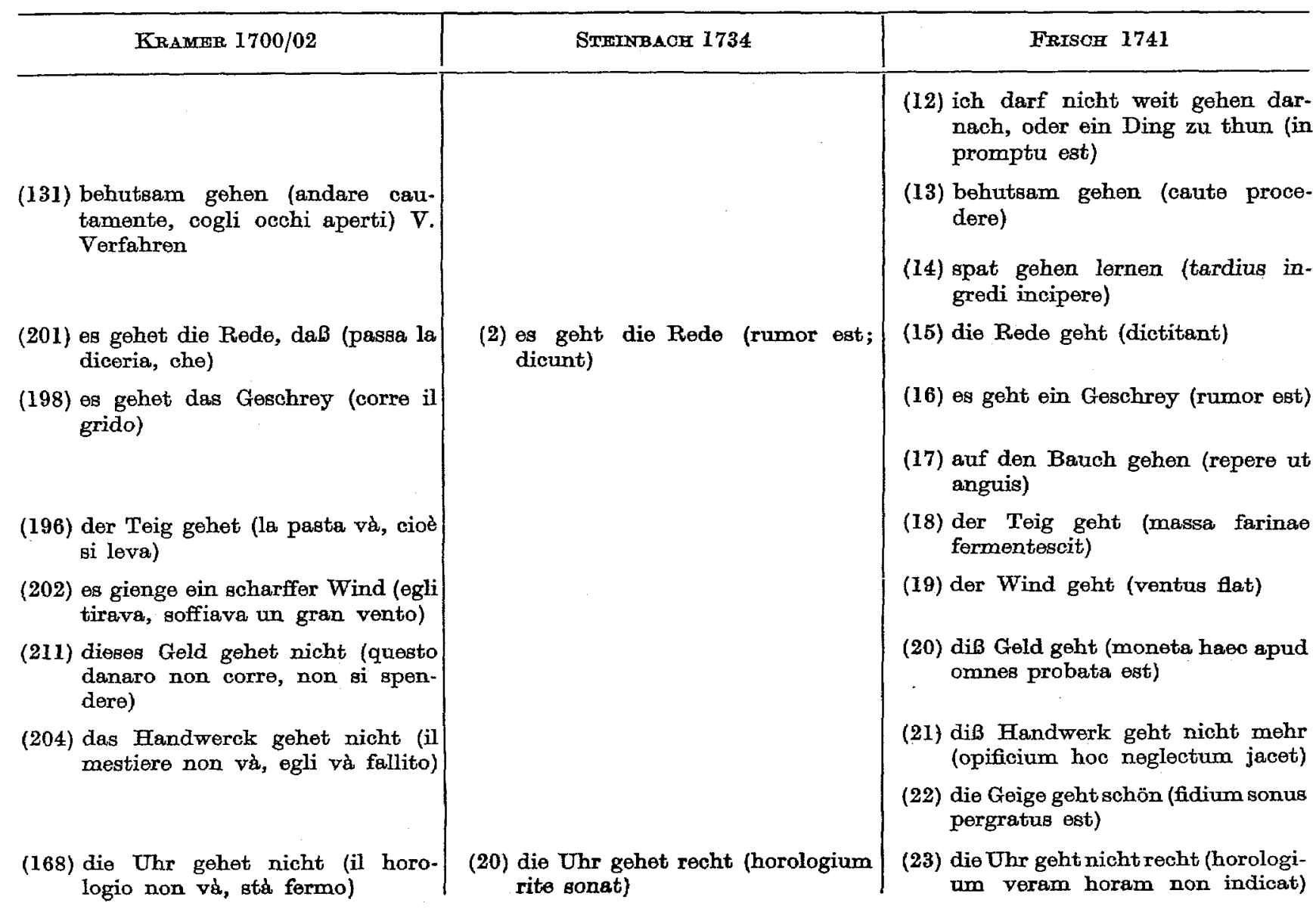




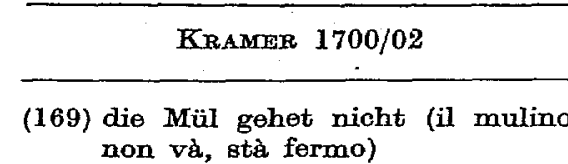

(172) wie gehets euch? (come và?)

(177) es gehet ihm nach Wunsch (tutto gli va alla seconda)

(186) es will nicht gehen (non vuol riuscire l'impresa)

(60) an Galgen gehen (andare alle forche)
(13) wie gehts deinem Bruder? (quomodo valet frater tuus?)

(14) es gehet ihm nach Willen (ex sententia ei evenit)

(6) es gehe, wie Gott will (fiat ut vult divina voluntas)

(18) es gehet langsam mit der Sache (frigescit opus)

(31) wie es pflegt zu gehen (ita ut fit)

(16) der Frau gehet es unrichtig (foemina abortum edit)

(34) gehet an den lichten Galgen (ite hine in malam crucem)

(36) die Noth gehet an den Mann (summum adest periculum)

(37) das Kleid geht bis an die Knie (vestis ad genua defluit)

(38) das Wasser ging ihn bis an den Hals (aqua collum ejus aequabat)
Frisch 1741

(24) die Mühl geht nicht (molae hujus rotae non moventur\}

(25) ein Stück Geschütz geht weit (tormentum bellicum globos suos longius projicit)

(26) wio gehts? (quid agitur? quomodo vales ?)

(27) es geht nach Wunsch (ex sententia)

(28) es mag gehen wie Gott will (quicquid feret divina voluntas)

(29) es will nicht gehen (hae non valt succedere; res caret successu)

(30) es geht langsam damit her (frigescit opus)

(3I) es pflegt so zu gehen (hic solet esse exitus)

(32) es ist dieser Frau unrichtig gegangen (abortum fecit)

(33) geh an den Galgen (abi in malam crucem)

(34) die Noth geht an den Mann (periculum adest)

(35) das Kleid geht an die Knie (vestis protenditur ad genua usque)

(36) das Wasser goht an den Hals (aqua collum aequat) 
(135) jemand an die Hand gehen (andare alla mano ad uno, cioè ajutarlo)

(61) auf der Grube gehen (andare sulla fossa, cioè esser decrepito)
(39) einen an die Hand gehen (adminiculari aliquem)

(40) an seine Geschäfte gehen (venire ad curanda negotia)

(35) es ging an ein großes Geschrey (oriebatur magnus clamor)

(41) er gehet auf der Grube (morti proximus est)

(42) die Menschen gehen nicht alle auf dem rechten Weege (non omnes homines ambulant in via recta)

(43) auf den rechten Grund gehen (inquirere fundamentum)

(44) auf der Post gehen (cursu publico uti)

(45) er läßt vieles darauf gehen (multum in hoc impendit)

(46) zwantzig Böhmen oder sechzehn Sächsische Groschen gehn auf einen Gulden (viginti grossi Silesiaci vel sedecim horum Saxonici valent florenum)

(49) sie gehen mit einander auf den Hieb (certant caedendo)
(37) einem an die Hand gehen (adminiculaxi aliquem)

(38) an seine Geschäffte gehen (abire ad curanda negotia)

(39) da gieng es an ein Geschrey (tum magnus ortus est clamor)

(40) es geht ans Leben (capitis res agitur)

(41) auf der Grube gehen (morti proximaum esse)

(42) auf dem Weege gehen (in via ambulare)

(43) auf den Grund gehen (inquirere fundamentum)

(44) auf der Post gehen (cursu publico uti)

(45) viel auf etwas gehen lassen (multum impendere alicui rei)

(46) wie viel solches Gelds geht auf einen Thaler? (quot horum nummorum valent uncialem)

(47) einem auf den Leib gehen (irruere in aliquem)

(48) auf den Hieb gehen (caedendo pugnare) 


\section{Krancer 1700/02}

(142) auf der Zeit gehen: sio gehot auf der Zeit (andare sul, cioè esser vicino al termine del parto)

(171) hierauf ist nicht zu gehen (sù questo non vi d̀ da far fondamento)

(227) diese Thür gehet auf die Gasвe (questa porta và, risponde in piazza)

(137) jemand aus den Augen gehen (levarsi d'innanzi ad uno)

(195) es gehet mir starck durch den Leib (egli và da lui come acqua, cioè egli hà il flusso di ventre)

(223) alle Verrichtungen gehen durch seine Hand (tutte le speditioni passano per le sue mani)

(30) durchs Feuer gehen (paseare il fuoco)
(52) auf den Zehen gehen (pedibus summis incedere)

(54) einem aus dem Weøge gehen (fugere aliquem)

(53) aus den Augen gehen (abire ex oculis)

(56) es gehet alles durch seine Hand (in manu ejus sunt omnia)
(49) auf den Zähen gehen (suspenso gradu ire)

(50) auf die Jagd gehen (venatum exire)

(51) auf der Zeit gehen, der GeburtsStunde nahe seyn (pariendi tempus attigisse; partui proximam esse)

(52) auf dieses ist nicht zu gehen, das ist - von keiner Wichtigkeit (hoc nullius momenti est)

(53) auf die Seitè gehen (secessum quaerere)

(54) diese Thür geht auf die Strasse (per hanc portam exitus est in plateam)

(55) aus dem Weege gehen (cedere, decedere de via)

(56) aus den Augen gehen (ex oculis abire; abscedere e conspectu)

(57) durch den Leib gehen wie Wasser (profluvio alvi laborare)

(58) es geht alles durch seine Hiand (omnia in ejus manu sunt)

(59) er geht einem durch ein Feur (obedientissimus est; per ignem alicui currit) 


KRAMER $1700 / 02$

(221) der Stich gienge ihm ins Hertz (il colpo gli trapasso il cuore)

(140) in das achtzigst Jahr gehen (haver' incominciato l'anno ottogesimo della sua età)

(136) in sich selbsten gehen (entrare in se stesso; raccogliersi)

(234) es gehen drey $\mathrm{MaB}$ in diese Flasche (capiscono, entrano tre boccali in questo fiasco)

(206) gehen im Schwange (andare, esser' in fiore, in voga)

(228) die Fenster gehen in Garten (le finestre rispondono nel giardino)

(231) der Fels gehet eine Meil Wegs ins Meer (lo scoglio vè, sporge una lega in mare)

(212) die Thür gehet in ihren Angeln (la porta si raggira attorno a i suoi cardini)
Frisch 1741

(60) der Stich gieng ihm durchs Herz (hic ictus cor ejus transfixit)

(57) er gehet in tiefen Gedancken (deliberabundus est)

(58) das Kind gehet schon ins vierte Jahr (infans quartum jam agit annum)

(60) er ist in sich gegangen (in se descendit)

(61) das Bier gehet nicht in den Krug (urceus non capit tantam quantitatem cerevisiae)

(62) es gehet im Schwange (viget, fervet)

(66) es gehet mit der Sache langam (opus frigescit)
(61) in Gedanken gehen (cogitabundum ambulare)

(62) ins vierdte Jahr gehen (annum agere quartum)

(63) in sich gehen (secum exquirere quid in re peccatum sit)

(64) so viel in das Geschirr geht (quantum vas capere potest)

(65) im Schwang gehen (vigere; florere; consuetudine invalescere; celebrari)

(66) dieses Fenster geht in den Garten (man kan daraus in den Garten sehen; prospectus horti per hanc fenestram est)

(67) diese Felsen gehen in das Meer (rupes extenduntur in mare)

(68) warum ${ }^{\mathrm{T}}$ gehst $d u$ in dein Verderben? (cur te is perditum?)

(69) die Thür geht in den Angeln (valvae januae vertuntur in cardinibus)

(70) es geht langsam mit dieser Sache daher (tardius res procedit) 


$\frac{\text { Kramere 1700/02 }}{(190) \text { der Rhein gehet mit Eis (il Reno }}$
mena ghiaccio)

(126) nach Brod gehen (andare al pane, cioè cercarlo, procacciarlo, proeurare di guadagnarlo)

(7) nach Haus gehen (andare a casa)

(236) es wird alles über dich gehen (andarà adosso a te, si roverscierà su'l tuo capo)
Frisor 1741

68) es ging alles im Hause nach des Vaters Kopfe (vigebat in illa domo patrius mos et disciplina)

(69) er gehet nach Leipzig (Lipsiam proficiscitur)

(71) kurtz, wollt ich nach der Ordnung gehn, so würd' ich Sprach' und Kraft verliehren (si ordine omnia persequi vellem) Günther

(70) nach Hause gehn (domum se recipere).

(72) es wird über mich gehen (in me haec cudetur faba)

(79) wenn sich grosse Herren raufen, gehts über der Unterthanen Haare (quidquid delirunt Reges, plectuntur Achivi)

(73) er geht über das Meer (trans mare iter facit)
(71) der Fluß geht mit Eiß (fluvius fractam glaciem vehit)

(72) es soll alles nach seinem Kopf bent) proficisci)

(74) nach der Ordnung gehen (ordine sequi)

(75) nach Brod gehon (betteln; mendicari) recipere)

(77) alle Wetter gehen über mich (omnes tempestates mihi subeundae sunt)

(78) wann die Herren fehlen geht es über die Unterthanen (delirant: reges, plectuntur Achivi)

(79) über Meer und über Land gehen (mari terraque proficisci)

(80) über Leipzig nach Nürnberg gehen (per Lipsiam tendere Noribergam) gehen (omnia suo nutu agi de-

(73) nach Leipzig gehen (Lipsiam

(76) nach Hause gehen (domum se 
(77) er läßt sein Gesinde nicht über alle

(78) er strebt nicht mit Gewalt nach

(80) es geht über den Beutel (requi-

(163) das Recht über jemand gehen lassen (prononciare la sentenza)

(121) unter die Loute gehen (andare, cioè lasciarsi vedere frà le genti)

(139) jemand unter Augen gehen (andare sotto gli occhi ad alcuno, ciò̉ affrontarlo, bravarlo)

(8) zu Bett gehen (andar' a letto)

(113) zu Grunde gehen (andar a fondo, perire, rouinarsi) Kisten und Kasten gehen (non admittit servos ad omnes capsas) Dingen, die über sein Vermögen gehn (non adspirat ad ea, quae vires ejus excedunt) Günther runtur eum sumtus)

(81) einen über Kisten und Kasten gehen lassen (omnem rem familiarem fidei alicujus committere)

(82) das [geht] über mein Vermögen (hoc vires meas excedit)

(83) das geht über meinen Beutel (hoc meis sumtibus fit; haec mei fundi calamitas est)

(84) das Recht über einen gehen lassen (legum rigori aliquem subjicere)

(85) über das Gobirge gehen (transire, transgredi montes)

(86) der Graben geht um die Stadt (fossa cingit urbem)

(82) er gehet ihm ums Maul (praesentem eum laudat)

(87) einen ums Maul gehen (schmeicheln; adulari alicui)

(88) unter die Leute gehen (in publicum prodire)

(89) unter Augen gehen (in conspectum alicujus venire)

(90) vor die Obrigkeit gehen (adire magistratum, judicem)

(91) zu Bette gehen (lectum petere)

(85) zu Grunde gehen (perire)
(92) zu Grunde gehen (verderben; pessum ire, perire, profundum petere)

(93) zu Grunde gehen (sich auf dem Boden setzen; desidere, subsidere) 


\begin{tabular}{|c|c|c|}
\hline KraMER $1700 / 02$ & STExNBACH 1734 & Frisch 1741 \\
\hline $\begin{array}{l}\text { (213) zu 'Trümmern gehen (andare in } \\
\text { fregole) } \\
\text { (72) zu Tische gehen (andar' a tavola) }\end{array}$ & $\begin{array}{l}\text { (84) wenn die Welt zu Trümmern } \\
\text { geht (si fractus illabatur orbis) } \\
\text { (86) zu Tische gehen (accumbere, } \\
\text { assidere) }\end{array}$ & $\begin{array}{l}\text { (94) zu Trümmern gehen (rumpi; } \\
\text { frangi; perire) } \\
\text { (95) zu Tische gehen (accumbere) } \\
\text { (96) zu Tische gehen bey einem } \\
\text { (mensa cibisque alicujus uti) }\end{array}$ \\
\hline $\begin{array}{l}\text { (33) zur Leiche gehen (accompagnare } \\
\text { i funerali, andar' all' essequie) }\end{array}$ & $\begin{array}{l}\text { (87) zur Leiche gehen (convenire ex- } \\
\text { sequias cohonestandas) } \\
\text { (90) zu Rathe gehen (deliberare, com- } \\
\text { municare consilium cum aliquo) }\end{array}$ & $\begin{array}{l}\text { (97) zur Leiche gehen (ad funus } \\
\text { prodire) } \\
\text { (98) mit zu Grabe gehen (mortuum } \\
\text { ad tumulum comitari) } \\
\text { (99) zu Rathe gehen (deliberare) }\end{array}$ \\
\hline $\begin{array}{l}\text { (76) zu Stul gehen (andare, uscire di } \\
\text { corpo) }\end{array}$ & $\begin{array}{l}\text { (91) zu Stuhle gehen (dejicere alvum) } \\
\text { (89) es geht mit ihm zur Neige (in } \\
\text { ultimo vitae vel fortunae peri- } \\
\text { culo constitutus est) }\end{array}$ & $\begin{array}{l}\text { (100) zu Stuhle gehen (alvum dejicere } \\
\text { in sella foricaria) } \\
\text { (101) es geht mit ihm zur Neige (ad } \\
\text { restim res rediit, bona sua fere } \\
\text { consumta sunt) }\end{array}$ \\
\hline $\begin{array}{l}\text { (216) einem etwas zu Hertzen gehen } \\
\text { (toccare, passare il cuore) } \\
\text { (54) zu Felde gehen (andar' in cam- } \\
\text { pagna) }\end{array}$ & $\begin{array}{l}\text { (92) es ging ihm zu Hertzen (afficiebat } \\
\text { eum) } \\
\text { (93) zu. Felde gehen (castra sequi) }\end{array}$ & $\begin{array}{l}\text { (102) es geht ihm zu Herzen (afficit } \\
\text { eum; cordi illi est) } \\
\text { (103) zu Felde gehen (expeditionem } \\
\text { facere) }\end{array}$ \\
\hline $\begin{array}{l}\text { (70) zu Gast geben (andar' a pransare } \\
\text { con uno; andar da convittato) } \\
\text { (1) (zu Fuß) gehen (andare a piedi, } \\
\text { caminare) }\end{array}$ & $\begin{array}{l}\text { (99) zu Gaste gehen (epulari apud } \\
\text { aliquem) } \\
\text { (98) zu Fusse gehen (peragrare passi- } \\
\text { bus) }\end{array}$ & $\begin{array}{l}\text { (104) zu Gaste gehen (ad convivium } \\
\text { ire) } \\
\text { (105) zu Fusse gehen (pedibus iter } \\
\text { facere) } \\
\text { (106) zu Schiff gehen (navem con- } \\
\text { scendere) }\end{array}$ \\
\hline
\end{tabular}


Der Befund deutet darauf hin, daß Frisch die Darstellung des Wortes 'Gehen' in den Wörterbüchern STringaors und Kramors einsah, bevor er mit der Augarbeitung des eigenen Artikels begann. Zwar ist weder die grammatische Anordnung STEINBAOHS noch die semantisch-grammatische Gliederungsweise KraMERs als Ganzes übernommen worden. Beiden Aufbauplänen hat FrisCH jedoch wesentliche Einzelgesichtspunkto entlehnt. Kennzeichnend ist die Verknüpfung semantischer und grammatisch-syntaktischer Kategorien nach dem Vorgange KRAMERs. Allerdings strebt FrisoH einer Lösung zu, die es ihm ermöglicht, eine Hauptgruppe Steinbaors (6. Gehen, mit Präposition) in die eigene Darstellung einzuarbeiten. Belege für die feiner untergliederten syntaktischen Gruppen SterNBAOHS (1.-5.) und Krambrs (3.4.) hat Frisor nioht selbständig behandelt.

FrIsor benutzt die Quellen, denen er Gesichtspunkte der Stoffanordnung entlehnt, auch für die Gewinnung des Belegstoffes selbst. Zahlreiche Textübereinstimmungen lassen zunächst erkennen, daß die Wörterbücher KRAMERs und STEINBACHs auf die Darstellung der Wortbedeutung und des Wortgebrauchs in erheblichem Umfange eingewirkt haben. Obwohl die Lehnbestandteile teilweise lexikalisches Gemeingut bilden, ermöglicht es der Vergleich der Belegabfolge, des Belegtextes und des Interpretamentums, die jeweils benutzte Vorlage in der Mehrzahl der Fälle zu bestimmen. Folgendes Zahlenverhältnis ergibt sich für den Artikel gehen:

Gesamtzahl der Belege

Davon:

Belege lexikalischer Herkunft

Kramer

STEINBAOH

30

andere Quellen

Belege ohne Herkunftenschweis
49

13

Aufgeschlüsselt auf die vier Gliederungsgruppen des Artikels vermitteln die Zahlenwerte Einblick in die Gesichtspunkte der Quellenbenutzung:

K S Nebenqu. o. N. Gesamt

I. Bedeutungsgruppen

1. Gehen, im eig. Sinne

2. Gehen, übertragen

\begin{tabular}{rrrrr}
7 & 3 & 2 & 2 & 14 \\
6 & - & 2 & 3 & 11 \\
\hline 13 & 3 & 4 & 5 & 25
\end{tabular}

II. Gramm.-synt. Gruppen

3. 'Es geht'

4. Gehen, mit Präposition

\begin{tabular}{rrrrr}
2 & 4 & 1 & - & 7 \\
15 & 42 & 8 & 9 & 74 \\
\hline 17 & 48 & 9 & 9 & 81 \\
13 & 3 & 4 & 5 & 25 \\
\hline 30 & 49 & 13 & 14 & 106
\end{tabular}


Die Zahlenverhältnisse erweisen, daß für die Darstellung der Wortbedeutung das Wörterbuch Kramears, für die Darstellung der syntaktisch-grammatischen Gebrauchsweisen das Wörterbuch STHINBACHs ïberwiegend benutzt worden ist. Aus Kramers Artikel gehen, der den Abschnitten 1 und 2 zugrunde liegt, hebt Frrsort einzelne Belege oder geschlossene Beleggruppen heraus (F I-4 = K 18-21; F $5-6=K 110-111 ; F 15-16,18-21=$ Auswahl aus $\mathrm{K} 196-211 ; \mathrm{F} 23-24=$ K 168-169) und ergänzt den gewonnenen Bestand durch Angaben STreINBaOHs sowie durch Zusätze anderweitiger Herkunft. Andererseits dient für die Gruppe 4 des grammatisoh-syntaktischen Artikelteils STEINBACrrs alphabetische Aufstellung als Grundlage. Frssor schließt sich hier der alphabetischen Anordnung an, geht SteInBaors Angaben Präposition für Präposition durch und ergänzt von Fall zu Fall, indem er auch die nichtalphabetische Belegreihe Kramers planmäßig

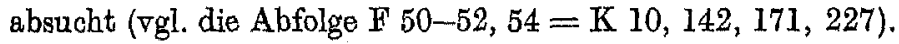

Zwei für das Werden des Artikels wesentliche Arbeitsgänge sind damit erfaßt. Erkennbar wurde, daß FrIsci als Hauptquellen die umfangreichen zeitgenössischen Wörterbuchwerke MatThIas Kramers (1700/02) und Christoper ERNST STEINBACHs (1734) zugrunde legt und sie bei der Ausarbeitung des Artikels planmäßig nutzt. Da jedoch trotz sorgfältiger Prüfung der Vorlagen für eine Reihe von Belegen Entlehnung aus diesen Quellen nicht oder nicht sicher nachweisbar ist, muß $B$ weiterhin geklärt werden, ob FrIsor auch andere lexikalische Quellen als die Wörterbücher KramERs und StminBaOHs befragt hat. Zwischen mittelbarer und unmittelbarer Entlehnung ist allerdings streng zu scheiden. So hat zwar SxrELimRs 'Stammbaum' (1691) mittelbar eingewirkt auf jene Teile des von Frrsor übernommenen Beleggutes, die Kramer und SteinbaCH ihrerseits dem Wörterbuch Strocmirs entlebnen (z. B. F 27, 29, 41, 94), ist aber als unmittelbare Quelle nicht oder nur vereinzelt (F 106, Interpretamentum F 97) von FRISCr hinzugezogen worden. Anders verhält es sioh mit dem 'Promtvarivm Latinitatis' (1729) von BENJAMTN HEDERIOH ${ }^{1}$, eine der lexikalischen Hauptvorlagen für das Wörterbuch Steinbacris. Abweichend von dem sonst geübten Verfahren hat Strmivbacr das Promtvarivm HEDERICHs für den Artikel 'Gehen' nioht oder nur in sehr begrenztem Umfange benutzt. Die Zahl der HEDERICH-Belege im 'Teutsch-Lateinischen Wörter-Buch', von denen nicht feststeht, ob sie der Erstquelle entstammen oder aber durch STEINBACH vermittelt worden sind (z. B. F 56), ist daher gering. Unabhängig von STEINBaCH verzeichnet FrISOH jedooh mehrere auf HEDERICHS Promtvarivm zurückzuführende Belege (F 11, 33, 86; auch 106?) und Interpretamenta (F 16, $19,49,55,88,102)$. Zwei dieser Fälle seien hier näher gekennzeichnet:

1. Zu dem Beleg F 86: Der Graben geht um die Stadt (fossa cingit urbem) fehlt in den Wörterbüchern Kramers und Streisaachs jede Entsprechung. H\#UmRTCH bietet jedoch: Der Graben gehet um die Stadt (fossa cingit vrbem).

1 B. Hi்nerior, Promtvarivm Latinitatis ... oder Vollatändigstes Teutsch-Lateinisches Lexicon. Leipzig 1729. 
2. Der Beleg F 55: Aus dem Weege gehen (cedere, decedere de via) hat zwar eine Vorlage in S 54: Einem aus dem Weege gehen (fugere aliquem), aber das Interpretamentum scheint dem Artikel HzDwRIOHs entnommen zu sein. HEDERTOF bucht: aus dem Wege gehen (decedere de via).

Textbestandteile dieser Art lassen erkennen, daß mit der Einwirkung des 'Prom. tvarivms' HEDERToHs als lexikalischer Nebenquelle zu rechnen ist.

Zu der Lösung der Aufgaben, die die Bearbeitung des Artikels gehen stellte, konnten die hinzugezogenen lexikalischen Hilfsmittel in ungleichem Maße und in unterschiedlicher Hinsicht beitragen. Die stoffreichen, unmittelbar auf das Deutsche gerichteten Werlie Kramers und StemxBaCHs waren geeignet, als Hauptquellen für die Beschaffung eines Grundbestandes deutschen Beleggutes zu dienen. In dieser Hinsicht vermochten die knapper angelegte Darstellung STrELERs und das vom Lateinischen ausgehende Schulwörterbuch HzDERIOHs nur ergänzende Dienste zu leisten. Anders lagen die Verhältnisse hinsichtlich der Formulierung der lateinischen Bedeutungsangaben, die den verzeichneten Wörtern und. Wendungen beizugeben waren. Hier kam STEINBaOrs gleichfalls deutsch-lateinischer Darstellung eine Vorzugsstellung zu; sie lieferte im allgemeinen Beleg und Interpretamentum in einem. Dagegen mußte Frisor Belege aus dem deutsch-italienischen Wörterbuch KraMERs sowie änderungsbedürftige STrEnBACH-Belege selbst ins Lateinische übertragen. Als Hilfsmittel ist in diesem Zusammenhang das 'Promtvarivm' HeDERICHs stärker hinzugezogen worden. Aus der Benutzung dieser Quelle für Interpretationszwecke erklärt sich, daß an einem Beleg Frusors nicht selten zwei Vorlagen beteiligt sind. Dies gilt im Artikel gehen beispielsweise für die Belege F 19, 49, 55, deren deutsche Textteile nach Ausweis des Gleichlaufs der Abfolge den Wörterbüchern KRAMERs und STEINBACHs entstammen, während das lateinische Interpretamentum nachträglich aus dem 'Promtvarivm' HEDERICHs entnommen wurde. HEDERIOHs Wörterbuch war zur Wahrnehmung dieser Aufgabe vermöge eines reichen phraseologischen Bestandes klassisch-lateinischer Prägung in besonderem Maße geeignet.

Die Einsichten in die Arbeitsweise FrrsoHs, die am Artikel gehen gewonnen wurden, bedürfen der Sicherung durch Untersuchungen auf breiterer Stoffgrundlage. $\mathrm{Zu}$ diesem $\mathrm{Zweck}$ seien im folgenden elf Artikel größeren Umfangs hinzugezogen, deren Entstehung gemäß dem am Beispiel gehen angewandten Verfahren soweit möglich von Stufe zu Stufe verfolgt wurde. Rücksichten auf den Umfang des Stoffes gestatten hier nur die Darstellung der Ergebnisse. Da das Schwergewicht bei Herkunftsnachweisen liegt, sei darauf hingewiesen, daß die Eigenart der lexikographisohen Arbeitsweise FrIsoHs die Vorlagenbestimmung in hohem Grade erschwert. Unsicherheiten ergeben sich auch daraus, daß die deutsche Wörterbuchschreibung um 1700 hinsichtlich der Erfassung des gemeinsprachlichen Grundwortschatzes einen verhältnismäßig hohen Leistungsstand erreicht hat. Der 
in den Wörterbtichern verzeichnete Sprachstoff ist nunmehr zu wesentlichen Teilen lexikalisches Gemeingut, das sich nur in begrenztem Umfange auf eine bestimmte Vorlage zurückführen läßt. Nicht in jedem Falle ist daher der Anteil der einzelnen Vorlagen scharf voneinander abzusetzen. Das im folgenden angewandte statistische Verfahren sollte jedoch wenigstens die Grundzüge der Ent. lehnungsverhältnisse und der lexikographischen Arbeitsweise FrarsoHs erkennbar werden lassen.

\section{BRINGEN}

Gesamtbestand 85 Belege, davon 66 Entlehnungen $=78 \%$. Hauptquellen Kramer und StrensBach, Nebenquelle HEDERIOH, STTELER nicht benutzt.

$\begin{array}{ccccccccc}K & \mathrm{~S} & \mathrm{KS} & \mathrm{KH} & \mathrm{SH} & \mathrm{KSH} & \mathrm{St} & 0 . \mathrm{N} . & \text { Gesamat } \\ 31 & 24 & 7 & 2 & 1 & 1 & - & 19 & 85\end{array}$

\section{GEHEN}

Gesamtbestand 106 Belege, davon 92 Entlehnungen $=87 \%$. Hauptquellen StrenvBAOH und KraMmR, Nebenquelle HEDERTOH, Benutzung StrELERs nicht sicher nachweisbar.

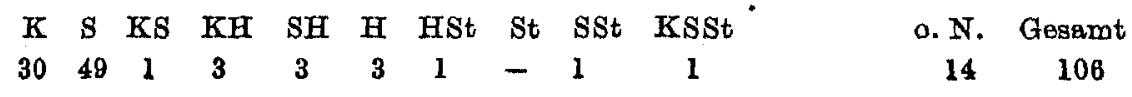

\section{KOMMEN}

Gessmatbestand 72 Belege, davon 55 Entlehnungen $=76 \%$. Hauptquellen STernBACH und KraNcEr, Benutzung HEDERICHs nicht gicher nachweisbar, StxeLER nicht benutzt.
K S KS SH St
o. N. Gesamt
$\begin{array}{lllll}20 & 26 & 8 & 1 & -\end{array}$
$17 \quad 72$

\section{NEHMEN}

Gesamtbestand 53 Belege, davon 41 Entlehnungen $=77 \%$. Quellen SteinsadH und Kramer; Hedirtor und Strexim nicht benutzt.
$\begin{array}{lllll}\mathrm{K} & \mathrm{S} & \mathrm{KS} & \mathrm{H} & \mathrm{St}\end{array}$
o. N. Gesamt
$\begin{array}{llllll}13 & 19 & 9 & - & -\end{array}$
$12 \quad 53$

\section{SCHLAGEN}

Gesamtbestand 86 Belege, devon 74 Entlehnungen $=86 \%$. Hauptquelle Kramer, Nebenquellen Steinbach, Hepierich und Streler.
K $\quad \mathrm{S}$ KS KH KSH H KSt
$\begin{array}{lllllll}46 & 5 & 6 & 6 & 5 & 2 & 4\end{array}$
o. N. Gesamt
$12 \quad 86$

\section{STOSSEN}

Gesamtbestand 24 Belege; 24 Entlehnungen $=100 \%$. Quellen HFDERIOH und Kramera; Sternaagh und Streler nicht benutzt.
$\mathrm{K} \mathrm{H}$
$8 \quad 16$

o. N. Gesamt 
$\mathrm{AOGE}$

Gesamtbestand 75 Belege, davon 52 Entlehnungen $=69 \%$. Hauptquellen Sreis. badi, Kramer, Hederich, Nebenquelle Stimier.

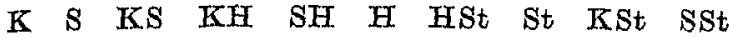
o. N. Gesamt
$\begin{array}{lllllllllll}10 & 14 & 1 & 2 & 9 & 9 & 2 & 1 & 1 & 3\end{array}$
$23 \quad 75$

FEUER

Gesamtbestand 59 Belege, davon 48 Entlehnungen $=81 \%$. Quellen Kramer, SterN. BAOH, HEDERICH; Stxeler nicht benutzt.
K $\quad \mathrm{S} \quad \mathrm{KS} \quad \mathrm{KH} \quad \mathrm{SH} \quad \mathrm{KSH} \quad \mathrm{H} \quad \mathrm{St}$
o. N. Gesamt
$\begin{array}{llllllll}16 & 9 & 3 & 5 & 9 & 1 & 5 & -\end{array}$
$11 \quad 69$

GNADE

Gesamtbestand 30 Belege, davon 28 Entlehnungen $=93 \%$. Quellen Kramer, SteiN . baok, Hedertoh; Streler nicht benutzt.
K $\quad \mathrm{S} \quad \mathrm{KS} \quad \mathrm{KH} \quad \mathrm{SH} \quad \mathrm{KSH} \quad \mathrm{H} \quad \mathrm{St}$
o. N. Gesamt
$\begin{array}{llllllll}6 & 4 & 2 & 3 & 8 & 2 & 3 & -\end{array}$
230

\section{HERZ}

Gesamtbestand 68 Belege, davon 46 Entlehnungen $=68 \%$. Hauptquellen Kramer,

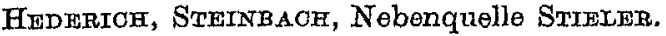
K $\mathrm{S}$ KS $\mathrm{SH}$ KSH $\mathrm{H}$ St
o. N. Gesamt
$\begin{array}{lllllll}22 & 3 & 2 & 6 & 3 & 8 & 2\end{array}$
$22 \quad 68$

\section{LEBEN}

Gesamtbestand 34 Belege, davon 30 Entlehnungen $=88 \%$. Hauptquellen STErNBACH, KRAMrir, HeDfortch, Nebenquelle Stietier.
$\mathrm{K} \quad \mathrm{S} \quad \mathrm{KS} \quad \mathrm{SH} \quad \mathrm{H} \quad \mathrm{St}$
o. N. Gesamt
$\begin{array}{llllll}8 & 12 & 1 & 1 & 7 & 1\end{array}$
434

\section{RECHT}

Gesamtbestand 42 Belege, davon 27 Entlehnungen $=64 \%$. Hauptquelle Kramer, Nebenquelle StIELER; STminbach und Hederion nicht benutzt.
K $\quad \mathbf{S} \quad \mathrm{H} \quad \mathrm{St}$ KSt
o. N. Gesamt
$22-1 \quad 1 \quad 4$
15
42

\begin{tabular}{lccc}
\multicolumn{4}{c}{ ZUSAMMENFASSUNG } \\
& $\begin{array}{c}\text { Zahl } \\
\text { der Belege }\end{array}$ & $\begin{array}{c}\text { Zahl } \\
\text { der Entlehnungen }\end{array}$ & $=\%$ \\
bringen & 85 & 66 & $78 \%$ \\
gehen & 106 & 92 & $87 \%$ \\
kommen & 72 & 55 & $76 \%$ \\
nehmen & $\mathbf{5 3}$ & 41 & $77 \%$ \\
schlagen & 86 & 74 & $86 \%$ \\
stoBen & 24 & 24 & $100 \%$ \\
\cline { 2 - 4 } & 426 & 352 & $83 \%$
\end{tabular}

8 Powitz, Frischs Wörterbuch 
Zahl der Belege

Auge

Fever

Gnade

Herz

Leben

Recht

Verben

Subst.
Zahl

der Entlehnungen $\quad=\%$

52

48

28

46

30

27

231

362

231

583
$69 \%$

$81 \%$

$93 \%$.

$68 \%$

$88 \%$ $64 \%$

\begin{tabular}{lll}
426 & 352 & $83 \%$ \\
308 & 231 & $75 \%$ \\
\hline 734 & 583 & $79 \%$
\end{tabular}

\begin{tabular}{lrrrrrrrrrrrrr} 
& K & S & KS & KH & SH & KSH & H & HSt & St & KSt & SSt & KSSt \\
bringen & 31 & 24 & 7 & 2 & 1 & 1 & - & - & - & - & - & - \\
gehen & 30 & 49 & 1 & 3 & 3 & - & 3 & 1 & - & - & 1 & 1 \\
kommen & 20 & 26 & 8 & - & 1 & - & - & - & - & - & - & - \\
nehmen & 13 & 19 & 9 & - & - & - & - & - & - & - & - & - \\
schlagen & 46 & 5 & 6 & 6 & - & 5 & 2 & - & - & 4 & - & - \\
stoßen & 8 & - & - & - & - & - & 16 & - & - & - & - & - \\
\cline { 2 - 12 } & 148 & 123 & 31 & 11 & 5 & 6 & 21 & 1 & - & 4 & 1 & 1
\end{tabular}

\begin{tabular}{|c|c|c|c|c|c|c|c|c|c|c|c|c|}
\hline Auge & 10 & 14 & 1 & 2 & 9 & - & 9 & 2 & 1 & 1 & 3 & - \\
\hline Feuer & 16 & 9 & 3 & 5 & 9 & 1 & 5 & - & - & - & - & 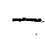 \\
\hline Gnade & 6 & 4 & 2 & 3 & 8 & 2 & 3 & - & - & - & - & - \\
\hline Herz & 22 & 3 & 2 & - & 6 & 3 & 8 & - & 2 & - & - & - \\
\hline Leben & 8 & 12 & 1 & - & 1 & - & 7 & - & 1 & - & - & - \\
\hline \multirow[t]{2}{*}{ Recht } & 22 & - & - & - & - & - & - & - & 1 & 4 & - & - \\
\hline & 84 & 42 & 9 & 10 & 33 & 6 & 32 & 2 & 5 & 5 & 3 & - \\
\hline
\end{tabular}

$\begin{array}{llllllllllllll}\text { Verben } & 148 & 123 & 31 & 11 & 5 & 6 & 21 & 1 & - & 4 & 1 & 1\end{array}$

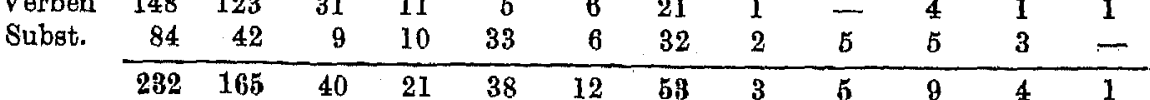

Die vorliegende statistische Utbersicht ermöglicht Rüclsschlüsse auf die lexikographische Arbeitsweise F'RIsOHs. Es ergibt sich, daß für die Gewinnung des Wortgutes, das dem Usuale generale angehört, lexikalisobe Vorlagen in erheblichem Unfange benutzt worden sind. Der Anteil der Entlehnungen am Gesamtbelegbestand der einzelnen Artikel bewegt sich in den untersuchten Fällen zwischen 64 und $100 \%$; er liegt im Durchschnitt bei 70-80\%. Ein fest ausgebildetes Verfahren der Quellenverwertung ist namentlich in den Artikeln der ersten Hälfte des Alphabets erkennbar. So benutzt Friscr für die Reihe bringen-nehmen und Auge-Leben die Werke StrindacHs (118 +42 Entlehnungen) und Kramers $(94+62$ Entlehnungen) ziemlich gleichmäßig als Hauptrorlagen. Die Wörterbücher HEDERIOHs $(3+32$ Entlehnungen) und STrELERs $(0+4$ Entlebnungen), 
werden für die Reihe der verbalen Artikel nur vereinzelt oder gar nicht als Quellen herangezogen, erhalten jedoch eine gewisse Bedeutung als Nebenquellon der Sub. stantivartikel, da sie für deren semantische Gliederung Anhaltspunkte liefern konnten.

Das in diesen Abschnitten angestrebte Verfahren der Quellenverwertung erscheint in den späteren Buchstaben des Alphabets jedoch gestört. Bereits die ' Darstellung des Substantivs Recht zeigt ein abweichendes Bild. Zwar wahrt das Wörterbuch KRAMERs seine Stellung als Hauptquelle, aber die bis dahin als Nebenquellen herangezogenen Werke STEINBACHs und HrDERICHS werden nicht benutzt. Auch in den Artikeln schlagen und stoßen tritt das Wörterbuch STEINBACHs als Quelle zurück, und selbst Kramers Darstellung bildet die Hauptrorlage Frisors nur für den Artikel schlagen (46 Entlehnungen); dem Artikel stoßen liegt das Promtvarivm HeDerICHs (16 Entlehnungen gegenüber 8 Entlehnungen aus dem Wörterbuch Kramers) als Hauptquelle zugrunde. Nur in diesem Falle ließen sich auch sämtliche 24 Belege des Artikels eindeutig auf zwei lexikalische Vorlagen zurückführen. Berücksichtigt man ferner, da $B$ sich die Artikel der Buchstaben $\mathrm{T}-\mathrm{Z}$ wegen ibres geringen Belegbestandes für eine vergleichende Untersuchung als nicht geeignet erwiesen, so liegt die Annahme nahe, daß Friscri gezwungen war, den Schlußteil des Werkes übereilt fertigzustellen und auf eine gleichmäßige Verarbeitung der Quellen zu verzichten.

Frisch griff bewußt zu den lexikalischen Hilfsmitteln, die sich ihm anboten. Im Vorbericht des 'Teutsch-Lateinischen Wörter-Buchs' bekennt er, es habe ihm

'die $A \& \xi$ zropılia, oder Liebe zum Lexicon-Schreiben so vieler gelehrten Leute, ja so gar die $A \varepsilon \xi$ vro $\mu \alpha v i a$ oder damit vorgehende Raserey dieses Seculi allerdings viel geholfen'.

Als Bearbeiter des Usuale generale mußte es für ihn bedeutsam sein, daß in den Jahrzehnten um 1700 die ersten umfassenden Darstellungen des Wortschatzes der deutsohen Gemeinsprache erschienen: die Wörterbücher STrELERs (1691), Kramers (1700-02) und Steminbachs (1725; 1734). Zwei dieser Werke, das 'Teutsch-Italiänisohe Dictionarium' Kramers und das 'Deutsche Wörter-Buch' STEINBaCHs (in der zweiten Auflage 1734), hat Frisch als Hauptvorlagen benutzt. Der Leistungsfortschritt, den die deutsche Wörterbuchschreibung in der Zeit um 1700 erzielt hatte, konnte sich nunmehr auswirken. Allerdings wählte Frrsor zwei Vorlagen von unterschiedlich ausgeprägter Eigenart. War das Wörterbuch STERNBACHs (28\% der Entlehnungen) vorzugsweise der altfremdsprachlichen Überlieferung und der Literatursprache des 17. Jahrhunderts verhaftet, so gewann er mit dem zweibändigen 'Teutsch-Italiänischen Dictionarium' Kramers, dem $40 \%$ der Entlehnungen entstammen, eine methodisch moderne, inhaltlich außerordentlich reichhaltige Wortschatzdarstellung als Quelle. Sie vermittelte ihm den Anschluß an den neufremdsprachlichen Utberlieferungszweig und eröffnete ihm Ein-

${ }^{1}$ FrIsch, TLWb. (1741) Vorbericht $)\left(4^{\mathrm{b}}\right.$. 
blick in die semantische und phraseologische Mannigfaltiglreit des Wortschatzes der Zeit um 1700, auch in Sprachschichten, die in der Literatursprache des 18. Jahrhunderts erst später zur Geltung kamen. Das stofflich wenig ergiebige Wör. terbuch STImLERs war als Vorlage nicht geeignet. Demgegenüber bot das deutschlateinische Fremdsprachenwörterbuch HEDERIOHs (9\% der Entlehnungen) ein $\theta$ Reihe von Angaben, die das aus den Wörterbüchern Kramers und Stannaachs gewonnene Bild des Sprachgebrauchs ergänzen konnten. Den Wert dieses Werkes für die Erfassung der Sprache des beginnenden 18. Jahrhunderts hatte STEINBAOH, der es selbst ansgiebig benutzte, 1734 in der Vorrede seines Wörterbuches nachdrücklich hervorgehoben:

'Wer ein Glossarium von der heute zu Tage üblichen Sprache verlangt, der lkan Herr Hedrichs Promptuarium latinitatis probatae et exercitae statt anderer mit großem Nutzen gebrauchen.'

4

Das Leistungsvermögen der Wörterbücher, die Frisorr als Vorlagen benutzte, war im einzelnen unterschiedlich, sowohl hinsichtlich des Umfangs als auch hinsiohtlich der Zusammensetzung des Beleggutes. Um eine Grundlage für die Beurteilung wenigstens des. Umfanges der von FriscH verwerteten Quellen zu ge. winnen, erweist es sich als zweckmäßig, die Zahl der Belege festzustellen, die in den zwölf untersuchten Artikeln von den Bearbeitern der einzelnen Wörterbücher verzeichnet werden.

\begin{tabular}{|c|c|c|c|c|c|c|c|}
\hline \multirow{7}{*}{$\begin{array}{l}\text { bringen } \\
\text { gehen } \\
\text { kommen } \\
\text { nehmen } \\
\text { gchlagen } \\
\text { stoßen }\end{array}$} & \multirow{3}{*}{$\begin{array}{r}K \\
156\end{array}$} & \multirow[b]{2}{*}{109} & \multirow{2}{*}{$\begin{array}{r}\text { H } \\
49\end{array}$} & \multirow{2}{*}{$\begin{array}{l}\text { St } \\
\text { (15) }\end{array}$} & \multirow{2}{*}{$\begin{array}{r}F \\
85\end{array}$} & $\begin{array}{l}\text { Belege d. } \\
\text { Vorlagen }\end{array}$ & \multirow{2}{*}{$\begin{array}{c}\text { Entlehnungen } \\
\text { Frischs } \\
66\end{array}$} \\
\hline & & & & & & 329 & \\
\hline & & 103 & 78 & (22) & 106 & 447 & 92 \\
\hline & 302 & 128 & 121 & (8) & 72 & 559 & 55 \\
\hline & 90 & 71 & 43 & (14) & 63 & 218 & 41 \\
\hline & 270 & 72 & 44 & (21) & 86 & 407 & 74 \\
\hline & 73 & 43 & 44 & 8 & 24 & 168 & 24 \\
\hline Auge & 165 & 65 & 109 & 21 & 75 & 360 & 62 \\
\hline Feuer & 70 & 58 & 51 & (24) & 59 & 203 & 48 \\
\hline Gnad $\theta$ & 82 & 31 & 25 & (15) & 30 & 153 & 28 \\
\hline Herz & 109 & 48 & 59 & (20) & 68 & 238 & 46 \\
\hline Leben & 103 & 61 & 147 & (22) & 34 & 333 & 30 \\
\hline Recht & 180 & (17) & 95 & 33 & 42 & 325 & 27 \\
\hline & 1844 & 806 & 865 & 223 & 734 & 3738 & 583 \\
\hline
\end{tabular}

Die Zusammenstellung läßt zunächst erkennen, daß die Wörterbücher HWDTRTCHs, STEnsachs und das Usuale generale FrisoHs annähernd die gleiche Zahl von Belegen enthalten; die Angaben Kramers belaufen sich demgegenüber

1 Streisbach, Vollst. Deutsches Wörter-Buch 1 (1734) ** 5a. Hederich geinerseits benutzt unter anderem Friscers 'Nouveau dictionnaire' (1712) als Quelle. 
auf mehr als das Doppelte, die Angaben Strow ters etwa auf ein Viertel dieses 'Normalbestandes'. Es ergibt sich weiterhin, daß FRIsch in den von ihm benutzten Vorlagen in jedem Falle eine hohe Zahl von Belegen (insgesamt 3738) vorfand, von denen nur ein geringer Teil (insgesamt $583=16 \%$ ) in das "TeutschLateinische Wörter-Buch' einging. Selbst wenn man berücksichtigt, daß es sich bei den Angaben der Vorlagen im erheblichen Umfange um lexikalisches Gemeingut handelt und daß Frisor nicht in jedem Falle sämtliche Quellen herangezogen hat, kommt in dem sich ergebenden Zahlenverhältnis ein starkes Streben nach Zusammenfassung zum Ausdruck. Die Darstellung des Wortgebrauchs ist bis in die einzelnen Artikelteile hinein von diesem Streben bestimmt. Als Beispiel dafür diene eine Gruppe von Belegen des Artikels gehen, und zwar die Gruppe 'Gehen, als Prädikat eines nichtpersönlichen Subjekts, außerhalb der Verbindung mit Präpositionen' (z. B.: die Uhr geht). Diese Belege bilden bereits in der Vorlage Frischs (Kramer 168-170; 187-211) eine nahezu geschlossene Gruppe, die von FRISOH (F 15-16;18-21; 23-24) zusammenhängend ausgewertet worden ist

\section{KRAMER}

1. (168) die Uhr gehet nicht (170) sie gehet zu geschwind (169) die Mül gehet nicht

2. (192) er striche ihm, daß das Blut darnach gienge

(193) es gienge Eiter und Blut

3. (202) es gienge ein scharffor Wind

4. (198) es gehet das Geschrey (199) es gehet die Sage (200) es gehet der Ruf (201) es gehet die Rede

5. (203) der Handel gehet nicht (204) das Handwerck gehet nicht (205) das Einkommen gehet nioht (187) die Sachen gehen wol (188) die Sachen gehen übel (189) die Sachen müssen recht gehen

6. (208) diese Mode gehet jetzund

(210) diese Gewonheit gehet nicht mehr

(211) dieses Geld gehet nicht

7. (196) der Teig gehet

(1.97) der Teig will nicht gehen
FrIBOH

(23) die Uhr geht nicht recht

(24) die Mühl geht nicht

(19) der Wind geht

(16) es geht ein Geschrey

(15) die Rede geht

(21) diB Handwerk geht nicht mehr

(20) diB Geld geht

(18) der Teig geht

Deutlich zeichnet sich das Bestreben ab, auswählend Wesentliches zu erfassen. Von den 21 Belegen der Vorlage werden nur 8 Belege übernommen, und diese 8 Belege verteilen sich nahezu gleichmäßig auf die verschiedenen Sinneinheiten der Gruppe. Auch in dem grammatisch-syntaktischen Teil des Artikels, dem Srmis- 
BAOHs alphabetisch $\Theta$ Reihe zugrunde liegt; während KRAMER-Belege nur ergänzend herangezogen worden sind, verfährt Frisor auf diese Weise, z. B.:

$\begin{array}{lrl} & \text { Kramer } & \text { Friscr } \\ \text { gehen, transitiv } & 9 \text { Belege } & 4 \text { Belege übernommen } \\ \text { 'gehen und stehen' } & 4 \text { Belege } & 2 \text { Belege übernommen } \\ \text { gehen auf } & 22 \text { Belege } & 4 \text { Belege übernommen } \\ \text { gehen durch } & 11 \text { Belege } & 2 \text { Belege übernommen }\end{array}$

Diese Abweichungen im Umfang des Belegbestandes deuten auf Unterschiede der lexikographischen Zielsetzung. Während KraMER versucht, durch Häufung und Variation der Satzangaben die Fülle und die Vielfalt des Wortgebrauchs anschaulich zu machen, beschränkt FriscH sich auf die Darstellung der Haupterscheinungen. Er umreißt die Geltung des Wortes lediglich in den Grundzügen, und zwar durch Ansatz von Einzelbelegen, die stellvertretend stehen für Verwendungsweisen gleicher oder ähnlicher Konstruktion, gleichen oder ähnlichen Sinnes. Das oben angeführte Beispiel zeigt, wie Frisor die reichhaltigen Angaben seiner Vorlage auf wenige paradigmatische Grundformen zurückzuführen sucht. Gleichsam nur ein Skelett des ursprünglichen Belegbestandes bleibt erhalten; die für KRAMER kennzeichnenden Mehrfachbelege (mehrere Belege für eine Sinn. einheit) werden ausgeschieden oder zahlenmäßig stark verringert.

Entsprechende Gesichtspunkte leiten FrisoH bei der Verwertung der Angaben Stenvbachs. Sinnverwandte (1) oder nur in der Satzform variierende Verwendungsbeispiele (2) sowie die Mehrzahl der Belege literarischer Herkunft (3) werden übergangen:

\section{STEINBACH}

(1) (58) das Kind gehet sohon ins vierte Jahr

(59) es gehet schon ins achte Jahr, $\mathrm{da} B$ das geschehen ist

(40) zwantzig Böhmen oder sechzehn Sächsische Groschen gehn auf einen Gulden

(47) wie viel Pfund gehen auf einen Zentner?

(2) (53) aus den Augen gehen

(55) er ist mir aus den Augen gegangen

(93) zu Felde gehen

(94) der Könich geht zu Felde

(95) er will nicht zu Felde gehen

(98) wieder einen zu Felde gehen

(3) 15 Belege literarischer Herkunft (10 GÜNThER; 3 HofManNSWALDAU; 1 OPITz; 1 GrypHIUS)

\section{Frisor}

(62) ins vierdte Jahr gehen

(46) wie viel solches Gelds geht auf einen Thaler?

(56) aus den Augen gehen

(103) zu Felde gehen

Zwei Belege (GÜNTHER) in vereinfachter Form übernommen (F 74; $82=\$ 71 ; 78)$; nicht übernommen: S $8 ; 9 ; 10 ; 11 ; 25 ; 63 ; 64 ; 65 ; 66$; 67 ; $101 ; 102 ; 103$. 
In dem Bemühen, sprachliche Vielfalt durch eine Auswahl wesentlicher Erscheinungen im Grundriß festzulegen, äußert sich ein Abstralktionsstreben, das kennzeichnend ist für die lexikographische Arbeitsweise FrIschs. Es entspricht zugleich dem Leistungsstand der deutschen Lexikographie in der ersten Hälfte des 18. Jahrhunderts. Nach der Zeit angestrengten Sammelns in den Jahrzehnten um 1700 erschließen sich Möglichkeiten des Fortschritts nun weniger in der Vermehrung als vielmehr in der kritischen Sichtung des Beleggutes. Während noch KramER und STEINBACH vor der Aufgabestehen, den Umfang des Wortbestandes auf verschiedenen Wegen zu erweitern (insbesondere durch Auszüge aus lexikalischen und literarischen Quellen sowie mit Hilfe des Umkehrverfahrens), sieht FrIsCH sich veranlaBt, die Fülle des überlieferten Sprachstoffes aufzuordnen und einzuschränken.

In diesem Zusammenhang sind Änderungen aufschlußreich, die der Zitierform der übernommenen Belege gelten. KRAMER und STwINBACH bieten in zahlreichen Fällen Angaben, die Stücke unmittelbarer sprachlicher Wirklichkeit zu sein scheinen : inhaltlich situationsgebundene Sätze und Satzteile in finiter oder duroh nicht notwendige Glieder erweiterter Fügung. Belege dieser Art werden im Wörterbuch Friscris in kennzeichnender Weise umgeformt.

(1) Die finite Satzform wird aufgelöst, die Situationsbeziehung getilgt:

Kramer/StTINBACH

S (71) Kurtz, wollt ich nach der

die Menschen gehen nicht alle auf dem rechten Weege Ordnung gehn, so würd' ich

Sprach' und Kraft verliehren.

Günther

ähnlich:

$\mathrm{K}(110)$ wo einer gehet und stehet, plagen einen die Bettler
Frisch

(42) auf dem Weege gehen

(74) nach der Ordnung gehen

(5) wo er geht und steht

(2) Attributive und adverbielle Bestimmungen sowie Objekterweiterungen werden erspart:

$\mathrm{K}$ (202) es gienge ein scharffer Wind

$S$ (57) er gehet in tiefen Gedencken.

$\mathrm{K}$ (231) der Fels gehet eine Meil

Wegề ins Meer

S (68) es ging alles im Hause nach des Vaters Kopfe

is (38) das Wasser ging ihn bis an den Hals
(19) der Wind geht

(61) in Gedanken gehen

(67) diese Felsen gehen in das Meer

(72) es soll alles nach seinem Kopf gehen

(36) das Wasser geht an den Hals

(3) Bestimmte Bezeichnungen werden durch allgemeine ersetzt:

S (46) zwantzig Böhmen oder sechzehn Sächsische Groschen gehn auf einen, Gulden

S (77) er läßt sein Gesinde nicht

über alle Kisten und Kasten
(46) wie viel solches Gelds geht auf einen Thaler?

(81) einen über Kisten und Kasten gehen lassen 
Auch darin, daß FRIsor den Angaben über den Wortgebrauch ungern eine beispielartige Fassung gibt, sich vielmehr bemüht, finite Fügungen aufzulösen und entbehrliche Satzglieder zu tilgen, äußert sich ein Zug zur Abstraktion. Gegenstand der lexikographischen Darstellung ist die einzelne Wortverbindung nicht in einer der vielfältig möglichen Verwirklichungen des Sprachvollzugs: sie soll vielmehr im Wörterbuch in einer allgemeingültigen lexikalischen Nominalform erscheinen, herausgelöst aus allen Fällen des tatsächlichen Gebrauchs, als Bestandteil des Wortschatzgefüges in Ruhelage. Sprachliche Wirklichkeit geht nicht unmittelbar in das Wörterbuch ein; sondern die Vielfalt ihrer Erscheinungen wird auf das gleichbleibend Wesentliche zurückgeführt.

Es ergibt sioh somit: Frrsce entnimmt das Beleggut des Usuale generalo nicht den Werken der sprachlich vorbildlichen deutschen Schriftsteller, wie dies seit dem Auftreten HARSDöRFFERS und SchomreLs gefordert worden war, sondern in weitem Umfange den ihm vorliegenden lexilkalischen Hilfsmitteln. Er verharrt methodisch in der Tradition des 'Abschreibeverfahrens' und bleibt damit dem Ziel eines eigenständigen, auf Quellengrundlage ruhenden Deutschen Wörterbuches fern. Aber nicht mehr fremdsprachliche Wortschatzdarstellungen dienen in erster Hinsicht dem 'Teutsch-Lateinischen Wörter-Buch' als Vorlagen. Als Hauptquellen benutzt Frisor vielmehr die in den Jahrzehnten um 1700 entstandenen Wörterbücher der neuhochdeutschen Gemeinsprache. Die nachteiligen Folgen des Anschlusses an die fremdsprachliche Wortschatzüberlieferung vermögen sich daher nicht mehr unmittelbar auszuwirken. Zwar waren die deutschen Wörterbücher der Zeit um 1700 ihrerseits noch teilweise an diese Utberlieferung gebunden; sie waren jedoch auch vorangeschritten auf dem Wege zu einer wirklichkeitsgetreuen Darstellung des Wortschatzes, und zwar insbesondere dadurch, daß ihre Bearbeiter die Angaben über Wortbedeutung und Wortgebrauch erheblich vermehrten. Angesichts des verhältnismäßig hohen Leiştungsvermögens dieser Werke wäre es nicht sinnvoll gewesen, sie gänzlich ungenutzt zu lassen. Frisor hat ihnen denn auch einen Grundbestand lexikalischer Angaben ontnommen. Zugleich erweiterte auch er in gewissem Umfange den Erfassungsbereich und fügte dem überlieferten Beleggut aus eigener Sprachkenntnis Belege hinzu. Er setzte damit die Bestrebungen fort, den deutschen Wortbestand unabhängig von der Utbersetzungsvorlage eines fremdsprachlichen Vokabulars zu erfassen. Jedoch nicht die absolute Vermehrung der Angaben, sondern ein die wesentlichen Züge betonendes Bild des Sprachgebrauchs ist FrIsoHs Ziel. Er versucht daher einerseits, Lücken in der lexikalischen Bezeugung zu schließen, andererseits aber den überkommenen Bestand zu sichten: Ungültiges und Unwesentliches auszuscheiden. Angesichts dessen, daß die frühen lexikalischen Darstellungen des deutschen Wortschatzes ein nach Umfang und Zusammensetzung zufälliges Bild des Sprachgebrauchs entworfen hatten, bedeutet diese ergänzende und ausscheidende Revision der überlieferten Angaben einen bedeutsamen Fortschritt. Ihr Frgebnis ist die gestrafft-vollständige, ausgewogene 
Darstellung des Wortgebrauchs im Usuale generale des 'Teutsch-Lateinischen Wörter-Buchs'. Mit der planvollen kritischen Überprüfung der Vorlagen ist ein wichtiger Schritt auf dem Wege zur inneren Ablösung von der lexikalischen Utberlieferung getan.

\section{Die Quellen für die Erfassung des nicht gemeinsprachlichen Wortgutes}

War es möglich, die lexikalischen Vorlagen des Usuale generale zu ermitteln durch die Utberprüfung des Belegbestandes an Hand der Quellen selbst, so werden für den Herkunftsnachweis des nicht gemeinsprachlichen und des zu erklärenden Zwecken herangezogenen Wort- und Namengutes die Quellenangaben FrIscrs im Textteil und im Register des Wörterbuches zugrunde gelegt werden. Um die Zusammensetzung und den Umfang des Quellenbestandes zuverlässig zu bestimmen, wäre es allerdings wünschenswert gewesen, den Belegstoff unabhängig von den Hinweisen des Wörterbuchbearbeiters auf seine Ursprünge zurüokzuführen. Denn es fragt sich selbstverständlich, ob jedes benutzte Werk namhaft gemacht und ob es an jeder Stelle genannt ist, d. h. ob wir auf Grund der Stellenzitate im. Textteil des Wörterbuches den Quellenbestand in seinem Gesamtumfang und die Intensität der Benutzung jeder einzelnen Quelle zu erfassen vermögen. Eine kritische Uberprüfung des Belegstoffes an Hand der Quellen war angesichts der Masse und der Vielgestaltigkeit des hier in Frage kommenden Schrifttums jedoch von vornherein ausgeschlossen. Wenn dennoch versucht werden kann, ein Bild der tatsächlichen Quellengrundlage Friscrs zu entwerfen, so deshalb, weil das 'Teutsch-Lateinische Wörter-Buch' sich in die Reihe der gelehrten Wortschatzdarstellungen des 18. Jahrhunderts einfügt. Der Grundsatz, Belege mit Herkunftsnachweisen zu versehen, entstammt der Tradition der Wortforschung. Er ist dem gemeinsprachlichen Wörterbuch fremd: STrRLER, KRAMrR und STEnnBach führen benutzte Hilfsmittel in der Regel nur dort an, wo sio ihnen gelehrt-erklärende Angaben entnehmen (Belege literarischer Herkunft versieht lediglich StiminBach mit Hinweisen auf die Fundstelle). Dieser älteren Gewohnheit folgend hat auch Frisch das Wortgut des Usuale generale grundsätzlich nicht durch Quellenangaben bestimmt. Er verfolgt das Ziel, die Herkunft nicht jedes inhaltlichen Bestandteils des Wörterbuches, sondern nur jener Bestandteile nachzuweisen, die dem Usuale speciale, dem Archaeologum, Eponymologicum und Etymologicum angehören. ${ }^{1}$ In diesen Bereichen aber ist die Nennung der

1 Damit erhält die Quellenangabe im Wörterbuch FrIscrs eine über den Nachweischarakter hinausgehende unterscheidende Funtetion: sie trennt das nicht gemeinвprachliche Wortgut von dem des Usuale generale. 
Quellen Grundsatz. Nicht um vereinzelte, zufällige Angaben handelt es sich, und wenn Lücken bestehen sollten, so jedenfalls nur Lücken, die sich aus der nicht folgerichtigen Anwendung eines Prinzips ergeben. Im Untertitel des Wörterbuches heißt es ausdrücklich, das Wortgut werde verzeichnet 'Mit überall beygesetzter nöthigen Anführung der Stellen, wo dergleichen in den Büchern zu finden'. Bereits 1734 in dem Programm eines märkischen Mundartenwörterbuchs hatte FrISOH auf die Notwendigkeit von Quellenangaben hingewiesen:

'Sollten sie (die mundartlichen Ausdriicke) aber gedruckt zu finden seyn, muss man dezusetzen, wo es geschehen, als : Siehe Brandenburgische Schäfer-Ordnung oder Fischer-Ordnung von Anno - - cap. - - \$. - und dergleichen . . . Wann sie aber in alten oder neuen Briefschafften oder Schrifften, sonderlich in AmtsProtocollen, Inventarien, Contracten oder Bestellungen etc. gefunden werden, könte nur das Jahr dazugesetzt werden und der Ort.' 1

Das im folgenden vorgelegte Quellenverzeichnis umfaßt die Titel sämtlicher im Textteil und im Register des 'Teutsch-Lateinischen Wörter-Buchs' genannten Quellen. Seine Aufgabe ist es:

1. die von Frisor benutzten Quellen bibliographisch zu bestimmen;

2. Gesamtumfang und Zusammensetzung der Quellengrundlage erkennbar zu machen und damit Aufschluß zu geben über den sprachlichen Inhalt des Wörterbuches und über die philologischen Hilfsmittel, deren sich FrIsor bei der sprachwissenschaftlichen Verarbeitung des Belegstoffes bediente;

3. zusätzliche Angaben bereitzustellen für die Beurteilung der Entstehungsgeschichte des Wörterbuches und der lexikographischen Arbeitsweise seines Verfassers;

4. unter allgemeinerem Gesichtspunkt Einblick zu gewähren in die philologische Werkstatt eines germanistischen Sprachforschers des 18. Jahrhunderts und in die Wirkungsgeschichte des sprachwissenschaftlichen Schrifttums aus der Zeit vor der Begründung der germanischen Philologie.

Bei der Anlage des Quellenverzeichnisses kam es zunächst darauf an, dem Benutzer des 'Teutsch-Lateinischen Wörter-Buchs' einen Schlüssel in die Hand zu geben, der ihm die Auflösung der vielfach schwer verständlichen Quellensiglen und die bibliographische Feststellung der Einzelquelle ermöglichen konnte. Eine alphabetisch geordnete Liste der Verfassernamen und Werktitel, wie sie für Nachschlagezwecke wünschenswert schien, hätte jedoch die innere Zusammensetzung der Quellengrundlage Frischs nicht erkennbar gemacht. Um dieses Ziel zu erreichen, erwies es sich vielmehr als notwendig, von der alphabetischen Abfolge abzusehen und die Quellen nach Gattungen (Sachgruppen) geordnet aufzuführen.

1 Frisor, Der erste Auszug (1734) 3-4. 
Auf diese Weise traten geschlossene Quellengruppen und die durch sie dem Wörterbuch vermittelten Sprachschichten hervor. Die folgende Ubersicht ver. anschaulicht in gedrängter Form die ;Zusammensetzung der Quellengrundlage FrRISCHS:
1-272 A. Sprachwissenschaftliche Hilfsmittel
1-5
1. Sprachvergleichende Werke
6-162
$6-7$
$8-57$
$58-146$
$147-160$
$161-162$
168-192
$163-164$
$165-182$
$183-189$
$190-192$
198-272
$193-217$
$218-234$
$235-261$
$262-263$
$264-270$
271-272
2. Hilfsmittel für die Erfassung des Wortschatzes nichtgermanischer Sprachen
a) Arabisch. Hebräisch. Türkisch
b) Griechisch
c) Lateinisch
d) Romanische Sprachen (und Keltisch)
e) Slawische Sprachen
3. Hilfsmittel für die Erfassung des Wortschatzes der germanischen Sprachen (außer Deutsch)
a) Gotisch
b) Nordisch
c) Angelsächsisch
d) Niederländisch
4. Hilfsmittel für die Erfassung des deutschen Wortschatzes
a) Altdeutsche Texte
b) Altdeutsche Textausgaben und Textsammlungen, Glossare und wortgeschichtliche Untersuchungen
c) Frühneuhochdeutsche Wörterbücher
d) Mundartenwörterbücher
e) Grammatiken, Sprachlehrbücher
f) Selbstzitate FrISCHs

278-1182

278-282

283-364

$365-619$

$365-388$

$389-435$

389-392

$393-406$

$407-411$

$412-424$

$425-4.35$

1. Dichtung

2. Religion/Theologie logische Traktate

3. Geschichte
B. Literarische Quellen und nicht-sprachwissenschaftliche Hilfsmittel

Deutsche Bibelübersetzungen - Lutherbibel - Lutherwerke - Theo.

A. Welt- und Kirchengeschichte

B. Geschichte einzelner Völker (Deutsche Geschichte unter C)
a) (Griechen und Römer)
b) Orientvölker
c) Osteuropäische Völker
d) Skandinavische Völker
e) Friesen. Niederländer. Angelsachsen. Schotten
f) Franken 


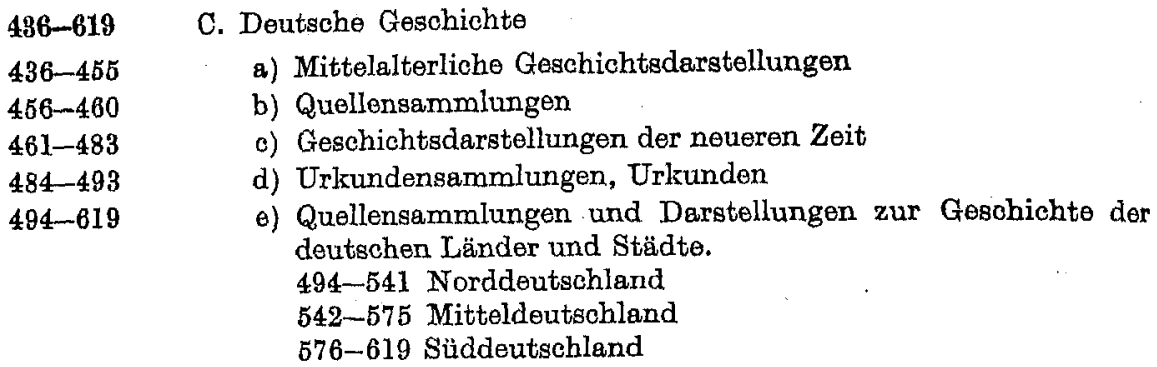

620-1028

4. Recht

$620-807$

A. Rechtsdarstellungen (Juristisohes Schrifttum)

808-1023

B. Rechtsquellen

$808-842$

$843-1004$

a) Kirchenrecht. Reiohsrecht

b) Rechtsordnungen örtlich begrenzter Geltung (Norddeutsch. land - Mitteldeutschland - Süddeutsehland)

$1005-1023$

c) Germanische Stammesrechte. Rechtsbücher des Mittelalters

1024-1182

5. Technik. Fach-, Natur-, Länderkunde

Das Verzeichnis umfaßt die Titel von mehreren hundert Werken, die im einzelnen in sehr unterschiedlicher Weise benutzt worden sind. Unternimmt man es, die Hauptquellen von den Quellen zweiten und dritten Ranges sowie von den nur vereinzelt herangezogenen Schriften zu scheiden, so ergibt sich: das Quellengut besteht etwa zur Hälfte aus Werken, die nur ein einziges Mal angeführt werden; ein weiteres. Viertel ist vereinzelt hinzugezogen worden; der Restbestand (etwa 250 Titel) entfällt auf die Hauptquellen. Dieser Befund ermöglicht eine Reihe von Rückschlüssen auf die lexikographische Arbeitsweise FrIscrs. Die im Text des Wörterbuchs fortlaufend zitierten Hauptquellen müssen in jahrzehntelanger Arbeit planmäßig für alle Buchstaben des Alphabets exzerpiert worden sein. Wie die Exzerption vor sich ging, schildert Frisor selbst in einer bereits angeführten Außerung vom Jahre 1727. ${ }^{\perp}$ Er berichtet hier, er habe eine Reihe von Deichordnungen gesammelt, auf fachsprachliche Ausdrücke bin durchgelesen und das inm wichtig Erscheinende herausgeschrieben; auf gleiche Weise wolle or mit Quellen für das Wortgut anderer Berufsgebiete (Bergbau, Jagd, Fischerei) verfahren. Wir beobachten hier den Philologen FrIsch bei der Wörterbucharbeit und erfassen den Gesichtspunkt, der ihn bei der Auswahl der Belege leitet: or ist auf der Suche nach dunklem, erklärungsbedürftigem Wortgut der Fachsprachen, der Mundarten und des geschichtlichen Wortschatzes. Gleichzeitig forscht er nach Spracherscheinungen, die zur Erklärung dessen dienen können, was für das Sprachbewußtsein des frühen 18. Jahrhunderts nicht oder nicht mehr voll verständlich ist. Während auf diese Weise Belegstoff frei zusammenströmte, gab die

1 Vgl. S. 59. 
lexikographische Aufbereitung des bereits gewonnenen Bestandes Anlaß zu plan. mäßigem Absuchen des Quellenschrifttums und der einschlägigen Hilfsmittel (in diesem Arbeitsgang werden die vereinzelt oder einmalig verwerteten Quellen hinzugezogen worden sein). Einzelne Wortgeschichten scheinen FrIscH besonders stark gefesselt zu haben; für sie sammelte er Belege in größerer Zahl und für sie zog er mit erhöhter Umsicht die Vorarbeiten der älteren Forschung heran. Dieso Artikel sind teilweise im Vorabdruck erschienen; sie bilden die Kerne, aus denen das Wörterbuch zusammenwuchs. ${ }^{1}$ Selbst eine Reihe von Quellen und Hilfsmitteln, die erst im Laufe der zwanziger und dreißiger Jahre veröffentlicht wurde, ist noch benutzt worden. Zahlreiche dieser Werke gehören zu den Hauptquellen des Wörterbuchs; ihr hoher Anteil am Belegbestand zeugt davon, daß FRISOH bis unmittelbar vor Abschluß des lexikographischen Sohaffens weitersammelte. ${ }^{2}$

Zusammenfassend sei festgestellt: Während die Belege des Usuale generale überwiegend lexikalischen Vorlagen entstammen, gewinnt FrIscH geschichtliches, fachsprachliches und landschaftliches Wortgut in weitem Umfange durch die Exzerption literarischer Quellen. Die FrschlieBung des. Ausdrucksbestandes dieser sprachlichen Bereiche bildet für ihn zweifellos ein vorrangiges Anliegen. Sie ermöglicht es ihm zum einen, den Wortschatz der Gegenwartssprache, dessen nicht gemeinsprachliche Bestandteile (Landschaftssprache, Berufssprache, Namengut) bis dahin in den neuhochdeutschen Wörterbüchern weniger beachtet worden waren, in umfassender Weise darzustellen. Zum anderen läßt die Einbeziehung des geschichtlichen Wortgutes erstmals ein neuhochdeutsches Wörterbuch auf historischer Grundlage entstehen. Eine Fülle aufschluBreichen Sprachstoffes ist auf gedrängtem Raum sowohl im geschichtliohen als auch im gegenwartssprachlichen Teil des Wörterbuches zusammengetragen worden. Dabei ruht der Nachdruck unverkennbar auf dem Wortgut aus dem Bereich der Realien. Denn der Anteil der Dichtung und der Werke religiös-theologischen Inhalts am Quellenbestand des Wörterbuches ist verhältnismäBig gering; ungleich stärker ist der Umfang des historischen, rechtlichen, natur- und fachkundlichen Quellenschrifttums. In der außerordentlich intensiven Nutzung dieser Werke offenbart sich eine

1 Hierher gehören beispielsweise sprachgeschichtlich aufschlußreiche Wörter wie Aar, Abenteuer, Adel, Aue, reuten, Waid, Zeidel (vgl. brennen, Land); Rechtswörter (Allmend, Allod, Bann, Bete, Ding, Fehm, Fron, TruchseB, Ungeld, Vare, Zehend, Ziese); Namen (Beghart, Wenden, Zigeuner); Formwörter und Wortbildungamittel (Ab, -sal, -thum, Ur-, vor, zu).

2 Auf die wichtigsten dieser Quellen sei hier verwiesen: 1. Sprachwissenschaftliche Hilfsmittel und Quellenwerke: Quellenverzeichnis $\mathrm{Nr}$. 193, 195, 197-199, $204,206-208,210,227-232,259,260$. 2. Quellensammlungen und Darstellungen geschichtlichen Inhalts: Quellenverzeichnis $\mathrm{Nr} .456,459,460,484,485,499,505-507$, $544,550,552,554,565,569,578,602,603,613-615$. 3. Rechtsquellen: Quellenverzeichnis Nr. $625,724,1016,1021.4$. Quellen fachkundlichen Inhalts: Quellenverzeichnis $\mathrm{Nr} .1030,1069,1082,1088,1089,1095$. 
Vorliebe für das Studium jener Bestandteile des Wortschatzes, die den Sprach. forscher in die geschichtliche, rechtsantiquarische, naturwissenschaftliche und gewerbliche Sachkunde hinüberführen. Für das Namengut der Geschichte, für Ausdrücke der Rechtssprache, für Tier-, Pflanzen-, Gesteins- und Krankheitsnamen, für geographische Eigennamen sowie für das stark sachgebundene Wortgut der Fachsprachen und der Mundarten ist das 'Teutsoh-Lateinische Wörter-Buch' daher eine überaus reichbaltige Quelle. Es tritt in die Nähe des Sach- und Namenwörterbuchs - durchaus im Sinne LEIBNIzens, in dem sich ähnlich wie in FrrscH mit sprachwissensohaftlichen Antrieben der Sachsinn des geschichtlich denkenden Gelehrten und des Naturforschers paarte.

Die enge Beziehung von Wort und Sache wirkt sich auch aus auf die Erklärung des im Wörterbuch verzeichneten Sprachstoffes: FRISOHs Interpretationen führen vielfach über das Sprachliche hinaus in das Gebiet der Sachkunde und der Sachgeschichte. Neben den zahlreichen historischen, juristischen und fachlichen Hilfsmitteln, die in diesem.Zusammenhange befragt worden sind, steht allerdings die weitaus bedeutsamere Gruppe der eprachwissenschaftlichen Quellen- und Nachschlagewerke: Ihre hohe Zahl und ihre ausgiebige Nutzung können als Gradmesser gelten für die Stärke des Bemühens um die etymologisch-wortgeschichtliche und semantische Erhellung des deutschen Wortschatzes. Frrsch zieht das Wortgut der Fremdsprachen, der historischen Sprachstufen des Deutschen, der deutschen Mundarten und der Fachsprachen heran; sein Bemühen, auf dieser breiten empirischen Grundlage den Ursprung, das geschichtliche Werden und den Geltungswert der einzelnen Bestandteile des deutschen Wortschatzes erkemnbar zu machen, läßt das 'Teutsch-Lateinische Wörter-Buoh' zu einem der ersten orklärenden Wörterbücher der deutschen Sprache werden.

Die Quellenuntersuchungen ermöglichen schließlich Rückschlüsse auf die geschichtlichen Voraussetzungen des Wörterbuchs. Es bestätigt sich, daß es die Tradition der gelehrten historisch-etymologischen Wortforschung war, die FrIsoHs lexikographischem Schaffen entscheidende Impulse erteilte. Denn die Darstellung lebt (nicht nur stofflich) noch weithin von der Substanz dessen, was Männer wie GotDast, Besold, WeHever und SoHmter während des 17. Jahrhunderts geschaffen hatten. Auch der Zusammenhang mit der mittellateinischen und romanistischen Forschung (Dv CANGE; Vossios; MéNAGE) und mit LeIBNIz wird von den Quellen her faBbar. Fine vergleichende quellengeschichtliche Untersuchung, die sich etwa auf ECKARTs Historia studii etymologici (1711), von STades Lutherglossar (1711), WaCHTERs Glossarium Germanicum (1737) und auf die Bibliotheca glottica in HEUManNs Opuscula (1747) stützen könnte, würde im einzelnen erkennen lassen, wie sehr sich in der Zusammensetzung des Quellenbestandes persönliche Eigenart ausprägt und in welchem Grade die von Frisor benutzten Quellen und Hilfsmittel bereits traditionsgemäß von den Vertretern der historisch-sprachvergleichenden Wortforschung herangezogen wurden. 


\section{Vorbemerkung zum Quellenverzeichnis}

Gliederung: Das Verzeichnis ist - ohne Strenge - in der Weise systematisch gegliedert, daß die insgesamt 1182 Titel sich auf zwei Hauptgruppen verteilen :

A. Sprachwissenschaftliche Hilfsmittel (Textausgaben, Wörterbücher, Einzeluntersuchungen auf dem Gebiet der Wortforschung) für die Erfassung und Deutung des im Wörterbuch enthaltenen Wortgutes.

B. Literarische Quellen und nicht sprachwissenschaftliche Hilfsmittel, zugeordnet den fünf Abteilungen: Dichtung - Religion/Thenlogie - Gesohichte Recht - Technik/Fach-, Natur-, Länderkunde.

Die Problematik des gewählten Gliederungsverfahrens kann hier nicht erörtert werden. Bemerkt sei, daß das Verzeichnis kein systematischer Katalog im bibliographisch-bibliothekarischen Sinne sein will; sprachwissenschaftliohen Gesichts. punkten und den Besonderheiten der einzelnen Quellengruppen mußte in erster Hinsicht Rechnung getragen werden. Auf Verweise von Quelle zu Quelle, von Gruppe zu Gruppe wurde grundsätzlich verzichtet. Für Nachschlagezwecke ist das alphabetische Namenregister am Ende dieser Arbeit zu benutzen.

Bibliographische Angaben: Sie beziehen sich auf die nachweislich von FrIsOH benutzte Ausgabe; ist diese nicht bestimmbar, auf ein in FrIsces Bibliothek vorhandenes Exemplar des Werkes (Angaben auf Grund des Auktionskataloges Bibliotheca Viri Clarissimi et Doctissimi Domini Joh. Leonh. Frischii. Berlin 1743. Ablürzung: B. [zitiert nach Seiten]); läßt sich auch ein Besitznachweis nicht erbringen, so wird entweder die Erstausgabe oder eine bestimmbare zeitgenössische Ausgabe genannt, Regelmäßig angegeben ist, ob FrisoH selbst im Quellenregister des 'Teutsch-Lateinischen Wörter-Buchs' Qqq $1^{\text {b }}-2^{\text {b }}$ das angeführte Werk als Quelle bezeichnet (Ablzürzung: QR.). Mittelbar benutzte Werke werden, soweit die nicht selbständige Benutzung erkennbar oder nachprüfbar war, unter der vermittelnden Quelle aufgeführt; für eine Reihe wichtiger Werke weicht das Verzeichnis jedoch von diesem Grundsatz ab. - Die für die bibliographische Ermittlung der Quellen benutzten Hilfsmittel sind im Literaturverzeichnis aufgeführt.

Belegstellen: Das Verzeichnis erfüllt nicht die Aufgabe einer Quellenkonkordanz. Nur die Belegstellen der einmalig oder vereinzelt benutzten Werke sind vollzählig angegeben, die Belegstellen der häufiger angeführten Quellen dagegen in einer Auswahl, für die folgende Gesichtspunkte leitend waren:

die Belege sollen die bibliographischen Angaben stützen;

sie sollen einen Überblick vermitteln über die verschiedenen Zitierweisen des Werkes;

sie sollen den Benutzungszweck des Werkes erkennbar werden lassen;

sie sollen Aufschluß geben über die Konstanz der Quellenbenutzung, d. h. sich über das Alphabet des Wörterbuches möglichst gleichmäßig verteilen. 
Die Zahl der Belegstellen ist kein Gradmesser für die Intensität der Quellen. benutzung. Die Hauptquellen des Wörterbuches sind kenntlich gemacht durch Fettdruck, die Quellen zweiter Ordnung durch Kursivdruck der laufenden Nummer. Alle übrigen Quellen (laufende Nummer in normalem Satz) hat Fruscr nur vereinzelt oder ein einziges Mal herangezogen. Für eine kleine Anzahl von Werken, die im Quellenregister des 'Teutsch-Lateinischen Wörter-Buchs' genannt sind, war im Textteil des Wörterbuches keine Belegstelle nachweisbar. - Die Bandziffer vor dem Komma bleibt fort, wenn mehrere Stellenangaben des gleichen Bandes unmittelbar oder nur durch einen kurzen $Z$ wischentext getrennt aufeinanderfolgen. 


\section{A. SPRACHWISSENSCHAFTLICHE HILFSMITTEL}

\section{A. 1. Sprachvergleichende Werke}

1. Konrad Gesner (1516-1565): Mithridates. De differentiis linguarum, tum veterum tum quae hodie apud diversas nationes in toto orbe terrarum in usu sunt, observationes. Zürich 1555. Frisch besaß (B. 22) und benutzte die von Caspar Waser kommentierte Neuausgabe Zürich 1610. QR. 1, 20c; $94 \mathrm{c} ; 2,438 \mathrm{~b}$.

2. Wolfgang Lazius (1514-1565): De aliquot gentium migrationibus, sedibus fixis, reliquiis linguarumque initiis et immutationibus ac dialeotis libri XII. Basel 1557. $1,220 \mathrm{~b} ; 315 \mathrm{~b} ; 326 \mathrm{a} ; 539 \mathrm{~b} ; 587 \mathrm{c} ; 2,364 \mathrm{~b}$.

3. Mericus Causabonus (1599-1671): Commentatio de quatuor linguis (Hebr., Graec., Lat., Sax.). London 1650. 1, 235c; 2, 125 b.

4. Gottfried Wilhelm Leibniz (1646-1716): Collectanea etymologica illustrationi linguarum, veteris Celtica $\theta$, Germanicae, Gallicae, aliarumque inservientia, cum praefatione Jo. Ge. Eccardi. Hannover 1717. B. 35. QR. 1, 91a; 235a; 311a. Keltisches Glossar 1, 2 a. Abraham van der Myle: Archaeologus Teuto 1, 6a; 29 b; $348 \mathrm{~b} ; 350 \mathrm{a}$.

5. Jakob Rhenferd (1654-1712): Opera philologica. Utrecht 1722. 1, 39b.

\section{A. 2. Hilfsmittel für die Erfassung des Wortschatzes nichtgermanischer Sprachen}
a) Arabisch. Hebräisch. Türkisch
b) Griechisch
c) Lateinisch
d) Romanische Sprachen (und Keltisch)
e) Slawische Sprachen

Die Gruppe vermittelt nur sehr bedingt ein Bild von dern Umfang des Fremdsprachenbereichs, den FRIsor mit dem Ziel der sprachvergleichenden Erhellung deutschen Wortgutes in jahrzehntelanger Arbeit durchforschte. Denn nicht sämtliche Sprachen, denen Belegstoff entnommen ist, sind im Verzeichnis durch Quellen vertreten. Die Schwerpunkte heben sich immerhin $a b$ : im Vordergrund stehen, vom Quellenbe. stand her gesehen, Filfsmittel aus dem Bereich der lateinischen (insbesondere mittellateinischen) und der romanischen Philologie, darunter drei Hauptquellen des 'Teutsch-Lateinischen Wörter-Buchs': Do CANGE Glossarium ad seriptores mediae et infimae Latinitatis; Vossrus De vitiis sermonis et glossematis Latino-barbaris; MŕnaGe Origines de la langue françoise. Diese Werke sind für FrIsoH in erheblichem Umfange auch Vermittler von Belegen, die er aus zweiter Hand zitiert, ohne dies in jedem Falle zu kennzeichnen. Nicht sehr bedeutend ist der Quellenanteil des griechisch-lateinischen Schrifttums der Antike und des Mittelalters; denn die Mehrzahl der in den Gruppen A 2 b und A 2 c aufgefithrten Werke ist nur vereinzelt 
benutzt worden. FRISOH verwertet in erster Hinsicht die Schriften spätgriechischer, spätrömischer und mittelalterlicher Lexikographen und Kommentatoren, ferner Werke naturkundlich-technischen (auch geographischen und medizinischen) Inhalts sowie die Darstellungen antiker Geschichtsschreiber der deutschen Vorzeit.

a) Arabisch. Hebräisch. Türkisch

6. Johann Leunclavius (Löwenklau; um 1530-1593): Onomasticon Turco-Arabicưm. $1,54 \mathrm{~b}$.

7. Valentin Schindler (gest. 1604): Lexicon pentaglotton hebraicum, chaldaicum, syriacum, Talmudico-Rabbinicum et arabicum. Hanau 1612 (Frankfurt 1653 B. 81). 1,632c.

\section{b) Griechisch}

8. Homer (um 800): 1, 211a; 2,335b. Ilias 2, $10 \mathrm{c}$.

9. Hesiodos (um 700): 2, $156 \mathrm{c}$.

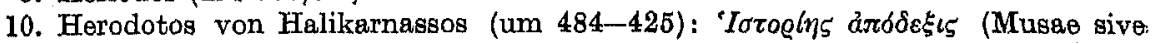
historiarum libri IX) I, $211 \mathrm{a} ; 228 \mathrm{c} ; 499 \mathrm{a}$.

11. Platon (427-347): K@atúlog 1, 264 a.

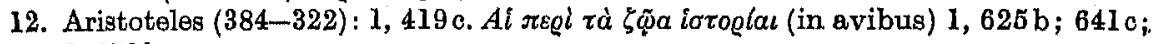
$2,373 \mathrm{~b}$.

13. Alexander der Große (358-323): 1, 167 a.

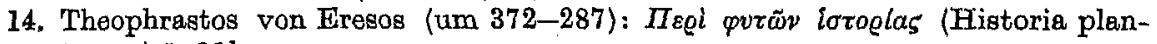
tarum) $1,20 \mathrm{~b}$.

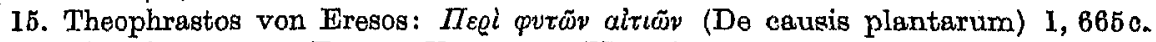

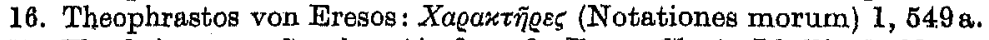

17. Theokritos von Syrakus (Anfang 3. Jh. v. Chr.): Idyllia 1, 3 b.

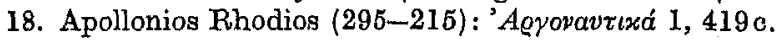

19. Kallimachos von Kyrene (um 310-240): Hymni 1, $3 \mathrm{~b}$.

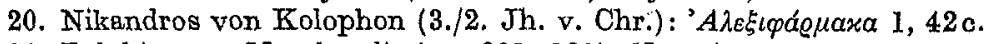

21. Polybios von Megalopolis (um 201-120): 'Ioroela $1,556 \mathrm{c} ; 2,294 \mathrm{~b}$.

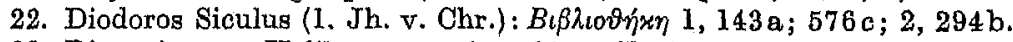

23. Dionysios von Halikarnassos (um $30 \mathrm{v}$. Chr.): $2,124 \mathrm{a}$.

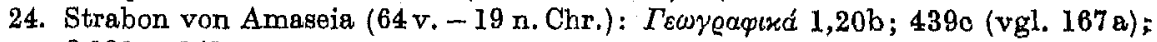
2,130 c; 141 a.

25. Philon von Alexandria (Philon Judaios; 1. Jh. n. Chr.): 1,492a.

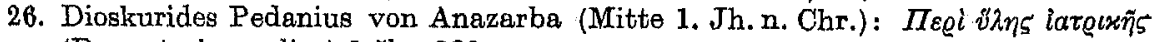
(De materia medica) $1,6 b$; 320c.

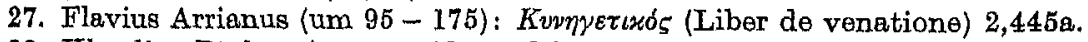

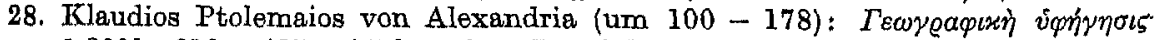
$1,309 \mathrm{~b} ; 312 \mathrm{c} ; 437 \mathrm{c} ; 447 \mathrm{~b} ; 2,29 \mathrm{a}$. Frisch benutzt die Ausgabe Xylanders (Wilhelm Holtzmanns) $1571 \mathrm{I}, 447 \mathrm{~b}$.

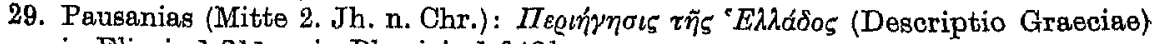
in Eliacis 1,211a; in Phocicis 1,642b.

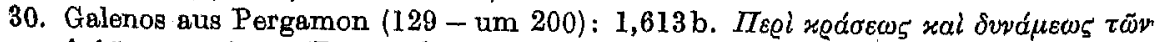

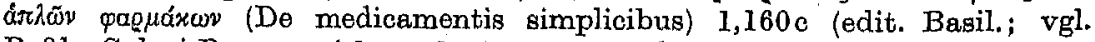

B. 81: Galeni Pergameni [opera] quae exstant, latine. Basel 1562).

31. Galenos aus Pergamon: De facilitate alimentorum 1,508 b.

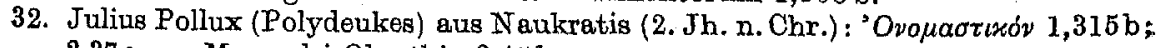
$2,37 \mathrm{c}$; ex Menandri Olynthia 2,45 b. 


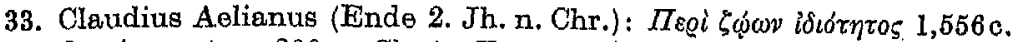

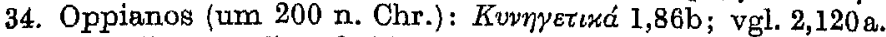

35. Herodianos (Mitte 3. Jh.): "Iotoglal 2,45b; vgl. 1,392c.

36. Heliodoros aus Emesa (3. Jh.): Aìroлi*á (Aethiopicorum libri X, ed. Hieron. Commelinus 1596) 1,23b. B. 21 .

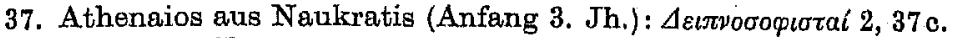

38. Johannes Chrysostomos aus Antiocheia (347-407): 1, $490 \mathrm{c}$.

39. Stephanus Byzantinus (5. Jh.): 'E $9 v$. á (Dictionarium geographicum) 1, 20b; 3350 .

40. Hesychios von Alexandria (5. Jh.): Lexikon $1,13 \mathrm{a} ; 72 \mathrm{~b} ; 140 \mathrm{~b} ; 200 \mathrm{c} ; 315 \mathrm{~b}$; $407 \mathrm{~b} ; 500 \mathrm{c} ; 2,46 \mathrm{~b} ; 290 \mathrm{~b} ; 481 \mathrm{a}$. Vgl. $1,75 \mathrm{a}$.

41. Glossarium Philoxeni (ed. Vulcanius Leyden 1600; ed. Labbaeus Paris 1679) $1,3 \mathrm{~b} ; 20 \mathrm{~b} ; 40 \mathrm{~b}$.

42. Prokopios von Caesarea (6. Jh.): 'Ioropıóv (darin: Geschichte des Ostgotenkrieges: De bello Gothico) $1,20 \mathrm{~b} ; 2,344 \mathrm{a}$.

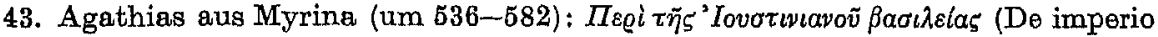
et rebus gestis Justiniani Imperatoris libri V) $1,28 a$.

44. Euagrios aus Epiphania (um 536-Ende 6. Jh.): Historiae ecclesiasticae libri VI I 506a.

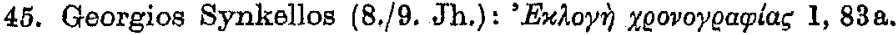

46. Suidas (Suda) (10.Jh.): I, $56 \mathrm{~b} ; 85 \mathrm{~b} ; 325 \mathrm{a} ; 343 \mathrm{a}$.

47. Etymologicum magnum Graecum (9./12. Jh.): 1, 72 b.

48. Glossaria Graeco-barbara: Gloss. Graec. 1, 266c. Gloss. L. Graec. Labb. (= Cyrilli, Philoxeni, aliorum veterum glossaria, ed. Ph. Labbaeus. Paris 1679) 1, 646 a. Gloss. Graeco-barb. 2, 182 a. Gloss. Graec. Lat. 2, 376 a. ein altes Griechisch-Lateinisches Lexicon 1, $492 \mathrm{a}$.

49. Scholien zu Theokrits Idyllen $1,2 \mathrm{~b} ; 23 \mathrm{~b} ; 145 \mathrm{~b} ; 2,104 \mathrm{a} ; 134 \mathrm{c} ; 261 \mathrm{a} ; 332 \mathrm{~b}$; $362 \mathrm{c}$.

50. Oppianos-Scholien 2, 44a.

51. Eustathios (12. Jh.) : Homer-Kommentar (B. 81 : Homerus cum Eustathii Commentario Graece. Basel 1560) 1, $20 \mathrm{~b}$; aus Pausanias 1, 653c. Ilias 1, 3b; 94c; $495 \mathrm{c} ; 2,28 \mathrm{c} ; 120 \mathrm{c}$. Odyssee 1 , 1c; $103 \mathrm{a} ; 496 \mathrm{a} ; 2,156 \mathrm{c}$.

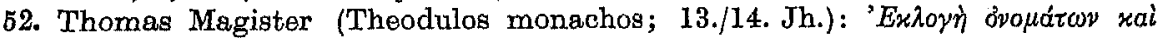

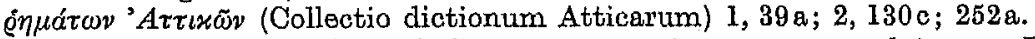

53. Xenophontis Cyropaedia ad Crusii grammaticam accommodata per Kaufmannum. Tübingen 1611. B. 51. Nota $2,163 \mathrm{c}$.

54. Johann Konrad Dieterich: Commentarium in Hesiodi 'Opera et dies' (= Hesi-

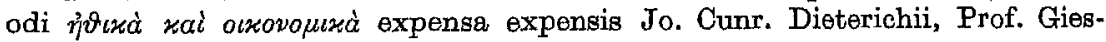
seni, Gießen 1659. B. 56) 2, 53a.

55. Charles Du Cange (Du Fresne; 1610-1688): Glossarium ad scriptores mediae et infimae graecitatis. Lugd. 1688. 1, 1140; 2, 44 a. aus: J. Meursius 'Glossarium. graeco-barbarum' Leyden $16141,325 \mathrm{a}$.

56. Johann Albert Fabricius (1668-1736): Bibliotheca Graeca. Hamburg $1707 \mathrm{ff}$. (B. 76) aus Eustathios 2, $252 \mathrm{a}$.

57. Johann Paul Gumprecht: Blumenlese der Grammatik oder vollständige Anweisung zur griechischen Sprache. Leipzig 1707. B. 49. 1, $495 \mathrm{c}$.

c) Lateinisch

58. Plautus, Titus Maccius (um 244-184): Captivi 1, $298 \mathrm{c}$.

59. Terentius Afer, Publius (um 190-159): 1, 12lb. Vgl. 1, 179a die lateinischen Comoedien-Schreiber; 1,1840 die Zeiten des alten Comici. 
60. Lucilius, Gajus (180-102): Saturao 2, 471c.

61. Varro, Marcus Terentius $(116-27): 1,1 b$. Rerum rusticarum libri III 1, $123 \mathrm{c}$; $2,428 \mathrm{c} ; 439 \mathrm{c}$.

62. Varro, Marcus Terentius: de lingua latina 2, 141 a.

63. Cicero, Marcus Tullius (106-43): Cato maior sive de senectute 2, 447 c.

64. Cicero, Marcus Tullius: de officiis ad Marcum filium I, $323 \mathrm{~b}$.

65. Cicero, Marcus Tullius: de finibus bonorum et malorum; epistularum ad Attioum libri XVI; epistularum ad familiares libri XVI 1, $62 \mathrm{a}$.

66. Caesar, Gajus Julius $(100-44): 1,83 a ; 167 a ; 419 \mathrm{c} ; 2,471 \mathrm{a}$; de bello Gallico $1,25 \mathrm{~b} ; 572 \mathrm{c}$.

67. Lucretius Carus, Titus $(98-55)$ : de rerum natura $1,78 \mathrm{c}$,

68. Sallustius Crispus, Gajus (86-34): bellum Catilinarium 2, $296 a$.

69. Vergilius Maro, Publius (70-19): Georgica 2, $456 \mathrm{c}$.

70. Horatius Flaccus, Quintus (65 8): epistulae 1, $177 \mathrm{~b}$.

71. Vitruvius Pollio (um 25 v. Chr.): de architectura libri X 1, 39a; 208b; 2, 119b; $240 \mathrm{c} ; 278 \mathrm{a} ; 348 \mathrm{~b} ; 376 \mathrm{a} . \mathrm{Vgl}$. 1, $165 \mathrm{c}$.

72. Livius, Titus (59 v. -17 n. Chr.) : rerum Romanarum ab urbe condita libri V $1,43 b ; 2,294 b ; 348 b$.

73. Ovidius Naso, Publius (43 v. - 18. n. Chr.): Fasti $1,31 \mathrm{~b} ; 335 \mathrm{c} ; 2,124 \mathrm{a}$.

74. Manilius, Marcus (Anfang 1. Jh. n. Chr.): Astronomicon 1, $669 \mathrm{~b}$.

75. Grattius Faliscus (Anfang 1. Jh. n. Chr.): Cynegeticon 2, 84a.

76. Celsus, Aurelius Cornelius (um 30 n. Chr.): de re medica libri VIII 1, $224 \mathrm{~b}$.

77. Seneca, Lucius Annaeus (um 4 v. $-65 \mathrm{n}$. Chr.): 2, $471 \mathrm{c}$.

78. Columella, Lucius Junius Moderatus (Mitte 1. Jh. n. Chr.): de re rustica libri XII $1,10 \mathrm{~b} ; 114 \mathrm{~b} ; 199 \mathrm{~b} ; 300 \mathrm{c} ; 510 \mathrm{c} ; 2,144 \mathrm{c}$.

79. Seribonius Largus (Mitte 1. Jh. n. Chr.): de compositionibus medicamentorum liber unus 1, 20 a.

80. Curtius Rufus, Quintus (um 50 n. Chr.): Historiarum Alexandri Magni libri $X 2,9 b ; 234 b$.

81. Persius Flaccus, Aulus (34-62): Satirae 1, 206c; 2, 223a. Vgl. 1, 183a.

82. Cornutus, Lucius Annaeus (1. Jh. n. Chr.): ad Persii satiras 1, 62a.

83. Lucanus, Marcus Annaeus (39-65): bellum civile (Pharsalia) 2, 9b.

84. Plinius Secundus, Gajus (23-79): naturalis historiae libri XXXVII 1, 94a; $225 \mathrm{~b}$ varians lectio; $318 \mathrm{a} ; 380 \mathrm{c} ; 613 \mathrm{~b} ; 2,35 \mathrm{c} ; 56 \mathrm{c} ; 124 \mathrm{a} ; 240 \mathrm{c} ; 259 \mathrm{~b} ; 329 \mathrm{c}$; $372 \mathrm{c} ; 417 \mathrm{~b} ; 47 \mathrm{lc}$.

85. Quintilianus, Marcus Fabius (um 35-96): de institutione oratoria libri XII $1,612 \mathrm{c}$.

86. Silius Italicus, Tiberius Catius (25-101): de bello punico secundo 2, $9 \mathrm{~b}$.

87. Frontinus, Sextus Julius (Ende 1. Jh.): 1, 59 c; $619 \mathrm{a}$.

88. Tacitus, Cornelius (um $55-$ um 120): Germania 1, 25b;231 b; $351 \mathrm{c} ; 444 \mathrm{c}$; $2,28 \mathrm{c} ; 57 \mathrm{c} ; 297 \mathrm{~b} ; 488 \mathrm{c}$.

89. Tacitus, Cornelius: Annales 1, 1lc.

90. Suetonius Tranquilius, Gajus (Anfang 2. Jh.): de vita Caesarum libri VIII in Vitellio 1, $92 \mathrm{a}$; in Galba 1, 337 b; in Claud. 2, $487 \mathrm{c}$.

91. Juvenalis, Decimus Junius (um 60-140): Satirae 1, 107a.

92. Florus, Publius Annius (erste Hälfte 2. Jh.): epitoma de T. Livio libri duo $1,320 \mathrm{c}$.

93. Justinus, Marcus Junianus (um 160) : epitoma historiarum Pompei Trogi 1, 83a; $346 \mathrm{c} ; 2,180 \mathrm{~b}$.

94. Gellius, Aulus (um 175): noetes Atticae 1, 115a; aus Varro 1, $576 \mathrm{c.}$

95. Hyginus (der Jüngere; Ende 2. Jh.): fabulae 1, 517a. 
96. Festus, Sextus Pompejus (2./3. Jh.): de verborum significatione $1,20 \mathrm{~b} ; 39 \mathrm{~b}$; $81 \mathrm{~b} ; 117 \mathrm{a} ; 235 \mathrm{c} ; 343 \mathrm{a} ; 492 \mathrm{a} ; 641 \mathrm{c} ; 2,95 \mathrm{~b} ; 241 \mathrm{c} ; 296 \mathrm{a} ; 372 \mathrm{c} ; 393 \mathrm{~b}$.

97. Tertullianus, Quintus Septimius Florens (um 155 - nach 220) : de pallio $1,15 \mathrm{lb}$.

98. Apicius, Caelius (3. Th.): de re coquinaria 'in den alten editionen' $1,140 \mathrm{~b}$.

99. Solinus, Gajus Julius (3. Jh.): collectanea rerum memorabilium (Polyhistoria) $1,10 \mathrm{~b} ; 40 \mathrm{~b} ; 35 \mathrm{lc}$.

100. Lactantius, Lucius Caecilius Firmianus (um 300): 1, 159a.

101. Ausonius, Decimus Magnus (um 310 - um 395): $1,259 \mathrm{~b} ; 2,336 \mathrm{c}$.

102. Nonius Marcellus (4. Jh.): compendiosa doctrina ad filium 1, $152 \mathrm{~b}$ citat Lucilii verba; $1,576 \mathrm{c}$ aus Sisenna.

103. Donatus, Aelius (Mitte 4. Jh.): Terenzkommentar 1, 2000 ad Eunuch. Terentii.

104. Palladius, Rutilius Taurus Aomilianus (4. Jh.): de re rustica 2, 350b; $479 \mathrm{c}$.

105. Claudianus, Claudius (gest. 404): 1, 92a. de bello Pollentino (Gothico) liber $1,419 \mathrm{c}$.

106. Vegetius Renatus, Flavius (um 400) : epitome institutorum rei militaris $1,187 \mathrm{c}$; $315 \mathrm{c} ; 505 \mathrm{c} ; 2,182 \mathrm{a}$; vgl. 2, 294b.

107. Servius Marius Honoratus (um 400): Vergilkommentar 1, 38a; 343 a. Georgica und Aeneis 1, 20b. Georgica 1, $40 \mathrm{~b} ; 2,455 \mathrm{~b}$. Aeneis 1, 200 c; $391 \mathrm{~b}$.

108. Macrobius Theodosius, Ambrosius (um 400): Saturnalia convivia 1, 6b; $40 \mathrm{~b}$.

109. Vetus scholiastes Juvenalis (um 400): 1, 496a.

110. Orosius, Paulus (nach 414): historiarum adversus paganos libri VII 1, 320o; 2, $141 \mathrm{a}$.

111. Rutilius Namatianus, Claudius (416): Itinerarium seu de reditu suo $1,2 b$.

112. Augustinus, Aurelius (354-430): locutionum libri VII 1, 343 a locutio de Josua.

113. Augustinus, Aurelius: epistulae 1, 66 a.

114. Paulinus Nolanus (353-431): epistulae 2, 265c de capta Constantinopoli.

115. Priscianus (um 500): institutionis libri XVIII 1,6 a.

116. Cassiodorus Senator, Flavius Magnus Aurelius (487-583) : variarum epistolarum libri XII 2, $402 \mathrm{c}$.

117. Jornandes (Jordanes; Mitte 6. Jh.): de Getarum sive Gothorum origine et rebus gestis $1,20 \mathrm{c} ; 51 \mathrm{a} ; 83 \mathrm{a} ; 341 \mathrm{a} ; 2,59 \mathrm{a} ; 403 \mathrm{c} ; 480 \mathrm{c}$.

118. Fortunatus, Venantius Honorius Clementianus (um 535-600): carmina (mis. cellanea) 2, $137 \mathrm{~b}$.

119. Isidorus Hispalensis ( $u$ 570-636): Originum sive Etymologiarum libri $X X$ $1,20 \mathrm{~b} ; 33 \mathrm{a} ; 65 \mathrm{~b} ; 320 \mathrm{c} ; 500 \mathrm{c} ; 641 \mathrm{c} ; 660 \mathrm{a} ; 2,37 \mathrm{c} ; 44 \mathrm{~b} ; 141 \mathrm{a} ; 159 \mathrm{a} ; 283 \mathrm{c} ; 348 \mathrm{~b}$.

120. Isidorus Hispalensis: de officiis ecclesiasticis $2,37 \mathrm{~b}$.

121. Glossae Isidori $1,7 \mathrm{~b}$ latino-barbare; $1,62 \mathrm{~b} ; 166 \mathrm{~b} ; 257 \mathrm{a} ; 526 \mathrm{a}$ lingua Gallica.

122. Iso Magister (gest. 871): Glossee 2, $44 \mathrm{c}$.

123. Papias (Mitte 11. Jh.): elementarium doctrinae rudimentum (vocabularium) $1,27 a ; 34 a ; 62 a ; 65 b ; 273 a ; 320 c ; 336 b ; 582 c ; 641 \mathrm{c} ; 2,137 \mathrm{c} ; 291 \mathrm{a}: 376 \mathrm{a} ; 378 \mathrm{a}$; $455 \mathrm{~b}$.

124. Hugutio (Ugutio; Mitte 12. Jh. - 1210) : liber derivationum (glossarium) 1, 265 a; $2,152 \mathrm{~b} ; 294 \mathrm{~b}$.

125. Eberardus Bethuniensis (Eberhard von Béthune; um 1200): Graécismus de figuria et octo partibus orationis sive grammaticae regulae versibto Latinis explicatae 1, 62 a.

126. Johannes de Garlandia (13. Jh.): Synonyma 1, $62 a$.

127. Johannes de Janua (um 1280): Catholicon $1,637 \mathrm{c} ; 2,39 \mathrm{a} ; \mathrm{vgl}$. 1, $490 \mathrm{~b} ; 2,487 \mathrm{c}$

128. Andreas Althamer (1500-1539): Scholia, ad Tacitum. Nürnberg 1536. 2, 433 a.

129. Petrus Nannius Alcmarianus (1500-1557) : Miscellaneorum decas cum auctario. et retractationibus. Leyden $1548.1,259 \mathrm{~b}$. 
130. Julius Caesar Scaliger (1484-1558): Exotericae exercitationes de subtilitate adversus Cardanum. Paris 1557. (Frankfurt 1692. B. 20) 1,6 b;81 c; 160 c; 361 a; $501 \mathrm{~b} ; 2,340 \mathrm{a}$. Vgl. 1, $20 \mathrm{~b}$.

131. Adrianus Turnebus (1512-1565): Adversariorum libri XXX. Paris 1564-1573. $1,566 \mathrm{~b}$.

132. Etienne Pasquier (1529-1615): 1, $127 \mathrm{~b}$.

133. Joseph Justus Scaliger (1540-1609): notae in Catullum 1, 52a. notae in Varro. nem de lingua latina $1,140 \mathrm{~b}$. notae in Varronem de re rustica $1,258 \mathrm{c}$. notae in Senecam de beneficiis $1,231 \mathrm{~b}$.

134. Matthias Martinius (1572-1630): Lexicon philologioum in quo latinae et a latinis autoribus usurpatae tum purae tum barbarae voces ex originibus declarantur. Bremen 1623. 2, $394 \mathrm{a}$.

185. Henry Spelman (1562-1641): Glossarium archaiologicum continens latinobarbara, peregrina, obsoleta et novatae significationis vocabula. London 1687. (QR. B. 81).

Gattfried von Viterbo 1, 11b; 37c; Goldast 40a; 6lb; 65c; leges Bojorum 234a; $407 \mathrm{~b} ; 446 \mathrm{~b} ; 501 \mathrm{c} ; 621 \mathrm{a} ; 2,20 \mathrm{a} ; 113 \mathrm{~b} ; 316 \mathrm{~b}$.

136. Gerhard Johannes Vossius (1577-1649): Aristarchus sive de arte grammatica libri VII. Amsterdam 1635. 2, 44b; 335c.

137. Gerhard Johannes Vossius: De vitiis sermonis et glossematis Latino-barbaris libri IV. Amsterdam 1645. QR. 1, 143a; 209c; 320c; aus den Leges Wisigothorum $387 \mathrm{~b} ; 416 \mathrm{c} ; 433 \mathrm{~b} ; 576 \mathrm{c} ; 2,52 \mathrm{c}$; aus den Leges Werinorum $88 \mathrm{c} ; 160 \mathrm{a}$; aus Matthaeus Parisiensis $163 \mathrm{~b} ; 182 \mathrm{a} ; 252 \mathrm{a}$; Konjelktur zu Palladius de re rustica $350 \mathrm{~b} ; 408 \mathrm{c}$; aus der Constitutio Caroli Calvi $452 \mathrm{~b}$; aus dem Catholicon $487 \mathrm{c}$.

138. Gerhard Johannes Vossius: Etymologicon linguae latinae et de litterarum permutatione tractatus. Amsterdam 1653 (Amsterdam 1662. B. 80). 1, 454a; $2,10 \mathrm{c} ; 91 \mathrm{c} ; 487 \mathrm{c}$.

139. Gerhard Johannes Vossius: De analogia. 1, 75a; $320 \mathrm{a}$.

140. Isaak Casaubonus (1559-1614): notae in Persium 1, $357 \mathrm{c}$.

141. Matthias Bernegger (1582-1640): Quaestiones in Taciti Germaniam (Cornelius Tacitus Berneggeri. Straßburg 1664. B. 20). in complem. 1, $411 \mathrm{c}$.

142. Claudius Salmasius (1588-1653): Annotationes in Solinum. 2, $262 \mathrm{a} ; 417 \mathrm{~b}$. notae in Flavium Vopiscum 2, $127 \mathrm{c}$. Vgl. $1,151 \mathrm{~b}$.

143. Christoph Adam Rupertus (1612-1647): Dissertationes ad Valerium Maximum et Vellejum Paterculum. Nürnberg 1663. (B. 46). 1,652c.

144. Georg Caspar Kirchmayer (1635-1700): In C. Tacitum de Germania liber commentarius. Wittenberg 1664. B. 44. 1, $20 \mathrm{c}$.

145. Charles Du Cenge (Du Fresne; 1610-1688): Glossarium ad scriptores mediae et infimae Latinitatis. Frankfurt a. M. 1681 (1, 114b. B. 81). QR.

$1,11 \mathrm{~b}$; zu Isidor 20b; glossarium Anglo-Saxonicum Aelfrici $46 \mathrm{a}$; Adalardus in statutis monasterii Corbeiensis $60 \mathrm{~b}$; Brief des Kaisers Heinrich $63 \mathrm{c}$; Godo. fredus monachus; annales Bertiniani $65 \mathrm{~b}$; annales Colmarienses 76a; lex Bajuwarum 90a; monasticum Anglicum 93c; Vita S. Eulogii 95a; 114b; monasticum Anglicum; Bollandus: Acta Sanctorum 143 b; concilium Budense 124c; Acta Mainbodi 147a; Anglo-Saxonicum 169a; in den Engelländischen Sohrifften 189 a ; aus einem alten Buch $218 \mathrm{a}$; in apologis veterum Germanorum 223 a; lex Bojorum 234a; 'Der gelehrte und der Wörter des fremden Lateins unvergleichliche Sammler' 31.0c; 'die Herren Glossatores, Du Fresne, und andere' 321 o; Meursius und das glossarium Arabico-Latinum 325 a; Concilium Torunense; Breviloquus 325c; Alexander Iatrosophista: de passionibus 357c; 
alter französischer Brief (Uricunde) 434c; Catholicon 490b; "Vermehrung des Gloss. Du Cange' 644a; in Dissert. 653a; lex Bajuwarum 665c; in den alten Gesetzen 2, 82a; lex Longobardorum 100a; $113 \mathrm{~b} ; 145 \mathrm{~b}$; lateinische Urkunden $156 \mathrm{c}$; in den alten Gesetzen $233 \mathrm{~b}$; Hundius: Metropolis Salisburgensis 264a; Gloss. Longobard. S, Germani Paris ex Glossis 376a; 'Sogar das Gloss. des Herrn Du Cange hat das Wort Juricapium nicht' $396 \mathrm{c} ; 408 \mathrm{c}$; chronicon Colmariense 421 a; Vetus Scheda de S. Aderaldo Trecensi apud Camusatum. $455 \mathrm{~b}$; leges forest. Scoticarum $467 \mathrm{c}$.

146. Christoph August Houmann (1681-1763): Poecile. Halle 1722-1731. 1, 53c; 2,230 c.

\section{d) Romanische Sprachen (und Keltisch)}

147. François Rabelais (1494-1553): Les Oeuvres de Rabelais. 1596. (B. 12). $1,123 \mathrm{c}$; vgl. $1,6 \mathrm{~b}$.

148. Molière (1622-1673): Les précieuses ridicules. Paris 1660, 1, 145a.

149. Robert Estienne (Stephanus) (1503-1559): Dictionaire françois-latin. Paris 1539. $2,431 \mathrm{~b}$.

150. Jean Nicot (1530-1600): Dictionaire françois-latin. Paris 1614. (B. 62). 1, 37a; $63 \mathrm{c} ; 207 \mathrm{a} ; 321 \mathrm{c} ; 451 \mathrm{a} ; 2,149 \mathrm{c} ; 223 \mathrm{a} ; 236 \mathrm{~b} ; 381 \mathrm{c} ; 421 \mathrm{a} ; 431 \mathrm{~b}$.

151. Johann Isaak Pontanus (1571-1639): Glossarium Prisco-Gallicum. In: Itinerarium Galliae Narbonensis. Leyden 1606. 1, 167a.

152. Marcus Zverius Boxhorn (1612-1653): Originum Gallicarum liber: acc. antiquae Linguae Britannicae Lexicon Britannico-latinum. Amsterdam 1654. 1, 211 a; im Brittannischen 1,393a; 2, 376c. Hornius in praefatione ad Boxhornii Origines Gallicas 2, 65a. Vgl.: 'Cambrice beym Boxhorn' 1, 626a; Lexicon Cambro-Britannicum 2, 363a.

153. Gilles Mónage (1613-1692): Dictionnaire étymologique de la langue françoise (Origines de le langue françoise). Avec les 'Origines de la langue françoise' de Pierre de Caseneuve (1591-1652) et le vocabulaire hagiologique de Chastelain. Paris 1694. (B. 80). 1, 45a; Menagius hat schöne Oerter aus dem Griechischen zusammen getragen $105 \mathrm{~b}$; aus einem alten Glossar $123 \mathrm{c} ; 135 \mathrm{~b}$; Theodulfus Aurelianus 174c;285a; 298b; 325b; 349c; notas Frischii $433 \mathrm{~b} ; 452 \mathrm{c} ; 470 \mathrm{c}$; $526 \mathrm{c} ; 537 \mathrm{~b} ; 566 \mathrm{c} ; 642 \mathrm{~b} ; 2,37 \mathrm{c}$; Jauchet $40 \mathrm{c}$; Ulitius: notae in Grattium $830 ; 113 \mathrm{~b} ; 211 \mathrm{c} ; 223 \mathrm{a} ; 323 \mathrm{~b} ; 378 \mathrm{a} ; 420 \mathrm{c}$. QR.

Caseneuve $1,401 \mathrm{~b}$.

154. Dictionnaire de l'Académie française. Paris 1694. (B. 81). 1,810; $135 \mathrm{~b}$; $146 \mathrm{a} ; 157 \mathrm{~b} ; 162 \mathrm{~b}$.

155. François Pomey: Dictionnaire royal. Frankfurt 1700. (B. 62). 2, 172b.

156. Dictionnaire universel françois et latin. Imaprimé par ordre du Prince de Dombes. Trévoux 1704. (B. 81). 1, 40a; 86a; 'Die vornehmsten Französischen Wörter-Bücher, als Dictionaire Academique, und das von Trevoux oder vielmehr die woraus es dieses leztere genommen' $135 \mathrm{~b} ; 180 \mathrm{~b}$; additiones $199 \mathrm{~b}$; $265 \mathrm{a} ; 438 \mathrm{a} ; 484 \mathrm{c} ; 2,52 \mathrm{c} ; 84 \mathrm{~b} ; 265 \mathrm{c} ; 353 \mathrm{c} ; 356 \mathrm{~b} ; 401 \mathrm{c} ; 414 \mathrm{a}$.

157. Histoire et Mémoires de l'Ácadémie des sciences. Paris (170lff.) 1714. 1, $165 \mathrm{c}$.

158. Vocabolario degli accademici della Crusca. Venedig 1612. 1,66c.

159. Octavius Ferrarius (1607-1682): Origines linguae italicae. Patavii 1676. $2,378 \mathrm{a}$.

160. Sebastian Covarruvias y Orozco: Tesoro de la lengua castellana. Madrid 1611. 2, 424a; vgl, 1, $83 \mathrm{c}$. 


\section{e) Slawische Sprachen}

161. Daniel Adamus a Weleslavina: Sylva quadrilinguis vocabulorum et phrasium Bohem. Lat. Graec. et Germ. linguae. Prag 1598. (B. 63). 2, $353 a$.

162. Heinrich Wilhelm Ludolf: Grammatica russica. Additi sunt modi loquend communiores ... cum brevi vocabulario. Oxford 1696. (B. 67). 2, 221 a append.

\section{A. 3. 4. Hilfsmittel für die Erfassung des Wortschatzes der germanischen Sprachen}

3. a) Gotisch

b) Nordisch

c) Angelsächsisch

d) Niederländisch

4. a) Altdeutsche Texte
b) Altdeutsche Textsammlungen, Glossare und wortgeschichtliche Unter. suchungen
c) Frühneuhochdeutsche Wörterbücher
d) Mundartenwörterbücher
e) Grammatiken. Sprachlehrbücher
f) Selbstzitate FrIscHs

Die Gruppen A. 3. 4. lassen erkennen, in welchem Umfange FrISCA die zu seiner Zeit zugänglichen Denkmäler der altgermanischen Sprachen und die Hilfsmittel der zeitgenössischen germanistischen Wortforschung für die historisch-etymologische Erhellung des deutschen Wortschatzes nutzbar macht. Außerhalb des Kroises der altdeutschen Quellen werden das Gotische, das Altnordische und das Angelsëchsische in etwa gleichem Umfange berücksichtigt. Die Texte der altdeutschen Zeit liegen Frisch in den zu jener Zeit gültigen Einzel- und Sammelausgaben vor, deren Heraus. geber durch Utbersetzungen, Glossare und erläuternde Anmerkungen dem Textverständnis vielfach vorgearbeitet hatten. Die in dieser Form niedergelegten Ergebnisse historisch-etymologischer Wortforschung verwertet Farsor - ebenso wie die Angaben einer Reihe selbständig erschienener Glossare und Untersuchungen in reichem Umfange.

Stand für die Erfassung des Wortschatzes der altgermanischen Sprachen eine Anzahl philologischer Hilfsmittel bereits zur Verfügung, so mußte sich Frisor den Weg in das Gebiet des Frühneuhochdeutschen selbst bahnen. Außer DrwomrioH voN STADes Glossar zur Bibelübersetzung LuTHERs (1711; 1724) bot die Wortforschung der Zeit kaum eine Stütze, die Sammlung und Verständnis des frühneuhochdeutschen Wortgutes hätțe erleichtern können. Dagegen vermochten die Fremdsprachenwörterbücher der frühnethochdeutschen Zeit solbst Hilfestellung zu leisten. FrIsor ist der erste deutsche Lexikograph, der diese Werke in größerem Umfange für die historische Sprachforschung nutzbar macht. 1739 würdigt er in dem Schulprogramm 'De primis in Germania typis editis lexicis Germanicis' eine Reihe der wichtigsten Wörterbücher des 15. und 16. Jahrhunderts. Er ist sioh des Wertes ihrer Angaben für das geschichtliche Vexständnis des deutschen Wortschatzes bewuBt; so urteilt er über das 'Novum dictionarii genus' (1540) des ErasMUS AteBerus: 'Licet nune multa eorum (vocabularum) obsoleta facta sint, ad inveniendas tamen radices Derivatorum et detegenda simplicia Compositorum quae in usu sunt, Etymologis nostri temporis liber utilissimus est' $)\left(3^{\mathrm{b}}\right.$. Unter dem doppelten Blickpunkt, das in diesen Werken enthaltene Wortgut um seiner selbst willen lexikographisch zu erfassen und es als Mittel für die Errläuterung anderer Wortschatzbestandteile zu nutzen, zieht Frisor zahlreiche der frühneuhochdeut- 
schen Wörterbücher hinzu. Manche dieser Werke sind ihm zugleich Quellen für die Kenntnis der landschaftlichen Sprechgebräuche; sie ergänzen für ihn somit die geringe Zahl der um 1700 vorhandenen deutschen Mundartenwörterbücher. Die lexikalischen Hilfsmittel für die Erfassung des Wortschatzes der neuhochdeutschen Gemeinsprache sind bereits im ersten Abschnitt des Kapitels III nachgewiesen worden. Die wenigen Quellenzitate lassen die Dichte der tatsächlichen Benutzung und den Anteil der einzelnen Vorlagen nicht erkennbar werden. Friscer nennt diese Hilfsmittel hauptsächlich dort, wo sie ihm Anlaß zur Polemik bieten oder Angaben liefern, die von der Norm des gemeinsprachlichen Wortgebrauchs abweichen.

\section{A. 3. Hilfsmittel für die Erfassung des Wortschatzes der germanischen Sprachen (außer Deutsch)}

\section{a) Gotisch}

163/164. Die im Codex argenteus überlieferte Evangelienübersetzung des Ulfilas (QR. 1, 361 c; 308 b) benutzt Frisch in zwei Ausgaben (zitiert nach Evangelien. vielfach ohne Nennung des Herausgebers):

Franciscus Junius - Thomas Mareschallus: Quatuor D. N. Jesu Christi Euangeliorum Versiones perantiquae duae, Gothica scil. et Anglo-Sexonica, Accessit et Glossarium Gothicum opera Franoisci Junii. Dordreeht 1665. QR. B. 62 .

Georg Stjernhjelm: D. N. Jesu Christi SS. Evangelia ab Ulfila ex Graeco Gothice translata, nunc cum parallelis versionibus Sveo-Gothica, Norraena seu Islandica ot vulgata Latina edita. Stockholm 1671. Glossarium UlphilaGothicum. Stockholm 1671. QR. B. 69.

$1,6 \mathrm{~b}$; Jan. Ulitius in notis ad praefationem gloss. Goth. Junii 20c; 25b; $50 \mathrm{a} ; 71 \mathrm{a} ; 197 \mathrm{a} ; 308 \mathrm{~b} ; 361 \mathrm{c} ; 433 \mathrm{c} ; 446 \mathrm{~b} ; 536 \mathrm{a} ; 557 \mathrm{~b} ; 2,17 \mathrm{~b} ; 157 \mathrm{~b} ; 166 \mathrm{c}$; $250 \mathrm{c} ; 397 \mathrm{c} ; 404 \mathrm{c} ; 457 \mathrm{~b} .=$ Nephilas $1,486 \mathrm{~b}$.

\section{b) Nordisch}

165. Olaus Wormius (1588-1654): Specimen lexici runici, obscuriorum quarundam vocum, qua in priscis occurrunt historicis et poetis danicis enodationem exhibens. Kopenhagen 1650. QR. 1, 1c;11b;117a;234b;254b;340c;569c.

166. Olaus Wormius : Runer seu Danica Literatura antiquissima. Kopenhagen 1636. $1,2 \mathrm{~b} ; 149 \mathrm{~b} ; 433 \mathrm{a} ; 573 \mathrm{~b} ; 2,155 \mathrm{a}$.

167. Olaus Wormius: Fasti danici. Kopenhagen 1643. 2, $137 \mathrm{~b}$.

168. Olaus Wormius: Danicorum monumentorum libri VI. Kopenhagen 1643. $2,137 \mathrm{~b}$.

169. Johannes Loccenius (1597-1677): Antiquitates Sueo-Gothicae cum hodiernis institutis comparatae. Upsala 1654. QR. 1, 146a;676a;2, 155a; 370c; 418b; $433 \mathrm{a} ; 440 \mathrm{c}$.

170. Johannes Loccenius: Lexicon Juris Sueo-Gothici. Upsala 1665. QR. B. 19. $1,6 \mathrm{~b} ; 11 \mathrm{c} ; 19 \mathrm{~b} ; 27 \mathrm{c} ; 32 \mathrm{~b} ; 72 \mathrm{~b} ; 118 \mathrm{~b} ; 463 \mathrm{c} ; 514 \mathrm{c}$.

171. Petrus Resenius (1625-1688): Edda Islandorum an. Chr. MCCXV Islendice conscripta per Snorronem Sturlae Islandiae nomophylacem. Kopenhagen 1665. QR. B. 69. 1, Ic; Noten zur Woluspa und Index der Namen von Resenius 2a; Index 2b; 146a; Noten von Resenius 301a; Index 442a; 'da die Namen der Lanzen erzehlt werden' 2, $295 \mathrm{c}$. 
172. Petrus Resenius: Philosophia antiquissima Norvego-Danica quae est pars Eddae Saemundi. Kopenhagen 1665. Noten zur Woluspa (Edda Islandorum Saemundi) 1, $2 \mathrm{a}$.

173. Olaus Verelius (1618-1682): Gothrici of Rolfi Westrogothiae regum historia lingua antiqua Gothica conscripta ... vers. notisque illustr. Ol. Verelius. Acc. J. Schefferi notae politicae. (Gautreks-Saga). Upsala 1664. B. 28. Note von Verelius 1, 4b; Note von Scheffer $311 \mathrm{~b}$; Index des Verelius 314c; $336 \mathrm{a}$.

174. Olaus Verelius: Hervarar Saga pä Gammal Götska med Ol. Verelii Vttolkning och Notis. Upsala 1672. B. 82. 1, 2b; 30a; 215a; 343b; im Gothischen 571b; $572 \mathrm{~b}$.

175. Olaus Verelius: Herrauds och Bosa saga med en ny vttolkning jämpte Gamla Götskan h. e. Herraudi et Bosøe historia. Upsala 1666. 1, 311a; Index dès Verelius $335 \mathrm{c}$.

176. Olaus Verelius: Index linguae veteris-scytho-scandica $\operatorname{sive}$ gothicae ex vetusti aevi monumentis collectus. Upsala 1691. 1, 314c;335c;421a; $422 \mathrm{c}$; $442 \mathrm{a} ; 529 \mathrm{~b} ; 2,278 \mathrm{~b}$.

177. Olaus Rudbeck (1630-1703): Opera (QR.) 1, 19b;433a;2,9b;143b;239c. Atland eller Manheim. Upsala 1675-1698. 1, 51a; 71a;224b;236a; 319c; $2,113 \mathrm{c} ; 168 \mathrm{c}$.

178. Alte runische Grabschriften 1,372b. In den Cippis Runicis 1, 231 b; 433c.

179. Frag. Gloss. Upsal. 1, $7 \mathrm{~b}$.

180. Isländische Evangelienübersetzung 2, $300 \mathrm{~b}$.

181. Schwedische und dänische Übersetzung der Bibel $1,489 \mathrm{c}$.

182. Stephanus Johannes Stephanius (1599-1650): Nomenclator Latino-Danica. Kopenhagen 1634. 2, $174 \mathrm{c}$.

\section{c) Angelsächsisch}

183. William Somner (1606-1669): Dictionarium Saxonico-latino-anglicum. Access. Aelfrici abbatis grammatica latino-saxonica cum glossario suo ejusdem generis. Oxford/London 1659. QR. 1,7b;65 b; 235c;320a; 442c;446b; 568c; vetus glossarium 2, 323a; 408c. Glossarium Aelfrici 1, 65b; 44.2a.

184. Thomas Benson: Vocabularium Anglo-Saxonicum lexico Gul. Somneri magna parte auctius. Oxford 1701. (B. 63). 1, 14b;27a;396c;442c;514b;2,52a; $411 \mathrm{~b} ; 439 \mathrm{a}$.

185. Thomas Mareschall (Herausgeber der angelsächsischen Evangelienübersetzung und Verfasser der Observationes in versionem Anglosaxonicam in Quelle 163).

Ags. Evangelienübersetzung 1, 10; Mareschallus: observationes ad versionem Anglosaxonicam Novi Testamenti 607 a; 2, 457 a.

186. George Hickes (1642-1715): Institutiones grammatica $\theta$ Anglo-Saxonicae et Moesogothicae. Oxford 1689. 1,228c.

187. William Wats: $1,102 \mathrm{~b}$.

188. Oratio Dominica Anglo-Saxonica: 1, $1 \mathrm{a} ; 170$ a.

189. Glossae Pithoeanae: 1, $65 \mathrm{~b}$.

\section{d) Niederländisch}

190. Johannes Goropius Becanus (1518-1572): Opera hactenus in lucem non edita, nempe. Hermathena, Hieroglyphica, Vertumnus, Gallica, Francica, Hispanica. Antwerpen 1580. (QR.). 1,81 b; $264 \mathrm{a} ; 415 \mathrm{~b} ; 632 \mathrm{c}$. 
191. Cornelius Kilianus (gest. 1607) : Etymologicum Teutonica linguae. Antwerpen $1588.1,3 \mathrm{~b} ; 16 \mathrm{c} ; 416 \mathrm{~b} ; 2,87 \mathrm{~b} ; 162 \mathrm{c} ; 263 \mathrm{a} ; 310 \mathrm{~b} ; 408 \mathrm{c}$.

192. Jean Louis d'Arsy: Le grand dictionnaire françois-flamand. Edition nouvelle. Rotterdam 1651. QR. 1, 103b; 235c;366a; 2, 408c.

\section{A. 4. Hilfsmittel für die Erfassung des deutschen Wortschatzes}

\section{a) Altdeutsche Texte}

193. Monseer Glossen (Bernhard Pez: Thesaurus eneedotorum. Augsburg 1721) QR. 1, 5a; 162b; 396c;549c;2, 107c;146b;272a;346c;376b;410c;427b.

194. Hrabanische Körperteilglossen (Goldast: Alamannicarum rerum scriptores aliquot vestuti. Frankfurt 1606). QR. 1, 7b;29a;3140;402a; $2,147 \mathrm{~b} ; 359 \mathrm{a}$.

195. Hrabanische Bibelglossen (Dieomann: Specimen glossarii ms. Latino-theotisci quod Rabano Mauro inscribitur illustrati. Bremen 1721). QR. B. 63. $1,62 \mathrm{~b} ; 238 \mathrm{a} ; 2,461 \mathrm{a}$.

196. Glossae Keronis (Goldast: Alam. rerum scriptores. Frankfurt 1606). 1, 4a; $169 \mathrm{~b} ; 470 \mathrm{a} ; 557 \mathrm{~b} ; 2,403 \mathrm{~b} ; 482 \mathrm{c}$.

197. Florentiner Glossen (Eckart: Commentarii de rebus Franciae orientalis. Würzburg 1729). I, 199o; 228b;433b;525b;2,24a; 343a; 373b; $446 \mathrm{c}$.

198. Glossarium Ebnerianum (Eckart: Comm. de rebus Frano. or. Würzburg 1729). $1,300 \mathrm{a} ; 450 \mathrm{~b} ; 675 \mathrm{~b} ; 2,24 \mathrm{a} ; 260 \mathrm{a}$.

199. Glossarium Lindenbrogianum (Friedrich Lindenbrog: Codex legum antiquarum cum glossario rerum vocurnque difficilium. Frankfurt 1613. Eckart: Comm. de rebus Franciae orient. Würzburg 1729). 1, 38a; Gloss. Theotisc apud Lindenbrog. $117 \mathrm{a} ; 215 \mathrm{~b} ; 336 \mathrm{~b} ; 401 \mathrm{a} ; 448 \mathrm{~b} ; 2,250 \mathrm{~b}$; aus einem glossario $377 \mathrm{~b} ; 452 \mathrm{c}$; apud Eccard. $465 \mathrm{~b} ; 471 \mathrm{c}$. Vgl. formulae Lindenbrogianae $1,27 \mathrm{a}$.

200. Glossarium Lipsii (Lipsius: Epistolarum selectarum centuria tertia ad Belgas. Antwerpen 1605). QR. 1, 1c;2c;22a; 147a; Note von Lipsius $266 \mathrm{~b} ; 396 \mathrm{c}$; in einer edition $485 \mathrm{~b} ; 2,175 \mathrm{a} ; 366 \mathrm{c}$; Register einiger übersetzter alten Teutschen Wörter 408c; 409a.

201. Glossae Boxhornii (Boxhorn: Historia universalis. Leyden 1652). 1, 3 b; 49 b; $108 \mathrm{~b} ; 336 \mathrm{c} ; 442 \mathrm{a} ; 2,410 \mathrm{c}$.

202. Tatian (Palthen: Tatiani Alexandrini Harmoniae Evangelioa antiquissima versio Theotisca, ut et Isidori Hispalensis de Domini nativitate, passione et resurrectione. Greifswald 1706). QR. B. 69. I, 7c; 64a; 79c; $4440 ; 557 \mathrm{a}$; $2,143 \mathrm{c} ; 160 \mathrm{a} ; 427 \mathrm{a}$.

203. Isidor (Ed. Palthen. Greifswald 1706. S. Quelle 202). 1, 51a; 110a; 114b; $225 \mathrm{a} ; 314 \mathrm{c} ; 636 \mathrm{a}$.

204. Otfrid (Flacius Illyricus: Otfridi evangeliorum liber. Basel 1571. Schilter: Thesaurus Antiquitatum Teutonicarum. Ulm 1727). 1, 13b; 417a; Vorrede des Flacius 501 c; ed. Flac. (im Specimen 'Land' 1723) 574a; Otfrid an Bischof Salomon $2,103 \mathrm{a} ; 391 \mathrm{a} ; 410 \mathrm{c} ; 478 \mathrm{c}$.

205. Straßburger Eide (Ed. Freher 1611). 1, $407 \mathrm{~b}$.

206. Ludwigslied (Schilter: Epinicium rhythmo Teutonico Ludovico regi acclamatum. Straßburg 1696. Schilter: Thesaurus. Ulm 1727). 1, 345a; 557a.

207. Notleer (Schilter: Thesaurus. Ulm 1727). Psalmen 1, 40; 51 a; 111 a; 314c; $610 \mathrm{~b} ; 438 \mathrm{c} ; 2,162 \mathrm{c} ; 226 \mathrm{c} ; 311 \mathrm{a} ; 410 \mathrm{~b} ; 480 \mathrm{c}$. Oratio dominica $1,169 \mathrm{c}$.

208. Williram: Paraphrase des Hoheliedes (Schilter: Thesaurus. Ulm 1727). 1, 30a; $320 \mathrm{c}$; lat. Vorrede $325 \mathrm{c} ; 432 \mathrm{c} ; 476 \mathrm{a} ; 609 \mathrm{~b} ; 2,347 \mathrm{a} ; 368 \mathrm{a} ; 476 \mathrm{c}$. 
209. Annolied (Opitz: Incerti Poetao Teutonici Rhythmus de Sancto Annone. Danzig 1639). QR. B. 2. 1, 18c;83b;224b;342b;399c;432c;668b; 2, 11a; $274 \mathrm{c} ; 394 \mathrm{~b} ; 486 \mathrm{~b}$.

210. Rolandslied (Schilter: Thesaurus. Ulm 1727). Fragmentum de bello Hispanico (Seracenico) Caroli Magni 1, 56b;80a;96a;111c;259c;342c;554c;646b; Stricker 2, 146 b; $405 \mathrm{c}$.

211. Lucidarius (Elucidarius MS. QR.). 1, 35c;135c;479b;2, 231 a; 369a; $393 \mathrm{c}$; $412 \mathrm{c}$; in MS. cujus titulus Elucidarius $434 \mathrm{a} ; 454 \mathrm{c}$.

212. Brandanglegende (Vita Sancti Brandani; MS. de Sancto Brandano). QR. 1, 3 b; $118 \mathrm{c} ; 342 \mathrm{~b} ; 513 \mathrm{c} ; 2,63 \mathrm{c} ; 322 \mathrm{c} ; 403 \mathrm{~b} ; 440 \mathrm{~b}$.

218. Vom Priester Johann (MS.). QR. 1, 174b;232b;278a;2, 31b;264c;462c; 458 \%.

214. Jeroschin: Übersetzung der Preußischen Chronik des Petrus Duisburgensis 'MS. in Teutschen Versen vom 14ten Seculo' QR. 1, 25c; Prolog 63c; $391 \mathrm{~b}$; 417a; im Poeten Jeroschin MS. 2, 144b; 236b; Prolog 290a; 378b; Prolog $421 \mathrm{a} ;$ Jeroschin und ein anderes MS. $486 \mathrm{~b}$.

215. Fin alter Poet (mhd.) 1,343b; 2,203a. Vgl. die Verse ohne Quellenangabe von 'Trimhilt der Königin' 2, 379b und den Hinweis auf die Nebelkappe 'bey den Alten Helden-Gedichten' 1, 500 b.

216. Das Heldenbuch. 'Henrich von Osterdingen (sic) Helden-Buch oder erdichtete Thaten von alten Helden' QR. I, 26a; 26c; $49 \mathrm{a}$; im Helden-Buch des sogenannten Auctoris von Osterdingen $370 \mathrm{c} ; 391 \mathrm{a} ; 428 \mathrm{~b}$; Vorrede $449 \mathrm{a} ; 631 \mathrm{a}$; Anhang $2,10 \mathrm{c} ; 77 \mathrm{c} ; 316 \mathrm{~b} ; 362 \mathrm{a} ; 410 \mathrm{a} ; 429 \mathrm{~b}$.

1, 303b zitiert Frisch aus Besold: Thesaurus practicus 'aus Wolfram von Eschenbach. authore des Helden-Buchs in praef.'; ohne Hinweis auf Besold benutzt Friseh diese Praefatio noch $1,626 \mathrm{~b} ; 627 \mathrm{c} ; 2,304 \mathrm{~b} ; 443 \mathrm{c}$.

217. Poeta Anonymus: MS. Historia Scholastica in der Anrede Jacobs an geine Söhne. MS. der Paulinerbibliothek zu Leipzig (Joachim Feller: Catalogus codicum mss. Bibliothecae Paulinae in Academia Lipsiensi [1686] 163).

Zitiert nach Johann Gottlob Horn: Handbibliothek von Sachsen P. VII (QR.) 1, 554c; sonst ohne Hinweis auf Horn: 1, 64a; $330 \mathrm{a} ; 357 \mathrm{~b} ; 556 \mathrm{c} ; 2,157 \mathrm{~b}$; $158 \mathrm{a} ; 483 \mathrm{a}$. Vgl. $1,27 \mathrm{c} ; 26 \mathrm{a}$.

\section{b) Altdeutsche Textsammlungen, Glossare und wortgeschichtliche}

\section{Untersuchungen}

218. Achilles Pirminius Gasser (Gassarus): Erklerung der alten Teutschen worten (Otfrid-Glossar). In: Flacius Illyricus: Otfridi evangeliorum liber. Basel 1571. Lex. 1, 55c; Dict. 170b; Gloss. 221 b; $413 \mathrm{a}$.

219. Goldast: Paraeneticorum veterum pars I. Lindau 1604. 1, 478b; 2, 10 o. Der Winsbecke 1, $103 \mathrm{~b}$; (Weinbeck) 2, 155a. Die Winsbeckin, König Tyro 2, 394b.

220. Goldast: Alaxaannicarum rerum scriptores aliquot vestuti. Frankfurt 1606 . QR. 1, 19c;422a;441b;446b;2, 376a; annales Hepidanni 457b; Jonas Abbas in vita Columbani 4800; Monatsnamon Karls des Großen 1, 350; 'daselbst mehr Exempel' 137a; alter Teutscher Poet 544a; 'übersetzt einer' 2, 477c; Freher 52 a. Vetus symbolum $2,17 \mathrm{~b} ; 284 \mathrm{~b} ; 364 \mathrm{c} ; 409 \mathrm{~b} ; 421 \mathrm{a}$. Vetus confessio $1,63 \mathrm{c} ; 168 \mathrm{~b} ; 348 \mathrm{~b} ; 2,29 \mathrm{a} ; 290 \mathrm{a}$. Ekkehard Junior 1, 186a; 187c; $511 \mathrm{a}$; 2, 150a; 275b. Charta Alamann. 1, 15b; $40 \mathrm{a}$.

221. Freher: Decalogi, orationis dominicae ot symboli apostolici versio Saxonica vetustissima. (1609 B. 34; 1, 169o) 1610. Alte Version des Symboli 2, 77b; 79a. Formula a Frehero edita 1609 1, 169 c. 
222. Junius: Observationes in Willerami abbatis Francicam paraphrasin Cantici Canticorum. Amsterdam 1655, 1, 551 b.

223. Lambecius: Commentariorum de bibliotheca Caesarea Vindobonengi libri VIII. 1665-1679. QR. Oratio Dominica (Notker) 2, 78a. Beichte Karls des Großen 1, 50a. U'ber Handschriften der Groldenen Bulle I, 197b. Vgl. I, 46a.

224. Vorstius: Observationum in linguam vernaculam specimen. Berlin 1669. QR. B. 4. $1,42 \mathrm{c} ; 77 \mathrm{a} ; 2,408 \mathrm{c}$.

225. Morhof: Unterricht von der Teutschen Sprache und Poesie. Kiel 1682. (Lübeck 1702 B. 22). 2, $376 \mathrm{c}$.

226. Eckart: Incerti monachi Weissenburgensis Catechesis Theotisca seculo IX conscripta. Hannover 1713. QR. B. 36. l, 50a; $93 \mathrm{c}$.

227. Eckart: Veterum monumentorum quaternio. Hannover 1720. 1, $197 \mathrm{c}$.

228. Eckart: Corpus historicum medii aevi sive soriptores rerum gestarum a tem. poribus Caroli Magni ad finem seculi XV. Leipzig 1723, QR. B. 82. Poerna germanicum (in Band II) $1,2 \mathrm{c} ; 15 \mathrm{a} ; 27 \mathrm{a} ; 395 \mathrm{a} ; 2,1520 ; 486 \mathrm{~b}$. Historia amissionis terrae Sanctae (in Band III) 2, $45 \mathrm{c}$.

229. Eckart: Commentarii de rebus Franciae orientalis. Würzburg 1729. QR. $1,183 \mathrm{~b} ; 289 \mathrm{a} ; 399 \mathrm{c} ; 428 \mathrm{~b} ; 438 \mathrm{a} ; 501 \mathrm{c} ; 2,295 \mathrm{c} ; 321 \mathrm{c} ; 437 \mathrm{c}$. Hildebrandslied ('In Glossario antiquo') 2, 166e ; in vet. Gloss.' 439a. Kapitular Karls des Großen $480 a$.

230. Schilter: Thesaurus Antiquitatum Teutonicarum (Band III: Glossarium Teutonicum QR.). Ulm 1727. B. 81. 1, 9a;17c;259c;301a;433a;473a; $539 \mathrm{a}$; $2,174 \mathrm{c} ; 411 \mathrm{~b} ; 427 \mathrm{~b}$. Diplomata Ludovici Germanici et Caroli Magni 1, 49c; Aota Noricorum Comitiorum (1470) 56 b; Tacitus, Ammianus Marcellus $62 \mathrm{~b}$; Johann a Leidis 143a; e libro Salico monasterii Ebersheim 194c; Walahfrid Strabo 203c; edictum Monetale Ruperti $289 \mathrm{a}$; Aota monasterii Murensis $300 \mathrm{~b}$; Reinesius 343c; Acta Comit. Noriberg. (1470) et Vienn. 2, $19 \mathrm{~b}$.

Kero, Glossarium Monseense 1, 170a; Diecmann 170b; Gloss. Vett. Belg. 49 o; Glossae MS. Anglo-Saxonicae 46a; $87 \mathrm{a} ; 149 \mathrm{~b} ; 396 \mathrm{c} ; 514 \mathrm{~b}$; Otfrid-Übersetzung $93 a$; 417a; Flacius, Goldast 636b; Soherz 417a; Palthen 225a; 609 c; Kalend. Germ. $7 \mathrm{c}$; Calend. Alam. 2, $20 \mathrm{c}$; Glaubensbekenntnis des Concilium Liptinense 1, 314c; MSC. Bibl. 374b; 380c; Historie Dieterichs von Berne 4c; Steinhöwel 21 a (Von den fürnohmsten Weibern); 338b; $497 \mathrm{a}$; Keisersberg 374a; 627c; Brösamlein 315c; Narrenschiff 2, $112 \mathrm{~b}$; Irrend Schaf $112 \mathrm{~b} ; 139 \mathrm{~b}$.

231. Wachter: Glossarium Germanicum. Leipzig 1737. QR. B. 90. 1, 433 a; 463c; $612 \mathrm{~b} ; 2,17 \mathrm{c} ; 159 \mathrm{a} ; 193 \mathrm{c}$; Halma: Niederländisches Wörterbuch $263 \mathrm{a}$; Cluver: Germania antiqua $263 \mathrm{~b} ; 291 \mathrm{~b} ; 346 \mathrm{~b} ; 418 \mathrm{a}$.

232. Haltaus: Calendarium medii aevi. Leipzig 1729. QR. 1, 31 a; 42 c;106 c; 234c; $402 \mathrm{a} ; 434 \mathrm{a} ; 457 \mathrm{~b} ; 2,20 \mathrm{c} ; 68 \mathrm{~b} ; 176 \mathrm{a} ; 213 \mathrm{a} ; 401 \mathrm{a} ; 419 \mathrm{c} ; 436 \mathrm{c} ; 489 \mathrm{c}$.

233. Pez; Miscellanea Theotisca. $1,9 \mathrm{a} ; 324 \mathrm{c} ; 337 \mathrm{a} ; 343 \mathrm{~b} ; 346 \mathrm{c}$.

234. 'Herr Grüwel zu Kremmen' (bei Berlin; Gewährsmann Frischs für eine etymologische Herleitung) 1, $503 \mathrm{~b}$.

\section{c) Frühneuhochdeutsche Wörterbücher}

235. Vocabularius theutonicus. Nürnberg: Zeninger 1482. QR. In der Regel als 'vocabularium vetus' zitiert ('ein alter teutscher und Latino-barbarus Vocabularius' QR.; ältestes deutsches Wörterbuch 1, 215b); 'Rusticanum (terminorum)' De primis lexicis; $1,531 \mathrm{~b}$. Vocabularium Anonymi $543 \mathrm{c}$; Verfasser: der Utbersetzer der deutschen Bibel Nürnberg: Koburger 1483? 306 b. Exemplar der Nürnberger Stadtbibliothek $325 \mathrm{a} .1,417 \mathrm{~b} ; 490 \mathrm{a} ; 2,398 \mathrm{~b} ; 409 \mathrm{c} ; 469 \mathrm{c}$. 
286. Wenzeslaus Brack: Vocabularius rerum. Straßburg: Prüß 1489. Diese Ausgabe De primis lexicis; eine Ausgabe von 1449 (so QR.; 2, 405c) existiert nicht. Verfasser irrtümlich Brand 1, 476c. 1, 1c; 2, 392 b; 405 c; 411 c;467a; $155 \mathrm{~b}$.

237. Johannes Altenstaig: Vocabularius vocurn, quae in opere Grammattico plurimorum continentur (cum addita Germanica explicatione). Hagenau 1508. (Hagenau 1522 B. 78) QR.; De primis lexicis. 1, 15c;375 b; $400 \mathrm{c} ; 470 \mathrm{a} ; 2,147 \mathrm{~b}$.

238. Gemma gemmarum. 'Lexicon Latino-Germanicum' QR.; dio Ausgabe Straß. burg 1508 'in Bibliotheca Regia Berolini' nennt Frisch in der Abhandlung De primis lexicis; Beleg mand. (mnfr.) Lautstands 1, 336a. 1, 4c;42b; $463 \mathrm{~b}$; 2, $217 \mathrm{a} ; 285 \mathrm{c} ; 368 \mathrm{c} ; 432 \mathrm{c}$.

289. Petrus Dasypodius: Diotionarium Latinogermanicum et vice versa Germanicolatinum. Straßburg 1536 (1537). Straßburg 1535. 1536. 1537 De primis lexicis. Editio 1537 QR.; B, 18; irrtümlich 1531 2, $475 \mathrm{c}$. Vielfach benutzt Frisch die Ausgabe vom J. 1536: $1,81 \mathrm{~b} ; 407 \mathrm{o} ; 2,147 \mathrm{~b} ; 437 \mathrm{c}$ uö.; aus dem lat.-dt. Teil gewonnene Belege 1, 503a (mit Verweis auf eine Formvariante 'im Teutschen Indice'); 2, 2800; $437 \mathrm{c}$ uö. 'Dasypodius in seinem Lexico Ger"* manico-Latino so auch eines von den ältesten ist' $2,417 \mathrm{c} ; 7 \mathrm{~b} .1,437 \mathrm{~b} ; 2,21 \mathrm{a}$; $137 \mathrm{~b} ; 387 \mathrm{a} ; 483 \mathrm{c}$.

240. Erasmus Alberus: Novum Dictionarii Genus. Frankfurt 1540. Lexicon 'worinnen die Wörter nach den Reimsylben stehen' QR.; De primis lexicis; B. 18. Lexicon Germanicum rhythmicum 1, $205 \mathrm{~b}$; Lexicon Poeticum $618 \mathrm{a}$; irrtiumlich 1640 2, 373c. 2, 421 a.

241. Johannes Serranus : Dictionarium Germanicolatinum (Dictionarium Latinogermanicum. Nürnberg 1539. Augsburg 1540). 1549. QR.; 1, 571a; 574a (rgl. Specimen I S. 24; 60).

242. Johannes Frisius: Dictionarium Latino-Germanicum. Zürich 1541, 1556. QR. (Zürich 1536 [ = 1556], additum est Germanico-Latinum . . a studioso quodam) De primis lexicis; o. O. u. o. J. B. 18; Zürich 1664 B. $63 ; 1,17 \mathrm{a} ; 77 \mathrm{c} ; 44 \mathrm{a}$; $2000 ; 479 a ; 360 a ; 485 a ; 503 a ; 2,261$ a.

243. Paul Eber/Caspar Peucer: Vocabula rei numariae, ponderum et mensurarum Graeca, Latina, Ebraica ... Addita sunt appellationes quadrupedum, insectorum, volucrium, piscium. Wittenberg (1552) 1558. QR. 1, 2a;12c;24a;40b; aus Georg Agricola $80 \mathrm{c} ; 420 \mathrm{c} ; 2,5 \mathrm{~b} ; 9 \mathrm{c} ; 128 \mathrm{c} ; 144 \mathrm{c} ; 243 \mathrm{~b} ; 304 \mathrm{~b} ; 399 \mathrm{~b} ; 443 \mathrm{c}$. Ausonius 2, $336 \mathrm{c}$.

244. Josua Maaler (Pictorius): Die Teütsch spraach. Zürich 1561. De primis lexiois; B. 63. 'Pictorius im Teutsch-Lateinischen Lexico Ann. 1561' 1, 27a; irrtümlich Pistorius 472c; 'Pictorius oder Mahler' $318 \mathrm{~b}$; 'Piotorius der ältesten Teutschen Lexicographorum einer' 2, 418a; des Pictorii altes Lexicon $397 \mathrm{a} ; 7 \mathrm{~b}$; Lexicon Helveticum 1, 425c. 1, 326a;354c;397c;477c;2,88a;228c;417c.

245. Petrus Apherdianus: Methodus discendi formulas Latinae lingua $\theta$. Nunc primùm ... accessit dictionum et phrasium Germanica interpretatio, per M. P. Köln 1577. QR.; B. 36. 'Das CöInische Vocabularium Apherdiani' 1, 4b; ndl. 170a; 'Apherdian. in seinem Nider-'Teutschen' 2, 77a; $486 \mathrm{c}$. Häufig als 'Tyrocinium (Latinae linguae)' zitiert (vgl. QR.) 2, 371 a; 371 b; 374b; 374.c; $446 \mathrm{a}$.

246. Theophilus Golius: Onomasticon Latinogermanicum. Straßburg 1585. Diese Ausgabe (o. O.) B. 19; (o. J.) 1, 264a. QR. 2, 155b; $217 \mathrm{a}$; $359 \mathrm{a}$.

247. Nicodemus Frischlin: Nomenclator trilinguis. Frankfurt 1586. QR. Editio Arthusii (Gotthard Arthus: Nicodemi Frischlini nomenclator, trilinguis auctus et illustratus. Frankfurt 1616) 1,20b. Frankfurt 1708. B. 18. 1, 339c;475a; $2,122 \mathrm{c} ; 432 \mathrm{c}$.

248. Martin Ruland: Nomenclator trilinguis. QR. 1, 88 a. 
249. Nathan Chytraeus: Nomenolator Latino-Saxonicus. Lübeck 1597. QR. 1, 342c. $1,23 \mathrm{~b} ; 226 \mathrm{c} ; 2,33 \mathrm{~b} ; 432 \mathrm{c} ; 477 \mathrm{~b}$. (Lübeck 1596 B. 19).

250. Hieronymus Megiser: Thesaurus polyglottus vel dictionarium multilingue. (Frankfurt 1603). 2, 82a.

251. Frisch verwertet mehrfach die Angaben eines lateinisch-deutschen Vokabulars, das als Anhang zu einer Vergil-Ausgabe des Jahres 1605 (1603: 1, 33b; 235c) erschienen ist: 'in einer alten Edit. Virg. im Vocabulario daran 1605' 2, $432 \mathrm{c}$. $1,23 \mathrm{~b} ; 80 \mathrm{~b} ; 204 \mathrm{a} ; 321 \mathrm{c} ; 338 \mathrm{~b} ; 396 \mathrm{c} ; 2,34 \mathrm{~b} ; 120 \mathrm{a} ; 265 \mathrm{~b} ; 288 \mathrm{c} ; 293 \mathrm{~b} ; 381 \mathrm{c}$; $390 \mathrm{~b} ; 452 \mathrm{a} ; 464 \mathrm{c}$.

252. Wolfgang Schönsleder: Promptuarium Germanicolatinum. Augsburg 1618. $2,162 \mathrm{~b}$.

253. Georg Pasor: Lexicon Graecum Novi Testamenti. (Herborn 1654 B. 18; Amsterdam 1641 B. 19). 1, 360a.

254. Johann Amos Comenius: Orbis sensualium pictus. Nürnberg 1658. 1, 45 b.

255. Erich Weismann: Lexicon bipartitum Latino-Germanicum et Germanico-Latinum. $1,13 \mathrm{a} ; 15 \mathrm{~b}$.

256. Kaspar Stieler: Der Teutschen Sprache Stammbaum und Fortwachs oder Teutscher Sprachschatz. Nürnberg 1691. B. 63. B. 64. 1, 13a; 32 c; $33 \mathrm{~b} ; 114 \mathrm{c}$; $213 \mathrm{a} ; 218 \mathrm{a} ; 265 \mathrm{a} ; 334 \mathrm{~b} ; 366 \mathrm{a} ; 2,70 \mathrm{a} ; 383 \mathrm{c} ; 408 \mathrm{c} ; 417 \mathrm{~b} ; 483 \mathrm{a}$.

257. Matthias Kramer : Das herrlich Grosse Teutsch-Italiänische Dictionarium. Nürn. berg 1700/02. B. 62. 1, 73a;157b;233b;2, 210a; 408c; vgl. 1, 429b.

258. Basilius Faber: Thesaurus eruditionis scholasticae. Leipzig 1710. B. 80. Deutscher Index 1, 123 c. 1, 397 c; 2, 356a.

259. Benjamin Hederich: Promtuarium Latinitatis probatae et exercitae oder Vollständigstes Teutsch-Lateinisches Lexicon. Leipzig 1729. B. 63, 1, 576 b.

260. Christoph Ernst Steinbach: Vollständiges Deutsches Wörter-Buch. Breslau 1734. B. 18. 1, 32c; $46 \mathrm{c} ; 576 \mathrm{~b}$; 'Herr Steinbach' 2, $263 \mathrm{~b}$.

261. Verdeckte Berufungen auf lexilkalische Quellen: 1, $77 \mathrm{~b} ; 91 \mathrm{c} ; 94 \mathrm{a} ; 99 \mathrm{c} ; 111 \mathrm{~b}$; $158 \mathrm{a} ; 187 \mathrm{c} ; 372 \mathrm{~b} ; 489 \mathrm{c} ; 530 \mathrm{a} ; 678 \mathrm{a} ; 2,57 \mathrm{c} ; 41 \mathrm{c}$. Glossarium Latino-Theotiscum 2, $296 \mathrm{~b}$.

\section{d) Mundartenwörterbü̈cher}

262. Johann Ludwig Prasch: Glossarium Bavaricum. In: Dissertatio altera de origine Germanica linguae Latinae. Regensburg 1689. B. 70. QR. 1, 572 b.

263. Christien Meisner: Silesia loquens. Wittenberg 1705. QR. 1, 37c; $127 \mathrm{~b} ; 205 \mathrm{c}$; $326 \mathrm{a} ; 544 \mathrm{~b} ; 576 \mathrm{~b} ; 2,34 \mathrm{~b} ; 37 \mathrm{c} ; 56 \mathrm{c} ; 69 \mathrm{~b} ; 76 \mathrm{a} ; 175 \mathrm{a} ; 208 \mathrm{a} ; 234 \mathrm{c} ; 440 \mathrm{~b}, V_{\mathrm{gl}}$. $1,505 \mathrm{a} ; 2,74 \mathrm{c} ; 302 \mathrm{~b}$.

\section{e) Grammatiken, Sprachlehrbücher}

264. Johannes Despauterius: Grammaticae institutionis libri VII. Köln 1679. De primis lexicis; $1,603 \mathrm{c} ; \mathrm{QR} .2,32 \mathrm{a} ; 216 \mathrm{c} ; 371 \mathrm{~b}$.

265. Justus Georg Schottel: Teutsche Sprachkunst. Braunschweig 1641, B. 35. 1, $232 \mathrm{~b}$.

266. Justus Georg Schottel : Ausführliche Arbeit von der Teutschen HaubtSprache. Braunschweig 1663. QR. B, 64. 1, 636a; 674a. Ohne Angabe des Titels: Tauler $1,60 \mathrm{c} ; 93 \mathrm{c} ; 133 \mathrm{c} ; 195 \mathrm{~b} ;$ Otfrid $635 \mathrm{c} ; 2,393 \mathrm{c} ; 408 \mathrm{c} ; 446 \mathrm{a}$.

267. Georg Philipp Harsdörffer: Teutscher Secretarius d. i. Titular- und FormularBuch. (Nürnberg 1661). 1, 401b; 524a; 2, 112a. Ohne Angabe des Titels $1,444 \mathrm{~b}$. 
268. Saib: Hofmäßiger Cancellist. 2, $56 \mathrm{c}$.

289. Adam Friedrich Glaffey: Anleitung zur weltüblichen Teutsohen Schreib-Art. Nürnberg 1730. QR. 1, 563 b; im Alphabet der juristischen Wörter 2, $114 \mathrm{c}$.

270. Johannes Bödiker: Grund-Sätze der Teutschen Sprache. Berlin 1690. B. 58. B. 26. 2, 350a.

\section{f) Selbstzitate FrISOHs}

271. Miscellanea Berolinensia. 1, 11 c; 28b;197a; 322b;433b;452c;469c;489c; $571 \mathrm{~b} ; 646 \mathrm{~b} ; 2,48 \mathrm{a} ; 59 \mathrm{~b} ; 84 \mathrm{a} ; 121 \mathrm{a} ; 312 \mathrm{c}$. QR. B. 78 .

272. Der Erste Auszug Von einigen die Teutsche Sprach betreffenden Stücken. Berlin 1734. $1,11 \mathrm{c} ; 378 \mathrm{c}$.

\section{B. LITERARISCHE QUELLEN UND NICHTSPRACH . WISSENSCHAFTLICHE HILFSMITTEL}

\section{B. 1. 2. Dichtung. Religion / Theologie}

Nur eine sehr kleine Gruppe von Quellen gehört der deutschen Dichtung des 16. und 17. Jahrhunderts an. Stetig benutzt sind ellerdings einige Werke des lehrhaften Schrifttums (Brant Narrenschiff; Scheidt Grobianus; eine Sprichwörtersammlung des 16. Jahrhunderts) sowie das Kirchenlied; auch auf die zahlreichen Belege aus dem Heldenbuch ist an dieser Stelle hinzuweisen. Dagegen beschränkt sich der Anteil der Barockliteratur auf einen Zufallsbeleg (Hofmannswandau), der dem Wörterbuch Stringacirs entnommen ist. Die Werke der führenden Dichter des 17. Jahrhunderts fehlen. In der Reihe der Quellen religiös-theologischen Inhalts schließen sich zunächst die vorlutherischen Bibelübersetzungen (darunter mehrere Handschriften) zu einer größeren Gruppe zusammen. Die Lutherbibel ist mit einer reichen Zahl von Belegen vertreten; ihre veralteten Wortschatzbestandteile hatte Frisce bereits 1723 in der Neuauflage der 'Grund-Sätze' BödikERs zu sammeln und zu erklären begonnen, und zwar im Anschluß an eine ältere Zusammenstellung BöDIKERs und an DIEDERICH von STADEs Lutherglossar (1711), das er später auch in der zweiten Auflage (1724) kennenlernte. Die deutschen und lateinischen Werke LUTHERs werden mehrfach nach der'Jenaer, einmal nach der Altenburger Ausgabe zitiert, doch entnimmt Friscr seine Belege in weitem Umfange Einzeldrucken der Reformationszeit; dabei bilden die Frühwerke der Jahre 1518-1524 eine besonders starke Gruppe. Das verbleibende Quellengut-überwiegend theologisches Erbauungs-, Lehr- und Streitschrifttum der Reformationszeit - tritt an Bedeutung zurück.

\section{B. 1. Dichtung}

273. WeltSpiegel / oder NarrenSchiff / . . alles auff Sebastian Brands Reimen gerichtet ... Weilandt / Durch den hoohgelerten Johan Geyler . . . in Lateinischer sprach beschrieben / jetzt aber ... inn das recht hoch Teutsch gebracht .... durch Nicolaum Höniger. Basel 1574. 'Kaysersbergers in Teutsche Reimen übersetztes Narrensehiff' QR. 'von Branden ins Teutsche übersetzt' $2,8 \mathrm{~b}$. 'in Seb. Brands Versen' $1,4 b ; 5 b ; 38 c ; 388 c$; Brand im Narrenschiff $669 c$; 2, 390b; Teutsche Edition 451 a.

274. Reinekse Vos mit dem Koker. Wolfenbüttel 1711. (Lübeck 1498). 1, 23 a.

275. Hans Sachs: Sehr Herrliche schöne vnd warhaffte Gedicht. Nürnberg $1558-$ 1579. 2, 166 a. 'Hanns Sachß in seiner Lebens-Beschreibung' 1, 62 b. 
276. Kaspar Scheidt: Grobianus / Von groben sitten, vnd vnhöflichen geberden. Worms 1551. (1586 1, 475b). 'Grobianus in Teutschen Versen' QR. 1, 4b; $4 \mathrm{c}$; Vorrede 11c; 395c; 2, $136 \mathrm{~b} ; 159 \mathrm{c}$; Vorrede $309 \mathrm{~b} ; 426 \mathrm{~b}$.

277. Alte Teutsche Sprichwörter. QR. (Vgl. Sammlung teutscher und andrer Sprüchwörter. Frankfurt 1565. B. 35). Mit dt. Eriklärung 1, $7 a$; 'In einer alten Samamlung dor Teutschen Sprichwörter' 105 b; 'ein Buch voll Teutscher Sprichwörter' $151 \mathrm{a} ; 392 \mathrm{~b}$; Zigeunerwort 430a; 484o; 2, 70b; 'Der Auctor setzt dazu' 86a; $168 \mathrm{a} ; 202 \mathrm{c} ; 476 \mathrm{a}$.

278. (Johann Fischart): Ernewerte Beschreibung der . . verwunderlichen Geschicht Vom Herren Petern von Stauffenberg genant Diemringer. Straßburg 1588. (1598) 1, 654b.

279. Christian Hofmann von Hofmannswaldau: 1, 369a (nach Steinbach 1, 637). 280. Johann Valentin Pietsch (1690-1733): Carmen an die russische Kaiserin Anna (= Der denckwürdige Tag der Krönung ... Ihro Kayserlichen Majestät ... Anna Ivanowna [1730]) 2, $29 \mathrm{c}$.

281. Georg Tobias Pistorius: Thesaurus paroemiarum Germanico-Juridicarum. Leipzig 1716. QR. B. 35 .

282. Erwähnungen und verdeckte Quellenberufungen: Theuerdank 2, $371 \mathrm{~b}$. Meistergesang 1, 657c. Froschmäuseler $300 \mathrm{c} ; 651$ a. Fabel von den Mäusen, die der Katze die Schelle umhängen wollen $505 \mathrm{~b}$. Einige Poeten $179 \mathrm{c} ; 334 \mathrm{~b} ; 378 \mathrm{a}$; $523 \mathrm{~b}$. Stellenzitate $180 ; 334 \mathrm{~b} ; 528 \mathrm{~b} ; 2,74 \mathrm{~b}$.

\section{B. 2. Religion / Theologie}

283. Talmud 1, 502a; 2, 141a.

284. Septuaginta $1,101 \mathrm{~b} ; 174 \mathrm{c} ; 324 \mathrm{~b} ; 359 \mathrm{c} ; 492 \mathrm{a} ; 2,210 \mathrm{c}$.

285. Vulgata $1,54 \mathrm{a} ; 137 \mathrm{c} ; 166 \mathrm{c} ; 492 \mathrm{a} ; 2,210 \mathrm{c} ; 280 \mathrm{c} ; 329 \mathrm{c}$.

286. Hieronymus 2, 14la. in Joel, 88 a. ad Eustachium 20c. ad Chromatium 44b. ad Euagrium $357 \mathrm{~b}$.

287. Biblia Germanica. Nürnberg: Koburger 1483. QR. (eine uhralte Teutscho Catholische Bibel, von 1484 durch C. Ant. Coburger in Nürnberg B. 80). Verfasser: der Bearbeiter des Vocabularius theutonicus Nürnberg 1482 ? 1, 306 b. Vorrede des Hieronymus $1,13 \mathrm{~b} ; 573 \mathrm{c} .12 \mathrm{~b} ; 29 \mathrm{~b} ; 33 \mathrm{a} ; 2,141 \mathrm{~b} ; 146 \mathrm{~b} ; 147 \mathrm{a} ; 388 \mathrm{c}$.

288. Codex MS. Bibliae 'welchen ich Spenerianum zum öfftern nenne, weil er in D. Ph. Iac. Speneri Bibliotheck gewesen' (1, $311 \mathrm{~b})$ QR. 1, $3 \mathrm{~b} ; 11 \mathrm{c} ; 29 \mathrm{~b} ; 450 \mathrm{~b}$; $488 \mathrm{c}$; in diesem Wörter-Buch offt citirt $626 \mathrm{a} ; 2,47 \mathrm{c} ; 218 \mathrm{a} ; 368 \mathrm{a} ; 437 \mathrm{~b}$; $488 \mathrm{c}$.

289. Codex MS. Bibliae (Vgl.: Vetus Codex, cujus initium deficit usque ad Exodi cap. 8. antiquo Germanico sermone, cum initialibus penna pictis cujus aetas incerta B. 80). 1, 3b; $4 \mathrm{c} ; 5 \mathrm{a} ; 53 \mathrm{~b} ; 197 \mathrm{a} ; 364 \mathrm{a} ; 372 \mathrm{~b} ; 439 \mathrm{~b} ; 547 \mathrm{c} ; 2,148 \mathrm{a}$; $399 \mathrm{c} ; 409 \mathrm{c} ; 410 \mathrm{~b} ; 471 \mathrm{c}$. Vgl. setzung der Bibel 2, $293 \mathrm{~b}$.

290. Codex MS. Novi Testamenti Bibliothecae Reg. Berolin. 1, 129b; $233 \mathrm{~b} ; 380 \mathrm{c}$; $417 \mathrm{c} ; 2,10 \mathrm{a} ; 133 \mathrm{~b} ; 148 \mathrm{a} ; 298 \mathrm{a} ; 368 \mathrm{a} ; 380 \mathrm{c} ; 409 \mathrm{c} ; 422 \mathrm{a} ; 437 \mathrm{~b} ; 454 \mathrm{c}$.

291. Concordantiae Evangelicae MS. Bibliothecae Reg. Berolin. QR. 1, 13c. 1c; $114 \mathrm{c} ; 129 \mathrm{~b} ; 182 \mathrm{~b} ; 202 \mathrm{c}$; Evangelienbuch MS. 226a; 506a; $566 \mathrm{a} ; 679 \mathrm{~b}$; Concordanz der Evang. MS. 2, $39 \mathrm{c} ; 179 \mathrm{a} ; 368 \mathrm{a} ; 437 \mathrm{~b} ; 440 \mathrm{~b} ; 477 \mathrm{c}$.

292. Evangelium Nicodemi MS. 1, 1410; $491 \mathrm{a}$.

293. Versio Saxonica Bibliae. 1520. 1, 169c;489c; 554o; 2, 77a; 214c;476c.

294. Lutherbibel. In der Regel ohne Nennung Luthers, des Titels und der Ausgabe zitiert nach den biblischen Büchern. QR. 1,20 ausser dem Biblischen Stylo

10 Powitz, Frischs Worterbuch 
nicht mehr gebrëuchlich; $3 \mathrm{a} ; 4 \mathrm{c} ; 9 \mathrm{c}$ in einigen Auflagen der Teutschen Übersetzung der Bibel; $13 \mathrm{~b}$ die meisten editionen der Übersetzung Lutheri; $25 \mathrm{c}$ welches sonsten nicht nachzuthun ist; $179 \mathrm{c}$ welches aber ausser der Teutschen Bibel-Uebersetzung nicht bey allen wohl lautet; 251a in der Teutschen Über. setzung $\mathrm{D}$. Luthers annoch gewöhnlich; 354 b; 396a nur noch in der Biblischen Version Lutheri; $417 \mathrm{c}$ veraltet ausser der Biblischen Übersetzung; $434 \mathrm{a} ; 2,55 \mathrm{~b}$; $96 \mathrm{~b} ; 97 \mathrm{~b} ; 127 \mathrm{a} ; 156 \mathrm{~b} ; 182 \mathrm{a} ; 204 \mathrm{~b} ; 221 \mathrm{a} ; 256 \mathrm{~b} ; 263 \mathrm{~b} ; 273 \mathrm{a} ; 274 \mathrm{a}$ in OberSachsen; 284b; 288c; 350a; 391 c noch im Xten Psalm; 427a Vergleich mit dem Tatian; $486 \mathrm{c}$ des Reineacii Edition in Folio.

295. Diederich von Stade: Erläuter- und Erklärung der vornehmsten Wörter, deren sich . . . Doct. Martin Luther in Uebersetzung der Bibel in die Deutsche Sprache gebrauchet. Stade 1711. 1724. QR. (1724 B. 18). 1, 13b; 40b; 300a; $434 \mathrm{a}$; Voc. Bibl. 565 c; Glosse einer ndl. Bibel 635 b; Anhang der Edition 1724 2, 409 a.

296. Zürcher Bibel (Die gantze Bibel nach einer eignen Teutschen Verdolmetschung: E. Christoph Froschauer. Zürich 1536. B. 80). 1, 29 b; in der Schweitzerischen Bibel des Froschhovers 324 a.

297. M. Fr. Lankisch : Deutsche, hebrëische und griechische Konkordanzbibel. Leipzig/Frankfurt 1696. (B. 80). I, 9c; $1696123 \mathrm{c} ; 156 \mathrm{~b} ; 179 \mathrm{c} ; 481 \mathrm{~b}$.

298. Luther: Werke (Vgl.: 'Lutherus in seinen ersten Schrifften' 1, 30a). QR. Jene.. Germ. 1555-1558: 1, 40; 63b; 152b; nach Stade 434a; 434b; 2, $413 \mathrm{~b}$. Jena. Lat. 1556-1558: 1, 152b. Altenburg 1661-1664: Vom Greuel der Stillmesse $2,395 \mathrm{~b}$.

299. Luther: Deutsch Auslegung des Vater vnnser fuer dye einfeltigen leyen. Leipzig: 1518. $1,114 \mathrm{a} ; 123 \mathrm{~b} ; 178 \mathrm{~b} ; 2,8 \mathrm{~b} ; 412 \mathrm{~b}$.

300. Luther: Ein Sermon von dem Gebet und Prozession in der Kreuzwoche. 1519. $1,4 \mathrm{~b} ; 152 \mathrm{~b}$.

301. Luther: Ein Sermon von dem Bann. 1520. 1, $58 \mathrm{c}$.

302. Luther: An den christlichen Adel deutscher Nation von des christlichen Standes. Beaserung. Leipzig 1520. 1, 12b;29c;32c;148c;336c;484a; 2, $171 \mathrm{~b} ; 299 \mathrm{c}$; $302 \mathrm{a} ; 358 \mathrm{c} ; 375 \mathrm{~b} ; 419 \mathrm{c} ; 477 \mathrm{~b} ; 479 \mathrm{a}$.

303. Luther: Von dem Papsttum zu Rom wider den hochberühmten Romanisten. zu Leipzig. 1520. 1, 149a; 367b; 540a; 638a; in der Schrifft wider einen Franciscaner in Leipzig $2,88 \mathrm{~b} ; 138 \mathrm{a} ; 283 \mathrm{c} ; 336 \mathrm{c} ; 375 \mathrm{~b} ; 483 \mathrm{a}$.

304. Luther: Das Magnificat verdeutschet und ausgelegt. 1521. 2, $19 \mathrm{a}$.

305. Luther: Kirchenpostille. 1522. 1, 124a; $587 \mathrm{c} ; 2,24 \mathrm{c} ; 33 \mathrm{c} ; 232 \mathrm{c} ; 459 \mathrm{~b}$.

306. Luther : Ursach und Antwort, daß Jungfrauen Klöster göttlich verlassen mögen.. 1523. 1, 127c;223c;2, 390c; $478 \mathrm{c}$.

307. Luther: Das Jhesus Christus eyn geborner Jude sey. 1523. 1, 632c; 2, $131 \mathrm{~b}$; $248 \mathrm{~b}$.

308. Luther: An die Radherrn aller stedte deutsches lands: des sie Christliche: schulen auffrichten vind hallten sollen. 1524. 1, $42 \mathrm{~b} ; 64 \mathrm{a} ; 202 \mathrm{c} ; 236 \mathrm{~b} ; 357 \mathrm{c}$; $2,33 \mathrm{c} ; 85 \mathrm{~b} ; 136 \mathrm{~b} ; 254 \mathrm{c} ; 364 \mathrm{c} ; 424 \mathrm{c}$; in gantzen Büchlein $437 \mathrm{~b} ; 453 \mathrm{c}$.

309. Luther: Der 127. Psalm ausgelegt an die Christen zu Riga in Liefland. 1524.. $1,418 \mathrm{c} ; 479 \mathrm{c} ; 493 \mathrm{c}$.

310. Luther: Sermon am Sonntag nach dem Christtag. 1524. 1, 115 b.

311. Luther: Deudsch Catechismus. 1529. (Der große Catechismus Lutheri durch M. Spangenberg. Leipzig 1542. B. 1). 1, $89 \mathrm{a} ; 2,486 \mathrm{~b}$.

312. Luther: Verantwortung der aufgelegten Aufruhr von Herzog Georg samt einem. Trostbrief an die Christen. 1533. 1, 173a; 356b;467b;2,81b;124a; 295a; $296 \mathrm{c} ; 361 \mathrm{~b} ; 368 \mathrm{c}$.

313. Luther: Hauspostille, 1544. 2, 2830. 
314. Luther: Vom neuen und alten Glauben. $1,374 \mathrm{~b} ; 511 \mathrm{a} ; 2,83 \mathrm{a} ; 139 \mathrm{~b}$.

315. Luther: Vom Alcoran. $1,517 \mathrm{~b} ; 2,16 \mathrm{c}$.

316. Luther: Commensal. (edit. Lips.). 1, $206 \mathrm{~b}$.

317. Konrad von Halberstadt: MS. 2, $467 \mathrm{~b}$,

318. Ein Buch Profectus genannt. MSt. von einem Teutschen Ritter gemacht, Ein Mystischer Tractat und Unterricht, wie man in Christenthum zunehmen soll. QR.

319. Historia passionis ex patribus. MS. Bibliothecae Reg. Berolin. QR. 1, 15b; $109 \mathrm{~b} ; 226 \mathrm{~b} ; 487 \mathrm{a} ; 625 \mathrm{a} ; 2,46 \mathrm{~b} ; 140 \mathrm{a} ; 245 \mathrm{c} ; 255 \mathrm{a} ; 426 \mathrm{~b}$.

320. Psalterium cum apparatu vulgari familiariter appresso. Lateinisch psalter mit dem teutschen nützlichen dabey gedruckt. Augsburg: Ratdolt 1494. (Ein uhralter Lateinischer und Teutsoher Psalter B. 62). 1, 93a; 321 c; 328c; 485b; $554 \mathrm{~b} ; 2,122 \mathrm{a} ; 408 \mathrm{c} ; 422 \mathrm{a}$.

321. Heinrich Bebel (1472-1518): Triumphus Veneris. In: Opera Bebeliana Sequentia. Pforzhoim 1509. $1,620 \mathrm{c}$.

322. Geiler von Keisersberg: Das irrig schaf. Straßburg (1510). 1, 112b.

323. Geiler von Koisersberg: Das schön buch genant der seelen Paradiss. Straßburg 1510. 1, 260a.

324. Geiler von Keisersberg: Die brösamlin Doctor Keiserspergs vffgelesen von Frater Joh. Paulin. Straßburg 1517. 1, 119a; 152c;171a; 320c; 525c;552b.

825. Geiler von Keisersberg: Postill: Uber die fyer euangelia durchs jor. Straßburg 1522. (Vgl. B. 83). QR. 1, 5a; 13a; 29b;226c; Vorrede 285b;345a; $388 \mathrm{a}$; $390 \mathrm{~b} ; 437 \mathrm{a} ; 446 \mathrm{c} ; 493 \mathrm{~b}$; zu Kaysersb. oder Doct. Gailers Zeiten A. $1400662 \mathrm{a}$; $2,43 \mathrm{~b} ; 165 \mathrm{c} ; 177 \mathrm{~b} ; 242 \mathrm{c} ; 279 \mathrm{~b}$; Albertus Magnus 344c;357a; 399c; 417c; $422 \mathrm{c} ; 463 \mathrm{c} ; 480 \mathrm{c} ; 489 \mathrm{a}$.

326. Johannes Oelkolampedius (1482-1531): Colloquium Bernense. QR, 1, $13 \mathrm{~b}$.

327. Dis büchlin ist genant der Gilgengart ainer yetlichen Cristenlichen seel. (Augsburg vor 1520). QR. B. 7. 1, $135 \mathrm{~b}$; in der Litaney 137a; in einem Catholischen Gebet-Buch der Gilgen-Garten genannt 217c;362c;372a; 679c; 2, 71b; $157 \mathrm{~b}$.

328. Leo Jud (1482-1542): Paraphrases zu tütsch. Die Epistlen sancti Pauli. In Latin durch Dr. Erasmum von Roterdam kürzlich beschryben vnd klarlich vszgelegt durch Meister Leonem Jud Pfarherrn zu Eynsidlen gentzlich dem Latin nach vertütscht. Zürich 1521 . QR. B. $62.1,5 \mathrm{~b} ; 35 \mathrm{~b} ; 147 \mathrm{c}$; Randschrift 154c;182b;432a;443c;490c;2, 267a;308c;132a;380b;403b; $422 \mathrm{c} ; 459 \mathrm{~b}$.

329. Bogen, den ein Prediger-Mönch von seiner Begebenheit 1522, zu Nürnberg ausgehen lassen. 1, 31 a.

330. Andreas Keller (Cellarius; 1503-1562): Ein schone auszlegung des xxiij Capitels / yn Mattheo, dardurch angezeygt / die art vnd eygenschafft, des Phariseyschen hauffens. Straßburg 1524. QR. 1,140c;327o; 372a; 412a; $489 \mathrm{a} ; 673 \mathrm{~b} ; 2,141 \mathrm{a} ; 148 \mathrm{c} ; 175 \mathrm{~b} ; 196 \mathrm{c} ; 212 \mathrm{a} ; 354 \mathrm{a} ; 357 \mathrm{c}$.

331. Johann Sonnentaller: Ursache, warum der vermeinte geistliche Haufe das Evangelium nicht annimmt, sondern verfolgt. 1524. QR. 1,370c; 2, 331c; $473 \mathrm{~b}$.

332. Urbanus Regius (Rhegius; 1489-1541): Unterricht, wie ain Christenmensch got seinem herren teglich beichten soll. Augsburg 1521 (1525 B. 7). 1, 209c; $636 \mathrm{c} ; 2,17 \mathrm{~b} ; 387 \mathrm{a}$.

333. Geystliche gesenge so man ytzt (Got zu lob) ynn der Kirchen singt ... Wittenberg 1525. Gedruckt zu Erffort durch Wolffgang Sturmer. 1, 5a; Symbolum nebst vielen Liedern $19 \mathrm{~b} ; 224 \mathrm{c}$; Collection Teutscher Gesänge, Erfurt 1325. 
im 36sten Lied 348b; 348a;352c; Agend-Büchlein oder Antiphen. Erfurt 1528 $608 \mathrm{~b} ; 656 \mathrm{~b}$; alte Antiphon $1525 \ldots$ zu Erfurt gedruckt 2, $475 \mathrm{c}$.

834. Geistliche Lieder, Kirchenlieder, Gebete. 1, 10c; 79b; Gebetsverse 87a; Passionsgesang 92e; Luther: Ein feste Burg 155b; in den Kirchen-Gesängen 168a; Morgenlied 244b; Paul Gerhard 311e; lat. 311c; Pfingstlied 351c; 357a; $489 a$; der Auctor eines bekannten Lieds $541 \mathrm{c}$; Luther: Hymnus Am. brosii $544 a ; 610 a ; 626 a$; Luther 632 c;636a; Vom Himmel hoch ... 642a; $646 \mathrm{~b} ; 654 \mathrm{~b} ; 2,14 \mathrm{c} ; 61 \mathrm{c} ; 95 \mathrm{~b} ; 111 \mathrm{c}$; Weihnachtslied $143 \mathrm{~b} ; 169 \mathrm{c} ; 279 \mathrm{c}$; Vom Himmel hooh ... 300b; 319b;375 c; 385a; 410b;486b. Vgl.: 'beim singen ehmals unter gemeinen Volck' $1,481 \mathrm{~b}$.

835. Radtschlag Des allerheiligsten Vaters Bapsts Pauli des Dritten, Mit dem Collegio Cardinalium gehalten, wie das angesatzte Concilium zu Trient fürzunemen sey. 1545. B. 7. Satyra auf das Concilium Tridentinum QR. (Reinasatiro). $1,90 \mathrm{a} ; 123 \mathrm{~b} ; 1595313 \mathrm{~b} ; 536 \mathrm{a} ; 641 \mathrm{~b} ; 2,19 \mathrm{~b} ; 34 \mathrm{a} ; 389 \mathrm{~b} ; 394 \mathrm{c} ; 435 \mathrm{c} ; 467 \mathrm{a}$. Vgl,: 'in einer Sobrifft von An. 1545' 1, $3 \mathrm{~b}$.

336. 'Ein gewisser Auctori, der ein Buch geschrieben, das er den Hosen-Teufel genannt' 1, 542a = Andr. Museulus: Vom Hosenteufel. Franlkfurt/Oder 1556.

337. Sebastian Frank (1499-1542): Die gülden Arch, darein der Kern vnd dio besten Hauptspruch der heil. Schrifft, alter Leerer vnd Vätter der Kirchen ... eingeleibt soind. Bern 1557. QR. B. 83. 1, 328b; 2, $361 \mathrm{c}$; Sebastian Frank von Anno 1557 schreibt es auch in seinen Büchern also 1, 147a. Ohne Titel : 2, 172c ; $261 \mathrm{~b}$.

338. Felix Faber: Pilgerbuch. QR. (Eygentliche Beschreibung der Hin unnd Widerfarth zu dem hl. Landt. gen Jerusalem. 1558). 1, 226c; 523a.

339. Johann Mathesius (1504-1565): Historia von des erwürdigen Manns Gottes D. Martin Luther Anfang, Lehr, Leben, vnd Sterben. Nürnberg 1566. 1, $475 \mathrm{c}$; $642 \mathrm{a}$.

340. Johann Mathesius: Diluuium d. i. außlegung der erschräcklichen vnd widerumb tröstlichen Historien von der Sündflut in 54 predigten. Nürnberg 1587. $1,490 \mathrm{~b}$.

341. Johann Mathesius: Explicatio Evangel. Dom. XXII. post Trinit. 2, $258 \mathrm{c}$.

342. Philipp Nicolai (1556-1608): 2, $229 \mathrm{~b}$.

343. Thomas (Nicolaus?) Fuller: 1, 492a.

344. Zeuner: Laetar, vulgo Toden-Sonntag Jen, 2, $375 \mathrm{c}$.

345. Joachim Schröder (1603-1677): Helllklingende und durchdringende FriedensPosaune. Aufrichtigen und wahrhaftigen Bericht der löblichen Universität Rostock wegen Abschaffung der Schoristerey und Pennalismi. 1640. 1, 189c; 2, 34c; 168a. (Predigt). QR.

346. Johann Conrad Dannhauer (1603-1666): Evangelisches Momorial. Straßburg 1661. 1, 160 b. QR.

347. Joachim Lütkemann (1608-1655): Aufmunterung zum lebendigen Glauben. $1,560 \mathrm{a} ; 671 \mathrm{~b} ; 2,19 \mathrm{~b} ; 318 \mathrm{~b}$. Vgl. 1, 460a.

348. Libellus der ganzen Welt Religion. Amsterdam 1668. 1, $165 \mathrm{c}$.

349. Johann Musqeus (1613-1681): Ablehnung der ausgesprengten abscheulichen Verleumdung, als wäre in Jena eine neue Secte der Gewissener entstanden. Jena 1674: 2, 454b.

350. Jacob Thomasius (1622-1684): Dissertatio de poculo S. Johannis. Leipzig 1675. 1, 490a.

351. Veit Ludwig von Seckendorff (1626-1692): Commentarius historicus et apologeticus de Lutheranismo seu de reformatione. 1688-1692, QR. 1, 322a; 2, 395b. Ohnè Titel 2, 73 a. 
352. Paul Christian Hilscher (1666-1730): Diatribe de Dominica Laetare. Leipzig 1690. (Curiöse Gedancken Von dem Gebrauche am Sonntage Laetare Welchen man insgemein nennet Den Todt austreiben. Dresden/Leipzig 1701). 2, 375c.

353. Acta Sanctorum, quotquot toto orbe coluntur vel a catholicis scriptoribus celebrantur ... collegit ... J. Bollandus (u. a.). Mensis Junii. Antwerpen 1695-1717. 1, 382a.

354. Johann Andreas Schmidt (1652-1726): Abusum Psalmi CIX imprecatorii vulgo Das Tod-Beten. Helmstedt 1708. 2, 375a.

355. Johann Andreas Schmidt: Prolusionum Marianarum nona. Helmstedt 17.18. B. 103. 2, 461c.

356. David Chytraeus (1530-1600) in Contin. Schützii (Otto Friedrich Schütz: Verfasser der libri IV de vita Dav. Chytraei commentariorum). 2, 204.b.

357. Balthasar Philgus (Prediger in Lindau): Predigt vom Windsturm. 1, 285a.

358. Johann Michael Dilherr (1604-1669): Christliche Betrachtungen des gläntzenden Fimmels, flüchtigen Zeit- und nichtigen Weltlauffs. Nürnberg 1657. $1,452 \mathrm{c}$.

359. Johann Michael Dilherr: Propheten-Schul. Nürnberg 1662. 1, 506a.

360. Liebknecht: $D \ominus$ fraternitate hortensium. QR. 1, 322a.

361. Christian Gotthelf Blumberg: Kurtze Abbildung des Kalands oder deren Brüderschafft (Theologisches Bedenken zu Rostook) 1721. 1, 162a.

362. Carolus Kirchmaier: Der Cardinalshut. 1, $165 \mathrm{c}$.

363. Alte Stiftung eines Altars zu Berlin in der Nicolaj-Kirche. 1, 169a.

364. s. Quelle 808 .

\section{B. 3. Geschichte}

A. Welt- und Kirchengeschichte

B. Geschichte einzelner Völker

a) Griechen und Römer

b) Orientvöllker

c) Osteuropäische Völker

d) Skandinavische Völker

e) Friesen. Niederländer. Angelsachsen. Schotten

f) Franken

C. Deutsche Geschichte

a) Mittelalterlich $\Theta$ Geschichtsdarstellungen

b) Quellensammlungen

c) Geschiohtsdarstellungen der neueren Zeit

d) Urlzundensammlungen. Urkunden

e) Quellensammlungen und Darstellungen zur Geschichte der deutschen Länder und Städte (Norddeutschland - Mitteldeutschland - Süddeutschland)

Der umfangreiche Quellenbestand gliedert sich in zwei Gruppen: auf der einen Seite stehen Werke insbesondere der frühneuhochdeutschen Zeit, die Friscr als Sprachquellen planmäßig und in ziemlicher Dichte exzerpiert hat; auf der anderen Seite das historische Spezialschrifttum, das nur für den Einzelfall herangezogen wird und vielfach nicht eigentlich als Quelle, sondern als Hilfsmittel für die Klärung sachlicher und geschichtlicher Fragen dient. Den Kernbestandteil der ersten Gruppe bilden Stadt. und Landeschroniken der frühneuhochdeutschen Zeit sowie neuere 
Darstellungen zur Geschichte der deutschen Territorien. Neben den Werken, die Frisch in selbständigen Drucken oder in handschriftlicher Utberlieferung kennen. lernt, werden die umfassenden Quellensammlungen zur deutschen Geschichte, dio seit dem 16. Jahrhundert erschienen waren, für das 'Teutsch-Lateinische WörterBuch' bedeutsam. Landschaftlich verteilen sich die Quellen über das gesamte deutsche Sprachgebiet: Norddeutsohland (insbesondere der niedersëchsische Raum mit Oldenburg, Hamburg, Lübeck, Lüneburg, Braunschweig; Anhalt, Magdeburg und die Mark Brandenburg); Mitteldeutschland (Hessen, Thüringen, Sachsen und Schlesien) und Süddeutschland (Schwoiz, Elsaß, Rhoinpfalz, Schwaben, Bayern, Franken, Osterreich).

\section{A. WELT - UND KIROHENGESCHICHTE}

365. Jacobus de Vitriaco: Libri duo quorum prior orientalis sive hierosolymitanae: a)ter occidentalis historiae nomine inscribitur. Duaci $1597.1,166 \mathrm{~b}$.

366. Matthaeus Dresser (1536-1607): Historia orbis. QR. 1, 510; 820.

367. Adam von Bremen: Historia ecclesiastica. 2, $440 \mathrm{c}$.

368. Caspar Hedio (1494-1552): 'Teutsche Übersetzung des Chronicons Eusebii. Item, der Kirchen-Historie' QR. Vgl. B. 83: D. Caspar Fedion Chronica der alten Christl. Kirchen als 1. Eusebius, 2. Sozomeni Socratis und Theodoreti, 3. Continuation der letztern bis zu seiner Zeit. Teutsch. Straßburg 1545. (Vgl. B. 90). Eusebius: 1, $17 \mathrm{~b} ; 39 \mathrm{a} ; 201 \mathrm{a} ; 420 \mathrm{~b} ; 2,383 \mathrm{c}$. Kirchonhistorio 1, $14 \mathrm{c}$.

369. Bibliotheca veterum patrum et auctorum ecclesiasticorum. Hg. v. M. de la Bigne. Paris 1576-1579. 1, 76 b.

370. Johann Friedrich Gronov (1611-1671): Monobiblos observatorum in scriptoribus ecclesiasticis. Deventer 1651. 2, $59 \mathrm{c}$.

371. Adam Rechenberg (1642-1721): Historia ecclesiastica. QR. 1, 30a.

372. Caesar Baronius (1538-1607): Amales ecclesiastici. Rom 1588-1593. 2, 88 a.

373. Caesar Baronius: Martyrologium Romanum. Antwerpen 1589. 2, $45 \mathrm{c}$.

374. Claude Chastelain (1639-1712): Martyrologium. 1, 51 b; 3400.

375. Gilles Ménage (1613-1692): Catalogus Sanctorum. 1, 197b; $197 \mathrm{c}$.

376. Acta Literaria Sueciae Upsaliae publicata. (1720ff.) 1725 (nicht 1625). QR. Darin: Catalogus Archi-Praepos. Lincopiens. 1, $83 \mathrm{a}$.

377. Walahfrid Strabo (um 807-849): De rebus ecolesiasticis. 1, 22c; vgl. 203c.

378. Walahfrid Strabo: de visionibus Wettini monachi Augiensis. $1,51 \mathrm{~b} ; 228 \mathrm{c}$.

379. Wolfhardus (Mönch des 9. Jhs.): De miraculis S. Walburgis (Dt. Ưbersetzung). 2, 107b.

380. Caesarius von Heisterbach (1150-1240): Dialogus magnus vigionum ot mira. culorum 2, 164b; miraoul. 335a; mirabil. $402 \mathrm{a}$.

381. Rudolphus Hospinianus: $D_{\theta}$ origine monachatus. Zürich 1668. 2, 368b.

382. Rudolphus Hospinianus: De festis Judaeorum et Christianorum. Zürich 1592. 1, 19 a.

383. Nicolaus Guertler (1654-1711): Historia Templariorum. Amsterdam 1691. $2,368 \mathrm{~b}$.

384. Thomas Reinesius (1587-1667): De Valdensibus. 2, 333a. Vgl. 1, 343c; 646 a.

385. Gottfried Arnold (1666-1714): Unparteiische Kirchen- und Ketzer-Historie. Frankfurt 1699. 2, 454b. 
386. Daniel Papebroch (1628-1714): Notae ad vitam Bardonis. 1, 51c.

387. Ragguaglio del Dominio temporale del Papa. Paris 1676. (B. 30). 1, 576c.

388. 'Historie der Kriege im gelobten Land wider die Saracenen' 1, 154a.

\section{B. GESOHIOHTE EINZELNER VOLKER}

\section{a) Griechische und römische Geschichte}

(s. unter $A$ 2b und $A$ 2c)

\section{b) Orientvölker}

389. Johann Jacob Schudt (1664-1722): Compendium historiae Judaicae. Frankfurt 1700. (B. 33). 1, 228b.

390. Johann Leunclavius (Löwenklau) (um 1530-1593): Pandeatae historiøe Turcia日. Frankfurt 1588, 1, 485a.

391. Haitonus Armenius: L' Hystoire merueilleuse ... du grand Empereur de Tartarie ... nomme lo grand Can. Paris 1522. 1, 50a.

392. Blasius de Vigenère (1522-1596): Illustrations sur l'histoire de Chalcocondyle. $1,340 \mathrm{~b}$.

\section{c) Osteuropäische Völker}

393. Antonius Bonfinius (um 1500): Rerum Ungaricarum Deaades III. Basel 1543. Basel 1568. 2, 471a,

394. Stephan Zamosky (Zamoscius): Analecta lapidum vetustorum et aliarum in Dacia antiquitatum. Padua 1593. 2, 471 a.

395. Aeneas Sylvius (1405-1464): Historia Bohemica. Rom 1475. 1, 654b; 2, $165 a$.

396. Johannes Dubravius (gest. 1553): Historiae regni Boiemiae . . libri XXXIII. Proßnitz/Mähren 1552. 1, 173 a.

397. Wenceslaus Hagek a Liboczan (gest. 1552): Böhmische Chronica, von Ursprung der Böhmen, von ihrer Hertzogen und Könige . . . Ankunfft . . . deutsch von J. Sandel. Prag 1596. 2, $260 \mathrm{c}$.

398. Hagen: Chron. Bohem. 1, 376 b; Descript. Bohem. 2, $139 \mathrm{a}$.

399. Bohuslaus Aloysius Balbinus (1621-1688): Miscellanea historica regni Bohemiae. Prag 1679-1688. 2, $218 \mathrm{~b}$; $440 \mathrm{a}$.

400. Bohuslaus Aloysius Balbinus: Epitome historica rerum Bohemicarum libris VII comprehensa. Prag 1673-1677. 1,674c.

401. Paulus Stransky de Sapenska (gest. 1657): De republica Bojema, cum prae. fatione Frid. Rothscholtzii. Amsterdam 1713. (B. 9). 1, 376 b; 2, 404a.

402. Jan Herburt z Fulstyna: Chronicon sive historicae Polonicae ... descriptio. Basel 1571. 1, 355a.

403. Gottfried Lengnich (1689-1774): Geschichte der preußischen Lande kgl. polnischen Antheils. Danzig 1722-1755. QR. 2, 476a.

404. David Braun (1664-1737): De scriptorum Poloniae et Prussiae historicorum, politicorum, et JCtorum, typis impressorum ac manuscriptorum in Bibliotheca Brauniana collectorum, virtutibus et vitiis, catalogus, et judicium. Köln 1723. 2, $381 \mathrm{c}$.

405. Hector Gottfried Masius (1653-1709): Schediasma de Diis Obotritis. Kopenhagen 1688. QR. 2, 271 a.

406. Arnold von Lübeck (1177-1212; Fortsetzer der 'Slawenchronik' Helmolds) $1,475 \mathrm{~b}$. 


\section{d) Skandinavische. Völker}

407. Johannes Messenius (1581-1637): Scondia illustrata, seu chronologia de rebus Scondiae h. e. Sueciae, Daniae, Norvegiae atque una Islandiae Gronlandiaeque. Hg. v. J. Peringskiöld, Stockholm 1700-1705. QR. 1, 37c;82c.

408. Johann Georg Keysler (1693-1743): Antiquitates selectae septentrionales et Celticae. Hannover 1720. QR. B. 33. 1, 524c;2, $224 \mathrm{~b}$.

409. Saxo Grammaticus (gest. um 1208): Historiae Danicae libri XVI. St. Johannes Stephanius recognovit notisque illustravit. Sorö 1644. (Chronographus Saxo QR.). 1, 20b; 69b; 156b; 372b; 34lb; 2, 418b. Stephanius ad Saxonem Grammaticum (QR.) 1, 66a.

410. Johann Isaak Pontanus (1571-1.639): Rerum Danicarum libri $X$ usque ad domum Oldenburg. Amsterdam 1631. 1, 415b.

411. Thormodus Torfaeus: Series dynastarum et regum Daniae a Skioldo Odini filio ad Gormum grandaevum. Kopenhagen 1702. Islëndische Historie, Landnamasaga $1,569 \mathrm{c}$.

\section{e) Friesen. Niederländer. Angelsachsen. Schotten}

412. Olivarius Vredius (gest. 1642) : Historiae comitum Flandriae a J. Caesare ad a. 787 libri prodromi duo. Brügge 1650. (Vetus Flandria QR.). Lex HJudovici et Hlotarii 1, 316a; 324a; 437c;438a; 549b;568a; 636c; vetus lex 2, 29a; $37 \mathrm{~b} ; 47 \mathrm{c} ; 143 \mathrm{c} ; 220$; ex Pauli Merulae Glossario Franc. $385 \mathrm{~b}$.

413. Ubbo Emmius (1547-1625): Historia rerum Frisicarum. Leyden 1616. 2, 441 b.

414. Johann de Hocsem (1278-1348): 1, 621 a.

415. Beda Venerabilis $(673-735): 2,35 \mathrm{~b}$. Historiae ecclesiasticae gentis Anglorum libri V 1, 211 a. Martyrologium 2, $122 \mathrm{c}$.

416. James Ussher (Usserius; 1581-1656): Britannicarum ecclesiarum antiquitates et primordia. Dublin 1639. Aus dem Codex Cottonianus 1, 320a.

417. Gesta Alfredi 871 latino-barbare 1, 38a.

418. Matthaeus Parisiensis (gest. 1259): Historia Major (Angliae), 1, $51 \mathrm{~b}$; 540a; nach Vossius 2, $163 \mathrm{~b}$; Statuta S. Jul. in Anglia in addit. 335a; 438a; 452b.

419. Matthaeus Westmonasteriensis: Flores historiarum, praecipue de rebus Britannicis ab exordio mundi usque ad annum 1307. 2, $419 \mathrm{~b}$.

420. William Camden (Cambdenus; 1551-1623): Britannia sive florentissimorum regnorum Angliae, Scotia, Hiberniae et Insularum adjacentium . . . Descriptio. London 1586. In Daumonii 1, 542a.

421. Robert Sheringham (gest. 1677): Disceptatio de Anglorum gentis origine. Cambridge 1670. Götternamen der Edda 1, 20a.

422. Gervasius Tilburiensis (13. Jh.): Otia Imperialia (Teildruck in: Gervasii Tilburiensis ... de Imperio Romano et Gothorum, Lombardum, Brittonum, Francorum, Anglorumque regnis commentarius. Ed. J. Mader. Helmstedt 1673) 2, 456 b. 1, 59c; 443a; 642a.

423. Gottfried Wilhelm Leibniz: Excerpta veterum. Ex Gildae Hist. de introitu Sax. in Britanniam 2, 470 b. Gesta Dagoberti 1, 49 b.

424. George Buchanan (1506-1582): Rerum Scoticarum Historia. Edinburg 1582. 1, 211 a.

\section{f) Franken}

425. Gregor von Tours (um 540-594): Opera omnia necnon Fredegarii epitome et chronicon cum suis continuatoribus et aliis antiquis monumentis. Ed. 
Theod. Ruinart. Paris 1699. Gregorius Turonensis: Historiae Francorum libri $\mathrm{X} 1,49 \mathrm{~b} ; 167 \mathrm{~b} ; 324 \mathrm{c} ; 477 \mathrm{a} ; 2,344 \mathrm{a} .1,124 \mathrm{a}$. De vitis patrum liber unus 124a. Fredegarius 62 a. Ruinartus in notis ad Fredegar. $574 \mathrm{~b}$.

426. Flodokrdus (894-966): Chronicon. 1, 336 b.

427. Ademarus monachus (um 1030): Chronicon aquitanicum et francicum. (In: Phil. Labbaeus: Nova bibliotheca manuscriptorum, Bd. 2). 2, $444 \mathrm{~b}$.

428. Sigebertus Gemblacensis (um 1030-1112): Chronicon. 1,651c.

429. Guilielmus Brito (13. Jh.): Philippidos sive de bono principe carminis libri XII cum animadv. et comm. Casp. Barth. Zwickau 1657. B. 78. 1, 51 b; 445b; $2,43 a ; 376 \mathrm{c} ; 377 \mathrm{~b} ; 420 \mathrm{c} ; 424 \mathrm{a} ; 460 \mathrm{a}$.

Kaspar von Barth (1687-1658): Animadversiones in Wilhelmum Britonem. QR. 1, 11 b; 346c;372b; index 478c;2, 43a; $92 \mathrm{a} ; 129 \mathrm{a} ; 265 \mathrm{c} ; 376 \mathrm{c} ; 377 \mathrm{~b}$; $420 \mathrm{c} ; 424 \mathrm{a} ; 430 \mathrm{~b}$.

430. Jean Froissart (1338-1411): Croniques de France, Dangleterre, Descoce, Despaigne, de Bretaigne, de Gascongne, de Flandres. 1, 562 c; 572b.

431. David Blondel (1591-1655): Genealogiae francicae plenior assertio. Amsterdam 1654. 1, $51 \mathrm{~b}$.

432. Hadrianus Valegius (1607-1692) : Rerum Francicarum tomi III. Parig 1644 - 1658. 1, $324 \mathrm{c}$.

433. Hadrianus Valesius: Valesiana, ou les Pensées critiques, historiques et morales et les poésies latines d'Adrien Henry de Valois. Paris 1695. B. 2. 1, 340c.

434. La vie du Vicomte de Dohna. Genf 1630. 2, 433a.

435. Paulus Jovius (1483-1552): Vita Sfortiae ducis clarissimi. Rom 1553. 1, 441 c

\section{DEUTSCHE GESCHICHTE}

\section{a) Mittelalterliche Geschichtsdarstellungen}

436. Paulus Warnefridus (Paulus Diaconus): De gestis Langobardorum libri VI (Diversarum gentium historiae antiquae scriptores tres: Jornandes, Isidorus, Paulus Diaconus. Ed. Fr. Lindenbrog. Hamburg 1611. B. 69). QR. 1, 11 b; $33 \mathrm{c} ; 56 \mathrm{~b} ; 241 \mathrm{~b} ; 258 \mathrm{a} ; 362 \mathrm{c} ; 470 \mathrm{c} ; 2,37 \mathrm{a} ; 294 \mathrm{~b} ; 457 \mathrm{~b}$. Vgl. : Histor. Lombard. $1,7 \mathrm{c}$.

437. Vita Hrabani Mauri 2, 290c. (Vgl.: Hrabanus Maurus an Bataricus, Bischof zu Regensburg. 1, $51 \mathrm{c}$ ed. Brower).

438. Vita et gesta Caroli Magni per Eginhartum. Annales regum Francorum Pipini, Caroli, Ludovici. (Köln 1521 uö.). Eginhard: 1,6a; 2, 355b; 444a; 451b. Annales 1,6c.

439. Nithard: De dissensionibus filiorum Ludovici Pii libri IV $1,6 \mathrm{c} ; 11 \mathrm{~b} ; 2,114 \mathrm{~b}$.

440. Ditmarus von Merseburg: Chronicon 1,92a.

441. Bruno: De bello Saxonico 1,82c.

442. Auctor der Apologie für Heinrich IV, 1, $82 \mathrm{c}$.

443. Bertoldus Constantiensis 1,82c.

444. Otto von Freising: Chronicon sive rerum ab orbe condita ad sua usque tempora gestarum libri VIII. Ejusdem de gestis Friderici I libri II. (Basel 1569). $1,51 \mathrm{a} ; 475 \mathrm{~b}$.

445. Gottfried von Viterbo: 2, $140 \mathrm{~b}$.

446. Conradus Urspergensis (Konrad von Lichtenau): Chronicon a Nino rege Assyriorum magno usque ad Fridericum II. 1, 296a; $513 \mathrm{c}$. 
447. Albertus Argentinensis: De Carolo IV. 1, 56c.

448. Johannes Trithemius: Chronicon $1,68 \mathrm{c} ; 621 \mathrm{a}$.

449. Giovanni Garzoni (Garzon; Gorson): Leben Friedrichs, Landgrafs in Thiringen. 1546, (Ưbersetzung). QR. 1,173c; 218c;441c;662c;2,176b; $202 b ; 316 a ; 429 a ; 427 c$.

450. Alberus: Chronicon $1,439 \mathrm{c}$.

451. Eike von Repgow: Säohsische Weltchronik (Chronik von der Schöpfung an, bis 1229 des von Repkau, wie er sich in der Vorrede nennt. QR.). MS. Bibliothecae Reg. Berolin. 1, 11b. Chron. MS. $122933 \mathrm{~b} ; 39 \mathrm{a} ; 92 \mathrm{c} ; 399 \mathrm{c} ; 437 \mathrm{c}$; $1220642 \mathrm{~b} ; 2,140 \mathrm{~b} ; 409 \mathrm{c} ; 418 \mathrm{a} ; 477 \mathrm{c}$. In der alten Cölnischen Chron. von 1229 1, 325 b; 6c. allwo der Auctor eine Grube dazu gemahlt 540b.

452. (Cr. Botho:) Cronecken der Sassen. Mainz: Peter Schöffer von Gernsheim 1492. QR. I, 5a; 14b;23c;92c;671a;2,70b;220c;252a; $389 \mathrm{a} ; 406 \mathrm{~b} ; 432 \mathrm{~b}$. Vergleich mit dem von Leibniz: Scriptores Brunsuicenses T. III abgedruckten Text der Chronik: 1, 354c; 394c; 2, 93o; Edit. $1492477 \mathrm{a}$.

453. Nicht bestimmbare Berufungen: In einer Sächsischen Chron. 1, 477a; alte Chronik $480 \mathrm{c}$; Vet. Chron. 2, 185 b; $276 \mathrm{~b}$; alte nieders. Chron. 304o; $396 \mathrm{~b}$. Im QR. führt Frisch neben der 'Cronecken der Sassen' (452) eine zweite 'Chronik in Nider-Sächsischer Sprach von An. 1492' auf.

454. Chronicon MS. (hd. Reimohronik) 2, $423 \mathrm{a}$.

455. Werner Rolevinck von Laer: Fasciculus temporum omnes antiquorum chro. nicas complectens. Köln 1474. (Abdruck in: Pistorius, Rerum Germanioarum Scriptores, Bd. II). Dt. Utbersetzung: Bürdlein der zit. Basel 1481. (Bürdlin der Zeit. Fasciculus temporum QR.). Ed. Pistorius 1, 154a; Übersetzung $609 \mathrm{~b} ; 2,235 \mathrm{~b} ; 353 \mathrm{~b} ; 377 \mathrm{c} ; 395 \mathrm{a}$.

\section{b) Quellensammlungen}

456. Johannes Pistorius: Rerum Germanicarum scriptores aliquot insignes. Frankfurt 1583-1584. Ed. B. G. Struve Regensburg 1726. Sigismundus monachus: Chronicon Ecolesiasticum Augustanum 1, $201 \mathrm{~b}$. Regino monachus Prumiensis : Annales 6c; 324c; 367 a; 491 a. Wippo: Vita Conradi Salici 173a.

457. Heinrich Meibom: Rerum Germanicarum Tomi III. Helmstedt 1688. QR. $1,120 \mathrm{a} ; 2,21 \mathrm{a} ; 423 \mathrm{a}$.

Wittichindus Corbeiensis monechus: Annales Saxonicae 1, 475b; $491 \mathrm{a} .6 \mathrm{c}$. Beschreibung der Irminsäule 491 a. Diploma Ottos des Großen 2, $469 \mathrm{~b}$. Chronicon Marienth. 1, 11 c. Chronicon Marcan. $82 \mathrm{~b}$. Chronicon Osnabr. $82 \mathrm{~b}$; 2, 331 c. Chronicon Magdeburg. 1, 72a. Chronicon Comit. Schawenburg $214 \mathrm{~b}$. Chronicon Brem. Henr. Wolteri 224c. Chronicon Archicomitum Oldenburgensium Joan. Schiphhoweri 232 b. Gobelinus 81 b. Lat. Zitat 224c. Historio von den Landgrafen in Thüringen $274 \mathrm{~b}$.

458. Gottfried Wilhelm Leibniz: Accessiones historicae. Hannover 1698. QR. Chronicon Alberici monachi 1, 43a; $51 \mathrm{c} ; 117 \mathrm{~b} ; 197 \mathrm{~b} ; 372 \mathrm{~b} ; 2,33 \mathrm{a} ; 35 \mathrm{c}$; $41 \mathrm{~b} ; 57 \mathrm{a} ; 134 \mathrm{a}$. Chronicon Joh. Viti Durani 1, $6 \mathrm{c.}$

450. Raimundus Duellius: Miscellaneorum libri II. Augsburg/Graz 1723-1724. QR. 1, 393c;473a; 2, 401a; 405 b; $416 \mathrm{a}$.

Chronicon Joan. Rollii 2, 421b. Chronicon Sant Hippolyt 1, 99a; 2, 95a; $123 \mathrm{~b}$; monument. Sanct Hippolytens. 27a. Historia monasterii Chombergens. $198 \mathrm{~b}$. Ex statutis Ardacens. 2, $416 \mathrm{c}$. Statuta der deutschen Ordensritter $265 \mathrm{c}$. Statuta Basileensis consilii $1,490 \mathrm{~b}$. Chronicon Rothenburgense $1,610 \mathrm{c} ; 2,102 \mathrm{c}$. Diplomata: $13021,239 \mathrm{~b} ; 13222,35 \mathrm{~b} ; 1470$ 51 c, $262 \mathrm{~b}$. Chronicon Salisburgense $1,464 \mathrm{c}$. 
460. Johann Friedrich Schannat: Vindemiae litterariae h, e. veterum monumen. torum ad Germaniam sacram praecipue spectantium collectio. Fulde/Leipzig 1723-1724. QR. 1, 246a; 2, 113a; 143c;192a; 4500 .

\section{c) Geschichtsdarstellungen der neueren Zeit}

461. Albert Krantz (gest. 1517): Vandaliae seu de Vandalorum vera origine, variis gentibus, crebris e patria migrationibus et regnis ... libri XIV. Köln 1519. 2, 357a. Ohne Titel: 1, 183 b; nach Hamelmann $223 \mathrm{c}$.

462. Beatus Rhenanus (1485-1547): Rerum Germanicarum libri III. (Basel 1531). Straßburg 1610. B. 38. 1, 254b;639a; 2, 120b; 152b.

463. Petrus Bertius (1565-1629): Commentariorum rerum Germanicarum libri III. Amsterdam 1616. 2, 357a.

464. Philipp Cluverius (1580-1622): Germaniae antiquae libri III. Leyden 1616. $1,139 \mathrm{c} ; 2,53 \mathrm{~b} ; 374 \mathrm{c} ; 420 \mathrm{c}$; nach Wachter 263b. Ohno Titel 1, 437c.

465. Johann Nikolaus Hertius $(1652-1710)$ : Notitia veteris Germaniae populorum. Gießen 1709. B. 68. 1, 296 b; 339a.

466. Elias Schedius (gest. 1641): De. Diis Germanis seu veteri Germanorum, Gallo. rum, Britannorum, Vandalorum religione syntagmata IV. Amsterdam 1648. Halle 1728. 2, 457 \&.

467. Johann Alexander Döderlein (1675-1745): Schediasma historicum . . vallum sive murum die Pfahl-Feck, Pfahl-Rayn, it. die Teufels-Mauer vulgo dictum, in agris Nordgaviensibus ... conspiciendum exhibens. Nürnberg 1713. QR. $2,47 \mathrm{~b} ; 370 \mathrm{a}$.

468. Boecler: Imperium Germanicum (in Ottone II.). 1, $451 \mathrm{~b}$.

469. Antonius Steyerer: Commentarii pro historia Alberti II ducis Austriae cognomento Sapientis. Leipzig 1725. 2, 35b.

470. Johannes Joachim Müller (1665-1731): Historia von der evangelischen Stände Protestation und Appollation wider den Reichsabschied zu Speyer. Jena 1705. 2, 73 a.

471. Friedrich Hortleder (1579-1640): Handlungen und Ausschreiben, Sendbriefe, Berichte ... von den Ursachen des deutschon Krieges K. Caroli V wider die Schmallkald. Bundesobriste. Franlffurt 1617-1618. QR. 1,9b;33a; 399a; $417 \mathrm{a} ; 479 \mathrm{a} ; 2,110 \mathrm{c} ; 142 \mathrm{c} ; 415 \mathrm{a}$. Vgl.: De causis belli Germ. 2, 73a; in König Ferdinands Mandat I, $600 \mathrm{~b}$; Vom Türkenkrieg 2, $83 \mathrm{c}$.

472. Michael Caspar Londorp (Lundorp): Acta publica d. Röm. Kais. Maj. woil. Matthiä u. Ferdinand II Handlung und Aussehreiben. Frankfurt 1621. $1,11 \mathrm{a}$.

473. Theatrum Europaeum oder wahrhaftige Beschreibung aller denckwürdigen Geschichten, so sioh ... fürnehmlich ... in Europa ... von 1617-1718 zugetragen haben. Frankfurt 1635-1738. 1705 1, 230 a.

474. Ein Fistorienschreiber 2, $407 \mathrm{~b}$.

475. Cyriacus Spangenberg (1528-1604): Adelsspiegel. Histor. ausführl. Berioht, was Adel sei, woher er komme... Schmalkalden 1591-1594. QR. 1, 13c; $76 \mathrm{a} ; 365 \mathrm{a} ; 416 \mathrm{~b}$.

476. Michael Praun: Adeliches Europa und noch viel edleres Teutschland. Speyer 1685. QR. B. 33. 1, 355a; $433 \mathrm{a} ; 478 \mathrm{~b}$.

477. Christian Gryphius (I649-1706): Kurtzer Entwurff der Geist- und Weltlichen Ritter-Orden. Leipzig 1697. Breslau 1709. 1, $43 \mathrm{c}$.

478. Veit Ludwig von Seckendorff (1626-1692): Teutscher Fürsten-Stat. Frankfurt 1656. QR. 2, 144a. 
479. Friedrich Lucae (1644-1708): Des Heiligen Römischen Reichs Uhr-alter Fürsten-Saal. Frankfurt 1705. 2, 47 a.

480. Friedrich Lucae: .Des Heiligen Römischen Reichs. Uhr-alter Grafen-Saal. Frankfurt 1702. QR. 1, 232b; $365 \mathrm{~b}$.

481. Burkhard Gotthelf Struve: Neu-Eröffnetes Historisch- und Politisches Archiv. Jena 1706-1722. Etat. Archiv. 1, 441 b.

482. Siegmund Hosemann: Neuvermehrter Regentensaal. Zelle 1698. QR. 1; 145a; $210 \mathrm{~b} ; 669 \mathrm{c} ; 2,118 \mathrm{c}$.

483. Michael Pharetratus (um 1600) : De familia Nobilium de Brandenstein. QR. 1, 2 a.

\section{d) Urkundensammlingen, Urkunden}

484. Johann Jacob Moser: Bibliotheca Manuscriptorum. Nürnberg 1722. QR. Aus Rudolph. Archid. Austr. diplom. 1, 28c; Rudolph IV. Archidux Austr. im Diplorn. der Stadt Wien 348 b; 401 a; 507 c; 2, $323 \mathrm{a} ; 1359404$ a ; 443c. Handfeste Kaiser Friedrichs II. 1, $190 \mathrm{~b} ; 2,184 \mathrm{c}$. Variante zum Landrecht des Schwabenspiegels 1,349 c. 1, 391a; 2,158a; $159 \mathrm{~b}$.

485. J. Chr. Schöttgen - C. G. Kreygig: Diplomatische und curiöse Nachlese der Historie von Obersachsen. Dresden 1730. QR. 1, 565a; 2, 188a; 231 c;478c. Diploma eines Bischofs von Naumburg 281 a. Leben Strigenitii 232 a.

486. Johann Gottlob Horn: Nützliche Sammlungen zu einer historischen Hand. Bibliothec von Sachsen. Leipzig 1728. QR. 2, 1330.

487. Documenta rediviva monasteriorum praecipue in ducatu Wirtenbergico. Tübingen 1636. $2,254 \mathrm{~b}$.

488. Diplomatarium MS. des Klosters Diestorp: 1315 1, 177 a; $1326540 \mathrm{c} ; 1439$ $2,319 \mathrm{~b} ; 433 \mathrm{c}$.

489. Diplomatarium MS. des Klosters Himmelpforte (Mark Brandenburg). QR. Am Mecklenburgisohen 1, 1a; 32c; 95c; Vertrag mit der Stadt Lychen 1320 $118 \mathrm{a} ; 379 \mathrm{c}$; Vidimiertes Copey-Buch 643c; 2, 342b.

490. Fundatio monasterii S. Pancratii in Hammersleben 1112: 2,49 a.

491. Einzelurkunden (Vgl.: Sammlung alter Documenten QR.): Stadt Brandenburg $1170 \mathrm{1}, 122 \mathrm{~b}$; Fürstenwalde 1285, Marchio Otto 644a; Domherren zu Soldin $1363162 \mathrm{~b}$; Bischof Heinrich von Lebus $13651.62 \mathrm{~b}$; Pfalzgraf Friedrich an die Stadt Brandenburg 2, $79 c$; Confirmation Friedrichs II. Elect. Brandenburg. 1448 1, 644a; Brandenburg 365c; Osterburg 198c; Diploma Marchionis Lusatia $1296465 \mathrm{c}$; Diploma Rudolphi I. Elect. Saxon. $1329322 \mathrm{c} ; 644 \mathrm{a}$; Carolus IV. 1350 58b; Diploma 1350 33b; 2, 113c; Diploma Chomburg $1355147 \mathrm{~b}$; Diploma $14001,667 \mathrm{c}$; Vetus contractus $142532 \mathrm{c}$; Eulenburg $1456142 \mathrm{c}$; $172 \mathrm{~b}$; Diploma Friedrichs III. 1461 56 b; (Aeneas Sylvius: Historia rerum Friderici III. Imperatoris) 2, 394a; Kaiserliche Bestëtigung 1470 133 c; Diploma des Kaisers Sigismund, dem Capitel zu Rohr in Bayern gegeben 1, 1630; Diplomata 2, $37 a ; 397 a$.

492. Teutschherrische Acta: $2,385 \mathrm{c}$.

493. Inschriften: Sëuleninschrift 'zwischen Solothurn und Bern, bey einem Dorf Frauen-Brunn genannt' 1, 381 b. Epitaph zu S. Thom. in. StraBburg 141122 b. Gräbschrift 524a.

e) Quellensammlungen und Darstellungen zur Geschichte der deutschen Länder und Städte

Norddeutschland

494. Gottfried Wilhelm Leibniz: Scriptores rerum Brunsvicensium illustrationi inservientes antiqui omnes et religionis reformatione priores. Hannover $1707-$ 
1711. QR. 1, 22a; 424b;2,64c;452a. Index 1, 477a;2,64c;148b;185b; $248 \mathrm{c} ; 308 \mathrm{a}$.

Botho: Chronicon picturatum: 1, lc; $5 \mathrm{a} ; 14 \mathrm{~b} ; 472 \mathrm{c} ; 2,248 \mathrm{c} ; 358 \mathrm{~b}$; vgl. die unter Quelle 452 angeführten Stellen.

Chronicon Stadtwegii: 1, 37c;76b;227c;462c; 2, 57a; $359 \mathrm{a}$.

Chronik von Hildesheim: 1, 226c;324b;419c;615c;2, 370a; $423 \mathrm{c}$.

Lüneburgische Chronik: 1, 5a; 185c;491 b; 661 a; Lied 2, 105a; 379c.

Chronicon Rhythmicum: 1, 2c;501 b;2,85a;123a (vgl.1,365c);37 I c. Vergleich mit der von Gobler hergestellten Textfassung der Chronik (J. Gobler: Chronica vnd Historien der Braunschweigischen Fürsten herlzommen. Frankfurt 1566. Abgedruckt in: Leibniz, Script. Brunsv. B. III) 'Im Tom. III. Script. Brunsv. ist zu dem Nidersächs. Chron. Rhythmico Gobleri Ober-Teutscher Codex beygedruckt' 2,433b. 1,225 c;299b;354a; 461b;2, 32b;66a; 155b; $311 \mathrm{a} ; 361 \mathrm{~b}$; $431 \mathrm{c} ; 476 \mathrm{c}$.

Chronicon. Korneri: $2,361 \dot{\mathrm{a}} ; 394 \mathrm{c}$.

Chronicon Halberstadense: $2,419 \mathrm{c}$.

Chronicon Bremense Joh. Rhode Archiep.: 1, 652 b; 2, 385 b.

Chronicon Slavorum: 2, 396b; $405 \mathrm{a}$.

Chronicon Rhythmicum Gandersheimense (Rhythmi Everhardi de eccles. Gandesh.): $1,193 \mathrm{c} ; 212 \mathrm{a} ; 431 \mathrm{c} ; 472 \mathrm{~b}$.

Chronicon S. Aegidii: 1, 612a.

Chronicon Riddageshus.: $1,174 \mathrm{~b}$.

Annales Corbeyenses: $1,150 \mathrm{c} ; 646 \mathrm{c} ; 2,39 \mathrm{a} ; 370 \mathrm{a}$.

Buschius: Reformatio monasteriorum: $1,76 \mathrm{c} ; 154 \mathrm{a} ; 485 \mathrm{a} ; 2,306 \mathrm{a} ; 316 \mathrm{a}$; $353 \mathrm{~b} ; 372 \mathrm{~b}$.

Vita Meinwerci Episc. Paderborn.: 1, 298a; $298 \mathrm{~b}$.

Vita Godehardi Episc. Hildesh. : 2, 302 b.

Ditmar: 2, 344a; Vita Henrici 252 a.

Compilatio chronologica: 1, 173a; 391 a.

Catalogus reliquiarum Ecclesiae Collegiata Goslariae: 2, 262 a.

Arenpek: Do Guelfis : 1, 54b.

Collationes Witikindi Corbeiensis: 1, $83 a$; 341 a.

Emendationes Gervasianae: $2,35 a ; 419 c$.

Kirchenvisitation : 2, 134a.

Stifftische Fehde: 1, 220a; 624b; 2, 355a; $403 \mathrm{~b}$.

Notitia rei nummariae Luneburg.: $1,382 \mathrm{~b} ; 644 \mathrm{~b} ; 2,182 \mathrm{c} ; 454 \mathrm{~b}$.

Poota Saxo: 1, 224b; $433 \mathrm{~b}$.

Leges Brunsvicenses (Braunschweigische Gesetze; Stadtrecht von Braunschweig): $1,4 \mathrm{~b} ; 8 \mathrm{c} ; 38 \mathrm{c} ; 412 \mathrm{~b} ; 460 \mathrm{a} ; 2,399 \mathrm{c}$.

Goslarische Rechte: 1, 8c; 26a; 408c; 2, 367c; 44lc. Stadtrecht: 1, $343 \mathrm{c}$; 2, 427a. Erbgesetze: 2, 369a; 453a; 454b. Berggesetze:1, 17 c; 480a; 'In den Rammelbergischen Bergwerken bey Goßlar' $498 \mathrm{~b} ; 2,363 \mathrm{c} ; 435 \mathrm{c}$.

Leges Luneburgenses: $2,449 \mathrm{~b} ; 465 \mathrm{c}$. Stadtrecht: $2,88 \mathrm{~b}$.

Leges Cellenses: 1, 231 a.

Leges Saxonicae: $2,114 \mathrm{~b}$.

495. Albert Krantz (gest. 1517): Ecclesiastica Historia seu Metropolis, de primis christiana religionis in Saxonia initiis, deque ejus episcopis et horum vite, moribus, studiis et factis. Basel $1548,1,82 \mathrm{~b} ; 320 \mathrm{a} ; 2,432 \mathrm{c}$.

496. Werner Teschenmacher (nicht: Teschenreuter; gest. 1638): Annales Cliviae, Juliae, Montium, Marchiae, Ravensbergi, Geldriae, Zutphaniae, antiquae et modernae. Ed. J. Chr. Dithmar. Leipzig 1721. Codex diplomaticus 2, 141 b. 
497. Johann Just Winckelmann (1620-1699): Oldenburgische und der benachbarten Oerter Friedens- und Kriegshandlungen. Oldenburg 1671. QR. 1, 436a; $474 \mathrm{c} ; 664 \mathrm{a} ; 2,372 \mathrm{~b}$.

498. Hermann Hamelmann (1525-1595): Oldenburgisches Chronicon. Oldenburg 1599. QR. 1, 14b; 116c; 169c;223c;388c;402a; Reinesius 646a; 677c; $2,29 \mathrm{c} ; 369 \mathrm{a}$.

499. Nicolaus Staphorst (1679-1731): Historia ecclesiae Hamburgensis diplomatica, d. i. Hamburgische Kirchengeschichte aus . . mehrentheils noch ungedruckten Urkunden. Hamburg 1723-1729. QR. 1, 39a;428a;537b;2, 360b;391a;472b. Fregment eines alten Vokabulariums $1,1 \mathrm{c} ; 293 \mathrm{a} ; 545 \mathrm{~b} ; 2,394 \mathrm{~b}$.

500. Caspar Danckwerth (um 1607-1672): Newe Landesbeschreibung der zwey Hertzogthümer Schleswich und Holstein. Hg. v. Johannes Meier und Caspar Danckwerth. Husum 1652. B. 85. 1, 190 b.

501. Hans Regkmann: Lïbeckische Chronik. Hg. v. Johann Friedrich Faust. 1619. QR. $1,8 \mathrm{c}$; 350c; 408a; 425a; 2, 45c;360 b. Anhang von Wismar 1, 509a; Faustens Anhang $538 \mathrm{~b} ; 2,39 \mathrm{a} ; 85 \mathrm{a} ; 262 \mathrm{~b} ; 255 \mathrm{~b}$.

502. Morgenweg: Lübeckische Chronik (Beschreibung der Stadt Lübeck QR.). 1, $347 \mathrm{c} ; 2,34 \mathrm{~b} ; 53 \mathrm{a} ; 232 \mathrm{a} ; 487 \mathrm{c}$.

503. Caspar Sagittarius (1643-1694): Origines et incrementa Sulciae Luneburgensia. Jena $1675.1,174 c ; 553 \mathrm{~b} ; 2,146 \mathrm{a} ; 484 \mathrm{a}$.

504. Heinrich Meibom der Ältere (1555-1625): Bardewici historia. Helmstedt 1654. 2, 433 a.

505. Heinrich Bünting (1545-1606): Braunschweigische und Lüneburgische Chronica. Magdeburg 1584. (Fortgesetzt von Heinrich Meibom. Neuausgabe: ed. Ph. J. Rehtmeyer. Braunschweig 1722). QR. 1, $17 \mathrm{~b} ; 421 \mathrm{a} ; 451 \mathrm{~b} ; 2,401 \mathrm{~b} ; 446 \mathrm{c}$.

506. Philipp Julius Rehtmeyer (1678-1742): Der berühmten Stadt Braunschweig Kirchen-Histori $\theta .1707-1720$. QR. 1, $17 \mathrm{~b} ; 22 \mathrm{c} ; 172 \mathrm{a} ; 255 \mathrm{a} ; 393 \mathrm{c} ; 448 \mathrm{c} ; 453 \mathrm{c}$; 2,310c;390a; 396b. Braunschwoigisches Stadtrecht 1, 202a; 2, $111 \mathrm{c}$.

507. Sigismund Andreas Cuno (gest. 1745): Memorabilia Schoeningensia Historiae Brunsvicensi passim inservientia, cum documentis et diplomatibus. Braunschweig 1728. QR. I, 39c;324b;347b;2, 40a;145c;146a; $263 \mathrm{a} ; 353 \mathrm{~b}$.

508. Johann Michael Heineccius (1674-1722): Annalium seu antiquitatum Goslariensium et vicinarum regionum libri VI. In: Scriptores rerum Germanicarum. Frankfurt 1700. 2, 402c.

509. Johann Letzner (1531-1613): Von den Ruggrafen zu Dassel. QR, 2, 133b.

510. Johannes Buschius: Chronicon Canonicorum Regularium Ordinis S. Augustini Capituli Windesemensis. Antwerpen 1621. 1, 137b;620c;2, $109 \mathrm{~b}$.

511. Chronicon Mindensium Episcoporum. Ed. Pistorius. 1, 255a; 2, 248 b; $377 \mathrm{c}$; $433 \mathrm{a} ; 443 \mathrm{c}$.

512. Chronicon MS. Mindense 1, 498 a.

513. Johann Christoph Beckmann (1641-1717): Historie des Fürstenthums Anhalt. Zerbst 1710. QR. 1, 122b.

514. Joachim Moier (166I-1732): Origines et Antiquitates Plessenses. Ursprung und Denkwürdigkeiten der Herrn von Plessen. Goslar 1713. QR. B. 67. 1, 11 a; $263 \mathrm{~b} ; 574 \mathrm{c} ; 2,185 \mathrm{c} ; 374 \mathrm{~b} ; 425 \mathrm{a} ; 470 \mathrm{c}$.

515. Chronicon MS. Halberstadiense 1, $567 \mathrm{c}$.

516. Chronicon Montis Sereni 1, 1740; 2, $453 \mathrm{c}$.

517. Ernst Brotuff (1497-1565): Chronica und Antiquitates des alten Keys. Stiffts, der Röm. Burg, Colonia vnd Stadt Marsburg an der Salah in Obersachsen. Budissin 1556. QR. (Chronik von Merseburg). 1, 168a; 306 b; 322o; 2, 19a; $81 \mathrm{c} ; 157 \mathrm{c} ; 311 \mathrm{c}$. 
518. Erngt Brotuff: Genealogia und Chronica des ... Hauses der Fürsten zu Anhalt. Leipzig 1556. 1, 510;82c.

519. Christoph Sohultze: Aufnahme und Abnahme der Stadt Gardelegen. Stendal 1668. QR. 1, 144a;314c;592a;2, 50b;104c;182b;274b;364b;489a.

520. Johann Pomarius: Summarischer Begriff der magdeburgischen Stadt-Chroniken. Magdeburg 1587. QR. $1,411 \mathrm{~b} ; 2,111 \mathrm{c} ; 181 \mathrm{c} ; 321 \mathrm{c} ; 385 \mathrm{c} ; 460 \mathrm{~b}$.

521. Heinrich Merckel: Warhaffter Bericht der ... An. 1550 und 51 ergangenen Magdeburgischen Belagerung. 1702. 1, 72a;667c;2,71b;161b;363a; $415 \mathrm{~b}$; $457 \mathrm{a}$.

522. Caspar Sagittarius (1643-1694) : Antiquitates archiepiscopatus Magdeburgensis. Jena 1684. QR. 1,633a.

523. Georg Torquatus (gest. 1575): Annales Magdeburgenses et Halberstadenses. $1569-1574.2,21$ a.

524. Johann Wolfgang Rentsch (1637-1690): Brandenburgischer Cedern-Hayn. Bayreuth 1682. QR. B. 36. 1,360c.

525. Hoinxich Sebald: Breviarium historicum (Historischer Extract). Wittenberg 1655. QR. 1, 16a; 163a; 442 c;2,159c;182c;344a;432o;472b.

526. Engelbert Wusterwitz (gest. 1433): Märkische Chronik. QR. 2, 64b.

527. Peter Hafftiz (Hafftitius; um 1525 - um 1602): Kurtze und warhafftige Beschreibung des Zustandes der Kurmark Brandenburg von 1388 bis 1595. (Microchronologicum). Seit 1595 handschriftlich in der Mark Brandenburg ver. breitet. Chronicon Marchiae MS. (QR.), datiert 1590 (1, 502 b; 2, 398c). 2, 288 b; $342 \mathrm{~b}$.

528. Christoph Entzelt (1517-1583): Chronicon ... darinne begriffen, Wer die Alte Marck . . bewonet hat. Magdeburg 1579. Salzwedel 1732. 2, 477 b.

529. Andreas Rittner: Altmärkische und Tangermündische Chronik. QR. 1651 , $515 \mathrm{~b}$.

530. Stein: Chronicon MS. von Wittstock (Favelspergische Chronik MS. QR.) 1, 83a.

531. Martin Dieterich (1681-1749): Historische Nachricht von den Grafen zu Lin. dow und Ruppin. Berlin 1725. B. 34. 1, 72b;82c.

532. Johann Friedrich Chemnitius $(1611-1687)$ : Epitome genealogico-historica. Le henbrief an Mecklenburg $1348 \mathrm{I}, 59 \mathrm{c} ; 2,401 \mathrm{c}$.

533. David Heinrich Koepken (gest. 1731): Memoria Conradi Lostii episcopi Swerinensis. Rostock 1707. B. 76. 1, 59 b; 2, $421 \mathrm{a}$.

534. Peter Lindenberg (1562-1596): Chronicon Rostochiense. Rostock 1596. 2, 357a; vgl. 128 a.

635. Zacharias Grapius (1671-1713): Das evangelische Rostock oder kurzer Bericht von der Stadt Rostock Reformation und Bekehrung zur evangelisch-luthe* rischen Lehre. Leipzig/Rostock 1707. QR. 1, 582 b.

536. Ernst Heinrich Wackenroder (1660-1734): Altes und Neues Rügen. Stralsund 1732. $1,70 \mathrm{~b}$.

537. Daniel Cramer (1568-1637): Große Pommerische Kirchenchronik. Frankfurt 1602. $1,162 \mathrm{a} ; 162 \mathrm{~b}$.

638. Christoph Hartknoch (1644-1687): Preußische Kirchen-Historia. Frankfurt 1686. $2,376 \mathrm{~b}$.

539. Augustin Kehrberg: Erleuterter Historisch-Chronologiecher Abriß Der Stadt Königsberg in der Neu-Marck. (Prenzlau 1709). Berlin 1724. QR. 1,514b; $2,343 \mathrm{c} ; 401 \mathrm{c}$.

540. Johann Heinrich Zernecke (1672-1741): Thomische Chronica . . a aus bewehrten Scribenten und glaubwürdigen Documentis. Berlin 1727. QR. 1, $570 \mathrm{c}$.

541. Johann Jacob Rohde: De Rudaviensi praelio. Königsberg 1721. B. 102. 2, 204 b. 


\section{Mitteldeutschland}

542. Christoph Browerus (1559-1617): Antiquitatum et Annalium Trevirensium libri XXVI. Köln 1626. 2, 520.

543. Tilemann Elhen von Wolfhagen (1348-1420): Limburger Chronik. Benutzt in der Ausgabe Johann Friedrich Fausts von Aschaffenburg (Fasti Limpur. genses, Das ist Ein wolbeschrieben Fragment einer Chronilk von der Stadt vnd den Herren zu Limpurg auff der Lohne. 1617). QR. 1, 34b;252 c;336b;354b; $381 \mathrm{c} ; 424 \mathrm{~b} ; 2,148 \mathrm{c} ; 297 \mathrm{a} ; 362 \mathrm{a} ; 367 \mathrm{c} ; 369 \mathrm{a} ; 401 \mathrm{~b}$.

544. Nikolaus Serarius (1558-1609): Moguntiacarum rerum libri V. Mainz 1604. Frisch benutzt den Abdruck in: Georg Christian Joannis: Rerum Moguntiacarum libri V. Frankfurt 1722-1727. QR. 1,6b; 59a;110a;330a;436c;472b; $2,111 \mathrm{c} ; 142 \mathrm{~b} ; 188 \mathrm{~b} ; 277 \mathrm{a} ; 377 \mathrm{c} ; 437 \mathrm{a}$.

545. Johann Just Winckelmann (1620-1699): Gründliche und Wahrhafte Be. schreibung der Fürstenthümer Hessen und Hersfeld. Bremen 1697. 1, $381 \mathrm{c}$.

646. Johannes Textor von Höger (1582-1626) : Nassauische Chronik. Herborn 1617. Wetzlar 1712 , QR, 1, 170c; $423 \mathrm{~b} ; 463 \mathrm{~b} ; 564 \mathrm{c} ; 2,427 \mathrm{~b} ; 484 \mathrm{c}$.

547. Christoph Friedrich Ayrmann (1695-1747): Notitia monasteriorum et ecclesiarum Hassiae veterum. QR. 'im Catalogo der Hessischen Clöster' 1, 289 c; $381 \mathrm{c} ; 489 \mathrm{c} ; 2,448 \mathrm{a}$.

548. Wigand Gerstenberg (1457-1522): Frankenbergische Chronik. Benutzt in der Ausgabe Johann Friedrich Fausts von Aschaffenburg (Franckenbergisch Chronick und Zeit-Buch, zusammengetragen durch Weygand Gerstenbergern. Heidelberg 1619). QR. 1, 7a; 33b; 122b;396b; 414b;469a;477b;538b; 2, 414a; in einem Hessischen Diplornate 444c.

549. Johann Philipp Kuchenbecker (1703-1746): Analecta Hassiaca (Collectiones XII). Marburg 1728-1742. Frisch benutzt (QR.):

Collectio VII. 1,381 c. 1731): Wigandi Gerstenbergeri Chronicon Francobergense. $1,43 \mathrm{~b} ; 122 \mathrm{~b} ; 222 \mathrm{~b} ; 469 \mathrm{a} ; 2,201 \mathrm{~b} ; 332 \mathrm{c} ; 369 \mathrm{~b}$.

Collectio VIr. $1,381 \mathrm{c}$.

550. Traditiones Fuldenses. QR. 1, $190 ; 643$ b; 2,466a. Frisch benutzt zwei Ausgaben:

Johann Friedrich Schannat: Corpus Traditionum Fuldensium. Leipzig 1724. $1,6 \mathrm{~b} ; 51 \mathrm{c} ; 316 \mathrm{a} ; 394 \mathrm{~b} ; 46 \mathrm{la} ; 473 \mathrm{a} ; 2,144 \mathrm{~b}$.

Ed. Pistorius. $1,47 \mathrm{c} ; 401 \mathrm{c} ; 461 \mathrm{a} ; 472 \mathrm{a} ; 2,254 \mathrm{~b}$.

551. Johann Michael Weinrich (1683-1727): Kirchen- und Schulen-Staat des Fürstentums Henneberg. Leipzig 1722. QR. 1, 177a; 288c;376a; $401 \mathrm{c}$.

552. Johann Burkhard Mencke (1674-1732) : Seriptores rerum Germanicarum prae. cipue Saxonicarum. Leipzig 1728-1730. QR. 1, 2c; 395a; 2, 428a; Lambecius $1,492 \mathrm{c}$.

Monachus Pirnensis: $1,15 \mathrm{a} ; 26 \mathrm{c} ; 2,332 \mathrm{c} ; 403 \mathrm{a} ; 404 \mathrm{a} ; 405 \mathrm{c}$.

Vita Sanctae Elisabethae: 1,76o; 79b;356b;365c;396a; 2, 148a; 165c; $358 \mathrm{~b} ; 395 \mathrm{~b}$.

Johannes Rothe monachus Isanacensis: Chronicon Thuringiae: $1,34 a ; 44 b$; $454 \mathrm{c} ; 2,9 \mathrm{c} ; 367 \mathrm{~b} ; 457 \mathrm{~b}$.

Adam Ursinus: Thüringische Chronik: $1,442 \mathrm{a}$.

Thammius: Chronicon Colditz: 1, 225o;229o; $499 \mathrm{c} ; 680 \mathrm{a} ; 2,80 \mathrm{a}$.

Schertlini Augustani Historia belli Schmalkald. : 1, $40 \mathrm{c}$.

Georg Spalatinus: Historie der Hochzeit des Churfürsten Johann: 1, 490 a. P. M. Sagittarius: De nummis Saxonicis: $1,176 \mathrm{c} ; 375 \mathrm{c} ; 678 \mathrm{c} ; 2,181 \mathrm{c} ; 224 \mathrm{~b}$;
$304 \mathrm{~b}$.

Eberhard Windek: Historia Sigismundi Imper.: $1,479 \mathrm{a} ; 2,461 \mathrm{~b}$. 
Enoch Widemann: Chronicon Curiae: $2,469 \mathrm{c}$.

Anton de Musica de rebus a Carolo V. ad Sanct. Digerium gestis: 1, 560.

Zeidelgerichtsordnung des Burggrafen Johann: 2, $210 \mathrm{a} ; 451 \mathrm{~b} ; 469 \mathrm{~b}$; vgl. $242 \mathrm{c}$.

553. Caspar Sagittarius (1643-1694): Antiquitates Ducatus Thuringiae oder altthüringisches Herzogthum. Jena 1688. B. 71. 1, 6b;146a;433a;2, 80c; $220 \mathrm{a}$.

554. Samuel Reyhor: Thuringia sacra sive historia monasteriorum quae olim in Thuringia floruerunt. Frankfurt 1737. QR. 1, 33a; 429a; 474c;2, 169b;218a; $254 \mathrm{c} ; 404 \mathrm{~b} ; 467 \mathrm{c} ; 489 \mathrm{c}$. Chronicon Portense 1, 419b. Befreiungsbrief des Klosters Housdorf 2, $397 \mathrm{a}$; vgl. $405 \mathrm{~b}$. Diploma 1, $612 \mathrm{a}$.

555. Caspar Sagittarius: Historia Gothana. Ed. W. E. Tenzel. Jena 1700. QR. (W. E. Tenzel: Supplementa in Sagittarii historiam Gothanam. 1701-1716). 1,25 c; 228 c;623a. Suppl. 7c;658a.

556. Wilhelm Ernst Tenzel (1659-1707): Merkwürdigkeiten von Hartenberg. QR. $1,364 \mathrm{a}$.

557. Johann Friedrich Schannat (1683-1739): Historia Erfurtensis 1, 295 a. (Vgl,: 'Die Teutschen Annales Erfurtenses' 1, 492 c).

558. Johann Arnold Zeitfuchs (1671-1742): Stolbergische Kirchen- und StadtHistorie. Frankfurt/Leipzig 1716-1717. QR. 1, 162 b; 474c; $491 \mathrm{c} ; 639 \mathrm{~b} ; 2,63 \mathrm{c}$; $338 \mathrm{c} ; 406 \mathrm{~b}$.

559. Oyriacus Spangenberg (1528-1604): Sächsische Chronica. Frankfurt 1583. $1,274 \mathrm{~b}$.

560. Georg Fabricius (1516-1571): Originum Saxoniae libri VII. Jena 1597. 1, 274 b; $442 \mathrm{a}$.

561. Christian Gottlob Wabst: Historische Nachricht von des Chur.Fürstenthums Sachsen Verfassung der hohen und niederen Justitz. Leipzig 1732. QR. 1, 360 c.

562. Johann Jakob Mascov (1689-1761): 1, 492c.

563. Johann Christian Schöttgen (1687-1751): Historie der Chur-Sächsischen Stiffts-Stadt Wurtzen. Leipzig 1717. QR. 1, 169a;228c;585a;2,15b;24a; $71 \mathrm{c} ; 167 \mathrm{c} ; 181 \mathrm{c} ; 243 \mathrm{c} ; 486 \mathrm{c}$.

564. Mitweidische Chronik: QR. 2, 377 a.

565. Johann Konrad Knauth: Des alten berühmten Stiftsclosters . . . Alten Zella ... . geographische und historische Vorstellung. Dresden/Leipzig 1721-1722. QR. $1,6 \mathrm{c} ; 16 \mathrm{c} ; 172 \mathrm{c} ; 228 \mathrm{a} ; 323 \mathrm{~b} ; 343 \mathrm{c} ; 417 \mathrm{~b} ; 547 \mathrm{~b} ; 679 \mathrm{~b} ; 2,63 \mathrm{~b} ; 401 \mathrm{~b} ; 412 \mathrm{~b}$; $471 \mathrm{~b}$.

566. Christian Melzer : Beschreibung der Bergkstadt Schneeberg in vier berglkläuffigen Sermonen. Schneeberg 1684. QR. I, 30c;106a; 420a;438b;447c;2, 228c; $233 \mathrm{c} ; 241 \mathrm{c} ; 361 \mathrm{c} ; 392 \mathrm{a} ; 400 \mathrm{~b} ; 421 \mathrm{~b} ; 466 \mathrm{c} ; 489 \mathrm{~b}$. Albinus: Meisn. Chron. $1,567 \mathrm{~b}$. in einem Cabinet des Herrn Abraham von Schönberg 2, 76c; $489 \mathrm{~b}$.

567. Ohr. Lehmann: Annabergische Chronik. QR. 1, 474b; 2, 32b; 259b; $462 \mathrm{c}$.

568. Tobias Schmidt (gest. 1659): Chronica Cygnea Oder Beschreibung Der sehr alten ... Stadt Zwickaw. Zwickau 1656. 2, 213 a.

569. Christian Gotthold Wilisch: Kirchen-Historie der Stadt Freyberg. Leipzig 1737. QR. 1, 455b; 537c; 2, 65b. Codex diplomaticus $1,159 \mathrm{a} ; 2,254 \mathrm{c} ; 281 \mathrm{a}$.

570. Anton Weck (1623-1680): Der Chur-Fürstlichen Sächsischen Residenz und Haupt-Vestung Dresden Beschreib- und Vorstellung. Nürnberg 1680. QR. $1,143 \mathrm{c}$.

571. Johann Benedikt Carpzov (1675-1739) : Analecta fastorum Zittaviensium oder Historischer Schauplatz der Stadt Zittau. 1716. QR. 1, 109b;376a; 427c; $2,218 \mathrm{~b} ; 254 \mathrm{~b} ; 334 \mathrm{c} ; 385 \mathrm{c} ; 401 \mathrm{~b} ; 421 \mathrm{~b}$.

572. (Johann David Köhler): Schlesische Kern-Chronicke Oder Kurtze jedoch gründliche Geographisch- Historisch- und Politische Nachricht von dem Hert-

11 Powitz, Frischs Wörterbuch 
zogthum Schlesien. I Nürnberg 1710. II Frankfurt/Leipzig 1714. B. 35. QR. I, 34c; 76c; 106a; 164b; Fehdeordnung in Schlesien 1571 254c;476e; $490 \mathrm{a}$; Majestätsbrief der Böhmen 635c;2, 46c;299a; $465 \mathrm{~b}$.

573. Friedrich Lucae (1644-1708): Schlesische Fürstenchronik. QR. 1, 571 c.

574. Martin Hanke (1633-1709): De Silesiae rebus exercitationes. Breslau 1705. $2,375 \mathrm{c}$.

575. J. Schickfuss: New vermehrte Schlesische Chronica vand Landes-Beschreibung ... Itzo bis an das 1619. Jahr. Leipzig 1619. 1, 198a.

\section{Suddeutschland}

576. Petermann Etterlin (gest. 1509): Kronica von der loblichen Eydtgnoschaft. Basel 1507. QR. 1, 41a; 400c; $401 \mathrm{a} ; 2,37 \mathrm{~b}$.

577. Johannes Stumpf (1500-1578): Schweizerchronik. Zürich 1554. 1, 16o; 352a; $2,86 \mathrm{a} ; 88 \mathrm{c} ; 100 \mathrm{c} ; 361 \mathrm{o} ; 467 \mathrm{c}$.

578. Aegidius Tschudi (1505-1572): Chronicon Helveticum. (Entstanden um 1570). Ed. Johann Rudolf Iselin. Basel 1734-1736. QR. 1, 130 c; $387 \mathrm{~b}$; 'der gelehrte Herausgeber dieses 'Tschudi' $=$ Iselin $391 \mathrm{a} ; 418 \mathrm{a} ; 442 \mathrm{~b} ; 2,341 \mathrm{a} ; 360 \mathrm{a}$.

579. Christian Wurstisen (1544-1588): BaBler Chronick. Basel 1580. QR. 1, 40; $234 a ; 354 c ; 402 c ; 460 a ; 547 a ; 2,202 c$.

580. Christian Wurstisen: Germaniae historicorum illustrium libri. 1585, 1, 52a.

581. Michael Stettler (1580-1642): Gründliche Beschreibung uechtländischer Geschichten. 1626. (Annales oder Beschreibung der furnembsten Geschichten vnnd Thaten in gantzer Helvetia. Bern 1627). (Nüchtländische Chronil, Annales Helvetiae QR.). 1, 5c; Schweizerchronik 399a; 417c; $619 \mathrm{c} ; 2,235 \mathrm{c} ; 361 \mathrm{c}$.

582. Heinrich Murer: Helvetia Sancta seu paradisus Sanctorum Helvetiae florum. Luzern 1648. QR. 1, 620.

583. Johann Heinrich Hottinger (1620-1667): Speculum Helvetico-Tigurinum. Zürich 1663 . QR. 1, 29 a.

584. Bilibald Pirckheimer (1470-1530): Historia belli Helvetici 1, 574a. Vgl.: Con. rad Celtes in Pirkheimeri operibus a Goldasto editis (Pirckheimer: Opera. Ed. Goldast. Frankfurt 1610) 2, 33 a.

685. Jakob Twinger von Königshofen (1346-1420): Die älteste Teutsche so wol allgemeine als insonderheit Elsassische und Straßburgische Chronicke. Ed. Johannes Schilter. Straßburg 1698. QR. 1, 33b; 399b;2, 148a. Geißlerlieder$1,336 \mathrm{~b}$. Schilter in praefat. $355 \mathrm{a}$. Schilters Anmerkungen 2, $107 \mathrm{a} ; 291 \mathrm{c} ; 377 \mathrm{~b}$; $409 \mathrm{c} ; 419 \mathrm{c} ; 446 \mathrm{~b} ; 470 \mathrm{~b}$. Straßburgisches Stadtrecht 1, 436c; 2, 236 b. Suppl. 1, 115a. Schilter: Glossarium (aus Königshofen) 432 a.

586. Bernhard Hertzog (um 1590): Chronicon Alsatiae oder Edelsaßer Chronil und ausführliche Beschreibung des untern Elsasses am Rhein. Straßburg 1592. $1,86 \mathrm{a}$.

587. Jakob Wimpheling (1450-1528): Catalogus Episcoporum Argentinensium. Straßburg (I509) 165I. 1, 154a.

688. Carolus Toelner $(1660-1715)$ : Historia Palatina seu primorum et antiquissimorum comitum Palatinorum ad Rhenum Res gestae eorumque... indubitata ... successio. Adjectus Codex diplomaticus Palatinus. Frankfurt 1700. QR. 1, 18c;42b;408c;2, 360a; 439c. Landfriede am Rhein 1332 1, 197a; $410 \mathrm{a} ; 2,232 \mathrm{c} ; 1351283 \mathrm{a}$; vgl. 1, 440a; 2, 109a; 11 c. Transactiones Pfalzgrafs: Ruprecht am Rhein 2, 148a. Diplomata 1, 216a; 338a.

589. Marquard Freher (1565-1614): Origines Palatinae. Heidelberg 1699. (Heidelberg 1686 B. 68). QR. I, $2 \mathrm{a} ; 25 \mathrm{c} ; 436 \mathrm{a} ; 620 \mathrm{~b} ; 2,47 \mathrm{~b}$. 
590. Christophorus Lehmann (um 1570-1638): Chronicon Spirense. Chronica der Freyen Reichs-Statt Speyr. Frankfurt 1612. QR. 1, 7c: 35c;47b; 359c; $437 \mathrm{a}$; $488 \mathrm{~b} ; 2,221 \mathrm{~b} ; 403 \mathrm{c} ; 438 \mathrm{~b}$. Pithoeus: Annales $1,87 \mathrm{c}$.

591. Antiquitates Laureshamenses (Lorch in Württemberg?) 1, 19b. (In: Germanicarum rerum scriptores. Ed. Freher 1 [1600]. Vgl. : Annales [in vita Ludovici]. Ed. Frehor. 1, 480a).

592. Thomas Lirer: Cronick ... gar vil mengerley schöner alter geschichten, so ... geschehen zu den zeiten do die schwäbischen land ... Haiden gewesen sind. Ulm 1486. (Schwäbische Chronik QR.). Den zweiten Teil des Werkes zitiert Frisch als 'Chronicon Anonymi an Lyrers Schwäbischer Chronik' QR.

Lirer: Schwäbische Chronik: I, 30c;258a; 559b;2,64c;100b;194a; $329 \mathrm{~b}$; $374 \mathrm{c} ; 462 \mathrm{~b}$.

Chronicon Anonymi: $1,15 \mathrm{~b} ; 2,192 \mathrm{a} ; 335 \mathrm{~b} ; 415 \mathrm{a}$.

593. Martin Crusius (1526-1607): Annales Suevici. Frankfurt 1593. Dt. Ubbersetzung: Johann Jakob Moser. Tübingen 1733 (QR.). 1, 324a; 2, 233 b. Rathgeb: Badenfahrt 1, $48 \mathrm{~b}$.

594. Martin Zeiller (1589-1661): Chronicon parvum Sueviae. Ulm 1653, 1, 292b.

595. Johann Conrad Kreydenmann (1577-1655): Kurtzer Tractatus von dess teutschen Adels sonderlich der freyen Reichsritterschafft in Schwaben Staat, Stand, Ehren. Tübingen 1646. 2, 239 a.

596. Achilles Pirminius Gessarus (1505-1577): Annales civitatis ac reipublicae Augsburgensis. (Dt.: Basel 1595). In: J. B. Mencke: Scriptores rerum Germanicarum. I. 1728. QR. 1, 225a; 345a; 383a; 2, 57 c;141a;402b;431 b; $461 \mathrm{c}$.

697. Johannes Turmair (Aventinus) (1477-1534): Annales Bojorum. Ingolstadt 1554. Basel 1580. QR. 1, 62 b; 74b; $448 \mathrm{c} ; 451 \mathrm{~b}$.

598. Andreas von Regensburg (1. Hälfte des 15. Jhs.): Chronicon de ducibus Bavarize. $1,501 \mathrm{c}$.

599. Marcus Welser (1558-1614): Rerum Boicarum libri V. Augsburg 1602. 1, 51c.

600. Wiguleus Hund von Lauterbach zu Sulzenmos (1514-1588): Bayrisch Stammbuch. Ingolstadt 1585-1586. QR. 1, 1550;2, 144a.

601. Joachim Meier: De Bojorum migrationibus et origine, nee non de claris Böhmeris. Göttingen 1710. B. 68. 2, 455b.

602. Johann Heinrich von Falckenstein $(1682-1760)$ : Antiquitates Nordgavienses. 1733. (Frankenstein QR.). 1, 436c; 500c; 2, 90a; $323 \mathrm{a} ; 434 \mathrm{c}$.

603. Karl Georg Meichelbeck (1669-1734): Historia Frisingensis. Augsburg/Graz 1724-1729. QR. (I 1724 B. 89). 1, 156b;443a;627o;651b;2, 264a;330c; $475 \mathrm{c}$. Alt-Freisingisch. Tradit. 2,334c.

604. Conradus philosophus: Chronicon Schirense sec. XIII. conscriptum. J. Aventini chronicon Schirense. Ed. G. Chr. Joannis. Straßburg 1707 (2, 114b). QR. 1, 71c; $149 \mathrm{c} ; 2,174 \mathrm{c}$.

605. Konrad Celtes (1459-1508): Urbis Norimbergiae descriptio. In: F. Irenicus: Germaniae Exegeseos volumina duodecim. Hagenau 1518. 1, $419 \mathrm{c}$.

606. MS. vom Bayrischen Krieg mit den Nürnbergern. 1504. QR. 2, 36c;253 c; $419 \mathrm{a}$.

607. Historisohe Nachricht von dem Ursprung und Wachsthum des h. Römischen Reichs freyer Stadt Nürnberg. Franlsfurt 1707. B. 25. (N. H. Gundling zugeschrieben). QR. 1, 36a;88b;355a;441b;657b;2, 146a;219a;239a;481b.

608. Johann Christoph. Wagenseil (1633-1705): De S. Rom. Imp. libera civitate Norimbergensi commentatio. Altdorf 1697. Ex chron. MS. 2, 166 a.

609. Martin Hofmann (um 1600): Annales Barabergenses 2, $387 \mathrm{~b}$.

610. Georg Paul Hönn (1662-1747): Sachsen-Coburgische Historie oder Chronica. Coburg 1700 . QR. 1, 87o;441b;2, 154a; $211 \mathrm{~b} ; 315 \mathrm{c} ; 350 \mathrm{a} ; 393 \mathrm{a} ; 477 \mathrm{~b}$. 
611. Johann Georg Pertschius (Bertsch): Origines Voitlandiae et celebris in hac urbis Bonsideliae. Wunsiedel 1677. QR. B. 68. 1, 15c; $167 \mathrm{~b} ; 269 \mathrm{c} ; 640 \mathrm{c} ; 656 \mathrm{~b}$; $2,83 \mathrm{~b} ; 254 \mathrm{~b}$.

612. Friedrich Georgius: Nachricht von der Stadt und Markgrafschaft Ansbach. Frankfurt 1732. QR. 1, 117a; 594b; 2, 363a.

613. Hieronymus $P e z(1685-1762)$ : Scriptores rerum austriacarum veteres ac genuini. Leipzig 1721-1723. QR. Dissertationes Pezii: $1,324 a ; 419 c ; 2,33 b ; 469 b$. Chronicon Zwettlense 1, 411c. Chronicon Salisburgense $567 \mathrm{c} ; 2,27 \mathrm{a} ; 333 \mathrm{~b}$. Chronicon Mellicense 246c; $441 \mathrm{a}$; vgl. $362 \mathrm{c}$. Chronicon Leobiense 1, 483 b. Tabula Claustro-Neoburgense 232b; $448 \mathrm{c} ; 2,283 \mathrm{a}$.

614. Gregor Hagen: Osterreichische Chronik (entstanden um 1395). Frisch benutzt zwei Fassungen:

Hagen: Chronicon Austriacum, in: Pez, Script. rerum Austr. I 1721 (QR.): 1, $11 b ; 15 b ; 432 a ; 2,113 b ; 306 a ; 332 a$.

Hagen: Chronicon Austriacum. MS. Bibliothecae Reg. Berolin. (QR.): 1, 11 b; $381 \mathrm{~b} ; 404 \mathrm{~b} ; 2,175 \mathrm{c} ; 271 \mathrm{~b} ; 362 \mathrm{c} ; 418 \mathrm{a}$.

Vergleich beider Fassungen: $1,248 \mathrm{a} ; 455 \mathrm{a} ; 676 \mathrm{~b} ; 2,131 \mathrm{~b} ; 306 \mathrm{a} ; 401 \mathrm{c}$.

615. Philibertus Hueber: Austria ox Archiviis Mellicensibus illustrata. Leipzig 1722. QR. $1,30 \mathrm{c} ; 399 \mathrm{c} ; 428 \mathrm{~b} ; 472 \mathrm{a} ; 481 \mathrm{c} ; 643 \mathrm{a} ; 2,99 \mathrm{a} ; 103 \mathrm{a} ; 400 \mathrm{a}$.

616. Hans Jacob von Fugger: Spiegel der Ehren des ... Erzhauses Oesterreich. Hg. v. Sigismund von Birken. Nürnberg 1668. 2, $481 \mathrm{~b}$.

617. Wiguleus Hund von Lauterbach zu Sulzenmos (1514-1588): Metropolis Salisburgensis. Ingolstadt 1582. Ed. Chr. Gewold, Regensburg 1719. QR. 1, 11 b; $14 \mathrm{c} ; 314 \mathrm{a} ; 391 \mathrm{a} ; 425 \mathrm{~b} ; 428 \mathrm{~b} ; 505 \mathrm{a} ; 2,174 \mathrm{c} ; 254 \mathrm{c} ; 391 \mathrm{c} ; 402 \mathrm{c}$. Salzburger Edikt 1, 248 a. Diploma Ottonis Imperatoris 141 c; 367 a. Decretum Thassilonis $11 \mathrm{~b} ; 412 \mathrm{c} ; 2,313 \mathrm{c} ; 433 \mathrm{~b} ; 473$ a. Carolom. Reg. Bojar. donat. 159b. Kaiser Ludwigs Diploma 255a. 'beym Hundio in Gloss.' 410 b. Benutzt von Du Cange $264 \mathrm{a}$.

618. MS. Claustro-Neoburgense (Chronik von Kloster-Neuburg/Niederösterreioh). QR. Anno 1491 2, 254a. 1, $201 \mathrm{c}$; de origine principum Austriae 324c; $467 \mathrm{a}$; $658 \mathrm{a} ; 2,40 \mathrm{~b} ; 410 \mathrm{a} ; 462 \mathrm{a}$.

619. Beschreibung Tyrols. Augsburg 1703. 1, $441 \mathrm{~b} ; 2,181 \mathrm{c}$.

\section{B. 4. Recht}

A. Rechtsdarstellungen (Juristisches Schrifttum)

B. Rechtsquellen

a) Kirchenrecht. Reichsrecht

b) Rechtsordmungen örtlich begrenzter Geltung

Norddeutschland

Mitteldeutschland

Süddeutschland

c) Germanische Stammesrechte. Rechtsbücher des Mittelalters

Die 400 Quellen dieses Bereichs entfallen etwa zu gleichen Teilen auf die Gruppen 'Rechtsdarstellungen' und 'Rechtsquellen'. Aus der Vielzahl der Werke des juristischen Schrifttums (Rechtskompendien, Sammlungen gerichtlicher Urteile und Gutachten, Erläuterungsschriften und Untersuchungen namentlich auf dem Gebiet des Lehnrechts) heben sich einzelne Quellen heraus, die FRIscr nicht nur vereinzelt 
nutzt (Besold ; Gobler ; Sptridex ; Wehner ; Carpzov; Frutsch ; Limnaeds ; Lude. WIG; Schotren; SoHrLiter). FRISor entnimmt den Werken dieser Gelehrten nicht nur rechtssprachliches Beleggut, sondern verwertet in weitem Umfange auch die sachlich, begrifflich und sprachlich erklärenden Hinweise, die sie ihm bieten. - Den Hauptanteil an der Gruppe der 'Rechtsquellen' haben die Rechtsordnungen örtlich begrenzter Geltung. Sie verteilen sich ähnlich wie die landschaftsgebundenen $G_{\theta}$ echichtsquellen über weite Teile des deutschen Sprachgebietes. Im Norden sind in erster Hinsicht durch Quellen vertreten der Raum Cleve-Jülich-Köln, Ostfriesland mit Oldenburg, Holstein und Ditmarschen, Lübeck, Braunschweig, Merseburg, Magdeburg, die Mark Brandenburg, Mecklenburg und Pommern, die Neumark, Ostpreußen. Schwächer hebt sich das mitteldeutsche Gebiet ab (Hessen, Sachsen, Thüringen), während Süddeutschland angemessen berücksichtigt ist (StraBburg, Württemberg, Augsburg, Bayern-Franken, Nürnberg, Österreich und Böhmen). Den Rechtsordnungen dieser Gebiete entnimmt FrIsci nicht nur rechtssprachlich bedeutsames Wortgut; sie vermitteln ihm auch landschaftliche Sach- und Fachbezeichnungen nicht rechtssprachlichen Charakters. So etwa die Rostooker Kleiderund Hochzeitsordnungen, die Merseburgische Fischordnung, die nordwestdeutschen Deichordnungen in Hackimanss Jus Aggerum, die Pommerschen Jagd- und Forstordnungen und die OstpreuBische Bernsteinordnung. - Eine Sondergruppe bilden die germanischen. Stammesrechte und die Rechtsbücher des Mittelalters; diese Quellen reichen in die altgermanische Zeit zurück und sind ergänzend neben den literarischen Denkmälern der Gruppen A. 3. 4. als Zeugen des ëltesten Sprachzustandes herangezogen worden.

\section{A. REOHTSDARSTELLUNGEN (JURISTISCHES SCHRIFTTUM)}

620. Andrea Alciati (1492-1550): Paradoxorum iuris oivilis libri VI; Dispunctionum iuris libri IV. Lyon 1537. 1,652b.

621. Johann Althusius (1556-1617): 1, 568b.

622. Jo. Frane. Balthasar: Do operis subditorum. Salzburg 1656. 2, $123 \mathrm{~b}$.

623. Augustinus Barbosa (gest. 1649): De axiomatibus juris usufrequentioribus. In: Variae Tractationes Juris. Lugduni 1630. 1, 374a.

624. Johann Volkmar Bechmann (1624-1689): Comment. ad Pandectas. Frankfurt $1668.1,115 \mathrm{~b}$.

625. Johann Jodocus Beck (1684-1744): Tractatus de jure limitum. Vollständiges Recht der Gränzen und Marksteine. 1722. QR. 1, 19b; 74a; 214c; 234a; $395 \mathrm{a} ; 437 \mathrm{c} ; 2,10 \mathrm{~b} ; 83 \mathrm{~b} ; 217 \mathrm{c} ; 382 \mathrm{a} ; 422 \mathrm{c} ; 466 \mathrm{a}$.

626. Nikolaus Beckmann: Doctrina Juris. $1676.1,647 \mathrm{~b}$.

627. Christoph Besold (1577-1638): Thesaurus practicus. Tübingen 1629. 'mit Dietherrens und Ahasveri Fritschii Continuation' QR.

Besold: Register 1580 2, 107b; 169 a. Sprenger: Wechselpraktik 129c. Schwäbische Landgerichtsordnung 1, 199 a. Klock: de aerario 2, 404c. Limneeus: Jus publicum 464c. Bullaeus: Consilia 1,649a. Wolfram von Eschenbach: Praefatio des Heldenbuchs $303 \mathrm{~b}$.

Continuatio: Goldast 2, 216a. Gastelius: De statu publico Europae 113 a. Cadaeus: Syllog. liter. Var. 1, 658 b. Klock: Consilia 125b; 2, 110a. Persius: Satirae 1, $183 \mathrm{a}$.

Dietherr: 1, 228a; 2, 194a;335b;364b; $406 \mathrm{~b} ; 408 \mathrm{~b}$. Tabor: De criminal. $487 \mathrm{a}$. Fritsch: ad vocem Bergwerlss-Leute Redens-Arten 2, 117c. Olaus Magnus: De rebus Septentr. 1, 62 c. Strauch: De imperio maritimo; Stypmann: De jure 
maritimo ot nautico 2, 255 a. Chursächsische Exledigungen 1, 166a. Hagecius: Beschreibung des Königreichs Böhmen 471c. Hagenius: Descript. Bohem. $2,419 a ; 439 \mathrm{~b}$. Diploma regis Bohem. 329a. Subscript. recossus Ratisbon. 284b. Kaiser Leopolds Verbot französischer Waren 203a; vgl. 1, 667a; 321 b. In Speidelii Suppl. 1, 100; 410 a.

628. Christoph Besold: De Jure civitatum Germania imperialium liberarum et mixtarum. Tübingen 1019. 2, $233 \mathrm{~b}$.

629. Christoph Besold: Dissertatio de Comitibus et Baronibus Imperii. Tübingen 1619. 1, 61 b.

630. Hieronymus Bignonius (1590-1656): Notae ad formulas Marculphi 1, 190; 674a. (Vgl.: Steph. Baluzius: Capitularia regum Francorum. Additae sunt Maroulphi et aliorum Formulae veteres et notae doctiss. virorum. Paris 1677).

631. Jacob Blum: Unterricht vom Zehendrechte nebst einem Anhange vom Pfändungsrecht. Celle 1696, 2, 467 b.

632. Johann Bodinus (gest. 1596): Les gix livres de la république. Paris 1576. (De republica libri VI. Paris 1586). 2, $375 \mathrm{c}$.

633. Johann Bodinus: Methodus ad facilem historiarum cognitionem. Paris 1566. 2, 398c.

634. Braun: Do patriciis. QR. 1, 160a.

635. Johann Salomo Brunquell (1693-1735): 'in einer Disputat.' (über das Seß. Lehon) 2, 283 a.

636. Christian Gottlieb Buder (1693-1763): Disputatio de feudis Sceptri. Jena 1727. 1, 598b.

637. Christian Gottlieb Buder: Dissertatio de Sigilliferis Episcoporum oum primis Germaniae. Jena 1720. 2, $275 \mathrm{c}$.

638. Bullarus: Consilia. QR. (= Antonius Bullaeus: Decas consiliorum seu responsorum. Rinteln 1628?).

639. Philipp Camerarius: Horae subcisivae. Frankfurt 1609. 2, $398 \mathrm{c}$.

640. Benedict Carpzov (1595-1666): Practica nova Imperialis Saxonica rerum criminalium. Wittenberg 1635. 1, 58c;126 b; $456 \mathrm{~b} ; 673 \mathrm{a} ; 2,26 \mathrm{c} ; 409 \mathrm{c}$.

641. Benedict Carpzov: Opus definitionum ecclesiasticarum seu consistorialium. 1649. I, 94c;2, 134a;373a; $397 \mathrm{~b}$. Vgl. $364 \mathrm{~b}$.

642. Benedict Carpzov: Decisiones, 1646-1654. 1, 489a; 2, $86 \mathrm{c}$.

643. Benedict Carpzov: Volumen disputationum historico-politico-iuridicarum. 1651. 1, $498 \mathrm{c}$.

644. Benedict Carpzov: Commentarius in Legem Regiam Germanorum. 1623. 1, $489 \mathrm{a}$.

645. Matthias Colerus (1530-1587): Practica universalis de processibus executivis. 1586. 2, 479a.

646. Matthias Colerus: De jure emphyteutico. 2, $318 \mathrm{c}$.

647. Ernestus Cothmann (1557-1624): Responsiones sive consilia et consultationes. Frankfurt 1613, 1, 449c. Vgl, 1, 261 a.

648. Jacob Cujacius (1520-1590): Expositio novellarum. Genf 1570. 1, $311 \mathrm{~b}$.

649. Jacob Cujacius: De feudis libri V. Praefatio 1,598c.

650. Georg Friedrich Deinlein (1696-1757): Dissertatio de praestationibus gallinariis sive Hühner-Zinßen. 1731. 1, $473 \mathrm{c}$.

651. Jacob Döpler : Theatrum poenarum, suppliciorum et executionum criminalium, oder Sohau-Platz derer Leibes- und Lebens-Straffen. Sondershausen/Leipzig 1693-1697, 2, 57 a.

652. Johann Jacob Draco (1595-1648): De jure et origine Patriciorum. Basel 1627. QR. 2, 145b. 
653. Johann Drosaeus: Methodus Juris in L Magistratibus, 1, 652b. (Juris uni. versi Justinianea Methodus. Paris 1545).

654. Guilielmus Durandus (13. Jh.): Speculum juris. 1, 315a.

655. Guilielmus Durandus: Rationale divinorum officiorum. 1, 168a.

656. Johann George Estor (1699-1773): Auserlesene kleine Schriften. Gie日en 1732-1738. QR. Hess. Urkunden 1, 3150. Darin: Adrian Beier: De Jure Castrensi Vom Burg-Frieden 1, $155 \mathrm{c}$.

657. Dissertatio de clausula et caetera $1,310 \mathrm{c}$.

658. Gerherd Feltmann (1637-1696): Tractatus de iure in re et ad rem, id est Manuductio ad ius civilo Romanorum et Clivorum. Duisburg 1665. 1,393c; $4080 ; 2,315 a$.

659. Johann Fichard (1512-1581): Consil. Foudal. 2, 250a.

660. Georg Franzlkius (1594-1659): Tractatus de laudemiis. Jena 1660. 2,479b.

661. Marquard Freher (1565-1614): Commentarii de secretis judiciis olim in West. phalia. Heidelberg 1599. (B. 70). 1, 255 b.

662. Ahasverus Fritsch (1629-1701): Varii Tractatus. QR. 1,9b; 35b; 421b; 2,408 b.

Aldendorfisches Salzwerk in Heesen 1,319a. Hallisches Salzwerk $395 \mathrm{c}$. Salzungisches Salzwerk 2, 438a. Hallische Pfennerordnung 154a. Lünebur. gisches Salzwerk 1, 499o. Thoedenius: Haligraphia 2, $21 \mathrm{~b} ; 60 \mathrm{o} ; 338 \mathrm{o}$.

Sächsische Taxordnungen: der Böttcher 1, 338c;499c;2, 149b;246a; $377 \mathrm{a}$; 461 c. der Stellmacher 1, 453 b. der Seiler 421 a. der Töpfer 37 c. der Schmiede 2, 103c;474b; 484c. der Feilenhauer und Bohrerschmiede 1,97a; $498 \mathrm{a}$; 2, 443a. der Siebmacher 1,94c. der Bürstenbinder $532 \mathrm{~b}$. der Fürber $638 \mathrm{c}$. der Büchsenschmiede 309a. der Schneider 291a.

Gothaische Ruggerichtsordnung 2, 134a. QR.

663. A. Fritsch: Tractatus nomico-politicus de collegiis opificum eorumque statutis ac ordinationibus. Von Zünft- und Innungs-Recht. Jena 1664. Sächsische Kleiderordnung 2, 205o. Sächsische Schneidertaxe 1, 511b; 2, 276a. Ansbach: Leineweber 1, $497 \mathrm{c}$; Seiler 549a; Kürschner 550b; Schuster 2, 230o; Seiler 1, 395 a. Tuchmacher $424 \mathrm{~b}$. Parathmacher $442 \mathrm{~b}$.

664. A. Fritsch: Opuscula varia. Nürnberg $1690.1,384 \mathrm{a} ; 638 \mathrm{~b} ; 474 \mathrm{a} ; 2,109 \mathrm{~b}$; 459 a.

665. A. Fritsch: De regali viarum publicarum jure. Jena 1662. 1,435a; 568b; 6050 .

666. A. Fritsoh: De regali salinarum jure. Jena 1670, 1, 627 a.

667. A. Fritsch: De regali nundinarum jure et privilegís. Jena $1660.1,563 \mathrm{~b}$.

668. A. Fritsch: De jure pratorum. Jena 1670. 2, 414b.

669. A. Fritsch: De jure congrui Vom Gespilde-Reoht. Jena 1678. 2, 289b.

670. A. Fritsch: De jure bosoandi sive lignandi. Jena 1676. 1, 264a; 464b.

671. A. Fritsch: Conclusiones practicae miscellaneae de jure Tertii. Item discursus de jure optionis (Kühr- oder Wahl-Gerechtigkeit). Jena 1669. 1, 169a.

672. A. Fritsoh: De convenat. memb. $1,483 \mathrm{~b}$.

673. Andreas Gail: Observationes practicae Camerae Imperialis. Köln 1611. 2, 58a.

674. Christian Gastel: De statu publico Europae novissimo tractatus. Nürnberg 1675. QR. 1, 367 b; 2,57a; 444c. Vgl. $113 \mathrm{a}$.

675. Johannes Gemmelius (geb, 1503): Compendium juris feudalis. Amberg 1598. $2,274 \mathrm{c}$.

676. Gisland: Decisiones Camerae. QR. I, 305a.

677. Justinus Gobler (1503-1567): Der Rechten Spiegel, Ausz Natürlichen, den Beschriebenen, Geistlichen, Weltlichen ... Rechten auch gemaynen im 
H. Reich teutscher Nation Constitutionen vad übungen zugericht. Frenlkfurt 1550. QR. 1, 7a;15a; 133c;401 b; 438c; Aurea Bulla 605o; Landfriede 2, $92 \mathrm{c}$; $316 \mathrm{~b} ; 463 \mathrm{~b}$.

678. Godofredus Antonius: Disputationes feudales. Marburg 1613. QR. 1,71c; $324 \mathrm{~b}$.

679. Johannes Goeddaeus (1555-1632): Constit. de alluvione maris. 1, $372 \mathrm{c}$.

680. Henning Goede (gest. 1521): Consilia. 1541. (de jure irrigandi prata) 2, $441 \mathrm{~b}$.

681. Tractatus vom Groschen. 2, $218 \mathrm{~b}$.

682. Hugo Grotius (1583-1645): De jure belli ac pacis libri tres. Paris 1625. 2, 11 c.

683. Johann Gryphiander (Griepenkerl; gest. 1652): De Weichbildis Saxonicis sive Colossis Rulandicis. Frankfurt 1625. QR. 1, 386c; 4l1b; 2, 125a; 398c; noch Schottel $433 a$.

684. Johann Gryphiander: De insulis tractatus. Ex Iurisconsultis, Politiois, Historicis, ef Philologis collectus. Frankfurt 1624. 2, $441 \mathrm{~b}$. Gryphicander 356c. Vgl. Heyliander: De insulis. QR. $294 \mathrm{~b}$.

685. Nicolaus Hieronymus Gundling (1671-1729): Gundlingiana, darinnen aller. hand zur Jurisprudenz, Philosophie, Historie, Critic, Litteratur . . gehörige Sachen abgehandelt werden. Halle Stück 1-44 1715-1729. 1,6c; 5980; $2,433 \mathrm{a}$.

686. Adrian Gyllmann: 1, 232c.

687. Justus Hahn: Vom Erbmeierrechte. (Übersetzt von Ant. Kappel). Frankfurt 1697. QR. 1, 8c; 70b; 2, 141 b; $367 \mathrm{c}$.

688. Johannes Heumann (1711-1760): Commentatio Academica de Salmannis. Altdorf 1740. 2, 144 a.

689. Heinrich Hildebrand (1668-1729): De feudo clypeari. 1, 598 b; $597 \mathrm{~b}$.

690. Hincmarus Remensis (gest. 882): Epistolae. 1, 460 b. (De ord. Palatii) 1, 92 a nach Du Cange.

691. Johann Wilhelm Hoffmann (1710-1739): Observationum juris Germanici libri II. Leipzig 1738. QR.

692. Theodor Höping: Tractatus de insignium sive armorum prisco et novo jure. Nürnberg 1642. De jure sigillorum 2, 130c.

693. Caspar Heinrich Horn (1657-1718): Juris publici Romano-Germanici eiusdemque prudentiae liber unus. Halle 1707. 2, $235 \mathrm{c}$.

694. Ludwig von Hörnigk (gest. 1667): De regali jure Postarum. Marburg 1639. QR. 1, 634 c.

695. Hübner: De feudo franco. 1, $598 \mathrm{~b}$.

696. Ludolph Hugo: De statu regionum Germaniae. Gießen 1689. 2, $103 \mathrm{~b}$.

697. Adam Keller: Chiragogici libri III de officiis juridico-politiois. Konstanz 1607. 1,357 a.

698. Billinger: De Ganerbiis. 1, 316 a.

699. Hermann Kirchner (1562-1620): Morvillerius de officio et dignitate cancellarii libris IV expositus. Marburg 1613. 1, 164b.

700. Balthasar Klammer (gest, 1578): Promptuarium juris tam civilis quam feudalis. Frankfurt 1599. 2, 4540.

701. Caspar Klock (1583-1655): Tractatus juridico-politico-polemico-historicus de aerario. Nürnberg 1653. 1, 361a; 532 c;2, 28a;43a;48a;104c;247c.

702. Caspar Klock: Consilia juridica. Frankfurt 1649. 1, 207a;270b; 300a; 329a; $605 \mathrm{c} ; 2,375 \mathrm{c}$. Nach Besold 1, $125 \mathrm{~b}$.

703. Heinrich Kluver: Electa de jure canum. Stade 1711. 1, 476a.

704. Andreas von Knichen (1560-1621): De sublimi et regio territorii jure synoptica tractatio. Frankfurt 1600. QR. 1, 33b;228a;2, 56c;113b;477b. 
705. Andreas von Knichen: De vestiturarum pactionibus, 1 Frankfurt 1601. 2 Hanau 1603. 2, $282 \mathrm{c}$.

706. Philipp Knipschild (1595-1657): Tractatus politico-historico-juridicus de juribus et privilegiis civitatum imperialium. Ulm 1657. QR. 1, 84a;90 b;94c.

707. Philipp Knipschild: Dissertatio de fideicommissis familiae conservandae causa rolictis. Straßburg 1626. 1, 248a.

708. Philipp Knipschild: Tractatus ... de nobilitate in genere, et praesertim de juribus et privilegiis ordinis equestris liberi et immediati. $1,362 \mathrm{~b}$.

709. Kilian König (um 1470-1526): Processus und Practica der Gerichtsleuffte. Leipzig 1541. 1, 9b; 2, $472 \mathrm{c}$.

710. Johann von Köppen (1531-1611) : Decisiones quaestionum illustrium. Magdeburg 1600. QR. Decisiones Juris $1,71 \mathrm{~b} ; 418 \mathrm{~b} ; 2,430 \mathrm{c}$. Quaest. Juris $218 \mathrm{~b}$.

711. Johann Andreas Kopp: Auserlesene Proben des deutschen Lehnrechts. Mar. burg 1739. Specimen Jur. German. 1, 390b.

712. Kreutmann: Vom Zehendrecht. QR. 1,90a.

713. Erklärung der Landfreiheit: 1, 571c.

714. Johannes Leib (1591-1666): Tractatus de Ganerbiatu (Traktat von Ganerben). Schleusingen 1666. 1, 316a.

715. Leipold in: Dominicus Arumaeus: Discursus academici de jure publico. Jena 1617-1623. $1,58 \mathrm{c}$.

716. Christian Gottfried Leiser: Jus Georgicum seu tractatus de praediis (Von Landgütern). Leipzig 1698. QR. 1, I3 b; $399 \mathrm{c} ; 423 \mathrm{c} ; 456 \mathrm{~b}$; Prager reformiertes Landbuch Karls IV. 568b; 2, 82 c; $107 \mathrm{c}$; Kaiserliche Reuter-Bestallung 1570 $127 \mathrm{~b} ; 384 \mathrm{a} ; 416 \mathrm{~b} ; 468 \mathrm{~b}$.

717. Otto Philipp Lepper: Cynosura legalis. 2, 28 a.

718. Johann Limnaeus (1592-1665): Juris publici Imperii Romano-Germanici libri IX. Straßburg 1629-1632. Additiones 1647. 1660. 1680. QR. 1, 1550;

$356 \mathrm{c}$; Privileg des Kaisers Sigismund $603 \mathrm{~b} ; 2,216 \mathrm{a} ; 359 \mathrm{c} ; 401 \mathrm{a} ; 443 \mathrm{~b}$. Benutzt von Besold 464c. Vgl. 1, 497c; $2,76 \mathrm{c} ; 381 \mathrm{c} ; 385 \mathrm{c} ; 1,312 \mathrm{c}$.

719. Johann Limnaeus: Capitulationes Imperatorum et Regum Romano-Germanicorum. Straßburg 1651. 1, 459c.

720. Lindwodus (William Lindwood): 1, 165a.

721. Heinrich Linck (1642-1696): Disputatio de centena, vulgo Zentrecht. Altdorf 1676. 2, 472 a.

722. Georg Melchior von Ludolf (1667-1740): Variae observationes forenses. $1732-1738.2,435 \mathrm{c}$.

723. Georg Melchior von Ludolf: Symphorema consultationum et decisionum forensium. Frankfurt 1731-1739. 1,643c.

724. Johann Peter von Ludewig (1668-1743): Reliquiae manusoriptorum omnis aevi diplomatum ac monumentorum ineditorum. Frankfurt/Leipzig 1720-1741. QR. 1, 155c;410a;427c;2, 259c;350c;397a;409c. Diplomatarium Zwettlense 1, 4b; $557 \mathrm{~b}$. Privileg der Stadt Stendal $72 \mathrm{~b} ; 583 \mathrm{c} ; 2,182 \mathrm{c}$. Ad Auream Bullam Friderioi Ir. $410 \mathrm{c}$; 472 a. Meichsner: Decis. Cam. $81 \mathrm{c}$.

725. Johann Peter von Ludewig: Vollständige Erläuterung der güldenen Bulle. Frankfurt/Leipzig 1716-1719. QR. 1, 9b;230a; 605c;2, 47b; 418c.

726. Johann Peter von Ludewig: De jure olientelari Germanorum in feudis et coloniis. Frankfurt/Leipzig 1717. 1,570c; 2, 423 b.

727. Johann Peter von Ludewig: De feudis et curmedis. 1, 169b; 2, 249c;372c. $1,449 \mathrm{~b}$. 
728. Johann Christian Lünig (1662-1740): Corpus juris feudalis Germanici, Sammlung derer deutschen Lehenrechte und Gewohnheiten. Frankfurt/Leipzig 1727. QR. 1,577c.

729. Luning: Reichsabschied 2, 348a (= Johann Ohristian Lüni[n]g: Teutsohes Reichsarchiv. Leipzig 1710-1722?).

730. Lyser: De praed. feudal. 2, $106 \mathrm{c}$.

731. Martin Mager a Schönberg: De advocatia armata seu de clientelari Patro. norum jure et potestate, clientumque officio et obligatione (Von der Schutz und Schirmsgerechtigkeit). Frankfurt 1625. QR. I, 14a; 2, $184 \mathrm{c}$.

732. Marcellus Marcianus: Opera legalia posthuma. Neapel 1680. 2, 295b.

733. Erich Mauritius: Constit. 2, 191a.

734. Johann Meichsner: Decisiones camerales. Frankfurt 1603-1606. QR. 1, 169b; $187 \mathrm{c}$. Von Wehner benutzt $1,10 \mathrm{~b}$; von Ludewig benutzt $2,81 \mathrm{c}$.

735. Johann Melonius: Thesaurus Juris feudalis, aivilis ot criminalis novus. 164.5. QR. 2, $318 c$.

736. Noe Meurer: Wasserrecht und Gerechtigkeit fürnemlich des woitberühmten und goltreichen Rheinstromes. Frankfurt 1570. QR. 1, 22a; $360 \mathrm{~b}$.

737. David Mevius (1609-1670): Decisiones summi regii Tribunalis Wismariensis. Stralsund 1664-1675, $1,68 \mathrm{~b}$.

738. David Mevius: Commentarius in jus Lubecenge. (Leipzig 1642) Frankfurt 1679. (B. 82). QR. 1, 47b;392o;393a; 448c;467a; 560c;2,37c;282o;333a; $386 \mathrm{c} ; 421 \mathrm{~b}$. Schiffordnung $1,172 \mathrm{c}$.

739. Carolus Molinaeus (1500-1566): Tractatus contractuum et usurarum redituumque pecunia constitutorum. Paris 1545. QR. 1, 364b.

740. Johannes Joachim Müller (1665-1731): Des Heiligen Römisohen Reichs Teutscher Nation Reichstags.Theatrum. Jena 1713-1718. QR. 1,535b; $2,416 \mathrm{c}$.

741. Georg Mundius: De muneribus, honoribus et oneribus. Nürnberg 1645. 1, 357a.

742. Nicolaus Myler von Ehrenbach (1610-1677): Tractatus de principibus et statibus Imperii Romano-Germanici. Stuttgart 1658. 1, 572a.

743. Jog.chim Mynsinger von Frundeck (1514-1588): Responsorum juris seu consiliorum Decades VI. Basel 1573. 1, $292 \mathrm{c}$.

744. Georg Obrecht (1547-1612): Politisch Bedenken. Straßburg 1606. QR. 1, 363a; 2. $53 \mathrm{a}$.

745. Andreas Ockel (1658-1718): Tractatus juridious de praescriptione immemoriali, praesertim rerum domanialium et regalium principum. (Altdorf 1684) Halle/Magdeburg 1707, QR, 1, 59b; $87 \mathrm{c}$.

746. Johann $O e(t)$ tinger: Tractatus de jure et controversiis limitum. Ulm 1642. QR. 1,9c;234a; 2, 56c.

747. Auctor der Reichs-Vogtey (Daniel Heider: Gründlicher Historischer Bericht Von denen alten Reichsz-Vogteien. Ulm 1655). 1,61 c.

748. Arnold von Reyger (geb. 1559): Thesaurus Juris. 1605. QR. 1, 668c.

749. Johann Friedrich Rhetius (1630/33-1707): Dissertatio de astutiis opilionum, earumque poena. Von Bestrafung der Schäfer Parthierkunst. 1673. 1,658c.

750. Christoph Philipp Richter (1602-1673): Consilia. Jena 1665. 1, 538a; 2, 470a.

751. Konrad Rittershausen (Ritterhusius; 1560-1613): Partitiones juris feudalis. Hannover 1603. 2, 112a; $444 \mathrm{c}$.

762. Andreas Christoph Roesener. (1657-1719): Dissertatio de bonis domanialibus. $2,359 \mathrm{a}$.

753. Henricus a Rosenthal: De feudis. Frankfurt 1624. 2, 380 a.

754. Christion Rosteuscher (1620-1681): De admodiatione. 2, 320 b. 
755. Johann Rudinger: Singularium observationum juris cameralis, Saxonici, Civilis et Feudalis. (Straßburg 1611). Ed. Schilter. Straßburg 1701. B, 81. $2,6 a ; 263$ c. $364 b$.

756. Rütger Rulant (1568-1630): Tractatus de commissariis ef commissionibus camerae Imperialis. Frankfurt 1604. QR. 1, $410 \mathrm{c} ; 510 \mathrm{c}$.

757. Dissertatio (über den' Rutscher-Zins). Jena. 2, $139 \mathrm{~b}$.

758. Friedrich a Sande (gest. 1617): Tractatus praeliminarius ad consuetudines Geldriae. 2, 287 a.

759. Abraham Saur: Penus notaricum d. $i$. ein new auserlesen Formular vnd ein Notariat-Buch von allerley instrumenten, schrifften, Brieffen vad Acten. Frankfurt (1582) 1592. B. 89. QR. 1, 570c.

760. Schifordeker (= Caspar Schifferdeoker?): Tractatus Jur. 1, $198 \mathrm{c}$.

761. Johannes Schilter (1632-1705): Praxis juris Romani in foro Germanioo. Leipzig/Jena 1675. QR. 1, 19c;107a; 313a;403b;468a;2, 27a; 109c;170b; 319 a; 448 a. Jus Bohem. urbicarium $177 \mathrm{a}$.

762. Johannes Schilter: Exercitationes theoretico-practicae ad L libros Pandectarum juris. Jena 1672. 'der berühmte Jurist und Meister in der Teutschen Sprach, Herr Doct. Schilter' 1, 572c.

763. Johannes Schilter: Addenda ad Rudingeri Observetiones. QR. (Vgl. Quelle $755) .1,18 \mathrm{c} ; 260 \mathrm{c} ; 392 \mathrm{c} ; 417 \mathrm{c} ; 577 \mathrm{a} ; 2,133 \mathrm{~b} ; 236 \mathrm{~b}$.

764. Johannes Schilter: Dissertatio am Jure Feudali. 1, 218 a.

765. Johannes Schilter: Opusculum de curiis dominicalibus. 2, 274c.

766. Johannes Schneidewin: De rerum divisione. $2,51 \mathrm{~b}$.

767. Justus Georg Schottel (1612-1676): De singularibus quibusdam in Germania juribus. Wolfenbüttel 1671. QR. $1,39 \mathrm{c} ; 71 \mathrm{c} ; 15 \mathrm{la} ; 169 \mathrm{~b} ; 324 \mathrm{~b} ; 2,125 \mathrm{a}$; 182e; Gryphiander: De Weichbildis Saxonicis $433 \mathrm{a}$. Vgl. 1, $70 \mathrm{~b}$.

768. Schröder: De jure belli (in Dispp. Basil.). 2, 301 c; $417 \mathrm{a}$.

769. Christoph Sohwanmann (1569-1653): Decisiones. 2, $123 \mathrm{~b}$.

770. Christian Gottlieb Schwarz (1675-1751): Exercitatio academica ex antiquitatibus German. et Franc. de Butigulariis praecipue is qui Norimberga olim floruerunt, Altdorf 1723. 2, 228 b; 349a; 469c. Vgl. 90a.

771. Georg Schwarzkopf: De differentiis juris civilis et Saxonici. (Dt. Übersetzung) Helmstedt 1588. QR. 1, 2180; 339a;516a; Unterschied des Kayserl. und Sächs. Rechts $599 \mathrm{c} ; 2,182 \mathrm{c}$.

772. Louis Servin: Plaidoyer du droict de l'Amirauté. 1, $12 \mathrm{c}$.

773. Johannes Sichard (um 1499-1552): ad l. libert. 2, 360 c.

774. Johannes Sichard: ad Rubric. Cod. Loc. I, 569 a.

775. Jacobus Sirmundus: Capitula Caroli Calvi et Success. Paris 1622, 2, 452b.

776. Johann Jacob Speidel: Speculum juridico-politico-philologico-historicarum observationum et notabilium verborum, rerum et antiquitatum. Nürnberg 1657. QR. 1, 195b; $472 \mathrm{a} ; 2,33 \mathrm{~b} ; 145 \mathrm{~b} ; 433 \mathrm{a}$. Hundius: Speyerisch Stemm-Buch $1,655 \mathrm{~b}$; Besold 2, 354c; Continuation 200b; $201 \mathrm{a} ; 219 \mathrm{c}$.

777. Johann Theodor Sprenger: Delineatio statuum Imperii. 1, 652 c; 2, 417b.

778. Johann Theodor Sprenger: Institutiones jurisprudentiae publicae. Frankfurt 1667. $2,145 \mathrm{~b}$.

779. Georg Heinrich Springfeld: De apanagio. Wittenberg 1641. QR. 1,494b.

780. J. Stiernhock: 2, 144a.

781. Georg, Adam Struve (1619-1692): Jurisprudentia Romano-Germanica forensis. Jena 1670. 2, 479 a.

782. Georg Adam Struve: Exercitationes juridicae. Jene 1675. 2, 134an 
783. Semuel Stryk (1640-1710): Tractatus de successione ab intestato. Frankfurt 1687. 1, 68 b.

784. Johann Stuck (gest. 1653): Consilia juxidica. 2, $438 \mathrm{~b} ; 454 \mathrm{c}$ nach Besold.

785. Franciscus Stypmann (1612-1650): De salario clericorum. Greifswald 1650. QR. 1,660a.

786. Francisous Stypmann: Tractatus de jure maritimo et nautico. 1652. QR. $1,119 \mathrm{~b}$.

787. Johann Baptist Suttinger (gest. 1672): Observationes practicae. Nürnberg 1703. $2,229 \mathrm{c} ; 468 \mathrm{a}$.

788. Johann Otto Tabor (1604-1674): Comment. de metatis et epitemeticis. Strabburg 1645. 2, 36a.

789. Johann Otto Tabor: De jure socidae, de suffragio et de obligatione success. in officios. Straßburg $1646.1,425 \mathrm{c}$.

790. Johann Otto Tabor: De jure cerevisiario. Straßburg 1656. 2, 404a.

791. Johann Otto Tabor: Dissertatio de altero Tanto. 1652, 1, 654c.

792. Johann Otto Tabor: Partitiones elementariae jurisprudentiae methodicae. Straßburg 1641. 1, 358a. - Vgl. : Diether in addit. ad Besold. Thes. Pract. aus Tabor de Criminal. 2, 487 a.

793. Wilhelm Ernst Tenzel (1659-1707): Monatliche Unterredungen einiger guten Freunde von allerhand Büchern. Leipzig 1689-1698. 1689 1, 54 b; $1690197 \mathrm{~b}$.

794. Dissertatio Tubingae. 2, 234a.

795. Unpartheiisches Urtheil über Juridisch und Historische Bücher. 2, $330 \mathrm{c}$.

796. Adam Volkmann (1612-1664): Inform. Notar. 2, 102 a.

797. Paul Matthias Wehner (1583-1612): Observationes practicae. Ed. Schilter. Straßburg 1701. B. 81. QR. 1, 153 c. 36b;198c;389c;421 b; 536 b; 2, 164b;305b. Meichsner: Decisiones $1,10 \mathrm{~b}$. Goldast $169 \mathrm{c} ; 365 \mathrm{c} ; 544$. Privileg der Tübingischen Akademie 318b. Rothweilische Verordnung 2, 410b. Statut. Hambur. gens. $1,647 \mathrm{~b}$.

798. Tractet von der Averey. (Weitzen: Bericht von Avereyen QR.) 1, 234b; 622 c. (Quintilianus Weytsen: Tractatus de avara vulgo Avereyen. Amsterdam 1672).

799. Georg von Wentzky: Schlesische Ehrentafel. 1, $217 \mathrm{~b}$.

800. Johann Werndle: Zehend Recht. Ingolstadt 1656. 2, 467 b.

801. Ernst Joachim von Westphal: Tractatus de consuetudine ex sacco et libro in Germania. Rostock 1726. QR. 1, 87c;88a; 528 b; 2, 324b.

802. Christian. Wildvogel (1644-1728): Chronoscopia legalis seu tractatus de jure festorum et praecipuorum anni temporum. Jena 1702. QR. 1, 396 b.

803. Johann Hieronymus Wurfbain: Tractatus de differentiis juris civilis et reformationis Noricae. Nürnberg 1685. 2, 417a.

804. Balthasar Cornelius Zean: Tractatus de mendaciis. Frankfurt/Köln 1802. $1,356 \mathrm{c}$.

805. Ulrich Zasius (1461-1535): Respons. Singular, 1, $198 \mathrm{~b}$.

806. Christoph Zobel (1499-1560): Differentiae juris civilis et Saxonici. Leipzig 1588. $1,315 \mathrm{a}$.

807. Philipp Zorer: Quaest. 1, 318b; 2, 229 b.

\section{B. RECHTSQUELLEN}

a) Kirchenrecht. Reichsrecht

808. Jus Cenonicum: 1, $114 \mathrm{k}$. Decretum: de consercratione 1, $7 \mathrm{c}$. Clementinae 1, $76 \mathrm{~b}$. 800. Concilium I. Aurelianum: 2, 76b; concilium III. Aurelianum $113 \mathrm{c}$. 
810. Synodus Ticinensis: 1, 242a.

811. Synodus Laodicensis: $1,53 \mathrm{c}$.

812. Concilium Tridentinum: Decretum de Purgatorio 2, $254 \mathrm{~b}$.

813. s. Quelle 808.

814. Melchior Haiminsfeld Goldast (1578-1635): Reichshandlungen und Reichssatzungen. Hanau 1609. QR. 1,9b;15b;232b;399a;417a;425c. 2, $103 \mathrm{~b}$. Reformation Friedrichs IIT. (Fülschung): 1, 15c;206a; 504a; 2, 20b; 182b; $390 \mathrm{c} ; 427 \mathrm{a} ; 445 \mathrm{c}$. Vgl. $291 \mathrm{~b}$. Matrikel Friedrichs ITI. 1, 573 a. Aurea Bulla: $1,537 \mathrm{~b} ; 636 \mathrm{a} ; 2,390 \mathrm{c} ; 438 \mathrm{~b}$. Reformatio Sigismundi $1,612 \mathrm{~b} ; 2,446 \mathrm{c}$. Lehensempfahung Ferdinands I. 1, 67a; 339c. Kaiser Konrads Hofgerichtsordnung 5a; 2, 409 a. Kaiserliche Kammergerichtsordnung 1, 229a; 2, 418a; 436 c; vgl. 230 a. Rothweilische Hofgerichtsordnung 1, 9b; vgl. 2, $405 \mathrm{~b} ; 416 \mathrm{c}$. Reformation des westpfälischen Freigerichts $1,122 \mathrm{~b} ; 542 \mathrm{~b} ; 2,345 \mathrm{a}$; vgl. 1, 255 b. Const. Lud. IV. über den Nürnberger Forst 1, 287a. Vom Nürnbergischen Kampfgericht 547 a. Carol. IV. Confirmation der Zeidler-Rechte in Nürnberger Wald 1, 91 a; $94 \mathrm{a} ; 2,469 \mathrm{~b}$. Reichstagsordnung zu Augsburg $51 \mathrm{~b} ; 51 \mathrm{c}$. Augsburger Konfession 1, 284 b. Von der Türkensteuer $362 \mathrm{a}$. Probierordnung Ferdinands I. 1, 177 c;375c. Münzproclama zu Frankfurt 2, 370 c. Edikt Kaiser Maximilians 297b. Turnierordnung 1, 294a. Kammerordnung 2, 484c. Ad Constit. Caroli Magni 98a.

815. Caroli Magni capitularia: 1, 140; 145b; 146a; Constit. Caroli Magni 503a; $508 \mathrm{c}$. Nach Schilter 60 a. Vgl. $287 \mathrm{~b}$.

816. Capitulare de Villis: $1,531 \mathrm{c} ; 652 \mathrm{~b} ; 2,145 \mathrm{~b} ; 417 \mathrm{~b}$.

817. Capitulare Caroli Calvi : 2, 452b. Constit. Caroli Calvi $452 \mathrm{~b}$ nach Vossius.

818. Kaiser Friedrichs II. Recht. Frisch benutzt dreiAusgaben: Ed. Goldast: 2, 263c; 404a. Ed. Fritsch: 1, 195 b; $230 \mathrm{c} ; 2,33 \mathrm{~b} ; 90 \mathrm{c} ; 404 \mathrm{a}$. Ed. Ludewig: $1,410 \mathrm{c}$.

819. Friedrichs III. Constitution wegen des Landfriedens: $2,328 \mathrm{~b}$. Vgl. 1, 238c nach Goldast.

820. Goldene Bulle: $1,56 \mathrm{~b} ; 158 \mathrm{c}$.

821. Capitul. Caroli IV.: $2,177 \mathrm{~b}$.

822. Landfriede Kaiser Karls IV. 1351: 1, 571 a.

823. Aurea Bulla Sigismundi Imperatoris: 1, 34c.

824. Achtbrief wider Pfalzgraf Ruprecht. 1504. 2, $339 \mathrm{c}$.

825. Auszug der Beschwerungsartikel deutscher Nation über die Geistlichen, 1521 zu Worms übergeben. QR. 1, 99a; 2, 2630; 321 a.

826. Ordnung des Landfriedens, Worms 1521. 1, 571c.

827. Kaiserliche Konstitution, wie Bruder und Schwester ihre Erbschaft teilen sollen. 1529. 2, $369 \mathrm{c}$.

828. Peinliche Halsgerichtsordnung Karls V. QR. 1, 571c; 2, 470a; 472c.

829. Caroli V. Constitutio Publ. Judic. : 2, 472 c.

830. Reichsabschiede: Augsburg $15821,13 \mathrm{c}$; Speyer $154256 \mathrm{~b} ; 1551,1555,1577$ $320 \mathrm{~b}$; Regensburg 1476, $1551360 \mathrm{a} ; 1544415 \mathrm{c} ; 1555568 \mathrm{~b} ; 1521634 \mathrm{~b}$; Speyer $1452646 \mathrm{~b} ; 15772$, 61 a; $1555185 \mathrm{c}$; Augsburg $1551277 \mathrm{~b}$.

831. Schmalkaldische Artikel: 1, 656a.

832. Münzordnung Kaiser Ferdinands I. (Augsburg 1559 2, 51 b). Probierordnung QR. 1, 178a;348c;675b;2, 33c;80a.

833. Kaiserliche Reuterbestallung 1570: 1, 522b.

834. Kriegsordnung Kaiser Ferdinands IT. 1626. QR. 1, 37 a.

835. Reichshofordnung 1674: 1, 14c. Vgl. Compendium Praxis Imper. aulioae $9 \mathrm{~b}$.

836. Jagdordnung Kaiser Leopolds, 1675. QR. 1,560b.

837. Capitul. Leopoldi: 2, 320 a.

838. Capitulation Caroli VI. 1713. 1, 572 c; 2, 348 a. 
839. Kaiserliches Edikt 1724 'wegen der Specification aller Professionen'. 2, 400a. 840. Landrecht (Johann Friedrich Schannat: Sammlung alter historischer Schriften und Documenten, wobey das allgemeine Land-Recht. Fulda 1725), 1, 238c; $314 \mathrm{a} ; 2,481 \mathrm{a}$.

841. Rothweilische Hofgerichtsordnung. QR. 1, 9a; $9 \mathrm{~b} ; 2,184 \mathrm{c}$.

842. Weitere (nicht näher bestimmbare) Quellen: Ordinatio Camer. 2, $459 \mathrm{c}$. Carol. 481 a. Capital. (nova editio) 1,576c. Herrschaftliche Taxe auf den Schneidemühlen 118a. Kirchenordnungen 251 a. Alte Formeln der Verkaufung adliger Güter 2, 358a. Jus Giph. in Processu 489 a. Albertus II. Imperat. de P. P. et Austregis 234b. Polizeiordnung 278c. Vetus MS. $406 \mathrm{~b}$.

\section{b) Rechtsordnungen örtlich begrenzter Geltung}

843. Niedersächsischen Kreises Münzordnung (Valvation) 1610. QR. 1, 178a; 213a; $360 \mathrm{~b} ; 625 \mathrm{c} ; 2,126 \mathrm{c} ; 277 \mathrm{~b}$.

844. Seestädtische Mäklertaxe: 2, 148 a.

845. Clevische Rechtsordnung: 1, 15a; 35c;242b;339a;400a;678 c;2, 410 a.

846. Clevische Lehnsordnung: $1,597 \mathrm{c} ; 2,4 \mathrm{~b}$. Clevisches Lehnsrecht (QR.): 1, 535c; $633 \mathrm{~b}$.

847. Clevische Polizeiordnung. QR. 1,454 b.

848. Clevische Deichordnung. QR. $15751,229 \mathrm{~b} ; 425 \mathrm{a} ; 444 \mathrm{c} ; 445 \mathrm{c} ; 2,181 \mathrm{~b} ; 319 \mathrm{a}$. Vgl. 1, 437 a.

849. Jülchische Rechtsordnung. QR. 1, 31a; $387 \mathrm{a} ; 395 \mathrm{~b} ; 437 \mathrm{a}$; Hertzog Wilhelms Rechts-Ordnung. Anno 1574 577o; 2, 70a; 351c. Jülchische und Bergische Rechts.Ordnung 1, 90a.

850. Jülchisches Lehnrecht: $1,349 \mathrm{~b} ; 667$ a.

851. Jülchische und Bergische Historia Juris civilis: 1, 90a;119b;299a;601a; $2,191 \mathrm{a} ; 337 \mathrm{~b} ; 427 \mathrm{~b}$.

852. Jülchische und Bergische Polizeiordnung. QR. 1, 4b; 'In Herzog Wilhelms Jülchischer Policey-Ordnung von Ann. 1609 und von 1696' 169b;2,86c; $407 \mathrm{~b}$. Zusatz: 1, 5c; $26 \mathrm{a}$; $445 \mathrm{c}$; Erläuterungsrezess 2, $227 \mathrm{~b} ; 282 \mathrm{~b}$; observat. $1,75 \mathrm{a}$.

853. Jülchische und Bergische Hofgerichtsordnung. QR. 2, 99a; 324b.

854. InquisitionsprozeB (in Criminal. 1695): $2,18 \mathrm{~b}$.

855. Statuta Coloniensia: 2, 399a.

856. Reformatio Coloniensis. QR. 1, 142 b.

85\%. Kölnischer Schematismus. 1724. QR. 1, 56b; 312c;652a; 2, 336b; 456c;470o.

858. Wurster Landrecht. QR. (Haro Side Fouwes) 1, 135c,

859. Herzog Georg Wilhelms Resolution der Hoyischen Landschaft erteilt. 1697. QR. 1, II4a;526b;2, 55c;118a.

860. Privileg Ottos IV. für die Bürger der Stadt Stade. 1209. 2,396 c; 430c. Privilegium Friedrichs IV. $396 \mathrm{c}$.

861. Hildebaldus: Confirmation der Privilegien der Stadt Stade. 1209. 2, $396 \mathrm{c}$.

862. Georg Roth: Programma de Privilegio Ottonis IV. civibus Stadensibus dato. $2,396 \mathrm{c}$; in Registro MS. bonorum et Jurium castri Vorde $1,122 \mathrm{~b}$.

868. Jodocus Hackmann (1642-1710): Tractatus juxidicus de jure Aggerum, von Deichen und Dämmen und deren Gerechtigkeit. Mit einer Urkunden-Mantisse. Stade 1690. QR. 1, 309a; 400 c; 415a; Holsteinische Deichordnung in mantissa $500 \mathrm{c}$; Ostfriesländische Deichordnung $2,77 \mathrm{~b}$; in den Teich-Ordnungen der Länder an der See 121a; im Holsteinischen 133a; In den Teich-Ordnungen $201 \mathrm{~b} ; 294 \mathrm{a} ; 360 \mathrm{~b} ; 365 \mathrm{c} ; 423 \mathrm{a} ; 485 \mathrm{a}$; Oldenburgische Deichordnung $476 \mathrm{~b}$; $484 \mathrm{~b}$. 
864. Oldenburgische Deichordnung. 1658. QR. $1,156 \mathrm{~b} ; 2,366 \mathrm{c} ; 451 \mathrm{c}$.

865. Ostfriesländische Deichordnung. 1608. QR. 1, $329 \mathrm{a}$; nach Hackmann $449 \mathrm{~b} ; 569 \mathrm{a}$.

866. Essensche Deichordnung (Esens/Ostfriesland) : $1,516 \mathrm{c}$.

867. Constitutiones Ditmarsienses. QR. 1, 522c.

868. Dithmarschische Deichordnung (Königl. Dänische Teich-Ordnung in SuderDitmarschen 1, 461a; 551 c; 2, 238c; 276c). QR. 1, 460a.

869. Holsteinische Landgerichtsordnung. QR. 1, 16a; $102 \mathrm{a} ; 220 \mathrm{~b} ; 416 \mathrm{~b} ; 516 \mathrm{c}$; $2,11 \mathrm{a} ; 104 \mathrm{c} ; 148 \mathrm{~b} ; 362 \mathrm{c}$.

870. Lübisches Recht. QR. 1, 415c; $2,111 \mathrm{a} ; 176 \mathrm{a}$.

871. Hansestädtisches Seerecht: 2, 100 a.

872. Ernst Joachim von Westphal: Specimen monumentorum Meklenburgicorum. QR. 1, 1lc; 389a; 443b;2, 30c; 472a. Schwerinisches Recht 1, 113c; 231a; 522c. Confirmation der Grenzen der Stadt Rostock 643b. Diploma von 1357 $11 \mathrm{c}$.

873. Mecklenburgische Landsordnung. 1562. $1,169 \mathrm{c} ; 380 \mathrm{~b}$.

874. Mecklenburgische Polizeiordnung: 2, $51 \mathrm{c}$.

875. Rostockische Hochzeitsordnung. 1583. QR. 2, 157c;187 c;484a.

876. Rostockische Kleiderordnung. 1581:2, 150b. 1583:250e. 1585 (QR.): 1, 25b; $413 \mathrm{c} ; 448 \mathrm{c} ; 2,150 \mathrm{a} ; 359 \mathrm{~b}, 1587: 1,105 \mathrm{c} ; 415 \mathrm{a} ; 680 \mathrm{a} ; 2,165 \mathrm{a} ; 471 \mathrm{c} .1591$ : $1,448 c ; 680 a ; 2,1780 ; 216 a ; 332 a$.

877. Artikel der Seifensiederinnung zu Salzwedel: 1, 679a; 2, $181 \mathrm{c}$.

878. Hardevicus Dasselius: Comment. in consuetudines et statuta reipublícas Luneburgensis. 2, $310 \mathrm{c}$.

879. Braunschweigische Waldordnung. QR. 1, 17 a; 241 o. 1590: 2, 387 c; 449a. 1598: $1,158 \mathrm{a} ; 620 \mathrm{~b}$.

880. Braunschwoigische Jagd- und Forstordnung. QR. $15901,540 \mathrm{o.}$

881. Braunschweigische Deichordnung: $1,488 \mathrm{a} ; 550 \mathrm{a} ; 2,41 \mathrm{c} ; 148 \mathrm{~b} ; 186 \mathrm{a}$.

882. Taxordnung des Herzogs August von Braunschweig. QR. $1,159 \mathrm{c}$.

883. Braunschweigische Amtsordnung. QR. 1, 569 a.

884. Braunschweigischer Landabschied. 1597. 1, 652 b; 2, 435a.

885. Preußische Landsordnung. QR. 1, $9 a ; 392 \mathrm{c} ; 2,173 \mathrm{c} ;$ vgl. 1, 420a. Preuß. Königsb. Landsordnung 1, 171 c. 1577: 382 c;393e; 2, 464a. 1677: 40b.

886. Preußische Kammerordnung. 1648. QR. 1, $91 \mathrm{a} ; 417 \mathrm{~b} ; 2,58 \mathrm{~b} ; 381 \mathrm{c} ; 469 \mathrm{c}$.

887. Preußische Hofgerichtsordnung. (Nach) 1578. 1, 12b;436b;460c; 2, 78b;89b; $180 \mathrm{~b} ; 395 \mathrm{a}$. Hof- und Land-Gerichts-Ordnung Joachim. Elect. Brandenb. $1,563 \mathrm{c}$.

888. Merseburgische Fischordnung. QR. 1670: 1, 422 c. 1690:280a; 594b; 2, 175a; 292 c.

889. Fürstlich Sachsen-Merseburgische Wasser- und Mühlordnung. 2, 329c; $349 \mathrm{a}$.

890. Magdeburgische Ordnungen. QR. 1, 33b;123c;308a; 585c;2, 157a; 294a; $456 \mathrm{~b} ; 458 \mathrm{a}$. Edition $1673 \mathrm{I}, 16 \mathrm{a}$.

891. Magdeburgigche Deichordnung: 1, 569a.

892. Fürstlich Magdeburgische Kirchenordnung des Herzogs August. I652. 1, 495 a.

893. (Münz-)Register des Alberti Archiepise. Magd.: I524 1, 376 a.

894. Registratur der Generalbefahrung der Magdeburgischen Bergwerke zu Wettin. QR. 1, 338 a.

895. Magdeburgische Land- und Rügegerichtsverordnung des Amts Gibichenstein. $1656: 2,133 \mathrm{c} ; 1666: 133$ a.

896. Joachim Soheplitz (1566-1634): Etzliche Statuta und Gewohnheiten der Chur und Mark Brandenburg. Jena 1608. QR. 1, 34a; 395b; 2, 159o; 439b. Brau. ordnung $157 \mathrm{I} 477 \mathrm{~b}$. Edilkte 1, 222b; $254 \mathrm{~b} ; 572 \mathrm{a}$. 
897. Kurfürstlich Brandenburgisches Edikt wegen der Kirchensteuer: 2, 114c.

898. Ediot. Reg. 1692: 'in Preussen' 1, 70.

899. Kurbrandenburgische Münzordnung. 1667. 1, 238b; $675 \mathrm{a}$.

900. Märlkische Dorfordnung: $1,71 \mathrm{~b} ; 427 \mathrm{c}$.

901. Taxa der Landgüter in der Mark: 2, 349 b.

902. Mërkische Reverse: an. 34. 40. und 72. $1,122 \mathrm{~b} ; 1650,1672: 430 \mathrm{c} ; 1534,1538$, $1572: 605 \mathrm{c} ; 1640: 2,109 \mathrm{c} ; 1550: 388 \mathrm{a}$.

903. Kurfürstlich Brandenburgische Branordnung: 1, $568 \mathrm{~b}$; publizierte Brauordnung 2, $477 \mathrm{~b}$; vgl. $1,348 \mathrm{c}$.

904. Brandenburgische Amtsordnung: 2, $219 \mathrm{c} ; 477 \mathrm{~b}$; vgl. 1, $348 \mathrm{c} ; 504 \mathrm{~b}$. Märlkisohe Amtsordnung 1, 24la.

905. Brandenburgische Forstordnung des Kurfürsten Georg Wilhelm. 1622. 2, 210a; 469 a.

906. Brandenburgische Fischerordnung. QR. 1514: 2, 349a. 1525: 1, 306a. 1572, 1690: 2,413 c. 1574 : 1, 1b; $407 \mathrm{~b} ; 2,239 \mathrm{~b} .1574,1690: 1,16 \mathrm{~b} ; 278 \mathrm{c} ; 498 \mathrm{~b} ; 2,465 \mathrm{a}$. 1575 : 195c. 1594: 1, 270风. $1690: 148 \mathrm{~b} ; 2,377 \mathrm{~b}$.

907. Märkisches Fischerei-Register MS. QR. (Wittstock) 1, 33a; $86 \mathrm{~b}$. Vgl. auch $1,109 \mathrm{c} ; 2,363 \mathrm{c} ; 469 \mathrm{c}$.

908. Brandenburgische Weinmeisterordnung des Kurfürsten Johann Georg von Brandenburg. QR. 1, 34a; 428c;580o;2, 426a.

909. Diploma des Bischofs Busso I. von Havelberg. 1488. 1, 72 b.

910. Altes Kataster des Ober.Barnimischen Kreises. 1, $150 \mathrm{c}$.

911. Alte Schulgesetze des Berlinischen Stadtgymnasiums. 1, 345a; 1584 2,98b; $232 \mathrm{a}$.

912. Privileg der Stadt Pronzlau. 1320. 1, 32c.

913. Innungsartikel des Maurerhandwerks zu Prenzlau: $1,670 \mathrm{~b} ; 2,143 \mathrm{a} ; 181 \mathrm{c}$.

914. Fischerprivileg im Amt Liebenwalde in der Mark Brandenburg: 2, 343 a.

915. Lebusische Deichordnung. QR. $1,70 \mathrm{c} ; 154 \mathrm{~b} ; 550 \mathrm{a} ; 2,36 \mathrm{c} ; 366 \mathrm{c}$.

916. Kataster im Lebusischen Kreis in der Mark Brandenburg: 2, $246 a$.

917. Alter Kaufbrief. Storkau 1492. 1, 91a.

818. Prodromus Vindiciarum Gloriae et Nominis Pomeranorum. Rostock 1720. QR. 'in den Pommerschen Diplomatis' 2, $403 \mathrm{c}$.

919. Privileg Barnims I. 1243. 2, $403 \mathrm{c}$.

920. Pommerische Holz-, Mast- und Jagdordnungen. QR. Holzordnung: 1, 465 b; 2, 247 a. Holz- und Jagdordnung: 1, 498b. Holzordnung 1681: 604 b; 2, 66 b; $315 \mathrm{c} ; 450 \mathrm{a}$. Holzordnung 1711: 335 b. Holzordnung 1717: 1, 125a; 2, 73c; 458 a. Holz- und Mastordnung 1717; 1, 7a; 24c; $218 \mathrm{~b}$. Holz- und Jagdordnung 1717: 2, $219 \mathrm{c}$. Holzordnung 1719: 1, 118a; 500a; 2, 110 c; $361 \mathrm{c}$. Jagdordnung $1719: 1,201 \mathrm{c} ; 245 \mathrm{a} ; 483 \mathrm{~b}$. Holz-, Mast- und Jagdordnung 1719: 2, $159 \mathrm{c}$.

921. Edikt 1617 (wegen der Türkensteuer in Pommern). $1,551 \mathrm{~b}$.

922. Treptauische Amts- und Dorfordnung. QR. $1683: 1,383 \mathrm{~b} ; 603 \mathrm{~b} ; 2,87 \mathrm{~b} ; 446 \mathrm{c}$.

923. Rügenwaldische Amts- und Dorfordnung. QR. 1, 395b;2, 84b; 324 c. 1681 : $1,318 \mathrm{c} ; 410 \mathrm{c} ; 2,394 \mathrm{a} .1717: 1,540 \mathrm{c}$.

924. Von der Maierbesoldung in dor Neumark: $1,658 \mathrm{~b}$.

925. Confirmation der Privilegien der Neumark durch den Kurfürsten Johann zu Brandenburg: 2, 3810 .

926. Häckerbestallung in der Neumark Brandenburg. QR. 1667. 1, 395b.

927. Preußische Rentliammer in Königsberg. 1648. 1, 494a.

928. Bernstein- und Strandordnung Friedrichs III. 1693. QR, 1, 86 c; 2, 40 b; 189a; $218 \mathrm{c}$; vgl. 1, 498c. 1691: 1, 264a.

929. Consuetudines des Deutschen Ordens in Preußen: 2, 382a. 
930. Privilegia der Teutschen Ritter. MS. QR.

931. Teutsche Constitutiones des polnischen Preußen Sigismundi Regis Poloniae. $1,402 \mathrm{c} ; 2,65 \mathrm{a} .1538: 1,395 \mathrm{a} ; 2,176 \mathrm{a} ; 385 \mathrm{c} ; 420 \mathrm{~b}$. MS. 1638:1, $229 \mathrm{~b}$.

932. Registrum Prumiense: 2, 461 c. Leibniz: Breviarium Prumiense $1,11 \mathrm{~b}$.

933. Reformatio Francofurtensis. QR. (1509) 1, $129 \mathrm{c} .163 \mathrm{~b} ; 349 \mathrm{~b} ; 2,191 \mathrm{a}$; 462 c.

934. Hessische Jagd- und Forstordnung. 1624. 1, 540c; 2, 214b; 425 a.

935. Hessen-Kasselische Wasser- und Fischordnung. QR. 2, 53 a. Fürstlich Hessische Fischordnung $4 \mathrm{~b} ; 210 \mathrm{a}$.

936. Corpus Juris Saxonici. QR. 1, 14a; 81 a; 249b; 556c;2, 167c;205c;420c. Pirnische Eisenordnung 1, 271 a; Sächsisohe Taxordnung 274b.

937. Constitutiones Electoratus Saxonici: 1, 85a. Jus Electoratus Saxonici 2, 44 a. (Constitutiones Elect. Sax, QR.).

938. Kurfürstlich Sächsisch $\Theta$ Landordnung. QR. I, 89c; $344 \mathrm{c}$.

939. Ordinatio Polit. Saxo. Goth.: 2, 238 b.

940. Ordinatio Metall. Electoratus Saxonici: 1, 554c. (Churfürstlich Sächsische BergOrdnung B. 70).

941. Sächsische Jagdordnung. QR. 2, $345 \mathrm{c}$.

942. Sächsische Forstordnung. 2, $211 \mathrm{c}$.

943. Kurfürstlich Sächsische Gerichtsordnung. 1, 440b.

944. Kurfürstlich Sächsische Erledigung. 1, 498c.

945. Sächsische Justitiensachen. 2, 453a.

946. Sächsische Kirchenordnung. 1, $583 \mathrm{c}$.

947. Sächsische Polizeiordnung. 1, 48a; 2, $80 \mathrm{~b} ; 352 \mathrm{c}$; Polizei- und Kleiderordnung $464 \mathrm{c}$.

948. Sächsische Mühlenordnung. 1, $267 \mathrm{c}$.

949. Sächsische Bäckerordnung. 2, $427 \mathrm{c}$.

950. Fleischpatent (vom Hausschlachten) in Sachsen 1657 und $1671: 1,275 \mathrm{~b}$.

951. Sohultheißenordnung des Herzogs Ernst zu Gotha. 1652. QR, 2, 233 b.

952. Ruggerichtsordnung im Gothaischen. QR. Vgl. Quelle 662.

953. Constitutiones Gothan. 1, 296a.

954. Sachsen-Gothaische Fischordnung. 1667, 2, 338a.

955. Kursächsische Fischordnung. $1,108 \mathrm{c} ; 195 \mathrm{~b} ; 236 \mathrm{~b} ; 278 \mathrm{c} ; 486 \mathrm{~b}$.

956. Convention der Brüder von Rabenau. 1436, 1, 644 a.

957. Lausnitzische Landordnung. 2, 466 c.

958. Kaiser Rudolfs II. Majestätsbrief der Schlesier. QR. 1, 9a.

959. Glogauische Mühlordnung. 1566. QR. 1,35b.

960. Straßburgische Polizeiordnung. QR. 1628: 1, 4a; 393c; 595b. Anhang 14b. 1608: 315a. 1621: 2, 274 a. 1638: 133 c. Vgl, auch 1, 654c/655a.

961. Jus Argentoratense. Ed. Schilter: 1, 32c;37c;123a; $175 \mathrm{a} ; 254 \mathrm{~b} ; 438 \mathrm{c}$; 2,188 b. I, 436 c. 466 b. 2, 394b.

962. Ordinatio reipublicae Argentoratensis. 1, $318 \mathrm{~b}$.

963. Ordnung des Heiligen Nachtmahls zu Straßburg. 1525. (Schwanburger: Ordnung des Herrn Nachtmahl. Straßburg 1525. B. 7). I, 574a; 592c; 637b.

964. Oberrhoinische Münzordnung. 1610. 1, 200 b.

965. Solmische Landsordnung. QR. 1, $141 \mathrm{a} ; 271 \mathrm{~b} ; 567 \mathrm{~b} ; 2,60 \mathrm{c}$.

966. Schweizerisches Recht. I593, 2, $406 \mathrm{~b}$.

967. Acta Lindaviensia. QR. 1, 17a; $156 \mathrm{a} ; 215 \mathrm{c} ; 233 \mathrm{a} ; 347 \mathrm{~b} ; 456 \mathrm{~b} ; 629 \mathrm{c} ; 640 \mathrm{c}$; $2,12 \mathrm{a} ; 46 \mathrm{~b} ; 120 \mathrm{c} ; 229 \mathrm{c} ; 387 \mathrm{~b}$.

968. Statuta Friburgensia. 1, 248 a.

12 Powitz, Frischs Wörtierbuch 
969. Württembergisches Recht. 1, 674a.

970. Württembergisches Landrecht. 1,612b.

971. Statuta Würtembergensia. $1,89 \mathrm{a} ; 124 \mathrm{a} ; 509 \mathrm{~b} ; 606 \mathrm{a} ; 2,393 \mathrm{a}$.

972. Württembergisehe Jagd- (QR.) und Wald- (QR.) Ordnung. Jagdordnung: $2,465 \mathrm{~b} ; 466 \mathrm{~b}$. Forstordnung: $1,70 \mathrm{c} ; 579 \mathrm{~b}$. Jagd- und Forstordnung : $2,338 \mathrm{~b}$. Jagdordnung 1551: 1,80b. Waldordnung 1551: $383 \mathrm{a}$. Waldordnung 1588: 2,304a.

973. Württembergische Wildschützenordnung. 1588. 1, 571c; $2,448 \mathrm{a}$.

974. Württembergische Fischordnung. 1551. 1, $283 \mathrm{c}$.

975. Ordinatio Vindemiae Wirtenbergica. QR. 2, 263 a.

976. Constitutio Elect. Palat. 1, 613 a.

977. Schwäbisches Landrecht. 2, $125 \mathrm{c}$.

978. Landfriede. Augsburg 1548. 1, 320 b.

979. Codex MS. Juris Augustani (Augsburger Stadtrecht). Nach Schilter. 1, 102 c; $113 \mathrm{~b} ; 290 \mathrm{~b} ; 477 \mathrm{~b} ; 609 \mathrm{c} ; 2,329 \mathrm{~b}$. Vgl. 1, $59 \mathrm{~b}$.

980. Gräflich Hohenlohische Forst- und Jagdordnung. 1, $73 \mathrm{c}$.

981. Bayrisches Landrecht. QR. 1, 57c;425o;466a; 637c; 2,43 a. Neues bayrisches. Landrecht 2, $402 \mathrm{c}$. Churbayrisches Landrecht 1,600c. Bayrisches Landrecht, nach: Johann Marquart: Tractatus politico-juridicus de jure mercatorum et. commerciorum. Frankfurt 1662, 1, 463a.

982. Bayrische Land- und Polizeiordnung. 1, 291 a; 2, 228a; $440 \mathrm{c}$. Landordnung: $1,372 \mathrm{c} ; 672 \mathrm{c} ; 2,237 \mathrm{a} ; 466 \mathrm{~b}$. Polizeiordnung: $1,516 \mathrm{c}$.

983. Jus Bavaricum. 1, 296a; 599a; 2, 409c; 449c. Constitut. Bavar. 1, $295 \mathrm{c}$.

984. Fürstlich bayrische Ordnung des Mühlwerks. QR. $1,279 \mathrm{a} ; 584 \mathrm{c} ; 637 \mathrm{~b} ; 2,126 \mathrm{a}$; $276 \mathrm{e} ; 465 \mathrm{a}$.

985. Gerichtsordnung (in Bayern). 1, 198a.

986. Khraisser: Jus venandi, aucupandi ot piscandi in Bavaria. Bayrisches Jagdund Fischrecht. QR. Jus venandi : $1,395 \mathrm{a} ; 649 \mathrm{a} ; 2,432 \mathrm{~b}$. Jus piscandi: $1,32 \mathrm{c}$; 2, 112b; vgl. 1, 389a. Ohne Nennung des Herausgebers: Jus venandi : 1 , 44 ; $188 \mathrm{~b}$. Jus piscatorum: $38 \mathrm{a}$.

987. Fürstlich bayrische Fischordnung. $1,283 \mathrm{c} ; 2,228 \mathrm{a}$.

988. Bayrische Forstordnurg. 1, 180 c; $579 \mathrm{~b}$; vgl. 2, $121 \mathrm{a}$.

989: Bayrische Jagd- und Forstordnung. 1, $603 \mathrm{c}$.

990. Churbayrische Jagdordnung. 2, 28 a.

991. Eheordnung zu Rothenburg ob der Taubor. 1656. 2, $371 \mathrm{c}$.

992. Diploma des Kaisers Rudolf, so er den Zeidlern in Nürnberg gegeben. 1, $91 \mathbf{a}$. 993. Nürnberger Fünferordnung. 2, 46a.

994. Nürnbergische Deduktionsschrift. 2, $385 \mathrm{c}$.

995. Reformatio Norimbergensis. $1,318 \mathrm{~b} ; 2,436 \mathrm{c}$. Reformatio Norica (QR.). $2,171 \mathrm{c}$ 996. Peinliche Halsgerichtsordnung im Bambergischen. 2, $43 \mathrm{c}$.

997. Acta Franconica. QR. Urkunden des 14. Jhs, 2, 143c; Ortenburgisehe Urkunde $144 \mathrm{a}$.

998. Ahasverus Fritsch: Jagd-und Forstordnung. QR. 1, 15a;32c;90a; 245b; $381 \mathrm{~b} ; 2,415 \mathrm{c} ; 1651465$ a. Bayrische Jagdordnung 1, 228a. Fritsch de Jure. Venatorio-Forestali 1,487 c (Corpus juris venatorio-forestalis Romano-Germanici. Jena 1675).

999. Osterreichische Fischordnung ob der Ens. 1, $474 \mathrm{c}$.

1000. Statuta Academiae Viennensis in Austria. 1, 46a.

1001. Tirolische Landordnung. Nach Zeiller. QR. 1, 35 b. 
1002. Melchior Haiminsfeld Goldast (1578-1635): Commentarii de regni Bohemiae incorporatarumque provinciarum juribus ac privilegiis. Frankfurt 1627. QR. $\mathrm{I}, 117 \mathrm{~b} ; 177 \mathrm{c} ; 354 \mathrm{c} ; 375 \mathrm{~b} ; 648 \mathrm{c} ; 2,252 \mathrm{a} ; 315 \mathrm{a} ; 370 \mathrm{c} ; 391 \mathrm{~b}$.

1003. Opus tripartitum oder Decretum des Ungarischen Landrechts von Vermarkung und Unterscheid der Hotter. 1, 471a.

1004. Verbesserte Hofgerichtsordnung. 1078. 2, $403 \mathrm{c}$.

\section{c) Germanische Stammesrechte, Rechtsbüicher des Mittelalters}

1005. Lex Wisigothorum. 1, $33 \mathrm{a}$; nach Vossius $387 \mathrm{~b}$; nach Du Cange 2, $185 a$.

1006. Lex Ostrogothorum. 2,418b.

1007. Leges Uplandicae. 2, $418 \mathrm{~b}$.

1008. Lex Burgundorum. I, 25 c;122a;24l b;2, $223 \mathrm{a}$.

1009. Lex Inae Reg. Westisax. 1, $71 \mathrm{~b}$.

1010. Leges Aethelstani regis Angliae. 1, 557b; 2, 433a. Vgl. 1,61b.

1011. Leges Burgorum Scoticorum. 1, 241 b.

1012. Codex legum Normann. 2, 390a; nach Ludewig 1, 89a; 2, 20c; $165 \mathrm{~b}$.

1013. Leges Frisonum. 1, 56b; $65 \mathrm{c} ; 668 \mathrm{~b} ; 2,440 \mathrm{c}$; nach Vossius $291 \mathrm{~b}$.

1014. Lex Ripuariorum. 1,312a; 401b;433c;2,152c;464b. Fleroldi edition $2,49 \mathrm{c}$. Nach Vossius $1,556 \mathrm{c} ; 2,80 \mathrm{c}$.

1015. Lex Salica. 1, 30a; 72c;323b;442o;2, I40a; 223a;374b;419c;464b. Nach Vossius $80 \mathrm{c} ; 214 \mathrm{~b}$.

1016. Johann Georg Eckart: Leges Francorum Salicae et Ripuariorum. Frankfurt/ Leipzig 1720. QR. B. 82. 1, 83a; $213 \mathrm{a} ; 411 \mathrm{~b} ; 2,126 \mathrm{a} ; 143 \mathrm{~b} ; 262 \mathrm{c}$.

1017. Godefr. Wendelinus: Leges Salicae illustratae (Glossarium legis Salicae). Antwerpen 1649. 1, 564b; 2, 144a; 464b.

1018. Lex Bajuwarum, 1,2a; Heroldi edition $30 \mathrm{a}$; nach $\mathrm{Du}$ Cange und 'andern Codicibus' 90a; 32l c; 437a; 2, 52c; 164b; 234a; nach Vossius $291 \mathrm{a} ; 450 \mathrm{c}$. Leges Bojorum 1, 92a; 234a; 433c; 2, 368c.

1019. Leges Longobardorum. I, 33c;112a;234b;312a; 2, $10 \mathrm{a} ; 56 \mathrm{c} ; 155 \mathrm{a}$. Edictum Rotharis regis Longobardorum $1,642 \mathrm{~b}$; vgl. $49 \mathrm{c}$. Lex Longobardorum nach Du Cange 2, 100a; $156 \mathrm{c}$.

1020. Lex Alamannorum. 1, 2a; 72c;219a;315a; 2, 16a; 164b;294b;377b;446b.

1021. Schwabenspiegel. 'Schilteri Edition in seinen alten Teutschen Auctoribus' QR. 1, 2c;461a; 2, 120a; 230a; 360 b. Frisch benutzt mehrere Ausgaben: $1,414 \mathrm{a} ; 2,85 \mathrm{a} ; 120$ a. Ed. Moser 1,216a; 349c;640b; 2, 7c. Ed. Goldast $1,459 a ; 493 a ; 2,255 a ; 263 c ; 414 b ; 436 a$. Jus Feudale Alem. 1, 58c;63a. Jus provinciale Alem. MS. 1, 152c; 4100 . Nach Schilter 123 a. Schilter und 'andere editionen' 193a.

1022. Sachsenspiegel. 'Jus Saxonicum bey den Alten' QR. Spec. Sax. s. Jus provinc. Sax. 1, 34a; Jus Saxonicum 233 b; vgl. 2, 140 b s. v. Sachsenspiegel. Frisch benutzt ein MS. vom Jahre 1269 und mehrere Ausgaben:

MS. $1269: 1,26 a ; 404 \mathrm{c} ; 451 \mathrm{a} ; 2,158 \mathrm{~b} ; 280 \mathrm{c}$. Andere Ausgaben: 1, 26a; $87 \mathrm{a}$; $158 \mathrm{~b} ; 200 \mathrm{a} ; 2,112 \mathrm{a} ; 138 \mathrm{a} ; 152 \mathrm{a} ; 406 \mathrm{~b}$. Ed. Zobel: 1, 358c;2, 348 b; 458a. Ausgabe 1539 (Sachsen-Spiegel, corrigiert aufs neue. Leipzig 1539. B. 83) $1,522 \mathrm{a} / \mathrm{b}$.

Vorrede: 1, 4c; 14a; 63c;334b;422a; 2, 18a; 226c;438c. Repgow 84c; Repkow 148b; Repkau $477 \mathrm{c}$; vgl. 1, 564 a.

Glossen: $1,8 \mathrm{c} ; 18 \mathrm{a} ; 2,134 \mathrm{a}$; der alte Ausleger des Sachsenrechts 144a; $156 \mathrm{~b}$; 409 c. Vocabularius vetus Speculo Saxonico annexus $1,168 \mathrm{c} ; \mathrm{vgl} .1,9 \mathrm{~b}$. Weichbild: $1,30 \mathrm{a} ; 2,47 \mathrm{~b} ; 313 \mathrm{c} ; 408 \mathrm{~b} ; 433 \mathrm{a} ; 448 \mathrm{a}$. 
1023. (Johann von Buch): Richtsteig MS. (QR.) 1269 'am Sachsenspiegel' 1, $187 \mathrm{c.}$ 'Ein Auszug des Sächsischen Land- und Lehen-Rechts, (eines ungewissen Verfassers; der sich auf Kaiser Frider. berufft,)' 2, 117 c. I, 4b; 14b; $434 \mathrm{a}$; $489 \mathrm{c} ; 673 \mathrm{c} ; 2,36 \mathrm{a} ; 172 \mathrm{a} ; 281 \mathrm{~b} ; 333 \mathrm{c} ; 359 \mathrm{c} ; 416 \mathrm{~b}$.

\section{B. 5. Technik. Fachn, Natur-, Lönderlsunde}

Die Gruppe umfaßt eine größere Anzahl von Werken des fachkundlichen Schrift. tums. Neben einigen Zeitschriften und enzylklopädischen Wörterbüchern benutzt FRIsar in reichem Umfange Darstellungen einzelner Fachgebiete als Quellen für das berufssprachliche Wortgut und als Hilfsmittel für die Klärung sachlsundlicher Fragen. Sie gehören folgenden Bereichen an : Mechanik - Mathematik - Baukunst Münzwesen - Bergbauwesen - Mineralogie - Salinenwesen - Landwirtschaft Pferdezucht - Imkerei - Jagd- und Forstwesen - Fischerei - Kriegswesen - Medizin - Geographie. Außerdem verwertet Friscr eine Reihe von Reise- und Länder. beschreibungen sowie als Quellen für das naturkundliche Namengut mehrere Werke aus dem Bereich der Tier- und Pflanzenkunde.

1024. Observationes Naturae Curiosorum. 1, 620a. Johann von Muralt in: Epheme. rides Naturae Curiosorum 1, 420 .

1025. Sammlung von Natur- und Medizin- wie auch hierzugehörigen Kunst- und Literatur-Geschichten ... von einigen Breslauischen Nat. Curios. und $\mathbf{M}_{0-}$ dicis. Breslau (1.-38. Versuch. 1717-1726). Register 1, $496 \mathrm{~b}$.

1026. Schlesische Neuigkeiten. 2, 86 a.

1027. Acta literaria Sueciae Upsaliae publicata. QR. Bd. 2. 1725. (Olaus Bromel) 2,349 a.

1028. Histoire et Mémoires de l'Académie des sciences. Paris (1701ff.) 2, $373 \mathrm{~b}$.

1029. Johann Heinrich Zedler (1706-1763): Großes vollständiges Universal-Lexicon aller Künste und Wissenschaften. Leipzig/Halle 1732 (-1750/1754). QR. $1,361 \mathrm{~b} ; 2,188 \mathrm{c}$.

1030. Adrian Beier (1634-1712): Allgemeines Handlungs-, Kunst-, Berg- und Handwercks-Lexicon. Jena 1722. QR. B. 63. 1, 23b;65b; $73 \mathrm{~b} ; 118 \mathrm{~b} ; 181 \mathrm{c}$; $347 \mathrm{~b} ; 2,328 \mathrm{c} ; 332 \mathrm{~b} ; 448 \mathrm{c}$.

1031. Justus Lipsius (1547-1606): Poliorceticon sive de machinis, tormentis et telis libri V. Antwerpen 1596. 1, $505 \mathrm{c}$.

1032. Heinrich Zeising: Theatrum machinarum, in welchem vielerley künstliche Machinae so fürnehmlich zum bawen nützlich, schöne Wasserkünste, Wassersprützen und künstliche Mühlwerk in . . .761 Kupferstücken zu sehen sindt. Beneben eigentlicher Erklërung derselben. Leipzig 1612-1618. 1, 166a.

1033. Joseph Furttenbach: Mannhafter Kunstspiegel, allerhand mathematischund mechanisch- hochnutzlich delectationen. Augsburg 1663. 1, 357 a.

1034. Robert Hooke (1635-1705): Micrographia or some physiological descriptions of minute bodies made by magnifying glasses. London $1665.1,118 \mathrm{c}$.

1035. Nicolaus Bion: Neueröffnete mathematische Werkschule, vermehrt durch J. G. Doppelmayr. Franlkfurt/Leipzig 1712. QR. B. 66. (Ưbersetzung aus dem Französigchen). 1, 13a.

1036. Basilius Valentinus (Johann Thoelde): (Rätsel vom Vitriol) 2, $367 \mathrm{c}$.

1037. Heinrich Lautensack: Dess Circkelsz vnd Richtscheyts, auch der Perspectiva vnd Proportion der Menschen vad Rosse ... vnderweisung. Mainz 1584. B. 86. 1, 557 c.

1038. Daniel Schwenter (1585-1636): Deliciae physico-mathematicae oder Mathematisch-philosophische Erquickstunden. Nürnberg (1636) 1651. B.66. Glückstunden $1,222 \mathrm{c}$. 
1039. Georg Mars(ch)mann: Tractatus mathematico-juridicus de metrologia et miliologia. Jena 1674. QR. 1,570c.

1040. Christian Wolff (1679-1754): Mathematisches Lexicon. Leipzig 1718. B. 63. $2,384 \mathrm{a} ; 388 \mathrm{a}$.

1041. Seth Calvisius (1556-1615): Opus chronologicum. Leipzig 1605. 2, 433a.

1042. Paul Jakob Marperger (1656-1730): Plantagen-Tractat. Neueröffneto Wasserfahrt auf Flüssen und Canälen. Dresden 1722. QR.

1043. Walther Hermann Ryff (Rivius): Vitruuius Teutsch. Nürnberg 1548. 1, $215 a$.

1044. Nicolaus Goldmann (1623-1665): Nic. Goldmanns Vollständige Anweisung zu der Civilbaukunst. Hg. v. L. Chr. Sturm. Braunschweig 1699. QR. 1, 116 b; $120 \mathrm{a} ; 178 \mathrm{a} ; 444 \mathrm{~b} ; 2,119 \mathrm{~b} ; 121 \mathrm{c} ; 153 \mathrm{c} ; 269 \mathrm{a}$.

1045. Guilielmus Budaeus (1467-1540): De asse et partibus ejus libri V. 1522. 2, $332 \mathrm{~b}$.

1046. Olaudius Salmasius (1588-1653): De usuris liber. Leyden I638. I, 58 a.

1047. Franciscus Le Blanc: Traité historique des monnoyes de France. Paris 1690. 2, $377 \mathrm{c}$.

1048. Polydorus Vergilius (gest. 1555): 2, 332 b.

1049. Marquard Freher (1565-1614): De re monetaria veterum Romanorum ot hodierna apud Germanos Imperii. Leyden 1605. 1, 382 b.

1050. Tileman Friese: Müntz-Spiegel, d. i. . . . Bericht von der Müntz, deren Anfang, Materia, Form, Korn, Schrot. Frankfurt 1592. 1, 382a; 570c; 615c; 644b; 2 , $51 \mathrm{~b} ; 332 \mathrm{~b} ; 377 \mathrm{c} ; 401 \mathrm{a}$.

1051. Jacob Alemann: Palaestra consultationum iuris illustrium prima. Magdeburg 1613. QR, 1, 17a; $71 \mathrm{~b} ; 176 \mathrm{c} ; 375 \mathrm{c} ; 477 \mathrm{c} ; 663 \mathrm{c} ; 2,51 \mathrm{~b} ; 218 \mathrm{~b} ; 224 \mathrm{~b} ; 370 \mathrm{c}$; $377 \mathrm{c} ; 401 \mathrm{a} ; 416 \mathrm{c}$.

1052. Johann Theodor Sprenger: Kurtze Wechsel-Practic. Frankfurt 1662. QR. $2,332 \mathrm{~b}$; nach Besold $129 \mathrm{c}$.

1053. Christian Keimann (1607-1662): Libellus de variis in Romano Imperio valentibus nummis seu Wechselbüchlein Gideonis Hofmanni arithmetici quondam Zittaviensis. Auf allerhand im Römischen Reich gebräuchliche Gattungen der Müntzen gerichtet. (Leipzig 1616). Hg. v. Chr. Keimann. Zittau 1658. QR. 1, 376a.

1054. Wilhelm Freiherr von Schröter (gest, 1689): Fürstliche Schatz- und RentKammer. Leipzig 1686. 1, 262b.

1055. Joachim Siegmann: Resolvierbüchlein der Münzen in der Lausnitz, Meißen, Schlesien und Böhmen. Bautzen 1703. QR. 1, 376a.

1056. Christian Schlegel (1667-1722): De nummis antiquis Gothanis, Cygneis, Coburgensibus, Vinariensibus et Merseburgensibus. Frankfurt 1715. QR. $1,307 a ; 375 \mathrm{c} ; 469 \mathrm{a} ; 492 \mathrm{c}$.

1057. Christian Schlegel: De nummis antiquis Salfeldensibus, Arnstadiensibus et Jenensibus. Dresdén 1697. 1, $571 \mathrm{~b}$.

1058. Georg Agricola (1490-1555): De re metallica libri XII. Basel 1530. 1, 85 b; $2,377 \mathrm{a} ; 466 \mathrm{c}$.

1059. Johann Mathesius (1504-1565): Sarepta oder Bergpostill, darinn von allerley Bergwerck vnd Metallen ... guter Bericht gegeben wird ...., sampt der Joachimszthalischen kurtzen Chronicken. 1562. QR. 1, 3a; 171b; 174a; $391 \mathrm{a} ; 397 \mathrm{c} ; 400 \mathrm{~b} ; 434 \mathrm{~b} ; 495 \mathrm{c} ; 2,399 \mathrm{a} ; 462 \mathrm{~b}$. Chron. 2, 332a; vgl. 1, $212 \mathrm{c}$.

1060. Georg Fabricius (1516-1571): Observationes variae et eruditae de metallicis rebus ac nominibus, quibus ea potissimum explicantur, quae Ge. Agricols praeteriit. 2, $454 \mathrm{~b}$.

1061. Lazarus Ercken (Erker, Erkner): Aula subterranea, d. i. Untererdische Hofhaltung oder Beschreibung der Sachen so in der Tieffe der Erde wachsen. 
1573. QR. Erkners Index von Bergwerks-Wörtern 2, 228a; 229a; $229 \mathrm{~b}$. Vgl. : Berward 'an Erikners Probier-Buch' $228 \mathrm{c}$.

1062. Georg Engelhard von Löhneyß : Bericht vom Bergwerck. Zellerfeld 1617. QR. 2, 478c; vgl. $392 \mathrm{~b}$.

1063. Christian Berward: Interpres phraseologiae metallurgicae oder Erklärung der fürnembsten Terminorum und Redearten, welohe bei den Bergleuten, Puohern, Schmeltzern, Probirern und Müntzmeistern . . . gebräuchlich sind. Franlsfurt 1673. QR. 1, 164c;597a;2,116c;270b.

1064. Abraham von Schönberg: Ausführliche Berg-Information zur dienlichen Nachrioht vor Alle, die bey dem Berg- und Schmeltzwesen zu schaffen. Anhang: Redensarten bei Berg- und Schmeltz-Wercken. Leipzig 1698. QR. $1,117 \mathrm{a} ; 320 \mathrm{~b} ; 329 \mathrm{a} ; 381 \mathrm{c} ; 407 \mathrm{c} ; 438 \mathrm{a} ; 588 \mathrm{a} ; 2,49 \mathrm{a} ; 65 \mathrm{~b} ; 132 \mathrm{a} ; 238 \mathrm{c} ; 280 \mathrm{~b}$; $414 \mathrm{c} ; 465 \mathrm{c}$. Vgl. $2,76 \mathrm{c} ; 489 \mathrm{~b}$.

1065. Balthasar Rössler (1605-1673): Speculum Metallurgiae Politissimum oder Hell polierter Berg-Bau-Spiegel. Dresden 1700. QR. 1, 349b.

1066. Christ. Karl Schindler: Metallische Probierkunst. Frankfurt 1705. B. 23. QR.

1067. Christoph Herttwig: Neues und vollkommenes Berg-Buch. Dresden/Leipzig 1710. Hartwich 2, 102c.

1068. Johannes Deucer: Corpus juris metallici oder königliches Bergbuch. Leipzig 1724. 2,4090 .

1069. Johann Friedrich Henkel (1679-1744): Pyritologia oder Kieshistorie als des vornehmsten Minerals. Leipzig 1725. QR. 1, 386b; $398 \mathrm{c} ; 477 \mathrm{~b} ; 514 \mathrm{a}$; $2,17 \mathrm{~b} ; 65 \mathrm{c} ; 144 \mathrm{~b} ; 381 \mathrm{a} ; 445 \mathrm{a}$.

1070. Johann Christian Lehmann (1675-1739): Terrebra Metalloscopia: Beschreibung des Bergbohrers. Leipzig 1714. 1,83c.

1071. Johann Thoelde: Haliographia oder Beschreibung aller Salzmineralien. Frankenhausen 1603. Thoedenus 2,320a. Vgl. Quelle 662 und 1036.

1072. Friedrich Hohndorf: Beschreibung des Salzwerks zu Halle in Sachsen. Halle 1670. QR. 1, 24c;42b;398b;2,154a; 291o; 370o; $439 \mathrm{a} ; 468 \mathrm{c}$. Thalordnung zu Halle I, 236 a; Thalordnung 1482378 a; Documente beim Salzwerk zu Halle $408 \mathrm{c}$.

1073. Janderson: Verzeichnis der Wörter und Werkzeuge beim Salzwerk. (Erklërung der beym Saltzsieden nöthigen Wörter, Werckzeuge, Gebäude etc. nach dem Alphabet. Magdeburg 1710. B. 93). 2, 34b.

1074. Petrus de Crescentiis (1230-1320): De agrioultura 1, 44a; $119 \mathrm{a}$.

1075. Johann Colerus (gest. 1639): Oeconomia ruralis et domestica worin das Ampt aller braven Hausväter und Hausmütter begriffen. Wittenberg 1591-1605. (Haus-Buch. 1602. B. 79). Editio prima in quarto 1, 34a. QR. 1, 2a; 389c; $465 \mathrm{a} ; 2,414 \mathrm{c}$. Bauernregeln $400 \mathrm{~b}$. Brandenburgische Brauordnung $477 \mathrm{~b}$. Sächsisches Holzkaufregister $1,7 \mathrm{a} ; 10 \mathrm{~b} ; 487 \mathrm{~b} ; 2,247 \mathrm{~b} ; 438 \mathrm{a}$.

1076. Emanuel König (1658-1731): Georgica Helvetica curiosa, oder Neu curioses Eydgnossisch Schweitzerisch Haußbuch. Basel 1706. QR. 1, 398b; 449b; $2,213 a ; 293 a ; 334 a ; 378 c ; 438 a$.

107\%. Wolff Helmhard von Hoh(en)berg (1612-1688): Georgica curiosa oder Unterricht für den Landbau fürs adelige Land- und Feldleben. Nürnberg 1687. QR. 1, 540b; 2,62a; 154c;178b;244c;345c;447a.

1078. Johann Carl von Carlowitz (1645-1714): Sylvicultura oeconomica oder Anweisung zur wilden Baumzucht und vom Turf. Leipzig 1713. QR. 1, 218a; $603 \mathrm{a} ; 2,39 \mathrm{~b} ; 490 ; 274 \mathrm{c} ; \mathrm{vgl} .377 \mathrm{~b}$.

1079. Charles Patin (1633-1693): Traité des tourbes combustibles, Paris 1663. 2, $377 \mathrm{~b}$. 
1080. Martinus Schoekius: De turbis. 2, $377 \mathrm{~b}$.

1081. Andreas Libavius (gest. 1616): Singularium medico-physicorum problematum partes IV. Frankfurt 1599. B. 31. 1,649a.

1082. Joh. Er. Fr. Kraus: Der Edle Gestütt Garten, oder aufrichtige Anleitung zur Gestütt und Pferd-Ziehung. Nürnberg 1724. QR. 1, 135b;243a;360b;472b; $679 \mathrm{~b} ; 2,94 \mathrm{~b} ; 162 \mathrm{~b} ; 295 \mathrm{~b} ; 394 \mathrm{c} ; 406 \mathrm{a} ; 489 \mathrm{a}$.

1083. Caspar Höfler: Die rechte Bienen-Kunst d. i. wie eine Bienenzucht zu legen, zu warten und ... zu geniessen sey. Leipzig (1614) 1700, B. 33. QR. 1, 14c; $44 a ; 210 b ; 2,89 a ; 126 \mathrm{c} ; 426 \mathrm{c} ; 469 \mathrm{a}$.

1084. Johann Grüwel: Brandenburgische Bienenkunst. Berlin 1699. B. 33. QR. $1,75 a ; 91 a ; 2,89 a ; 127 a ; 452 a$.

1085. Philipp Jacob Sachse von Lewenheimb (1627-1672): Ampelographia sive vitis viniferae ejusque partium consideratio physico-philologico-historicomedico-chymica. Leipzig 1661. B, 37. QR. 1, 445a; 2, 229a.

1086. Jacob Otto (1635-1703): Freier Pürsch-Beschreibung und insbesondere der allgemeinen Pürsch an der Donau. Augsburg 1680. Ulm 1725. 'edition mit Anmerkungen und Beylagen C. C. W.' 1, 100a.

1087. Wolff Helmhard von Hohberg (1612-1688): Waidmannschafft durchs gentze Jahr. In: F. A. von P.: Angenehmer Zeit-Vertreib, welchen die Vögel dem Menschen schaffen können. Nürnberg 1716. QR. 2, 1410; 3690; Unterricht von Vögeln $2,62 \mathrm{c}$; vgl. $1,161 \mathrm{c}$.

1088. Hans Friedrich vom Flemming: Vollkommener teutscher Jäger, von allem, was zur hohen und niedern Jagd gehöret. Leipzig 1719-1724. B. 85. QR. $1,4 \mathrm{c} ; 29 \mathrm{c} ; 32 \mathrm{a} ; 391 \mathrm{a} ; 452 \mathrm{~b} ; 2,29 \mathrm{a} ; 412 \mathrm{a} ; 432 \mathrm{~b} ; 447 \mathrm{c}$.

1089. Friedrich Ulrich Stisser (1689-1739): Forst- und Jagd-Historie der Teutschen. Jena 1737. QR. $1,395 a ; 456 a ; 482 o ; 2,120 c ; 164 a ; 410 a ; 432 \mathrm{c} ; 462 \mathrm{c}$. Waldordnung 1, 136b; Pirschordnung $485 \mathrm{a}$.

1090. Johann Täntzer: Von Jagd- und Waidwerk. (Der Dianen Hohe und Niedere JagtgeheimnüB. Kopenhagen 1682-1686). QR. 1,616b.

1091. Friderioi II. imperatoris reliqua librorum de arte venandi cum avibus; Albertus Magnus de falconibus, asturibus et accipitribus. Ed. M. Velserus. Augsburg 1596. B. 44. 1, 211a; 347a; 2, $207 \mathrm{c}$.

1092. Johann Conrad Aitinger: Kurtzer und Einfeltiger Bericht von dem Vogelstellen. 162b. QR. 1, 10 b; 2,307b; $453 \mathrm{~b}$.

1093. Angenehme Land-Lust, deren man in Städten und auf dem Lande ... geniessen kzan, oder von ... Fang .... und Abrichtung der Vögel. Frankfurt/ Leipzig 1720. (Landlust im Vogelfang. Auszug aus Aitingers Jagd- und Weidbüchloin). 1, 203a; 2, $307 \mathrm{~b}$.

1094. Unterricht von Vögeln. QR. 1, 616 b.

1095. Erhard Reusch (1678-1740): C. G. Zorgdrageri Grönländische Fischerei (Utbersetzung aus dem Niederländischen). Leipzig 1723. QR. 1, 276a; 378c; $396 \mathrm{c} ; 417 \mathrm{c} ; 2,9 \mathrm{~b} ; 38 \mathrm{c} ; 64 \mathrm{c} ; 197 \mathrm{~b} ; 222 \mathrm{a} ; 295 \mathrm{~b} ; 381 \mathrm{a} ; 415 \mathrm{c} ; 418 \mathrm{~b} ; 483 \mathrm{c}$. Anhang $1,46 \mathrm{~b}$. Vgl. $1,29 \mathrm{c} ; 35 \mathrm{~b} ; 384 \mathrm{c} ; 2,324 \mathrm{a}$.

1096. Leonhardt Fronsperger (gest. 1575): Vonn Geschütz vnnd Fewerwerck. Vonn erbawung der Beuestungen. Frankfurt (1557) 1564. 2, 353 b. QR. 1, 16 c; $390 \mathrm{a}$; $442 \mathrm{a} ; 2,162 \mathrm{a} ; 163 \mathrm{~b} ; 253 \mathrm{a} ; 385 \mathrm{a} ; 442 \mathrm{c}$.

1097. Leonhardt Fronsperger: Von Kriegsrüstung. 1564, 2, 238b. QR. 1, 4b; 23a; $390 \mathrm{c} ; 396 \mathrm{~b} ; 399 \mathrm{a}$. Vgl. 2, 377a.

1098. Leonhardt Fronsperger: Von Kriegsvorrat in Magazinen. QR. 1, $390 \mathrm{c}$.

1099. Hans Friedrich Hoerwarth von Hohenburg (gest. 1598): Von der hochberümpten vnd ritterlichen Kunst der Reyterey. Tegernsee 1577. QR. 1, $515 \mathrm{~b}$. 
1100. Michael Miethe (gest. 1686): Curieuse Geschützbeschreibung oder vollkom. menes Artilleriebuch. Dresden 1705. 1, 242 a.

1101. Alain Manesson Mallet: 1, 203 b. Vgl. B. 23.

102. Johann Sigismund Buchner: Theoria et Praxis Artilleriae. Nürnberg 1682 - 1685. QR. 1, $125 \mathrm{c}$.

1103. Ernst Braun: Novissimum Fundamentum et Praxis Artilleriae. Danzig 1682. QR. 1, $125 \mathrm{c}$.

1104. Thurnierbuch oder des Thurniers Anfang, Ursprung und Herkommen. 1532. $1,593 \mathrm{~b}$.

1105. Franciscus Modius (geb. 1556): Pandectae triumphales. Frankfurt 1586. $1,593 \mathrm{~b}$.

1106. Philipp Jacob Spener (1635-1705): Opus heraldicum. Frankfurt 1690. 1,160 a.

1107. Achmet (Ahmad Ibn-Sirin; gest. 728): Onirocritica. 2, 420c.

1108. Haly Abbas (Ali Ben Abbas; 10. Jh.): Regalis dispositionis theoricae libri decem et practicae libri decem (liber totius medicinae necessaria continens). $1,296 \mathrm{c}$.

1109. Avicenna (980-1037): 1, $91 \mathrm{c}$.

1110. Constantinus Africanus (11. Jh.): 1, 29 a nach Du Cange.

1111. Walther Hermann Ryff (Rivius): Spiegel vnd Regiment der Gesundheit. Frankfurt 1544. (1543 B. 65). QR. 1, 13b;22a; 392b; $400 \mathrm{~b} ; 2,68 \mathrm{~b} ; 101 \mathrm{c}$; $381 \mathrm{c} ; 412 \mathrm{a}$.

1112. Laurentius Friese: Spiegel der Artzney. Straßburg 1518. QR. 1, 375a; 582a; $2,46 a ; 280 \mathrm{c} ; 346 \mathrm{~b} ; 410 \mathrm{c} ; 412 \mathrm{a}$.

1113. Theodor Zwinger (1533-1588): Theatrum vitae humanae. Basel 1586-1587. 2,398 c.

1114. G. Apollinaris: Arznei- und Krüuterbüchlein. QR. 2, 19b. (Artzney-HandBüchlein. Straßburg 1651. B. 24).

1115. Franciscus Hildeseornus (Franz Hildesheim; 1551-1614): 'in Mundi Catho. licis ... de Islandia' $1,450 \mathrm{~b}$ (= De cerebri et capitis morbis internis spicilegia. In quibus primo morbi cujusque catholica proponuntur . . . Frankfurt 1612?).

1116. Bartolommeo Castelli: Lexicon medicum Graecolatinum. Venedig 1626. 2, $27 \mathrm{c}$.

1117. Petrus Forestus (1522-1597): Observationum et curationum medicinalium ac chirurgicarum opera omnia. Rouen 1653. 1, $296 \mathrm{c}$.

1118. Georg Wolfgang Wedel (1645-1721): Exercitationum medico-philologicarum decades tres. Jena 1686. 2, $417 \mathrm{~b}$.

1119. Philipp Verheyen (1648-1710): Anatomia corporis humani. (Deutsche Úbersetzung) Leipzig 1704. (Verhag.) 1, $277 \mathrm{o.}$

1120. G. Detharding/Georgius Hannaeus: Disputatio de febribus Eyderostadiensibus epidemicis vulgo Stoppolfiebern. 1735. 2, 340a.

1121. Odilo Guethrather (gest. 1731): Gebrauch der Land-Charten oder Anweisung zur Geographie. Salzburg 1713. B. 29. QR. 1, 132a.

1122. Samuel Bochart (1599-1667): Opera omnia, h. e. Phaleg, Canaan ot Hierozoicon ... Leyden $1712.1,20 \mathrm{~b} ; 2,60 \mathrm{c} ; 1,542 \mathrm{a} ; \mathrm{vgl.} 2,141 \mathrm{~b}$.

1123. Christoph Cellarius (1638-1707): Geographia antiqua. Zeitz 1686. 1, $17 \mathrm{c}$.

1124. Christian Juncker (1668-1714): Anleitung zur Geographie der mittleren Zeiten. Jena 1712. B. 68. 1, 324c.

1125. Aloysius Cadamosto: Von der ersten schyffarthe vber das Mere Oceanum in die Landtschaffte der Moren, ausz wellischer Sprach in die Dewtschen 
gebracht ... durch den wirdigen vad hochgelehrten Herren Jobsten Ru. chamer. 1508. QR. 1, 540 b; 2,112b. Deutsche Ubersetzung der ersten Sohiffahrten in die Neue Welt $15081,432 \mathrm{~b} ; 455 \mathrm{~b} ; 617 \mathrm{a} ; 2,343$ a. Deutsche Utbersetzung der Neuen Welt 1508 1, 13a; 209c; 505a. Utbersetzung des lateinischen Buchs Die Neue Welt genannt 181 c. Ubersetzung der Historie der Neuen Welt (QR.) 676a. (Titel des ital. Originals: Il Mondo Nuovo).

1126. Der Teutsche Übersetzer der ersten Portugisischen Reisen nach Africa ... Doctor Ruchamer. 1505. 1,350c.

1127. Michael Hemmersam: Guineische und West-Indianische Reissbeschreibung. Nürnberg 1663. QR. 1, 378b.

1128. Malabarische Nachrichten. B. 79. 2, 397c; 444c; vgl. 193 a.

1129. Salomon Schweigger (1551-1622): Newe ReyBbeschreibung aus Teutschland nach Constantinopel und Jerusalem. Nürnberg 1608. QR. 1, 69a; $571 \mathrm{~b}$.

1130. Michael Heberer von Bretten: Aegyptiaca servitus d. i. warhaffte Beschreibung seiner dreijährigen Dienstbarkeit und nachherigen Reisen in Böhmen, Polen, Schweden ... Heidelberg 1610. 2, $462 \mathrm{c}$.

1131. Olfert Dapper (gest. 1690): Reißbuch (Afrika), 1, $231 \mathrm{~b}$.

1132. Burchard Niederstedt (gest. 1684): Melita vetus et nova. Hg. v. Ch. C. v. Blumenthal. Helmstedt 1662, 2, 417 b.

1133. Siegmund Freiherr von Herberstein (1486-1566): Moscovia der Hauptstadt in Reissen, sambt des Moscoviter gepiet u. s. beschreibung und anzaigung. Wien 1557. Utbersetzung aus dem Lateinischen. QR. Frisch benutzt auch den Anhang: Georg Wernher: Ungarischer wunderbarer wasseren beschreibung. $1,183 \mathrm{a} ; 240 \mathrm{~b} ; 347 \mathrm{a} ; 2,182 \mathrm{c} ; 362 \mathrm{c} ; 366 \mathrm{a}$; Wernher $403 \mathrm{c} ; 471 \mathrm{a}$.

1134. Adam Olearius (1603-1671): (Reisebeschreibung. Schleswig 1640). 2, 129 c. 1135. Heinrich Rätel (1529-1594): Sehenswürdiges Prag. QR. 1, 376b.

1136. Scotus: Itinerarium. 2, $40 \mathrm{c}$.

1137. Sebastian Münster (1489-1552): Cosmographia, d. h. Beschreibung aller Lender ... und fürnemlich teutseher Nation. Basel 1543. QR. I, 652c; 2, 465a.

1138. Martin Zeiller (1589-1661): Itinerarii Germaniae novantiquae compendium d. i. Teutschlands neu verkürztes Raisebuch. Ulm (1632) 1662. 2, 449 c; $471 \mathrm{a}$.

1139. Martin Zeiller: Epistolische Schatzkammer, bestehend von 706 Sendschreiben. UIm 1683. Vgl. B. 38. $1,35 \mathrm{~b} ; 118 \mathrm{c} ; 203 \mathrm{c} ; 356 \mathrm{~b} ; 488 \mathrm{c} ; 2,123 \mathrm{~b}$.

1140. Martin Schoock (1614-1665): Tractatus de inundationibus, iis maxime, quae Belgium concernunt. Groningen 1652, QR. 1,571 b.

1141. Christian Friedrich Rast: Dissertatio de insula natante Gerdaviensi vulgo Schwimmbruch. Praes, Christianus Masecovius. Königsberg 1707. 1, 143a; $2,250 \mathrm{c}$.

1142. Georg Caspar Kirchmayer (1635-1700): Disputation von Harzgeroda. 1697. $2,113 \mathrm{c}$.

1143, Goth.: Poligraph. Meinung 1, 177 a (Beschreibung der Stadt Meiningen?).

1144. Johann Gottfried Gregorius (1685-1770): Historische Nachricht von der Stadt Tännstadt. Erfurt 1711. QR. (Historische Nachricht von Erfurt und Tennstädt) 2, $297 \mathrm{~b}$.

1145. Johann Christian Crell (Icander): Das prangende Dresden. Leipzig 1719. QR.

1146. Johann Christian Crell: Das königliohe Leipzig. Leipzig 1725. QR.

1147. Johann Christian Crell: Das königliche Freyberg. Chemnitz 1725. QR.

1148. Christian Lehmann $(1611-1688)$ : Historischer Schauplatz derer natürlichen Merckwürdigkeiten in dem Meißnischen Ober-Ertzgebirge. Leipzig 1698. QR. 1, 40b;2, 153a. 
1149. Georg Heinrich Burckhardt: Beschreibung der Zothenbergisohen Reise. Breslau 1736. QR, 1, 10; $17 \mathrm{a}$.

1150. Leonhard David Hermann (1670-1736): Maslographia: Beschreibung des Sohlesischen Massel. Breslau 1711. QR. 1, 3940.

1151. Josua Simler (1530-1576): Vallesiae at Alpium descriptio. Zürich 1674. QR. 1, 259a; 6520; 653a. Descriptio Helvetiae 2, $51 \mathrm{~b}$.

1152. Johann Baptist Plantinus: Helvetia nova et antiqua. Bern 1656. 2, 401 o.

1153. Beschreibung des Fürstentums Neuburg/Schweiz. 1708. (frz.) 1, 574 b.

1154. Peter Pfendler: Von Bergen. 2, 341 a.

1155. Johann Jacob Scheuchzer (1672-1733): Naturhistorie des Sohweizerlandes. Zürich 1716-1718. B. 65. QR. 1, 66 b;209b;489c;2, 18a; 108a; 356a. Hist. der Schwoitz 1, 354a. Sohweitz. Chron. 2, $473 \mathrm{c}$.

Helvetiae Stoicheiographia, Orographia et Oreographia. Stoicheiographia: QR. 1, 29b; 346c; 568c; 651 c; 2, 7a. Von den Bergen in der Sohweiz: QR. $1,27 \mathrm{c} ; 318 \mathrm{c} ; 468 \mathrm{c} ; 2,149 \mathrm{~b} ; 223 \mathrm{a} ; 338 \mathrm{a} ; 381 \mathrm{~b} ; 422 \mathrm{a}$. Von Grenzen und Bergen der Schweiz: 1, 258c; 2, $196 \mathrm{~b} .1,644 \mathrm{~b}$.

Hydrographia helvetica. (Von Wassern in der Schwoiz): QR. 1, 476c; 571 b; $651 \mathrm{c} ; 2,7 \mathrm{a}$.

Meteorologia et Oryctographia helvetica. 1, 561a.

1156. Johann Jacob Scheuchzer: Bibliotheca gcriptorum historiae naturalis. Zürich 1716. B. 26. 2, $447 \mathrm{c}$.

115\%. Franz Ruprecht von Ichtersheim: Ganz neve elsässische Topographie. Regensburg 1710. B. 68. QR. 1, 225c;375b;2, 57c;118b;123b;351 c.

1158. Oscar Schadaeus: Summum argentoratensium templum das ist ausführliche Beschreibung des Münsters zu Straßburg. Straßburg 1617. B. 70. 1, $648 \mathrm{c}$.

1169. Thermae Ferinae Entzianae Duc. Würtenb. vulgo Wild-Bad (Johannes Deucer: Heilsame und nützliche Badekur des Wildbades an der Entz im Herzogthum Wirtemberg) Straßburg 1637, 2, $447 \mathrm{c}$.

1160. Beschreibung des Tyrolischen Sauer- oder Räszbrunnen zu Prutz. Innsbruok 1671. 2, 87a.

1161. Mattheeus Merian (1593-1650): Topographia vom österreichischen Creyse. 1677. B. $84.2,236 \mathrm{c}$.

1162. Matthaeus Morian: Topographie von Crain. 1649. 2, 358b.

1163. Johann Weikhard von Valvasor (1641-1693): Die Ehre des Herzogthums Krain. Laibach 1689. 1,96a; 324a.

1164. Albertus Magnus (Albert von Bollstïdt; 1193-1280): De animalibus. 2, $207 \mathrm{c}$; vgl. 1, 298o; 2, 24a. Dict. 1, 1b. Nach Gesner 1, 2a; 2, 162 c. Nach Keisersberg $1,201 a ; 2,3440$.

1165. Paulus Venetus (gest. 1428): Expositio librorum naturalium Aristotelis. 1, 347 a.

1166. Theodorus Gaza (gest. 1478): Aristoteles: historia animalium. 2, $470 \mathrm{c}$.

1167. Georg Agricola (1490-1555): Appellationes quadrupedum, insectorum, volucrium, piscium. 1, 23c; nach Gesner $96 \mathrm{a}$.

1168. Konrad Gesner (1516-1565): Historia animalium (Historia naturalis QR.). $1,85 \mathrm{~b} ; 214 \mathrm{a} ; 335 \mathrm{~b} ; 338 \mathrm{~b} / \mathrm{c}$; ans Georg Fabricius 659b. 2, 364a.

De quadrupedibus. Zürich 1551-1554. 1,96a; $298 \mathrm{a}$.

De avibus. Zürich $1555.1,2 \mathrm{a} ; 23 \mathrm{c} ; 391 \mathrm{a} ; 422 \mathrm{c} ; 459 \mathrm{~b} ; 2,143 \mathrm{~b} ; 162 \mathrm{c}$.

Do piscibus ot aquatilibus. Zürich 1558. 1, 44c; 450 a.

1169. Konrad Gesner: De omni fossilium genere, gemmis, lapidibus, metallis et hujusmodi. Zürich 1565-1566. 1, 20a.

1170. Konrad Gesner: Descriptiones et ioones plantarum et de hortis Germaniae liber. Straßburg 1561, 1, 259a. 
1171. J. Adam Lonicerus (1528-1586): Naturalis historiae opus novum. Frankfurt 155l. QR. 1, 36b; $99 \mathrm{~b} ; 390 \mathrm{c} ; 416 \mathrm{c} ; 492 \mathrm{c} ; 2,24 \mathrm{~b} ; 373 \mathrm{~b} ; 399 \mathrm{~b} ; 466 \mathrm{c}$.

1172. Caspar Bauhin (1560-1624): Theatri botanici sive historiae plantarum ... liber I. cura Joh. Casp. Bauhini. Basel 1658. 1, 214a; 463b; 2, 445b.

1173. Johannes Jonston (1603-1675): Dendrographias sive historiae naturalis de arboribus et fructibus libri X. Frankfurt 1662. B. 85. QR. 1, $47 \mathrm{a} ; 377 \mathrm{c} ; 418 \mathrm{c}$; $648 \mathrm{c} ; 655 \mathrm{c} ; 2,5 \mathrm{c} ; 141 \mathrm{c} ; 262 \mathrm{a} ; 390 \mathrm{~b} ; 432 \mathrm{c} ; 467 \mathrm{c}$.

1174. Christian Mentzel (1622-1701): Kräuter-Buch. QR. (Vgl.: Index nominum plantarum universalis diversis terrarum gentiumque linguis. Berlin 1682).

1175. Konrad Johren (gest. 1716): Vademecum botanicum. Frankfurt 1726. QR. $1,15 \mathrm{~b}$.

1176. Heinrich Bernhard Ruppe (gest. um 1720): Flora Jenensis. Frankfurt 1718. QR. 1, $15 \mathrm{~b}$.

1177. Theodor Zwinger (1658-1724): Theatrum botanicum, das ist: Neu voll. kommenes Kräuter-Buech. Basel 1696. QR. 1, 10c;15b;99c;152c;325a; $454 \mathrm{~b} ; 490 \mathrm{a} ; 2,53 \mathrm{~b} ; 102 \mathrm{a} ; 240 \mathrm{c} ; 383 \mathrm{a} ; 480 \mathrm{~b}$.

1178. Petrus Artedi (1705-1735): Ichthyologia sive opera omnia de piscibus. Ed. Linné. Leyden 1738. 2, $110 \mathrm{~b}$. Vgl. 'Ein gewisser Ichthyologus' 1, 132b.

1179. 'Ein Helmstädtischer Doctor hat von einem solchen Wurm [Alp-, Elbwurm] ein Schediasma geschrieben'. 1, 20 a.

\section{Selbstzitate}

1180. Beschreibung von allerley Insecten in Teutsch-Land. Berlin 1720-1738. $1,20 a ; 474 c ; 476 a ; 494 b ; 652 a ; 653 b ; 2,93 b ; 163 b ; 239 a ; 303 a$.

1181. Vorstellung der Vögel Deutschlandes. Berlin 1733-1763. 1, 24a; 654b; $2,53 \mathrm{~b} ; 213 \mathrm{a} ; 240 \mathrm{~b} ; 242 \mathrm{a} ; 242 \mathrm{~b} ; 251 \mathrm{c} ; 295 \mathrm{a} ; 299 \mathrm{c} ; 307 \mathrm{~b} ; 310 \mathrm{a} ; 335 \mathrm{a}$; $344 \mathrm{c} ; 364 \mathrm{a} ; 450 \mathrm{a} ; 457 \mathrm{~b} ; 466 \mathrm{a} ; 476 \mathrm{c}$.

1182. Miscellanea Berolinensia. 2, 162c. 


\section{DAS TEUTSCH - LATEINISCHE WÖRTER-BUCH IM URTEIL DES 18. JAHRHUNDERTS}

Frrson war sioch bewußt, daß sein Werk der Weiterführung bedurfte. Unmittelbar vor Abschluß der Arbeiten (1739) hatte er in der Untersuchung 'De primis in Germania typis editis lexicis Germanicis' vorausschauend geschrieben: gelehrtere Männer würden erscheinen, die in der Lage wären, das von ihm Geleistete zu vervollkommnen. ${ }^{1} 1741$ in der Vorrede des Wörterbuches forderte er zum Sammeln auf für einen Nachtragsband. Es sollte 'in der folgenden Edition im Werck nichts geändert werden, daß man es gleich wieder neu müßte haben, sondern nur im Text auf das Supplement gewiesen werden'2. Namentlich in dem Altdorfer Rechtsantiquar und Philologen Jorrannms Hmumans (1711-1760) hoffte Frisor einen Fortsetzer seiner wortgeschichtlichen Studien zu finden. Ihm schrieb er um 1737:

'Sie können dereinst zu meinem Lexico ansehnliche Zusätze machen, dann ich habe nur einen Anfang zu dieser grossen Sammlung damit machen vvollen.'

Nachträge zum 'Teutsch-Lateinischen Wörter-Buch' sind um die Mitte des 18. Jahrhunderts von mehreren Seiten gesammelt, aber nur teilweise gedruckt worden.

Als das Wörterbuch im Jahre 1741 auf dem Büchermarkt ersohien, war der Name FrISOHs im Kreise der gelehrten Wortforschung bereits ein fester Begriff. Dem großangelegten lexikographischen Werk, von dessen Entstehen man seit langem gewußt hatte, sah man erwartungsvoll entgegen. Bereits am 20. April 1741 besprachen die Leipziger 'Neuen Zeitungen von Gelehrten Sachen' den zunächst gesondert ausgelieferten ersten Teil (A-M) 'von dem lange erwarteten deutsohen Wörterbuche des Hrn. Frisch':

'Man sieht daraus mit Vergnügen, daß die große Hoffnung, die man sich von diesem Werke gemacht, nicht fehl geschlagen ist.' FrIscrs Wörterbuch 'erfüllet dasjenige, was man von einem. Wörterbuche vornehmlich erfordert; daß man nämlich durch Hülfe desselben sohwere und unbekannte Wörter und Redensarten verstehen lerne.'4

1 FrISCE, De primis lexicis (1739) )(4b. S. unten S. 189.

${ }^{2}$ Frisce, TLWb. (1741) Vorbericht $/ 2^{\mathrm{b}}-3^{\mathrm{a}}$; vgl. 'bey dieser ersten Ausgab' ) ( $4^{\text {b; }}$ ' in dieser Auflage schon' $2,154 \mathrm{c}$.

\& Heumans, Opuscula (1747) 471.

4 Neue Zeitungen von Gelehrten Sachen (1741) 285-286. 
In der Besprechung des zweiten Teils (März 1742) bekräftigte der Rezensent sein anerkennendes Urteil:

'Sein Wörterbuch kann ungemein viel beytragen, den rechten Verstand und die eigentliche Bedeutung vieler Wörter aus den mittlern Zeiten, oder solcher Ausdrückungen, die nur diesem oder jenem Lande eigen sind, oder die theils nicht mehr gebraucht werden, oder auch ihren ersten Sinn verIohren haben, einzusehen. Er ist in deren Aufsuchung und der Bestimmung der Abkunft, Herleitung und Zusammensetzung ungemein sorgfältig gewesen, ... Hierbey ist er auf einen schönen Vorrath von eignen deutschen Redensarten bedacht gewesen, und hat auch die alten deutschen Sprüchwörter mit beyzubringen nicht vergessen; so daß sein Wörterbuch mit Recht ein Schatz der deutschen Sprache genennt werden könnte.'

Wenig später (Juli 1742) berichteten die 'Nova Acta Eruditorum' über das Erscheinen des ersten Teils des Wörterbuches. Anch ihr Urteil fiel günstig aus:

'Praedicamus justissimisque laudibus concelebramus Cel. Autoris insigne hoe Opus, avide exspectantes ejus continuationem.' ${ }^{2}$

Der Rezensent stellte das Werk sogar in eine Reihe mit den Akademiewörterbüchern Italiens und Frankreichs:

'Gratulamur praeterea Germanis nostris, qui nune in partem gloria日, Tuscorum, ac Parisiensium, veniunt, a quibus Lexica, linguae vernaculae sermonisque patrii recludentia, theseurum civitas accepit et lubens excepit erudita.'3

Zugleich aber übte er Kritik an Einzelheiten der Bedeutungserfassung und insbesondere der Etymologie; auch lieferte er, der Aufforderung FrIschs folgend, bereits eine kleine Reihe von Nachträgen:

'Praevidere nobis jam videmur iteratas praestantissimi hujus Thesauri editiones, et accessiones aliorum. Dabimus et nos symbolam nostram, ac vooulas adjiciemus lanci saturae nonnullas ...'4.

Eltas Caspar Reichard ordnete 1747 in der 'Historie der deutschen Sprachkunst' FrIschs Wörterbuch bereits in die Geschichte der Forschung ein. Das Werk, 'wornach die Kenner so sehnlich verlanget hatte', sei jedem Liebhaber der deutschen Sprache unentbehrlich und etwas Vollkommeneres in dieser Art habo man bisher nicht gesehen. 5

Aufschlußreicher als das Urteil der vorzugsweise registrierenden Instanzen, der Gelehrtenzeitsohriften und des Wissenschaftshistorikers, ist die Stellungnabme der Vertreter der zeitgenössischen Wortforschung. In ihr Schaffen griff das 'Teutsch-Lateinisohe Wörter-Buch' unmittelbar ein, und in ihrem Kreise erwachte das Für und Wider.

1 Neue Zeitungen von Gelehrten Sechen (1742) 198-199.

- Nova Acta Eruditorum (Juli 1742) 418.

- Nova Acta Eruditorum (Juli 1742) 418-419.

4 Nova Acta Eruditorum (Juli 1742) 418.

- Reromand, Versuoh einer Historie der deutsohen Sprachkunst (1747) 421-422. 
Das lexikographische Werk Frrschs erlangte zunächst Bedeutung für den Fortgang der Bestrebungen, die sich auf die Schaffung eines Wörterbuches der neuhochdeutschen Gemeinsprache richteten. Um die Mitte des 18. Jahrhunderts wurden diese Bestrebungen namentlich von GOTTSOHmD und der Gruppe seiner Anhänger getragen. In diesem Kreise erkannte man grundsätzlich an, daß das 'Teutsch-Lateinische Wörter-Buch' Ausgangspunkt jeder künftigen Darstellung des deutschen Wortschatzes werde sein müssen. Indessen erfüllte es nicht in vollem Umfange die Anforderungen, die man an ein Deutsohes Wörterbuch stellte. Das Schwergewicht der Arbeit auf lexikographischem Gebiet lag für GotTSOHED im Aufgabenbereich der normativen Festsetzung des Sprachgebranchs. Daß auch FRIsch diesem Teilgebiet der lexikographischen Gesamtaufgabe Aufmerksamkeit gewidmet habe, wurde zugestanden. So begegnete 1747 ein Rezensent des 'Neuen Büchersaals' der Klage des österreichischen Grammatikers JOHANN BALTHASAR VON ANTHSPERG, es gebe kein grammatisch-kritisches Wörterbuch der deutschen Sprache, mit dem Hinweis auf die Darstellung FrISCHS:

'wenigstens können wir uns nicht überreden, daß das vor wenig Jahren in Berlin herausgekommene Wörterbuch, des seligen Herrn Frisch, für eine Nulle zu rechnen sey; oder etwa kein grammaticalisches Dictionarium zu heißen verdienen sollte.' 1

Aber die grammatischen Einzelentscheidungen, die Frisch im 'Criticum' getroffen hatte, befriedigten GornsonwD nicht immer. Sieben Jahre nach dem Erscheinen des 'Teutsch-Lateinischen Wörter-Buchs' veröffentlichte er seine 'Deutsche Sprachkunst', und erst mit der Schaffung dieses Werkes war nach seiner und seiner Anhänger Überzeugung die Grundlage für ein vollgültiges Deutsches Wörterbuch gegeben:

'Des Herrn Frisch Wörterbuch übertrifft . . . das Steinbachisohe wie die Sonne den Mond; und wer künftig ein Wörterbuch liefern will, muß selbiges nothwendig zum Grunde legen. Allein, ohne eine richtige Sprachkunst kann solches unmöglich geschehen: denn hierinn war Frisch nicht überall auf dem rechten Wege. ${ }^{22}$

Schärfer noch prägt dieser Standpunkt sich aus in dem Briefwechsel GorTSCHEDs mit dem österreichischen Benediktiner Pracrous Amon (1700-1759), der seit 1751 im Kloster Melk an einem Deutschen Wörterbuch arbeitete. Am 2. März 1752 schrieb AMon an GormschmD, er habe seiner Darstellung die Wörterbücher Frischs und STEINBaOHs zugrunde gelegt;

'doch weil sie beyde in der Rechtschreibung, in Geschlechtswörtern, in Abänderung der Hauptwörter, in Zusammensetzung derselben, in Abwandlungen der Zeitwörter u. s. w. hier und da noch irrig und unrichtig sind; so werde ich

1 Neuer Büchersaal der schönen Wissenschaften und freyen Künste 4 (1747) 506.

2 Neuer Büchersaal 5 (1747) 153-154. 
es mir bestens angelegen seyn lassen, alles in eine Richtigkeit zu bringen, und mich dabey mehrentheils an die Grundlegung der deutschen Sprachkunst, und anderer Schriften, welche Eur. Hochedl. ans Licht gestellet, sorgfältig zu halten." I

GorrsCHed billigte in seiner Antwort vom 25. Mai die Wahl der lexikalischen Vor. lagen, stimmte aber auch in die Kritik Amons ein. Weder Sreingach noch Friscr seien mit der 'guten hochdeutschen Mundart allemal eins':

'Steinbach will alles nach der schlesischen Mundart einrichten ...; Frisch aber ist ein Märker, wo man mehr plattdeutsch als hochdeutsch spricht; daher klebt ihm viel unrichtiges an. Sonderlich in den Abwandlungen der richtigen und unrichtigen Zeitwörter kann man sich auf beyde gar nicht verlassen; und ihre Rechtschreibung ist auch vielmals falsch.' 2

Dessenungeachtet galten die Wörterbücher FRISCHS und Srerrbachs im Kreise der Anhänger Gortscheds als die bis dahin besten Darstellungen des deutschen Wortschatzes. Das geht auch aus der Antwort hervor, die Placrdos Amon dem jungen Rudolf GRaSer im Jahre 1752 auf die Frage erteilte, welches Deutsche Wörterbuch er ihm empfehlen könne:

'Meines Wissens ist bisher kein vollständigeres (Wörterbuch) zum Vorschein gekommen, als jenes des H. Christoph Steinbachs, in Bresslau gedrucket 1734. Das zweyte, welches mir auch sehr wohl gefällt, und grosse Dienste thut, hat H. Joh. Leonhard Frisch zu Berlin ans Licht gestellet 1741.'3

Das Wörterbuch Frisorss wirkte noch auf den Fortgang der sprachkritischen Bestrebungen in der zweiten Hälfte des 18. Jahrhunderts ein, und zwar nicht nur auf das lexikographische Hauptwerk dieses Zeitraums: ADELungs fünfbändigen 'Versuch eines vollständigen grammatisch-kritischen Wörterbuches der Hochdeutschen Mundart' (1774-1786). Seit der Mitte des 18. Jahrhunderts hatte das Bewußtsein der Verantwortung gegenüber der Sprache jedoch auch außerhalb des Kreises der Grammatiker und Lexikographen vom Fach Wurzel gefaßt. Führende deutsche Schriftsteller äußerten sich zu Fragen des Sprachlebens, und wenn sie Umschau hielten nach dem maßgebenden Deutschen Wörterbuch - vergleichbar den Akademiewörterbüchern Italiens und Frankreichs oder dem englischen Wörterbuch SAMUEL JoHNSONS (1755) -, so richteten auch sie ihre Blicke auf das 'Teutsch-Lateinische Wörter-Buch' Friscre. Die Erinnerung an das Werk erhielt

1 Sohacmiramer, Die Bemühungen des Benedictiners P. Placidus Amon um die deutsche Sprache und Literatur. In: Studien und Mitheilungen aus dem Benedictiner- und dem Cistercienser-Orden 10 (1889) 102. Amon hat FrisoHs Wörterbuch auch als Hilfsmittel benutzt für die lexikalischen Anmerkungen zu seinen $\mathrm{Ab}$ schriften mittelhochdeutscher Denkmäler. Vgl. BAstan, P. Placidus Amon. In: Germanica. Eduard Sievers zum 75. Geburtstage (1925) 9, 10, 11, 24.

2 Sohachinger a. a. O. 10 (1889) 105; vgl. Gotssomid an Schiyb 1752: 'er (Amon) muss ein recht grosses, ausführliches Wörterbuch machen, das besser ist als Frischens' 10 (1889) 644.

8 Sohachinger a. a. O. 10 (1889) 287. 
sich insbesondere in Berlin lebendig. LesssnNG, der von 1748 bis 1755 hier tätig war, hat das Wörterbuch ständig zur Hand gehabt und vielfältig benutzt, unter anderem für die 'Rettung' guter deutscher Wörter aus den Mundarten und der älteren Sprache. ${ }^{1}$ Der Berliner Verleger Nroolax, der wie Lessing selbst ein Deutsches Wörterbuch plante, wies 1763 in den 'Literaturbriefen' auf das Wirken der Historisch-Philologischen Klasse zurück und erinnerte in diesem Zusammenhang an FRISCH:

'Zu Berlin war schon beym Anfange dieses Jahrhunderts in der Gesellschaft der Wissenschaften eine Klasse zur Beförderung der deutschen Sprache. Das einzige deutsche Wörterbuch, das wir noch haben, hat daselbst seinen Ursprung gehabt." 2

Auch Herder, der 1771 als Preisschrift der Preußischen Akademie seine Abhandlung über den Ursprung der Sprache schrieb, wußte 1768 in den 'Fragmenten' nur ein Deutsches Wörterbuch zu nennen:

'Wenn jener Arabische Weise sechzig Kameele allein mit den Wörterbüchern seiner Sprache beladen konnte: so gehört kaum ein Maulesel dazu, unsern Frisch und uneern Bödiker wegzutragen.' 8

Noch 1802 in der 'Adrastea' äuBerte sich Herder in hohem Grade anerkennend über Frisch:

'Auch hat sich sogleich von Anfange seine (Leibnizens) Societät nützlich hierinn (in der Sprachforschung) ausgezeichnet; nach Schottel und Bödiker that der einzige Frisch in Ansehung der Deutsehen Sprache mehr, als nachher, Wachtern ausgenommen, ein halb Jahrhundert duroh gethan ward.' ${ }^{4}$

Zu dieser Zeit lag das Wörterbuch AdeLungs bereits vor. Als es in den Jahren 1774-1786 erschienen war, hatte die Kritik es unter anderem an dem 'Teutsch. Lateinischen Wörter-Buch' gemessen. Der Vergleich fiel nicht in jeder Hinsicht zugunsten ADBLUNGs aus. Obwohl er den Wortgebrauch der Gegenwartssprache vollständiger erfaßte und strenger sprachkritisch regelte, als es bis dahin geschehen war, ersetzte seine Darstellung nach Ansicht bestimmter Kritiker das Wörterbuch Frisorrs nicht völlig. Denn das Streben nach Festsetzung der gültigen hochsprachlichen Ausdrucksmittel hatte stofflich einengend gewirkt; damit aber bot sich jenen Benutzern ein Ansatzpunkt zur Kritik, die im Jahre 1774 von einem Deutschen Wörterbuch mehr erwarteten als die Darstellung des Wort-

1 Lessing, Sämtliche Schriften 8, 32; 11, 176;16,83 Lachmann-Muncker. 16,90 stellt Lessinct den Ansätzen Wachters und FrisoHs einen Ansatz des 'Erztlexikographen' Kramer entgegen.

${ }_{2}^{2}$ Briefe, die Neueste Litteratur betreffend 7 (1763) 158 (125. Brief); bereits zitiert von A. LASOH, Berlinisch 335.

${ }^{3}$ Herder, Sämmtliche Werke 2, 1 I Suphan.

4 Herder, Sämmtliche Werke 23, 462; vgl. 'Frisch in seinem sehr bekannten Wörterbuch' (1782) 15, 58; 18, 127; 18, 487 Suphan. 
bestandes der Schrift. und gehobenen Umgangssprache. Die stoffliche Vielschichtigkeit des 'Teutsch-Lateinischen Wörter-Buohs' entsprach den Forderungen dieser Kreise mehr. So erklärte J. E. SтоscH im Jahre 1781:

'Herr Adelung würde gewiß manchen einen Gefallen erzeiget haben, wenn er, so wie Frisch getan hat, auch zuweilen einige unbelkannte niederdeutsche Wörter, in der alphabetischen Ordnung, mitangeführet und erkläret hätte, indem man sich alsdann dieses Wörterbuohs, auch bei Lesung der niederdeut. schen Schriftsteller mit Nutzen hätte bedienen können.'

In ähnlichem Sinne äußerte sich 1794 J. F.A. KINDIRIING in seinem 'Ersten Grundriß einer Literatur der Plattdeutschen oder Niedersächsischen Sprache':

'Frisch erklärt viele alte auch Niedersächsische Wörter, und ist also unentbehrlich, die übrigen Wörterbücher Stielers, Steinbachs und Adelungs schränken sich mehr auf die Hochdeutsche Sprache ein, und berühren nur zuweilen das Niederdeutsche.'2

Auch WImLaNd hatte 1782 in seinem Aufsatz 'Uber die Frage: Was ist hoch. deutsch?' auf den ergänzenden Wert der Darstellung F'RISOHs aufmerksam gemacht:

'wonn in diosen (den Werken der hochdeutschen Schriftsteller) auch zuweilen Wörter oder Redensarten vorkämen, die bei Herrn Adelung vergebens gesucht würden, so werden sie sich durch Frischens Deutsch-Lateinisches oder Schwans Deutsch-Französisches Wörterbuch zu helfen suchen müssen.'

Damit ist der Gesichtspunkt hervorgetreten, unter dem das Wörterbuch FrisoHs für das 18. Jahrhundert vorzugsweise wertvoll wurde: als Nachschlagewerk für das Verständnis des nicht gemeinsprachlichen, nämlich altertümlichen, mundartlichen und fachsprachlichen Wortgutes der deutschen Sprache. Ein Zeugnis dafür, daß das Werk in dieser Hinsicht selbst auf das literarische Schaffen einwirkte, findet sich in der Vorrede zu J. J. CHR. Bodes Ubersetzung von STwRNEs 'Tristram Shandi'. Der Utbersetzer schreibt:

Sonst kann auch bey den Worten, welche ... nicht, oder nicht allenthalben bekannt genug seyn möchten, Frisch Teutsch-lateinisches Wörterbuch dem

1 Allgemeine Deutsche Bibliothels 45 (1781) 210. Zitiert nach Salow, Die dt. Sprachwissenschaft in der Allgemeinen Deutsehen Bibliothek. Diss. Greifswald (1926) 115.

2 KINDnRLing-WilienbüCHer-Koch, Für Deutsche Sprache Litteratur und Cultur-Geschichte. Eine Schrift der deutschen Gesellschaft zu Berlin (1794) 100; vgl. $34 ; 51 ; 54 ; 72$.

$s$ WIELAND, Sämmtliche Werke. Leipzig: Göschen 33 (1857) 364. - Kropstock in der Gelehrtenrepublik (1774) nimmt in dem Abschnitt 'Von einem zu schreibenden deutschen Wörterbuche' auf die bereits vorliegenden 'Deutschen Wörterbücher keine Rücksicht. Hamana hat ein (defektes) Exemplar des Wörterbuchs besessen, vgl. HamanN, Sämtliche Werke 5 (1953) 48 in der 'Biga Bibliothecarum'. - 'Frischs und Adelungs Wörterbücher dienten ihm als Quelle.' LANGen in: 'Dt. Philologie im Aufriß $1\left({ }^{2} 1957\right) 1112$.

13 Powitz, Frischs Wörterbuch 
Leser gute Dienste leisten, wie es mir bey der Uebersetzung wirklich Beystand geleistet hat."

In diesen Zusammenhang ordnen sich auch, so scheint es, die 'Zusätze zu Frischens Deutschem Wörterbuche' ein, die der Dorpater Bürgermeister FrImDRIor CONRAD GADIBUSOH. 1763-1767 in den 'Gelehrten Beiträgen zu den Rigischen Anzeigen' veröffentlichte. Fine weitere ungedruckte Sammlung von Nachträgen GADEBUSCrS (102 halbbeschriebene Bogen) befand sich noch um die Mitte des 19. Jahrhunderts in der Bibliothek der Altertumsforschenden Gesellschaft zu Riga. ${ }^{2}$ GaDEBUSCH hat später auch Zusätze zu dem Wörterbuch ADELUNGs ver. öffentlicht; er bezweckte

'in seiner Arbeit nur eine aus den verschiedensten deutschen Schriftstellern und Gegenden geschöpfte Ergënzung zu den Wörterbüchern von Frisch und Adelung, nicht aber eine Zusammenstellung von livländischen Mundartswörtern, deren übrigens in seiner Sammlung nicht wenige sich vorfinden.' 3

HrRDER hat von der Sammlung GadebusoHs Kenntnis gehabt und erwähnt sie, zugleich genauere Angaben über ihren Inhait vermittelnd, 1767 in den 'Frag. menten':

'Eine fleißige Seele in Liefland hat einen Anhang zu Frischens Wörterbuch, aus der Bibliothek der schönen Wissenschaften, Litteraturbriefen, Loßings, $\mathrm{Uz}_{\mathrm{z}}$ und dergleichen Schriften gemacht, aus dem ich, weil er doch zu gut ist, um in einem Winkel ohne Anwendung zu vermodern, wenn er vollendet seyn wird, einen Auszug liefern werde. Aus den Zeiten der Meistersänger, des Opitz und Logau, des Luthers u.s. w. sollte man die Idiotismen sammlen ... .'4.

Stark eingewirkt hat das 'Teutsch-Lateinische Wörter-Buch' auf die Mund. artenlexilkographie und auf die historisch-etymologische Wortforschung des 18. Jahrhunderts. Dabei ist die Nachwirkung FrisoHs von der Nachwirkung Lembizens, EOKarts, voN Stades, Schmmers und Wachrors nicht zu trennen. Seite an Seite mit den bereits vorliegenden Forschungsarbeiten dieser Gelehrten wurde das Wörterbuch FrIscess sofort nach seinem Erscheinen für das Studium des deutschen Wortschatzes benutzt. So verweist Matrmias voN WICHT, der Herausgeber des Ostfriesischen Land-, Deich- und Syblrechts 'durch ... Er. klärungen der veralteten Wörter und Redensarten erläutert', schon 1746 mehrfach auf Belege und etymologische Ansätze FRISOHs im 'Teutsch-Lateinischen Wörter-Buch'. Im folgenden Jahre legte Jorrannes Heumann seine 'Opuscula'

1 Tristram Schandis Leben and Meynungen, übersetzt von J. J. CHR. Bode. 1 (1776) VII-VIII; die Vorrede ist datiert August 1774.

v. Gunzerr, Wörterschatz der Deutschen Sprache Livlands 1 (1864) XIX.

3 v. GUTzerx a. a. O. VII; vgl. (A. W. HureL), Idiotikon der deutschen Sprache in Lief- und Ehstiand (1795) VII-VIII.

- Herder, Sämmtliche Werke 1, 165 Suphan.

$\checkmark$. WICHT, Das Ostfriesische Land-Recht (1746) in den Anmerkungen zur Vorrede $S .82 ; 97 ; 138 ; 142$ ('Wachter und Frisch in ihren schätzbaren Wörterbüichern'); $154 ; 171$. Auf germanistische Beiträge Frrsors in den Miscellanea Berolinensia verWeist WICHT S. $13 ; 581$. 
vor; er ließ hier unter anderem PRASOHs 'Glossarium Bavaricum' abdrucken, und zwar mit Erläuterungen, für die er Frisors Wörterbuch als Hilfsmittel heranzog. In der sonst nur Titelangaben vermittelnden Bibliotheca glottica, die er ebenfalls in die 'Opuscula' aufnahm, legte er sein Urteil über das 'Teutsch. Lateinische Wörter-Buch' in dem Satz nieder: 'hoo Lexicon Teutonicum reliquis omnibus praefero'1. Auch in einem juristischen Handbuch dieser Zeit, Jorrand GEORG EsToRs 'Bürgerlicher Rechtsgelehrsamkeit der Teutschen' (1757-67), fassen wir Spuren der Nachwirkung FrIscers; in dem Kapitel über die lexikalischen Hilfsmittel der Rechtswissenschaft wird dem angehenden Juristen neben den Werken Besolds, Sperdels und WadHTERs auch das "Teutsch-Lateinische WörterBuch' empfohlen.2

Limssirg hat für literatur- und sprachgeschichtliche Studien das Werk FrisoHs ausgiebig benutzt. 1751 ist es ibm als etymologisches Wörterbuch bereits ein bestimmter Begriff, und 1759 im LoGAJ-Wörterbuch dient es ihm neben den Arbeiten STIELERs, SoHILTERs und WACHTERs als ständiges Hilfsmittel, um den teilweise altertümlichen und mundartlichen Wortschatz des schlesischen Dichterg zu erläutern. Auch in den Anmerkungen zu den Gedichten des ANDreas SOULTETUS (1771), in den Vorarbeiten für ein Deutsches Wörterbuch sowie an zahlreichen weiteren Stellen verwertet LwssLra die Darstellung F'RIsCHs, indem er auf Angaben und Belege des 'Teutsch-Lateinischen Wörter-Buchs' verweist oder ihr Fehlen feststellt, etymologische Ansätze und Worterklärungen übernimmt oder berichtigt. ${ }^{3}$

Ein weiteres Zeugnis für die Nachwirkung FrisoHs im Bereich der historischetymologischen Wortforschung liegt vor in einem Exemplar des 'Teutsch-Lateinisohen Wörter-Buchs', das sich um die Mitte des 19. Jahrhunderts in der Hamburger Stadtbibliothek befand und von einer Hand wahrscheinlich der zweiten Hälfte des 18. Jahrhunderts mit Zusätzen aus Chroniken, Polizeiordnungen, Landordnungen und naturgeschichtlichen Werken versehen worden ist. ${ }^{4}$ Auch für wortgesehichtliche Einzeluntersuchungen diente das Wörterbuch als Grundlage; so wandte sich J. P. WockNER in einer $1760 \mathrm{zu}$ Wolfenbüttel erschienenen Abhandlung 'De vera significatione vocis Germanicae Laterndag' ausdrücklich

1 Hrumann, Opuscula (1747) 617. Berufungen auf Frisch in den Erläuterungen zu Prasohs Glossar S. 677; 681; 692. Berufung auf einen Miscellanea-Beitrag Farschs S. 417. Vgl, den Abdruck eines Briefes Friscirs an HrUManN S. 470-471.

2 Eswor, Bürgerliche Rechtsgelehrsamkeit der Teutschen 1 (1757) 16.

s LEssrNG, Sämtliche Schriften 4, 212 (1751); LogaU.Wörterbuch 7, 357; 364; 366; 368; 378; 387; 396; Anmerkungen zu den Gedichten des Scultetus 11, 176; $179 ; 182$; Vorarbeiten füx ein Deutsches Wörterbuch 16,$5 ; 6 ; 10 ; 44 ; 47 ; 48 ; 49 ; 51$; $52 ; 61 ; 67 ; 69 ; 76 ; 89$.

4 Vgl. SANDERs, Wörterbuch der deutschen Sprache (1860) 2, 2, 1818c. SANDERs hat die Zusätze zum Teil in seinem Wörterbuch verwertet. 
'contra Haltausii in Calendario medii aevi et Frischii in Lexico GermaniooLatino asserta' 1 .

Unausgesetzt erweiterte und vertiefte sich nach dem Erscheinen des 'TeutschLateinischen Wörter-Buchs' die Kenntnis sprachlicher Tatsachen und Zusammenhänge. Es konnte daher nicht ausbleiben, daß gegenüber Einzelheiten der Dar. stellung Frischs kritische Äußerungen laut wurden. Als Gesamtleistung fand das Werk jedoch nicht nur bei der zeitgenössischen Kritik, sondern auch im Urteil des späteren 18. Jahrhunderts volle Anerkennung. Zwar erlangte es nicht das Ansehen eines Akademiewörterbuches; aber es galt zeitweise - insbesondere um die Mitte des 18. Jahrhunderts - als das einzige Deutsche Wörterbuch von Rang. Viele kannten und viele benutzten es, unter ihnen führende deutsche Schrift. steller der 'vorklassischen' Generation (Lessing, NrcolaI, Herder, Hamanr, WIthLAND). Ihnen und dem breiten Kreis der Benutzer diente es in erster Hinsicht nicht als Wörterbuch für den Wortschatz der Gemeinsprache, sondern als glossarartiges Nachschlagewerk, von dem man Auskunft erwartete in Fragen der Etymologie und der Wortgeschichte sowie Hinweise zur Erklärung des altertümlichen, mundartlichen oder fachsprachlichen Wortgutes. Das "Teutsch-Lateinische Wörter-Buch' steht an wichtiger Stelle in der Reihe der Werke, aus denen das 18. Jahrhundert seine Kenntnis der deutschen Sprache, des deutschen Wortschatzes in seiner geschiohtlichen, landsohaftlichen und berufsständischen Erscheinungsform bezog.

Fin Grundwerk der Wortforschung in dem Sinne, wie Frisort es erwartet hatte, wurde das Wörterbuch allerdings nicht. Zwar fehlte es nicht an der Bereitschaft, Nachträge für einzelne Wortschatzbereiche zu liefern, aber es fand sich kein Fortsetzer, der die Herausgabe einer neuen Auflage des mehrschichtigen Gesamtwerkes übernommen hätte. So teilte das 'Teutsch-Lateinische Wörter-Buch' nicht das Schicksal der lateinischen Wörterbücher von CaLEPInUs und Faber, des mittellateinischen Glossars von Do CANGE und des französischen etymologischen Wörterbuchs MÉNAGEs, deren spätere Auflagen die Forschungsergebnisse noch der Folgezeit aufnahmen und auf diese Weise mit dem Fortgang der wissenschaftlichen Erkenntnis Schritt hielten. Statt dessen erschienen neue lexikalische Darstellungen, die FRIschs Wörterbuch ergänzten und teilweise auch ersetzten. GotTsomed und der Kreis seiner Anhänger, die das 'Teutsch-Lateinische WörterBuch' (neben der Darstellung SreinbacHs) trotz bestimmter Bedenken als stofflich grundlegendes Werk anerkannten, schufen allerdings kein Wörterbuch der neuhochdeutschen Gemeinsprache. FrisoHs Darstellung konnte sich daher während der Gottschedzeit durchsetzen und wurde erst durch das Wörterbuoh ADeLUNGs zurückgedrängt. Stärker als auf die Bestrebungen für ein Wörterbuch der neuhochdeutschen Gemeinsprache wirkte Frrsor - der Zielsetzung seines

2 Wochrma, Schediasma epistolicum de vera significatione vocis Germanica Laterndag (1760) Titelblatt. Vgl. KINDHRLING-WILLENBÜOHER-KooH a. a. O. 124. 
lexikographischen Schaffens entsprechend - auf die historisch-etymologische Wortforschung und auf die Mundartenforschung des 18. Jahrhunderts. Neben den Glossaren Schmiters und WacHTERs, später auch neben den Werken von Haltades und Scherz-OberLIN galt das 'Teutsch-Lateinische Wörter-Buch' als unentbehrliches philologisches Hilfsmittel bis in die Zeit der Begründung der germanischen Sprachwissenschaft.

Als Gesamtdarstellung des deutschen Wortschatzes nimmt das "TeutschLateinische Wörter-Buch' nicht die Aufgaben mehrerer Sonderwörterbücher wahr, sondern der Gedanke eines Deutschen Wörterbuchs in umfassendem Sinne ist erstmals zugrunde gelegt. Das 18. Jahrhundert hat vor und nach dem Auftreten Frischs diesen Gedanken unter dem Namen des Allgemeinen Deutschen Wörterbuchs vielfach erörtert. Bis zu dem Erscheinen des Deutschen Wörterbuchs der Brüder GRIMM ist jedoch eine in gleioher Weise stofflich umfassende, geschichtlich erlilärende Darstellung des deutschen Wortschatzes nicht entstanden. Wenn $J_{A C O B}$ GRLMM das Wörterbuch FrIsOHs als wortgeschichtliches Hilfsmittel in hohem Grade anerkennend beurteilte, so ist dies zum einen sachlich begründet: es war die einzige Wortschatzdarstellung verwandter Zielsetzung, die er vorfand. Zum anderen wird allerdings Persönliches im Spiele sein: die Freude daran, in einem Zeitalter der Sprachtheorie, der normativen Grammatik und des normativen Wörterbuchs einen empirisch beobachtenden Philologen und historisch denkenden Sprachforscher am Werke zu sehen. Seitdem J ein Jahrhundert vergangen. Die Sprachwissenschaft des 19. und 20. Jahrhunderts hat inzwischen stoffreiche bistorische Wörterbücher des gemeinsprachlichen Wortschatzes, der Mundarten, der Rechtssprache, des Namengutes und der Berufssprachen geschaffen oder arbeitet an ihrer Vollendung. Das 'TeutschLateinische Wörter-Buch' wurde auf diese Weise als historisches Wörterbuch Schritt um Schritt zurückgedrängt. So wird das Urteil der Wortforschung der Gegenwart zurückhaltender ausfallen müssen. Es sollte sich erfüllen, was Frisor selbst im Jahre 1739 vorhersagte:

'Venient post me Viri doctiores, et in hac vel illa studiorum parte exercitatiores, qui multa, quae et ipsi ad sermonis patrii culturam collegerunt, addent, meaque perficient, et $m \theta$, ob hanc felicitatem in antecessum gaudentem, in numero hac ratione superatorum ponent.' 1

1 Frisch, De primis lexicis (1739) $)\left(4^{\mathrm{b}}\right.$. 


\section{VERZEICHNIS \\ DER WERKE JOHANN LEONHARD FRISCHS1}

\section{A. Veröffentlichungen auf naturwissenschaftlichem Gebiet}

1. Aufsätze naturwissenschaftlichen Inhalts in den 'Miscellanea Berolinensia'. 1710-1743. S. $O 1$.

2. Der Seidenbau / Nach seiner Möglichkeit Und Nutzbarkeit / Nebst unvorgreifflicher Anzeige einiger allgemeinen Mittel / wie dessen Einführung zu befördern / Kürtzlich vorgestellet von Einem Mitglied der Königlichen Preußis. Societaet der Wissenschafften. Berlin 1713.

*3. Der Seidenbau in seiner nötigen. Vorbereitung, gehörigen Bestellung und endlichen Gewinnung vorgestellet durch ein Mitglied der Königlich Preußischen Societät der Wissenschaften. Berlin 1714. KKatalog der Deutschen Staatsbiblio. thek Berlin.

*4. Johann Leonhard Frisch: Einige Nachrichten, welche das erste Specimen eines Atlantis Germania Sacrae Evangelicae, das ist: Das erste Stück einer Sammlung der Land-Charten von den Kirch- oder Pfarr-Kreisen des ovangelischen Teutschlandes erfordert, auf welchem die Superintendur Neustadt an der Aisch ... mit möglichster Sorgfalt in ihre gehörige Lage gebracht. Berlin 1718. (British Museum. Catalogue of Printed Books 26 (1899).

5. Johann Leonmard Frisor: Beschreibung von allerley Insecten in TeutschLand. Teil 1-13. Berlin ${ }^{1} 1720-1738 .{ }^{2} 1730\left({ }^{3} 1766\right)-1753$.

6. Johand Leonhard Frison: Vorstellung der Vögel Deutschlandes und bey. läufig auch einiger Fremden; nach ihren Eigenschaften beschrieben. Klasse 1-12 und 1 Supplement. Berlin (1733-) 1763.

\section{B. Veröffentlichungen auf sprachwissenschaftlichem Gebiet}

1. Untersuchung des Grundes und Ursachen der Buchstab-Veränderung etlicher Teutschen Wörter, Welche denen hohen Besitzern der hierzu dienlichen Mittel, absonderlich der benöthigten Bücher, auch andern Liebhabern der Sprachen als eine geringe Angabe und Muster von einem grossen vorhabenden Werck zur Gnädigen Beförderung und gelehrten Prüfung demüthig und geziemend überreichet Johann Leonhard Frisch, Sub-Rector im Berlinischen Gymnasio. Berlin o. J. [1703].

2. Aufsätze sprachwissenschaftlichen Inhalts in den 'Miscellanea Berolinensia'. 1710-1740. S. $C 1$.

3. Johand Lmonhard Frisch: Nouveau Dictionaire des Passagers françois-allemand ot allemand-françois Oder neues Frantzösisch-Teutsches und Teutsch-

1 Werke, die dem Verfasser nicht vorlagen, sind durch ein Sternchen (*) gekennzeichnet. 
Frantzösisches Wörter-Buch. Leipzig *11712. *21719, ${ }^{3} 1725 .{ }^{4} 1730 . * 1733.1739$. *1746. 1752. *1755,*1763, *1767.*1771. 1772.*1780.*1788. *1793.

4. Aufsätze sprachwissenschaftlichen Inhalts in den 'Zufälligen Anmerckungen'. 1716-1718. S. $O 2$.

5. JohanNes Bödikrs: Grund-Sätze Der Teutschen Sprache. Meistens mit Ganz andern Anmerkungen und einem völligern Register der Wörter, die in der Teutschen Utbersetzung der Bibel einige Frläuterung erfodern. Auch zum An: hange mit einem Entwurff und Muster eines Teutsohen Haupt-Wörter-Buohs. Verbessert und vermehrt von Joh. Leonh. Frisch. Berlin 1723. 1729.

6. Johann Leonhard Frisor: Specimen lexici Germanici oder ein Entwurff samt einem Exempel, wie er sein Teutsches Wörter-Buch einrichtet. Wobey er verspricht, den Zusatz, den etwan ein Gelehrter hierinnen machen und ihm auch nur bey diesem Wort mittheilen würde, allzeit gebührlich zu melden; auch die Verbosserungen mit Danck anzunehmen und zu rühmen. Berlin 1723. (Anhang zu $B$ 5).

7. Jofind Lmonharo Frisch: Specimen lexici Germanici secundum oder das andere Exempel, wie er sein Teutsches Wörter-Buch einrichtet. Wobey or verspricht, den Zusatz, den otwan ein Gelehrter darinnen machen würde wie bey dem vorigen zu bemercken und zu seiner Zeit samt denen Verbesserungen gebührlich zu melden. Berlin 1727.

8. Johann Lmonhard Frisch: Origo characteris Sclavonici vulgo dicti Cirulici paucis generatim monstrata ortus vero et progressus characteris vulgo dicti Glagolitici pluribus sigillatim descriptus tanquam eximia historiae linguae Sclavonicae pars. (Berlin 1727). (Programm des Grauen Klosters).

9. JoHANN LeoNHaRd FrisoH: Historiam linguae Solavonicae oontinuat quatuor capitibus I. De origine characteris Cyrillici speciatim II. De cultura lingua Selavonicae beneficio hujus characteris III. De typis novis Sclavonico-Moscoviticis IV. De dialecto Russica, tanquam filia lingua Sclavonicae. (Berlin 1727). (Programm des Grauen Klosters).

10. JohanN LeONHARd Friscri: Historiae linguae Sclavonicae continuatio secunda continens historiam dialecti Venedicas meridionalis sive Vinidorum in provinciis Austriae vicinis nimirum in Carinthia, Stiria, Carniola, Istria et Marchia Vinidorum. Berlin (1729). (Programm des Grauen Klosters).

11. Jokann Lmonhard Frisch: Historiae linguae Sclavonicae continuatio tertia de dialectis Venedorum in Lusatia et in ducatu Luneburgico. Berlin 1730. (Programm des Grauen Klosters).

12. JoHann Leonhard Frisch: Historiae linguae Sclavonicae continuatio quarta sive oaput quintum de dialecto Bohemica. Berlin 1734. (Programm des Grauen Klosters).

13. Der erste Auszug Von einigen Die Teutsche Sprach betreffenden Stücken, Welche Der Königlichen Preußischen Societät der Wissenschafften, In der Dazu verordneten Abtheilung / Nach und nach übergeben worden. Berlin 1734. (Societätsschrift). (Teilneudruck: Archiv der 'Brandenburgia'. Band 2. Berlin 1896. S. $61-62)$. - Vgl. S. 6.

14. Historiam linguae Sclavonica continuatione quinta sive capite sexto de lingua Polonica finit ... J. I. Frisch. Berlin 1736. (Programm des Grauen Klosters).

15. Johand Leontrard Frisoh: De primis in Germania typis editis lexicis Germanicis. Berlin 1739. (Programm des Grauen Klosters).

16. Anmerkungen über die deutschen Reichssachen. ${ }^{2} 1741$. S. $O 3$.

1) 17. JoHANN LmonHARd FrIsor: Teutsch-Lateinisches Wörter-Buch, Darinnen Nicht nur die ursprünglichen, nebst denen davon hergeleiteten und zusammen- 
gesetzten allgemein gebräuchlichen Wörter; Sondern auch die bey den meisten Künsten und Handwerken, bey Berg- und Saltzwerken, Fischereyen, JagdForst- und Hauß-Wesen, u. a. m. gewöhnliche Teutsche Benennungen befindlich, Vor allen, Was noch in keinem Wörter-Buch geschehen, Denen Einheimischen und Ausländern, so die in den mittlern Zeiten geschriebenen Historien, Chroniken, Ubersetzungen, Reimen u. d. g. mit ihren veralteten Wörtern und Ausdrückungen verstehen wollen, möglichst zu dienen, Mit überall beygesetzter nöthigen Anführung der Stellen, wo dergleichen in den Büchern zu finden, Samt angehängter Theils versicherten, theils muthmaßlichen Ety. mologie und critischen Anmerkungen; Mit allem Fleiß viel Jahr über zusammengetragen, Und jetzt den Gelehrten zur beliebigen Vermehrung und Verbesserung überlassen. Nebst einem Register der Lateinischen Wörter. Berlin 1741.

\section{Nichtselbständige Veröffentlichungen}

1. Miscellanea Berolinensia ad incrementum scientiarum ex scriptis Societati Regiae Scientiarum exhibitis edita. 1-7. Berlin (5: Halle/Magdeburg) 1710 1743. Die Beiträge Frisors verzeichnet Harsaor, Geschichte der Königlich Preußischen Akademie der Wissenschaften zu Berlin (1900) 3, 100-101.

2. Zufällige Anmerckungen Von allerhand zum Schul-Wesen und Grundlegung der Gelahrtheit gehörigen Sachen. Stück 1-6. Berlin 1716-1718. Beiträge Frisces : 3 (1716) 172-185: Vom Buohstabiren in den teutschen Sehulen; und von Erleichterung einiger Schwierigkeiten in demselben.

4 (1717) 294-302: Von einigen Wörtern, so aus der Sclavonischen Sprach, und derselben Töchtern oder Mund-Arten genommen, aber von den meisten falsch buchstabirt, oder geschrieben, oder ausgesprochen werden.

5 (1717) 391-398: Vom Ursprung der Figur des Buchstabs $\langle y\rangle$ und woher es komme, daß or von einigen in so viel Wörtern geschrieben werde.

6 (1718) 463-467: Vom Zahl-Wort Zwei und dessen Declination.

*3. Anmerlkungen über die deutschen Reichssachen, nach Anleitung der deutschen Reichsrechte, der Historie, Genealogie, Geographie, annoch ungedruckter Geschichtschreiber, alter Diplomaten und Urkunden der alten und mittlern Zeit. Berlin ${ }^{2} 1741$. Enthält einen Beitrag FarscHs: Observationes ad Caroli du Fresne Glossarium mediae et infimae Latinitatis.

\section{* D. Schulbücher}

1. Ausgabe des Agapetos. Vgl. Fiscren, Frischs Briefwechsel mit Leibniz (1896) 58 Anm. 97.

2. Griechische Grammatilk. Vgl. Frschen, Frischs Briefwechsel mit Leibniz (1896) 59 Anm. 100; XXIV.

3. Versus memoriales, von $A(l t e m)$ u(nd) $\mathrm{N}$ (euem) $\mathrm{T}$ (estament) von Griechischen und Lateinischen autoribus, von langen Maaß und Röm(ischen) Zahl-Buchstaben. (BIedermanN, Acta Scholastica III 3 (1743) 263.

4. Ein Compendium Frantzösischer Sprichwörter. (BIEDERMaNN a. a. O. 263.

5. Ein Frantzösisch Vocabularium. (BIEDERMANN a. a. 0.263 ; nach WIPPEL, Das Leben des Rektors J.L. Frisch (1744) 6 ein Verzeichnis französischer Fachausdrücke des Militärwesens.

\section{E. Gelegenheitsschriften}

*1. Johand Leonhard Frisch: Die entdeckte und verworffene Unsauberkeit der falschen Dicht. und Reim-Kunst, Am 22. Nov. Anno 1700. Als am 126sten 
Gedächtniß-Tag der Auffrichtung des Berlinischen Gymnasii, In einem eizfältigen Schul-Spiel vorgestellet. Berlin o. J. - Neudruck: Johann Leonhard Frischs Schulspiel von der Unsauberkeit der falschen Dicht- und Reim-Kunst. Hg. v. L. H. Fischer. Schriften des Vereins für diẹ Geschichte Berlins. Heft XXVI. Berlin 1890.

2. Liber symbolicus Russorum Oder Der Grössere Catechismus der Russen Welchen auch Die gantze Griechische Kirche angenommen hat. Aus der Solavonischen Sprache wie sie in Rußland gebräuchlich ins Teutsche übersetzt von Johann

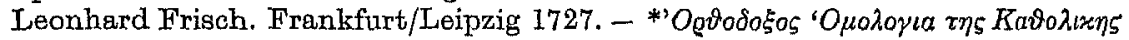

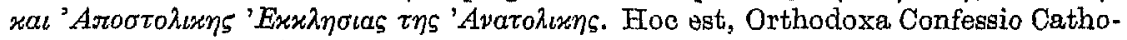
licae atque Apostolicae Ecclesiae Orientalis, cum interpretatione Latina et versione Germanica (von Johann Leonhard Frisch). Praemissa est historia hujus 'Opohoyıas seu Catechismi a D. C. G. Hofmanno. Breslau 1751. (British Museum. Catalogue of Printed Books 30 (1888).

\section{F. Briefe und Tagebiicher}

1. Joh. Leonh. Frischs Briefwechsel mit G. W. Leibniz. Ein Beitrag zur Geschichte des geistigen Lebens in Berlin zu Anfang 18. Jahrhunderts. Hg. v. L. H. Fischer. Archiv der Brendenburgia, Gesellschaft für Heimatkunde der Provinz Brandenburg zu Berlin. Band 2. Berlin 1896 (37 Briefe FrrsoHs an Leliniz, 3 Briefe LeIbnizens an FrisoH, aus den Jahren 1706-1716; nach LISELONTH RIOHTER, Leibniz und sein Rußlandbild (1946) 154 enthält die Sammlung des Lerroniz-Briefwechsels in der ehem. Königlichen Bibliothek zu Hannover 42 Briefe Frischs an LmIBNIz und 1 Antwort LeIBNIZens an FrISCH).

2. JoHANN HeINRTot voN SEELTN, Memoria Stadeniana. Hamburg 1725. (S. 337 - 339 ein Brief FrisoHs an v. SreLIeN vom 20. März 1716).

3. Johannes HeumanN, Opuscula. Nürnberg 1747. (S. 470-471 ein Brief Frisons an HEUMaNN aus der Zeit um 1737).

*4. Litterarische Blätter (Neuer oder fortgesetzter allgemeiner litterarischer An. zeiger). Nürnberg 4 (1804) I18-126 (Briefe FrISCHs).

5. JoHann Jacob WIPPEx, Das Leben des Rektors J. L. Friboh. Berlin 1744. (S. 6, 7, 10, 11 Auszüge aus den unveröffentlichten Reisetagebüchern FriscEs).

\section{G. Besprechungen}

1. Acta Eruditorum.Leipzig 1710. S. 140-143: Libri novi Russico idiomate conscripti. (E. EromLen in: Die deutsch-russische Begegnung und Leonhard Euler (1958) 97. 


\section{LITERATURVERZEICHNIS}

Johand Gotrutem BiedermanN, Acta Scholastica. III. 3. Leipzig/Eisenach 1743. S. $259-264$.

JoHANN JACOB WIPPEL, Das Leben des Weiland berühmten Rectors an dem Gymnasio zum grauen Kloster in Berlin, Johann Leonhard Frisch. Berlin 1744.

Elias Caspar ReIoHard, Versuch einer Historio der deutschen Sprachkunst. Hamburg 1747.

AUgust Fordinand Ribbeck, Oratio ad Joannis Leonardi Frischii olim Gymnasii Leucophaei Rectoris meritissimi memoriam secularem celebrandam. (Programm des Grauen Klosters zu Berlin) Berlin 1830.

JACOB GrIMm, Utber das Pedantische in der deutsohen Spraohe. (Akademievortrag 1847). In: Kl. Schr. 1, 352-353.

JAOOB GRIMM, Deutsches Wörterbuch. Bd, 1. Leipzig 1854. Sp. XIX-XXVI.

RUDOLF roN RADMER, Geschichte der Germanischen Philologie vorzugsweise in Deutschland. Münohen 1870.

Rudouf HItdmbrand, Deutsches Wörterbuch. Bd. 5. Leipzig 1873. Sp. I-VIII.

Julros Herdmanan, Geschichte des Grauen Klosters zu Berlin. Berlin 1874.

Leopold Hermann Frsaher, J. L. Frischs Schulspiel von der Unsauberkeit der falschen Dicht- und Reim-Kunst. Berlin 1890.

Leoporo Hermann Frscher, Joh. Leonh. Frischs Briefwechsel mit G. W. Leibniz. Berlin 1896.

Hermann PaUL, Geschichte der germanischen Philologie. In: Grundriß der germanischen Philologie. 1 (Straßburg ${ }^{2} 1901$ ) 9-158.

Gustar Roethe, Die Deutsche Kommission der Königlich Preußischen Akademie der Wissenschaften, ihre Vorgeschichte, ihre Arbeiten und Ziele. In: Noue Jahrbücher für das klassisohe Altertum. 1. Abt. 31 (1913) 37-74.

Artraur Sonmdi, Zum Fortschritt der etymologischen Erkenntnis des Deutschen in Wörterbüchern des 17. und 18. Jahrhunderts. Berlin 1927.

Agathe Lasce, Berlinisch. Berlin $\langle 1928\rangle$.

Konrad BURdaAH, Die Wissenschaft von deutscher Sprache. Berlin/Leipzig 1934.

Erwin Stresemann, Die Erscheinungsdaten von J. L. Frischs "Vorstellung der Vögel in Teutschland' (1733-1763). In: Ornithologische Monatsberichte. 49 (1941) 1-8.

Listomotrs Richter, Leibniz und sein Rußlandbild. Berlin 1946.

PaUd Hazard, Die Krise des europäischen Geistes 1680-1715. Hamburg (1949).

PaUt Hazard, Die Herrschaft der Vernunft. Das europäische Denken im 18. Jahrhundert. Hamburg (1949).

Josme DÜnninger, Geschichte der deutsohen Philologie. In: Deutsche Philologie im Aufrib. 1 (Berlin ${ }^{2} 1957$ ) 83-222. 
Pexrus Dasyrodios, Dictionarium Latinogermanicum et vice versa Germanicolatinum. Straßburg 1536.

JoHannes Frisios, Dictionarium Latinogermanicum. Zürich 1556.

Josda MaAligr, Die Teütsch spraach. Zürich 1561.

WOLFGANG SaHöNstimder, Promtuarium Germanico-Latinum. Augsburg 1618.

Levinus Hulstus - Franoisous Martinus Rayelius, Dictionarium Teutsch-Frantzösisch-Italiänisch. Frankfurt am Main 1616.

Nathanagi Dumz, Dictionarium Germanico-Gallico-Latinum. Amsterdam 1664.

JohanN Jacob Dentzler, Clavis linguao Latinae. Basel 1686.

Christian LUdwig, Teutsch-Englisches Lexicon. Leipzig 1716.

Benjamin HederIoH, Promtuarium Latinitatis probatae et exercitae. Leipzig 1729.

Edgar EwING Brandon, Robert Estienne et le dictionnaire français au XVI siècle. Thèse présentée à la Fauulté des Lettres de l'Université de Paris 1904. Baltimore 1904.

Schweizerisches Idiotikon. Wörterbuch der schweizerdeutschen Sprache. Bd. 9. Frauenfeld 1929.

De Witw T. Starngs, Renaissance Dictionaries. English-Latin and Latin-English. Austin 1954.

Der Fruchtbringenden Gesellschaft ältester Ertzschrein. Hg. v. G. Krause. Leipzig 1855.

Justus Grorg SoHOTTwL, Teutsche Sprachkunst. Braunschweig ${ }^{1} 1641 .{ }^{2} 1651$.

Grorg Phmipr Harsdöngren, Poetischer Trichter. Bd. 2. Nürnberg 1648.

Justus Grora Sonotred, Ausführliche Arbeit von der Teutschen HaubtSprache. Braunschweig 1663.

Justus Georg ScHotrde Horrendum Bellum Grammaticale Teutonum antiquissimorum. Braunschweig 1673.

JohanNes Bönrker, Grund-Sätze Der Deutschen Sprachen im Reden und Sobreiben. Cölln an der Spree 1690.

Kaspar Streler, Der. Teutschen Sprache Stammbaum und Fortwachs oder Teutscher Sprachschatz. Nürnberg 1691.

Matrhias Kramer, Das herrlich Grosse Teutsch-Italiänische Dictionarium. 1-2. Nürnberg 1700-1702.

Christran Gryphios, Der Deutschen Sprache untersohiedene Alter und nach und nach zunehmendes Wachsthum. Breslau 1708.

Jofrannes Bödiker, Neu-vermehrte Grund-Sätze Der Deutschen Sprachen Im Reden und Schreiben. Berlin 1709.

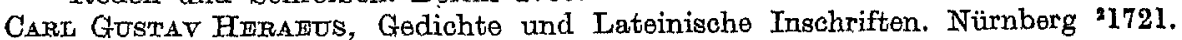

Christian ERnst Steinbaoh, Deutsches Wörter-Buch. Breslau 1725.

Christoph Ernst Strimbach, Vollständiges Deutsches Wörter-Buch. 1-2. Breslau 1734. Darin: J. U. KöNIG, Vorbericht 1 (1734)*1a-*4b.

Beyträge Zur Critischen Historie Der Deutschen Sprache, Poesie und Beredsamkeit, herausgegeben von Einigen Mitgliedern der Deutschen Gesellschaft in Leipzig. Leipzig Bd. 3 1735; Bd. 51738.

EDWard SorröDmR, Christoph Ernst Steinbach. In: Allgemeine Deutsche Biographie. 35 (1893) $684-686$.

Max Hermann Jwulingr, Geschichte der neuhochdeutschen Grammatik von den Anfängen bis auf Adelung. 1-2. Heidelberg 1913-1914.

Frindorion KuUGm, Von Luther bis Lessing. Leipzig ${ }^{5} 1918$.

Hans LaormanN, Gottscheds Bedeutung für die Geschichte der deutschen Philologie. Diss. Greifswald. O. 0. 1931. 
Genhard IsING, Die Erfassung der deutschen Sprache des ausgehenden 17. Jahr. hunderts in den Wörterbüchern Matthias Kramers und Kaspar Stielers. Berlin 1956.

Carouts do Fresne Dominus du Cange, Glossarium ad scriptores mediae et infima Latinitatis. Editio nova. Hg. v. Léopold Favre. Bd. 1. Niort 1883.

Nova Literaria Germaniae Collecta Hamburgi. Hamburg 1703.

JoHANN GeORG EOKART, Historia studii etymologici linguae germanicae hactenus impensi. Hannover 1711.

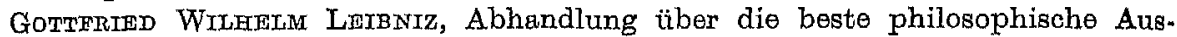
drucksweise; Ermanung an die Teutsche, ihren Verstand und Sprache besser zu üben; Unvorgreifliche Gedanken betreffend die Ausübung und Verbesserung der Teutschen Sprache. Hg. v. Paul Pietsch. Berlin 1916.

Miscellanea Berolinensia ad incrementum scientiarum ex scriptis Societati Regiae Scientiarum exhibitis edita. Berlin Bd. 1. 1710; Bd. 2. 1723.

Akten aus dem Archiv der Deutschen Akademie der Wissenschaften zu Berlin. IV, 38: Protokolle der Klasse für deutsohe Sprach- und Geschichtsforschung 171 1-1742. Die Protokolle werden nach Tag, Monat und Jahr zitiert.

JoHANN HeINRICH VON SEEIEN, Memoria Stadeniana. Hamburg 1725.

Ados Harrack, Geschichte der Königlich Preußischen Akademie der Wissen. schaften zu Berlin. 1-3. Berlin 1900.

Onso KLope, Leibniz' Plan der Gründung einer Societät der Wissenschaften in Wien. In: Archiv für österreichische Geschichte. 40 (1869) 157-255.

Starid voN DER SahulenbuRG, Leibnizens Gedanken und Vorschläge zur Erforschung der deutschen Mundarten. (Abh. d. Preuß. Akademie d. Wissen. sohaften. Philos.-Hist. Klasse 1937). Berlin 1937.

Hans TRÜMPY, Schweizerdeutsche Sprache und Literatur im 17. und 18. Jahrhundert. Basel 1955.

AUGUST LaNGEN, Deutsche Sprachgeschichte vom Barock bis zur Gegenwart. In: Deutsche Philologie im Aufriß. 1 (21957) 931-1396.

Die deutsch-russische Begegnung und Leonhard Euler. Berlin 1958. - Darin:

E. EtoHumR, Johann Leonhard Frisch und die russische Sprache. Ein Kapitel deutscher Slawenkunde. S. 94-111.

W. BernhageN, Johann Leonhard Frisch und seine Beziehungen zu Rußland. S. $112-124$.

Neue Zeitungen von Gelehrten Sachen. Leipzig 1741. 1742.

Nova Acta Eruditorum. Leipzig 1742.

Maxturas voN Wiont, Das Ostfriesische Land-Recht nebst dem Deich- und Syhl. rechte. Aurich 1746.

JoHannes HeUmanN, Opuscula quibus varia Juris Germanici itemque historica et philologica argumenta explicantur. Nürnberg 1747.

Neuer Büchersaal der schönen Wissenschaften und freyen Künste. Leipzig Bd. 4. 1747; Bd. 5. 1747.

JoHaNN Grorg Estor, Bürgerliche Rechtsgelehrsamkeit der Teutschen. 1-2. Marburg 1757-1758.

Briefe, die Neueste Litteratur betreffend. Bd. 7. (125. Brief: Nicolai) Berlin 1763. Gotwhold Ephraim Lessiva, Sämtliche Schriften. $1 \mathrm{ff}$. Stuttgart $1886 \mathrm{ff} . \mathbf{H g}$. v. Lachmann-Muncker. Bd. 4; 7; 8; 11; 16; Registerband.

Johans Gomprited Hirder, Sämmtliche Werke. 1ff. Berlin 1877ff. Hg. v. B. Suphan. Bd. 1; 2; 15; 18; 23; Registerband. 
Johann Geong Hamann, Sämtliche Werke. Hg. v. J. Nadler. Bd. 5. Wien 1953. Friedrioh GotruIm Kuopstock, Sämatiche Werke. Bd. 12. 1823.

Tristram Schandis Leben und Meynungen, übersetzt von J. J. Chr. Bode. Bd. 1. 1776.

Christoph Martin Wieland, Sämmtliche Werke. Bd. 33. Leipzig 1857.

J. F. A. Kinderima - J. P. WuLdenbücher - E. J. KocH, Für Deutsche Sprache Litteratur und Cultur-Geschichte. Berlin 1794.

(A. W. HuPEL), Idiotikon der deutschen Sprache in Lief- und Ehstland. Riga 1795. Darife SANDERS, Wörterbuch der deutschen Sprache. Bd. 2, 2. Leipzig 1865.

W. v. GuTzeIr, Wörterschatz der Deutschen Sprache Livlands. Bd. 1. Riga 1864.

Rudolf Sorachinger, Die Bemühungen des Benedictiners P. Placidus Amon um die deutsche Sprache und Literatur. In: Studien und Mittheilungen aus dem Benedictiner- und dem Cistercienser-Orden. 9 (1888) 430-445; 618-627. 10 (1889) 96-106; 282-290;477-485; 644-660.

Oтто BASLm, P. Placidus Amon. Ein Beitrag zu den Anfängen der altdeutschen Studien in Osterreich im 18. Tahrhundert. In: Germanica. Eduard Sievers zum 75. Geburtstage. Halle 1925.

Werner Salow, Die deutsche Sprachwissengchaft in der Allgemeinen Deutschen Bibliothek. Ein Beitrag zur Geschichte der deutschen Philologie im Zeitalter der Aufklärung. Diss. Greifswald 1926.

Bibliotheca Viri Clarissimi et Doctissimi Domini Joh. Leonh. Frischii ... Publica Auctionis Lege Die Ir. Septembris MDCCXLIII. in AEdibus Rectoris ... divendenda. Berlin 1743.

TheophILUS Georgi, Allgemeines Europäisches Bücher-Lexicon. Leipzig 17421758.

Christian Gotwhine Jöoher, Allgemeines Gelehrten-Lexicon. 1-4. Leipzig 1750 -1751 .

5. Chr. AdmLunG - H. W. Rotersurnd, Fortsetzung und Ergänzungen zu Christian Gottlieb Jöchers allgemeinem Gelehrten-Lexico. 1-6. Leipzig/Delmenhorat/ Bremen 1784-1819.

J. G. TH. GRajgsse, Trésor de livres rares et précieux. 1-8. Mailand/Now York 1950. Heinrich Verth, Deutsches Bergwörterbuch. Breslau 1870-1871.

Allgemeine Deutgche Biographie. 1-56. Leipzig 1875-1912.

R. Strntzing, Geschichte der Deutschen Rechtswissenschaft. 1-2. München/ Leipzig 1880-1884.

Catalogue of the Printed Books in the Library of the British Museum. London 1881-1900 (1905).

Karl Gowders, Grundriß zur Geschichte der deutschen Dichtung. 1-2. Dresden $21884-1886$.

W. S. Trufres, Geschichte der römischen Literatur. Hg. v. W. Kroll und F. Skutsoh. 1-3. Leipzig/Berlin '1910-1916.

Quellenheft zum Deutschen Rechtswörterbuch. Weimar 1912.

Register zu Lessings Werken (Vollständige Ausgabe in fünfundzwanzig Teilen. Hg. v. J. Petersen und W. v. Olshausen). Bearbeitet von W. v. Olshausen. 1. Bd.: Sach- und Personenregister. Berlin/Leipzig o. J.

Neue Deutsche Biographie. 1-3. Berlin 1953-1957. 
NAMENREGISTER

Die Ziffern beziehen sich auf die Seiten

Aohmet 176

Adalardus 126

Adam von Bremen 142

Adamus a Weleslavina 128

Adelung 183-186, 188

Ademarus 145

Aelfric 126, 130

Aelianus 123

Aeneas Sylvius 143, 148

Agapetos 3

Agathias 123

Agricola 134, 173, 178

Airmann s. Ayrmann

Aitinger 175

Albericus 146

Albertus Argentinensis 146

Albertus Magnus 139, 175, 178

Alberus (Chronist) 146

Alberus, E. 75, 128, 134

Albinus 153

Alciati 157

Alemann 173

Alexander der Große 122

Alexander Iatrosophista 126

Altenstaig 134

Althamer 125

Althusius 157

Ammianus Marcellus 133

Amon 182, 183

Anderson 52

Andreas von Regensburg 155

Antesperg 182

Anton de Musica 153

Apherdianus 134

Apicius 125

Apollinaris 176
Apollonios 122

Arenpek 149

Aristoteles 122, 178

Arnold 142

Arnold von Lübeck 143

Arsy 131

Artedi 179

Arthus 134

Arumaeus 161

Astmann 1, 3

Athenaios 123

Augustinus 125

Aurelianus 127

Ausonius 125, 134

Avemann 52

Aventinus 67, 155

Avicenna 176

Ayrmann 152

Balbinus 143

Balthasar 157

Baluzius 158

Barbosa 157

Baronius 142

Barth 145

Bauhin 179

Bebel 139

Becanus 130

Becher 18

Bechmann 157

Beck 157

Beckmann, J. Chr. 150

Beckmann, N. 157

Beda 144

Beier 159, 172

Benson 36, 42, 130 
Bernegger 126

Bertinianus 126

Bertius 147

Bertoldus Constantiensis 145

Bertsch s. Pertschius

Berward 174

Besold 36, 60, 63, 118, 132, 157, 158, 160, $161,163,164,173,187$

Besser 24

Betelius s. Bebel(ius)

Bignonius 158

Bion 172

Birken 156

Blondel 145

Blum 158

Blumberg 141

Bochart 176

Bode 185

Bödiker, J. VII, 3, 10, 23, 31, 43, 62-64, 136,184

Bödiker, K. E. 63,64

Bodinus 158

Boecler 147

Bollandus 126, 141

Bonfinius 143

Botho 146, 149

Boxhorn 127, 131

Brack 134

Brand s. Brack

Brant 136

Braun 158

Braun, D. 143

Braun, E. 176

Braun, M. s. Praun

Brito 145

Bromel 172

Brotuff 150, 151

Browerus 145, 152

Bruno 145

Brunquell 158

Buchanan 144

Buchner 176

Budaeus 173

Buder 158

Bullaeus 157, 158

Bullarus s. Bullaeus

Bünting 150

Burckhardt (Burchart) 178

Buschius 149,150

Cadaeus 157

Cadamosto 176
Caesar 124

Caesarius von Heisterbach 142

Calepinus 188

Calvisius 173

Camden (Cambdenus) 144

Camerarius, J. 34

Camerarius, $\mathrm{Ph} .158$

Camusatus 127

Carlowitz 174

Carpzov, B. 157, 158

Carpzov, J. B. 153

Casaubonus, I. 126

Casaubonus, M. 121

Caseneuve 127

Cassiodorus 125

Castelli 176

Catullus 126

Cellarius, A. s. Keller

Cellarius, Chr. 176

Celsus 124

Celtes 154, 155

Chastelain 127, 142

Chomnitius 151

Cholinus 74

Chrysostomos 123

Chytraeus, D. 141

Chytraeus, N. 135

Cicero 78, 124

Clauberg $38,41,51$

Claudianus 125

Cluverius 133,147

Colerus, J. 174

Colerus, M. 158

Columella 124

Comenius 3, 135

Conradus philosophus 155

Conradus Urspergensis 145

Constantinus Africanus 176

Corneille 66

Cornutus 124

Cothmann 158

Covarruvias 127

Cramer, D. 151

Cramer, M. s. Kramer

Crell 177

Crusius 155

Cujacius 158

Cuno 150

Curtius 124

Danckwerth 150

Dannhauer 140 
Dapper 177

Dasselius 167

Dasypodius 75, 76, 134

Deinlein 158

Dentzler 80-82, 89

Despauterius 135

Detharding 176

Deucer 174, 178

Diecmann 38, 52, 131, 133

Diesbach 8

Dieterich, J. K. 123

Dieterich, M. 151

Dietherr 157, 164

Dilherr 141

Diodoros Siculus 122

Dionysios 122

Dioskurides 122

Ditmar von Merseburg 145, 149

Döderlein 147

Donatus 125

Döpler 158

Draco 158

Dresser 142

Drosaeus 159

Dubravius 143

Du Cange $23,29,35,41,45,46,48,118$, $121,123,126,127,156,160,171,176$, 188

Duellius 146

Duez 80, 82-85, 89

Du Fresne s. Du Cange

Durandus 159

Eber 134

Eberardus Bethuniensis 125

Eberhard von Gandersheim 149

Eckart 38-40, 42-45, 67-69, 118, 121, $131,133,171,186$

Eginhart 145

Eilke von Repgow 146, 171

Ekkehard Junior 132

Elhen von Wolfhagen 152

Emmius 144

Entzelt 151

Erasmus 139

Ercken 173, 174

Erker, Erkner s. Ercken

Estienne s. Stephanus

Estor 159, 187

Etterlin 154

Euagrios 123
Eusebios 142

Eustathios 123

Faber, B. 21, 135, 188

Faber, F. 140

Fabricius, G. 153, 173, 178

Fabricius, J. A. 123

Falckenstein 155

Faust 150, 152

Feller 132

Feltmann 159

Ferrarius 127

Festus 125

Fichard 159

Fischart 137

Flacius Illyricus 35, 37, 131-133

Flavius Arrianus 122

Flavius Vopiscus 126

Flemming 175

Flodoardus 145

Florus 124

Forestus 176

Fortunatus 125

Francke 2

Frank 140

Frankenstein s. Falckenstein

Franzlkius 159

Fredegarius 145

Freher $36,38,62,131,132,154,155$, 159,173

Frick 39, 44

Friedrich I. (König), Friedrich III. (Kurfürst) 6, 23, 58; 54-57, 63, 64, 68

Friedrich II. (Kaiser) 175

Friedrich Wilhelm I. 7

Friese, L. 176

Friese, T. 173

Frischlin 134

Frisius 74, 75, 77-79, 134

Fritsch 157, 159, 165, 170

Froissart 145

Fronsperger 175

Frontinus 124

Fugger 156

Fuller 140

Furetière 66

Furttenbach 172

Gadebusch 186

Gail 159

Galenos 122 
Garzoni 146

Gassarus (Gasser) 35, 132, 155

Gastelius 157, 159

Gaza 178

Gelenius 34

Gellius 124

Gemmelius 159

Georgius 156

Gerhard 140

Gerson s. Garzoni

Gerstenberg 152

Gervasius Tilburiensis 144

Gesner 34, 74, 75, 121, 178

Gewold 156

Gichtel 2

Gisland 159

Glaffey 136

Gobelinus 146

Gobler 149, 157, 159

Godofredus Antonius 160

Godofredus monachus 126

Goedart 7

Goeddaeus 160

Goede 160

Goldast $15,36,40,60,63,118,126$, $131-133,154,157,164,165,171$

Goldmann 173

Golius 134

Gottfried von Viterbo 126, 145

Gottsched 62, 182, 183, 188

Grapius 151

Graser 183

Grattius 124, 127

Gregor von Tours 144, 145

Gregorius 177

Griepenkerl s. Gryphiander

Grimm, J. VII, 189

Gronov 142

Grotius 62, 160

Grüwel 133, 175

Gryphiander 160, 163

Gryphius, A. 110

Gryphius, Chr. 19, 147

Gueinz 14

Guertler 142

Guetrather 176

Gumprecht 123

Gundling 155, 160

Günther 21, 98, 99, 110, 111

Guntrather s. Guetrather

Gyllmann 160

I4 Powitz, Frischs Wörterbuch
Hackmann 157, 166, 167

Hafftiz 151

Hagek (Hagecius) 143, 158

Hagen, Gr. 156

Hagen(ius) 143, 158

Hahn 160

Haitonus 143

Halma 133

Haltaus 39, 133, 188, 189

Haly Abbas 176

Hamann 185, 188

Hamelmann 147, 150

Hanle 154.

Hannaeus 176

Harnack 23

Harsdörffer 14, 17, 21, 22, 29, 30, 59, 60, $73,112,135$

Hartiknoch 151

Hartwich s. Herttwig

Heberer 177

Hederich 21, 80-82, 90, 91, 102-108, 135

Hedio 142

Heidemann 41

Heider 162

Heineccius 150

Heinrich von Ofterdingen (Osterdingen) 132

Heliodoros 123

Hemmersam 177

Henisch 13, 14, 16, 19

Henkel 174

Hepidannus 132

Heraeus 20

Herberstein 177

Herburt 143

Herder 184, 186, 188

Hermann 178

Herodianos 123

Herodotos 122

Herold 36, 171

Hertius 147

Herttwig 174

Hertzog 154

Hesiodos 122, 123

Hesychios 123

Heumann, Chr. A. 127

Heumann, J. 40, 72, 118, 160, 180, 186, 187

Heyliander s. Gryphiander

Hickes 130 
Hieronymus 137

Hildebrand, H. 160.

Hildebrand, R. VII

Hildeseemus 176

Hilscher 141

Hincrnarus 160

Hoosemius s. Johannes de Hocsem

Hoerwarth von Hohenburg 175

Hoffmann 160

Höfler 175

Hofmann, G. 173

Hofmann, M. 155

Hofmannswaldau 21, 86, 110, 136, 137

Hoh(en)berg 174, 175

Hohndorf 174

Homer 122, 123

Höniger 136

Hönn 155

Hooke 172

Höping 160

Horatius 124

Eorn, C. H. 160

Horn, J. G. 132, 148

Hörnigk 160

Hornius 127

Hortleder 147

Hosemann 148

Hospinianus 142

Hottinger 154

Hrabanus Maurus 131, 145

Hübner 160

Hueber 156

Hugo 160

Hugutio 125

Hulsius $80,82-85,89$

Hund(ius) 127, 155, 156, 163

Hyginus 124

Ioander s. Crell

Iohtersheim 178

Irenicus 155

Iselin 154

Isidorus 37, 38, 125, 126, 131, 145

Iso Magister 125

Jablonski, Brüder VII, 19, 26, 29, 30, 58,69

Jablonski, D. E. 23, 24, 54-57

Jablonski, J. Th. 5, 23-25, 71

Jacobus de Vitriaco 142

Janderson 174
Jauchet 127

Jellinek VI

Jeroschin $\mathbf{1 3 2}$

Joannis 152,155

Johann von Buch 172

Johannes de Garlandia 125

Johannes de Hoosem 144

Johannes de Janua 125

Johannes a Leidis 133

Johannes Trithemius 146

Johnson 183

Johren 179

Jonas Abbas 132

Jonston 7, 179

Jornandes 125,145

Jovius 145

Jud 139

Juncker 176

Junius $36,41,42,62,129,133$

Justinus 124

Juvenalis 124, 125

Kallimachos 122

Kaufmann 123

Kehrberg 151

Keimann 173

Keisersberg 44, 63, 133, 136, 139, 178

Keller, Adam 160

Keller, Andreas 139

Kelp 52

Kero 131, 133

Keysler 144

Khraisser 170

Kilianus 131

Killinger 160

Kinderling 185

Kirchmaier, O. 14I

Kirchmayer, G. C. 126, 177

Kirohner 160

Klammer 160

Klock, 167, 160

Klopstock 185

Kluver 160

Knauth 153

Knichen 160, 161

Knipschild 161

Koepken, 151

Köhler 153

König, E. 174.

König, J. U. 71

König, K. 161 
Königshofen s. Twinger

Konrad von Halberstadt 139

Kopp 161

Köppen 161

Korner 149

Kramer 12, 13, 17, 18, 22, 23, 29, 30, 33, $60,61,73,80,85-88,90-111,113$, 135,184

Krantz 147, 149

Kraus 175

Kreutmann 161

Kreydenmann 155

Kreysig 148

Kuchenbecker 152

Kuhlmann 2

\section{Lactantius 125}

Lambecius $37,133,152$

Lange 40

Langenmantel 63,64

Lankisch 138

Lautensack 172

Lazius 35, 121

Le Blane 173

Lehmann, Christian 153, 177

Lehmann, Christophorus 155

Lehmann, J. Chr. 174

Leib 161

Leibniz VII, 1, 3, 4, 6, 7, 19, 20, 26, 40, $42,43,45,47-52,54-58,65-70,118$, $121,144,146,148,149,169,184,186$

Leipold 161

Leiser 161

Lengnich 143

Lepper 161

Lessing 184, 186-188

Letzner 150

Lounclavius 122,143

Libavius 175

Liebknecht 141

Limnaeus 36, 157, 161

Linck 161

Lindenberg 151

Lindenbrog $36,38,41,62,63,131,145$

Lindner 20

Lindwodus 161

Lipsius 36, 40, 131, 172

Lirer 155

Livius 124

Loccenius 129

Logau 186, 187

14*
Lohenstein 21

Löhneyß 174

Londorp 147

Lonicerus 179

Lucae 148, 154

Lucanus 124

Lucilius 124, 125

Lucretius 124

Ludewig 157, 161, 162, 165, 171

Ludolf, G. M. v. 161

Ludolf, H, 52

Ludolf, H. W. 128

Ludwig 80, 82-85, 90

Ludwig zu Anhalt-Köthen 14, 17

Lundorp s. Londorp

Lünig 162

Luning, Lüning s. Lünig

Luther $15,30,44,63,67,128,136-140$, 186

Lïtkemann 140

Lyser 162

Maaler $13,14,44,75-79,88,89,134$

Macrobius 125

Mager 162

Mallet 176

Manilius 124

Marcianus 162

Mareschallus 129, 130

Marperger 59, 173

Marquart 170

Mars(ch)mann 173

Martinius 126

Mascov 153

Masecovius 177

Masius 143

Mathesius 140, 173

Matthaeus Parisiensis 126, 144

Matthaeus Westmonasteriensis 144

Mauritius 162

Mayer s. Mager

Megiser 135

Meibom 146, 150

Meichelbeck 155

Meichsner 161, 162, 164

Meier, G. 52, 68

Neier, J. 150, 155

Meier, J. B. 52

Meisner 52, 135

$\mathrm{Mel}$ 52, 53

Melonius 162 
Melzer 153

Ménage $35,41,45,46,48,51,66,118$, $121,127,142,188$

Menander 122

Mencke 152, 155

Mentzel 179

Merckel 151

Merian 178

Merula 144

Messenius 144

Meurer 162

Meursius 123, 126

Mevius 162

Miethe 176

Modius 176

Molanus 52

Molière 127

Molinaeus 162

Monachus Pirnensis 152

Morgenweg 150

Morhof 38, 62, 67, 133

Moser 148, 171

Müller, J. C. 52

Müller, J. J. 147, 162

Mundius 162

Münster 35, 177

Muralt 172

Murer 154

Musaens 140

Musculus 140

Myle, A. van der 121

Myler 162

Mynsinger 162

Nannius 125

Nephilas s. Ulphilas

Neukirch 25, 26

Neumark 17

Nicodemus 137

Nicolai, Chr. G. 72

Nicolai, Fr. 184, 188

Nicolai, Ph. 140

Nicot 127

Niederstedt 177

Nikandros 122

Nithard 145

Nonius 125

Notker $37,38,45,131,133$

Oberlin 39, 189

Obrecht 162
Ockel 162

Oelrolampadius 139

Oelven 26

Oettinger 162

Olaus Magnus 157

Olearius 177

Opitz 21, 67, 110,132, 186

Oppianos 123

Orosius 125

Otfrid 35, 37, 38, 44, 45, 50, 63, 131 $-133,135$

Otto 175

Otto von Freising 145

Ovidius 124

Palladius 125, 126

Palthen 37, 131, 133

Papobroch 143

Papias 125

Paracelsus 67

Pasor 135

Pasquier 126

Patin 174

Paulinus Nolanus 125

Paulus Warnefridus (Diaconus) 145

Pausanias 122, 123

Persius $124,126,157$

Pertschius 156

Petrus de Crescentiis 174

Petrus Duisburgensis s. Jeroschin

Peucer 134

Pez, B. 38, 131

Pez, H. 156 (133)

Pfendler 178

Pharetratus 148

Philgus 141

Philon 122

Philoxenos 123

Pictorius s. Maaler

Pietsch 137

Pirckheimer 154

Pistorius s. Maaler

Pistorius, G. T. 137

Pistorius, J. 146, 150, 152

Pithoeus 130, 155

Plantinus 178

Platon 122

Plautus 123

Plinius 77, 78, 124

Pollux (Polydeukes) 122

Polybios 122 
Pomarius 151

Pomey 127

Pontanus 127, 144

Prasch 52, 67, 135, 187

Praun 147

Printzen 5

Priscianus 125

Prokopios 123

Ptolemaios 122

Quintilianus 124

Rabelais 127

Rachel 21

Rädel s. Rätel

Rast 177

Rätel 177

Rathgeb 155

Raumer 40

Ravellus 80

Ray 51

Rechenberg 142

Redi 7

Regino Prumiensis 146

Regius 139

Regkmann 150

Rethmeyer 150

Reichard 40, 181

Reinesius 133, 142, 150

Rentsch 151

Resenius 36, 129, 130

Reusch 175

Reyger 162

Reyher 153

Rhenanus 35, 147

Rhenferd 121

Rhotius 162

Rhode 149

Richter 162

Rittershausen 162

Rittner 15I

Rivius s. Ryff

Roesener 162

Rohde 151

Rolevinck 146

Rollius 146

Rosenthal 162

RöBler 174

Rosteuscher 162

Roth 166

Rothe 152
Ruchamer 177

Rudbeck 41, 130

Rudinger 163

Ruinart 145

Ruland, M. 134

Rulant, R. 163

Rupertus 126

Ruppe 179

Rutilius 125

Ryff 173, 176

Sachs, Hans 67, 136

Sachse von Jewenheimb 175

Sagittarius, C. 42, 150, 151, 153

Sagittarius, P. M. 152

Saib 136

Sallustius 124

Salmasius 126, 173

Sande 163

Sanders 187

Saur 163

Saxo Grammaticus 144

Saxo, Poeta 149

Scaliger, J. C. 126

Scaliger, J. J. 126

Schadaeus 178

Schannat 147, 152, 153, 166

Schedius 147

Scheffer 130

Scheidt 136, 137

Soheplitz 167

Schertlinus 152

Scherz 39, 133, 189

Scheuchzer 178

Scheyb 183

Schickfuss 154

Schifferdecker 163

Schilter 37-42, 44, 45, 67, 118, 131-133, $154,157,163-165,169-171,186,187$, 189

Schindler, Chr. K. 174

Schindler, V. 122

Schiphhower 146

Schlegel 173

Schlüter 26

Schmidt, J. A. 141

Schmidt, T. 153

Schnoidewin 163

Schoekius 175

Schönberg 153, 174

Schönsleder 80-82, 89, 135 


\section{Schoock 177}

Schott 23, 25

Schottel 13-17, 19-25, 29, 30, 32, 33, $36,41,50,51,59-62,66,67,73,112$, $135,157,160,163,184$

Schöttgen 148, 153

Schröder 163

Schröder, J. 140

Schröter 173

Schudt 143

Schultze 151

Schütz 141

Schwammerdam 7

Schwan 185

Schwanburger 169

Schwanmann 163

Schwarz 163

Schwarzlkopf 163

Schweigger 177

Schwenter 1.72

Scotus 177

Scribonius 124

Scultetus 187

Sebald 151

Seckendorff 140,147

Seelen 39

Seneoa 124, 126

Serarius 152

Serrenus 134

Servin 163

Servius 125

Sheringham 144

Sichard 36, 163

Siegrnann 173

Sigebertus Gemblacensis 145

Sigismundus monachus 146

Silius Italious 124

Simler 178

Sirmundus 163

Sisenna 125

Skinner 36, 42

Solinus 125, 126

Somner 23, 36, 42, 130

Sonnentaller 139

Spalatinus 152

Spangenberg 147, 153

Spate, der s. Stieler

Speidel 36, 60, 63, 157, 158, 163, 187

Spelman 35, 36, 41, 46, 47, 62, 126

Spener 1, 137, 176

Sprenger 157, 163, 173
Springfeld 163

Stade $37,39,62,67,68,118,128,136$, 138,186

Staphorst 150

Statwech 149

Stauffenberg s. Fischart

Stein 151

Steinbach 12, 13, 18-21, 27-30, 32, 33, $61,71,73,80,85-88,90-111,113$, $135-137,182,183,185,188$

Steinhöwel 133

Stephanius 130, 144

Stephanus Byzantinus 123

Stephanus, R. 74, 77, 127

Sterne 185

Stettler 154

Steyerer 147

Stieler 12, 13, 17-25, 28-30, 32, 33, 60, $61,73,80,85-89,91,102-109,113$, $135,185,187$

Stiernhock 163

Stipmann s. Stypmann

Stisser 175

StjernhjeIm 36, 41, 129

Stoppe 21

Stosch 185

Strabon 122

Stransky 143

Strauch 157

Stricker 38, 132

Struve, B. G. 146, 148

Struve, G. A. 163

Strylk 164

Stuck 164

Stumpf 35, 67, 154

Stypmann 157, 164

Suetonius 124

Suidas (Suda) 123

Suttinger 164

Synkellos 123

Tabor 157, 164

Tacitus 78, 124-126, 133

Täntzer 175

Tatian 37, 38, 44, 45, 131, 138

Tauler 135

Ten Kate 36

Tenzel 153, 164

Terentius 123, 125

Tertullianus 125

Teschenmacher 149 
Textor von Höger 152

Thammius 152

Theokritos 122, 123

Theophrastos 122

Thoeden(i)us, Thoelde 159, 172, 174

Thomas Magister 1.23

Thomasius 140

Toelner 154

Torfaeus 144

Torquatus 151

Trithemius s. Johannes Trithemius

Tschudi 154

Turmair s. Aventinus

Turnebus 126

Twinger von Königshofen 37, 154

Ugutio s. Hugutio

Ulitius 127, 129

UIphilas 129

Ursinus 152

Ussher (Usserius) 144

$\mathrm{Uz} 186$

Valentinus 172

Valerius 126

Valesius 145

Valvasor 178

Varro 124, 126

Vaugelas 5

Vegetius 125

Vellejus 126

Venetus 178

Verelius 36, 130

Vergilius Maro, Publius 124, 125, 135

Vergilius, Polydorus 173

Verhag. s. Verheyen

Verheyen 176

Vigenère 143

Vitruvius 124, 173

Vitus 146

Volkmann 164

Vorstius VII, 38, 61, 62, 133

Vossius $35,41,46,118,121,126,144$, 165,171

Vredius 144

Wabst 153

Wachter 5, 39, 44, 45, 49, 67, 71, 118, $133,147,184,186,187,189$
Wackenroder 151

Wagenseil 155

Walahfrid Strabo 133, 142

Wats 130

Week 153

Wedel 176

Wehner 36, 60, 63, 118, 157, 162, 164

Weinrich 152

Weismann 135

Weitzen s. Weytsen

Welser 155

Wendelinus 171

Wentzly 164

Werndle 164

Wernher 177

Westphal 164, 167

Weytsen 164

Wicht 186

Widemann 153

Wieland 185, 188

Wildvogel 164

Wilisch 163

Williram 38, 45, 131, 133

Wimpheling 154

Winckelmann 150, 152

Windek 152

Winsbeke 132

Winsbekin 132

Wippel 2, 72

Wippo 146

Wittichindus Corbeiensis 146, 149

Wochner 187

Wolff 173

Wolfhardus 142

Wolfram von Eschonbach 132, 157

Wolter 146

Wormius 36, 41, 129

Wurfbain 164

Wurstisen 154

Wusterwitz 151

Xenophon 123

Xylander 122

Zaan 164

Zamosky 143

Zasius 164

Zedler 172

Zeiller 155, 170, 177

Zeising 172 
Zeitfuchs 153

Zernecke 151

Zesen 67

Zeuner 140

Zobel 164, 171
Zorer 164

Zorgdrager s. Reusch

Zorn-Plobsheim 7

Zwinger, Th. 176

Zwinger, Th. 179 